\title{
Propositions
}

1. Rapid salinization along the south-west coasts of Bangladesh is the combined action of global climate change, regional hydrological modifications and local socioeconomic shifts.

(this thesis)

2. If current salinization trends continue, not only the Sundarbans mangrove's biodiversity but also the Bengal tigers will be in jeopardy. (this thesis)

3. Executing any development initiative should consider both local socio-economic settings and regional implications.

4. Water quality and quantity are equally important to conserve nature and natural resources.

5. The imbalance between bio-capacity and population growth is the major obstruction of sustainability.

6. Finishing a PhD thesis requires not only excellent scientific proficiencies but also having a long-term endurance under demanding circumstances'.

Propositions belonging to the thesis, entitled

'Impacts of climate change on coastal ecosystems of Bangladesh'.

Peerzadi Rumana Hossain

Wageningen, 4 April 2018. 

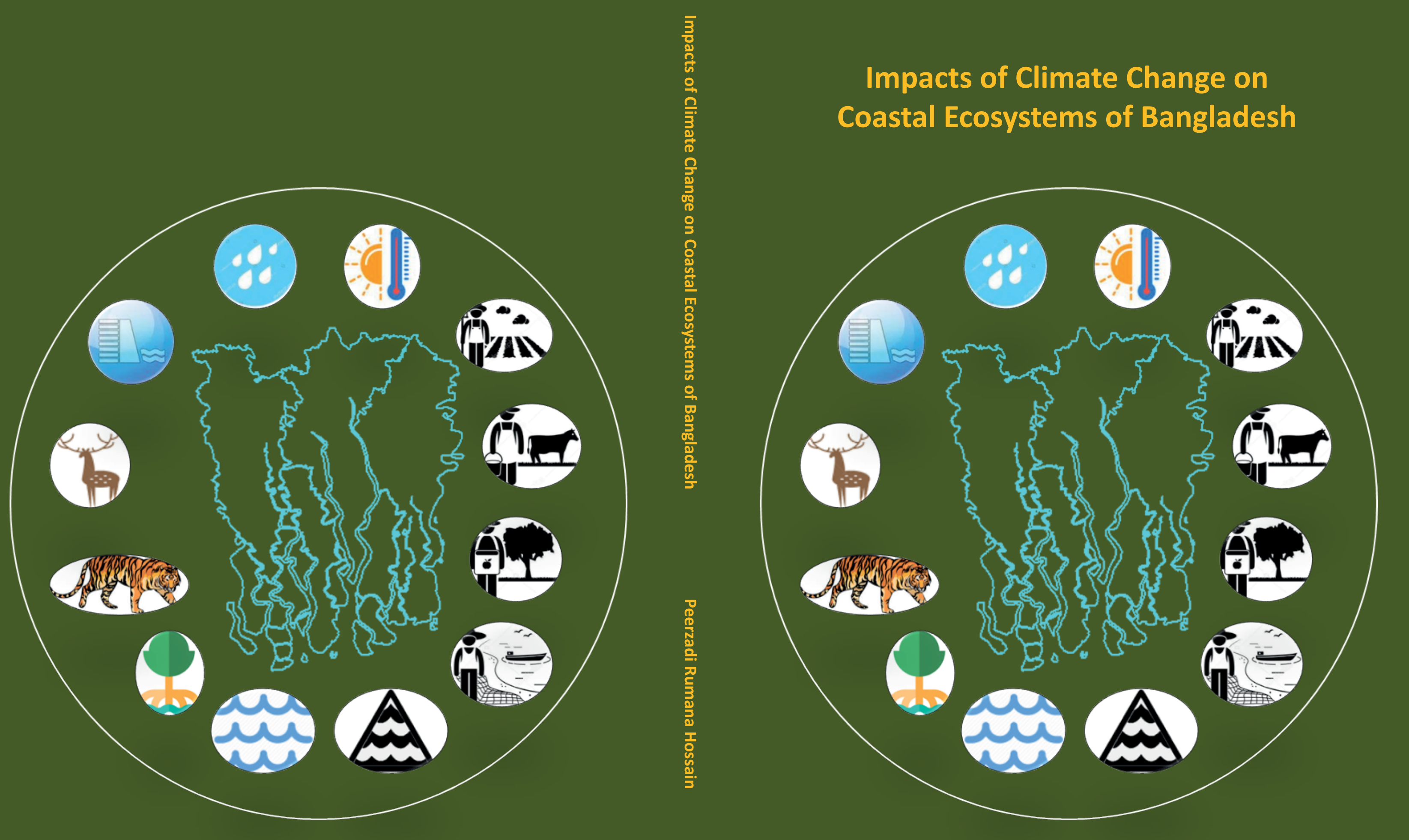

Peerzadi Rumana Hossain 


\section{Impacts of climate change on coastal ecosystems of Bangladesh}




\section{Thesis committee}

\section{Promotor}

Prof. Dr R. Leemans

Professor of Environmental System Analysis

Wageningen University \& Research

\section{Co-promotor}

Prof. Dr F. Ludwig

Personal Chair, Water Systems and Global Change Group

Wageningen University \& Research

\section{Other members}

Prof. Dr F.J.J.M. Bongers, Wageningen University \& Research

Prof. Dr U.K. Navera, Bangladesh University of Engineering and Technology, Dhaka, Bangladesh

Prof. Dr H. Olff, University of Groningen

Prof. Dr P.J.G.J. Hellegers, Wageningen University \& Research

This research was conducted under the auspices of the Graduate School for SocioEconomic and Natural Sciences of the Environment (SENSE) 


\section{Impacts of climate change on coastal ecosystems of Bangladesh}

Peerzadi Rumana Hossain

Thesis

submitted in fulfilment of the requirements for the degree of doctor at Wageningen University

by the authority of the Rector Magnificus

Prof. Dr A.P.J. Mol,

in the presence of the

Thesis Committee appointed by the Academic Board

to be defended in public

on Wednesday 4 April 2018

at 11 a.m. in the Aula. 
Peerzadi Rumana Hossain

Impacts of climate change on coastal ecosystems of Bangladesh, 152 pages.

PhD thesis, Wageningen University, Wageningen, the Netherlands (2018) With references, with summary in English

ISBN: $978-94-6343-765-3$

DOI: $\underline{\text { http://dx.doi.org/10.18174/443420 }}$ 


\section{Table of contents}

Chapter 1. General Introduction 1

$\begin{array}{ll}\text { Chapter 2. Recent Environmental Changes in South-West Coastal Region of } & 11 \\ \text { Bangladesh } & \end{array}$

Ecological Status of Mangrove Vegetation along Salinity Gradients in the 34
Sundarbans World Heritage Ecosystem

Chapter 4. Salinity increase and habitat degradation of Royal Bengal Tiger in the $\quad 52$

$\begin{array}{ll}\text { Chapter 5. } & \begin{array}{l}\text { Adaptation pathways to cope with salinization in south-west coastal } \\ \text { region of Bangladesh }\end{array}\end{array}$

$\begin{array}{llr}\text { Chapter 6. } & \text { Synthesis } & 89\end{array}$

$\begin{array}{ll}\text { References } & 113\end{array}$

$\begin{array}{ll}\text { Supplementary information } & 132\end{array}$

$\begin{array}{ll}\text { Summary } & 143\end{array}$

$\begin{array}{lr}\text { Acknowledgements } & 147\end{array}$

$\begin{array}{lr}\text { About the author } & 148\end{array}$

$\begin{array}{ll}\text { SENSE Diploma } & 149\end{array}$

Statement of authorship contribution 151 


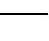




\section{Chapter 1. General Introduction}

\subsection{Motivation}

Beyond the local, national and regional importance, the Sundarbans mangrove of Bangladesh's south-west coastal region holds Outstanding Universal Value for which it is declared as a World Heritage Site. However, this ecosystem is potentially threatened by climate change and other anthropogenic impacts (e.g., exploitation, land-use change and pollution). Temperatures are gradually increasing due to the increased greenhouse gas concentrations. This results in the thermal expansion of ocean water and melting of mountain glaciers. Both are contributing to sea-level rise. The combination of climate-change induced sea-level rise and a lower fresh-water flow from upstream rivers due to infrastructural developments results in salt water intrusion and consequently salinity increase. All these climate-change induced problems and anthropogenic impacts negatively affect fresh water resources needed for diverse coastal ecosystems and coastal communities. For instance, although salinity is one of the essential physical factors needed for ecological development of the Sundarbans mangrove (Tomlinson 1986), it also limits the growth and development of the mangrove vegetation when salinity concentrations become too high (Nandy et al. 2007). How this globally important and irreplaceable ecosystem can be affected by all these environmental changes, is important for conservation efforts.

Moreover, direct influences of sea-level rise on freshwater sources come principally from seawater intrusion into surface waters and coastal aquifers with further encroachment into estuaries and coastal river systems (Hay and Mimura 2005). The resulting lack of drinking water sources and changes in land quality for food production affect adjacent coastal communities. Hence, millions of coastal people are looking for options to cope with the increased salinity threats, the lack of fresh water sources and also their livelihood loss. Therefore, to assess the impacts of salinization on different coastal systems for target-oriented adaptation planning is now imperative. This $\mathrm{PhD}$ project, therefore, aims to evaluate the impacts of salinity increase on the Sundarbans mangrove at different scales (mangrove vegetation and wildlife habitat) and for the adjacent coastal communities by identifying target-oriented measures to adapt to the climate-change impacts, particularly salinity increase. 
To achieve this aim, I have integrated and applied multidisciplinary research methods. My research outcomes can potentially contribute to cope with and enhance resilience to salinization in south-west coastal region of Bangladesh. This also supports the Bangladesh Climate Change Strategy and Action Plan 2008 and helps to achieve UN Sustainable Development Goals (particularly SDG13 on climate action and SDG15 on life on land). In the following sections, I introduce in details the bio-physical context of the research, its knowledge gaps and approaches to fill these gaps.

\subsection{Background and problem statement}

\subsubsection{Climate Change and Bangladesh}

Bangladesh is rated as one of the world's most vulnerable countries to climate change (Kreft et al. 2015). The country lies in the dynamic delta of three large river basins: the Ganges (Padma), the Brahmaputra (Jamuna) and the Meghna. It's physical geography is characterized by two distinctive features: the Bay of Bengal on the southern side and the Hindu Kush Himalaya region on the north. Besides, large parts of the country are less than $3 \mathrm{~m}$ above mean sea level (Rashid 1991) and its climate is governed by the monsoon (Singh 2001). Sitting at the head of Bay of Bengal and directed by the monsoon dominated climate, the country is subsequently affected by climate-change induced sea-level rise and large scale inter-annual climate variability. However, the country is also extremely vulnerable to climate change not only due to its geographic location and altitude but also because of its high population density $\left(\sim 1140\right.$ people per $\mathrm{km}^{2}$ ), poor infrastructure, high poverty levels, absence of technological provisions and high dependency on natural resources (NAPA 2009). Considering the climatechange induced risks, Bangladesh's Department of Environment (DoE) estimated potential future sea-level rise, which is $0.3 \mathrm{~m}$ to $1.5 \mathrm{~m}$ for 2050 (DoE 1993). A rise in sea level of more than $1.0 \mathrm{~m}$ would inundate $10 \%$ of the country, result in sea water intrusion more inland and consequently, salinity increase in the coastal regions (Barua et al. 2010).

\subsubsection{South-west coastal region of Bangladesh and climate change impacts}

Bangladesh's south-west coastal region is potentially vulnerable to climate change and its impacts (i.e., sea-level rise, salt water intrusion, inundation and salinity increase), mostly due to its environmental setting (Figure 1.1). This region is exposed to the sea and also connects the upstream and downstream Ganges basin. This exposed coastal region lies about $1.5 \mathrm{~m}$ 
above mean sea-level and this makes it vulnerable to sea-level rise and salinity increase (Chowdhury 2009). In addition, river flow and rainfall play an important role in maintaining the fresh water flow through the region and in determining the region's salinity levels (IWM 2014). However, during dry season, the flow in the Gorai River, a distributary of the Ganges and a major source of fresh water flow for this region, is being reduced due to the construction of Farakka Barrage on the upstream of Ganges river basin in India. This has resulted in a large increase in salinity of the area in addition to climate-change induced sea-level rise. Recent research has shown that salt-water intrusion increased up to $15 \mathrm{~km}$ north of the coast due to sea-level rise. Currently salt-water intrudes up to $160 \mathrm{~km}$ inland in the dry season due to reduced upstream river flows (SRDI 2010). This salt intrusion has large impacts on both ecological and socio-economic systems which provide essential social, economic and ecosystem services for the region. Hence, its highly diverse ecosystems, like the world's largest single tract of mangroves (the Sundarbans), wetlands (vast network of rivers of the Ganges-Brahmaputra tidal plains) and inlands (mostly crop-agriculture) have already started to be severely affected by this salinization (Rabbani et al. 2013, Rasel et al. 2013, Sarker et al. 2016). In addition, this salinization leads to extreme drinking water scarcity for about 6.2 million people in this region (Abedin et al. 2014). Moreover, people in this region mostly depend on agriculture, fishery and resources extraction from the mangroves. However, all these activities are highly sensitive to climate change, and subsequent increases in sea-level rise, salinity and decreased fresh water flows from upstream particularly during the dry season (World Bank 2014).

\subsubsection{Salinity increase and the Sundarbans mangrove}

The Sundarbans is the largest contiguous mangrove forest in the world spreading over the south western part of Bangladesh $\left(\sim 6,000 \mathrm{~km}^{2}\right)$ and the West Bengal State in India $\left(\sim 4,000 \mathrm{~km}^{2}\right)$ (BBS 2001). This unique ecosystem provides vital breeding and nursery grounds for diverse marine resources, serves as a natural defence to cyclones and tidal surges, supports the livelihood of about 3.5 million coastal people and most importantly harbours the last remaining habitat of many globally endangered species of flora, such as Sundri (Heritiera fomes), and fauna, such as Royal Bengal Tiger (Panthera tigris) and Ganges river dolphin (Platanista gangetica) (Gain 2002). It is declared as a Ramsar Site under the Ramsar Convention in 1992 and World Heritage Site by UNESCO in 1997 for its outstanding ecological importance, universal value, biological diversity and ecosystem services (Sanyal 1999). 
Introduction

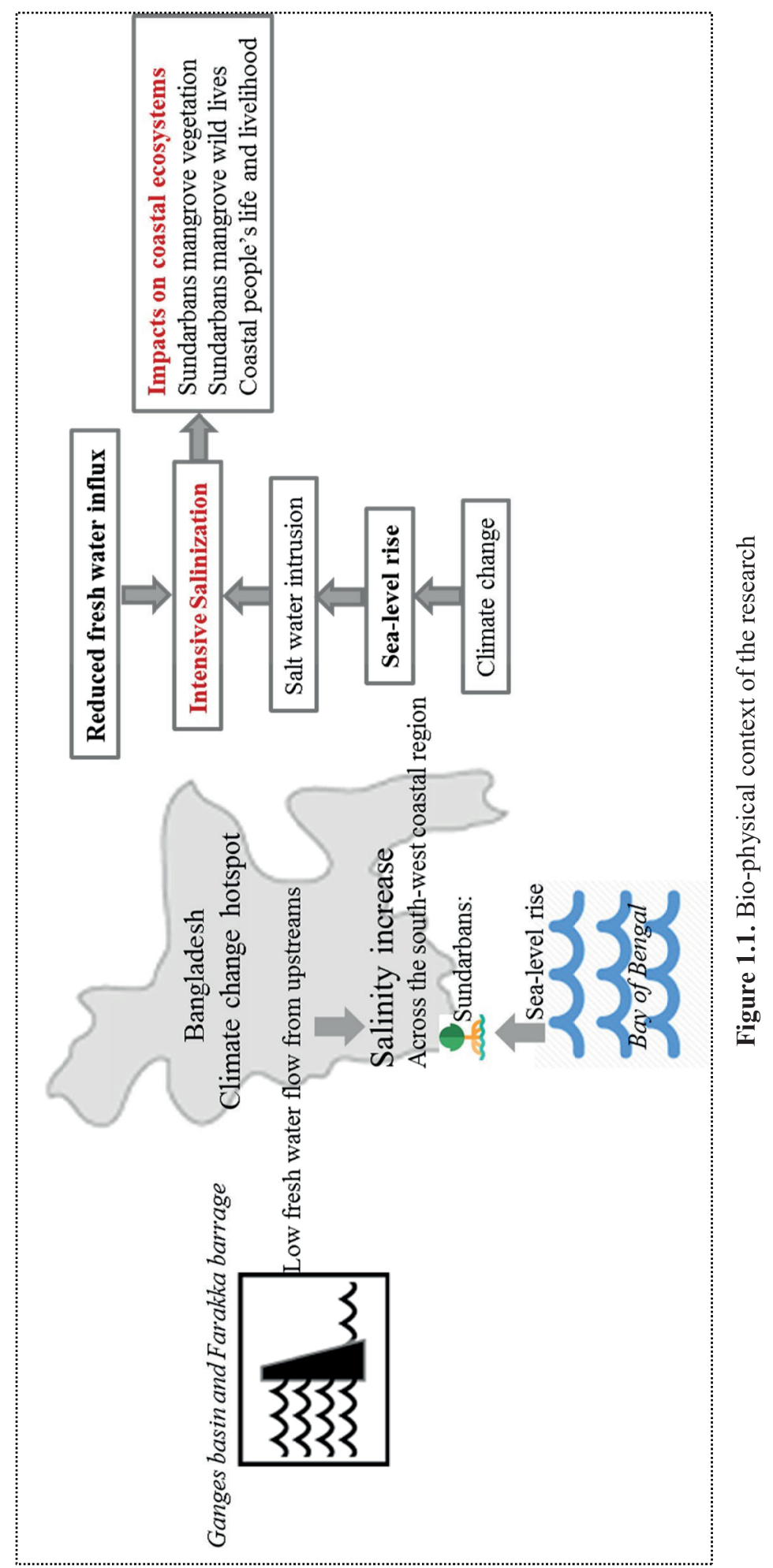


The Sundarbans has a balanced growth of flora and fauna in association with the fresh water flow from the Ganges basin and the salty sea water of the Bay of Bengal. However, its balance is now affected by climate change which results in further sea water intrusion and increasing salinity. A recent study on the Indian side of the Sundarbans showed that due to gradual increase in salinity, the fresh water loving Heritiera fomes disappeared and the area now is covered by shrubs and saline tolerant grasses (Chaudhury and Choudhury 1994). The long-term slow increase in salinity adversely influences the Sundarbans ecosystems. These influences are, for example, noticeable in the top dying and root rot diseases of $H$. fomes, retrogression of forest types, slow forest growth and reduced productivity of forest sites (MPO, 1986). If these noticed impacts continue, new species may invade the area of $H$. fomes and ultimately vegetation composition and regular succession patterns will change after a certain period of time. In particular because salinity determines to a large extent the dominating vegetation type (Ahmed et al. 1999).

These observed changes have already started to affect wildlife habitat in this mangrove. Wildlife is losing their habitat due to changes in vegetation composition (Gitay et al. 2002). Because each species of flora and fauna has a particular environmental envelope to sustain. If one of those components changes, the total system could collapse. Loucks et al. (2010) estimated that habitat for the Bengal tiger (Panthera tigris tigris) in the Bangladesh's Sundarbans would decline by $96 \%$ and the number of breeding individuals would reduce to less than 20 with a $28 \mathrm{~cm}$ rise above 2000 sea levels. WWF (2010) mentioned if actions to increase resilience of the Sundarbans are not initiated soon, Panthera tigris tigris of the Sundarbans may join the Arctic's polar bears (Ursus maritimus) as early victims of climate change-induced habitat loss. Barlow (2009) also mentioned the Bangladesh Sundarbans as the highest levels of human-tiger conflict sufferer in the world. The increase in salinity of the area is likely another threat.

\subsubsection{Salinity increase and the coastal communities}

Most of the people in this region still depend on resource extraction from the Sundarbans and crop-agriculture for their livelihoods and both activities are highly sensitive to climate change and its impacts (Danda 2007). Disruption of natural regeneration and top dying in H. fomes are hampering the production of the Sundarbans resources and services. This is affecting the local communities of the area (i.e., the bouali - wood and thatch cutters; mouali - honey extractors, jellay - fish and crab harvesters). Besides, extensive shrimp farming has created a 
direct conflict with crop agriculture. Shrimp farming has not only damaged agriculture but also agro-forestry, fisheries, livestock and physical infrastructures (Nowreen et al. 2014). In addition, salinization leads to extreme drinking water scarcity for about 6.2 million people in this region (Abedin et al., 2014). A saline environment has always been part of Bangladesh's south-west part and local people have been living with salt for the last three decades. However, the recent excessive salinization and its unfavourable impacts have forced people to already take mostly small scale adaptation measures, like cultivating salt tolerant crops, raising the plinth of the houses and tube-wells, afforestation and rain-water harvesting. However, to obtain greater benefits (i.e., food security, biodiversity conservation, environmental protection and sustainable livelihood), large scale adaptation planning is probably needed.

\subsection{Knowledge gaps and research focus}

An increasing number of recent studies has focused on salinity increase and its impacts. However, the above review indicates that the knowledge gaps for south-west coastal region of Bangladesh in relation with salinity increase and its impacts still exist. The first knowledge gap relates to the varying causes of salinization across the studied region. Several studies focused on climate change as the key grounds for salinity increase (Mahmuduzzaman et al. 2014; Mondal et al. 2013; Singh 2001). Others focused on the infrastructural developments (Moly et al. 2015; Mirza 1997) and a few highlighted important socio-economic processes (Nowreen et al. 2014; Deb 1998). However, local, regional and global drivers and their variations and interactions should be assessed to improve our understanding of the impact of environmental changes and the consequences for large scale adaptation planning. As there is substantial spatial variation in the impacts of different drivers at their rate of change (Singh et al. 2010). Even in Bangladesh's coastal area, significant spatial variations is observed (Khan et al. 2000). Hence, the salinization processes and their relationships across the south west coastal region of Bangladesh needs to be comprehensible and well-defined.

The second knowledge gap relates to the integrated climate-change impact study focusing on the relationship and dependency of different ecosystems components. For instance, if salinity increase triggers the Sundarbans mangrove vegetation to change, this will also distress the wildlife habitat in this mangrove and adjacent coastal communities who are dependent on resource extraction form the forest. In addition, although salinity is a key bio-physical 
component of the Sundarbans and it clearly has increased over the last decades (Hoque et al. 2006), to what extent this change can affect mangrove vegetation and wild habitats of the mangrove forest is poorly known. The Sundarbans is already regarded as the least studied forest in this line (Biswas \& Choudhury 2007). This knowledge gap makes forest management difficult to amend for long-term conservation. Therefore, impacts of salinity increase on different components of coastal ecosystems are essential to study.

The final knowledge gap relates to the target oriented large scale adaptation planning process. Policy makers often struggle where, when and which different measures need to be implemented due to highly uncertain future salt intrusion rates for unknowns in future climate change (Dessai and Sluijs 2008) and infrastructural developments. Recent excessive salinization and its unfavourable impacts have forced people to already take small scale adaptation measures, like cultivating salt tolerant crops, raising the plinth of the houses and tube-wells, afforestation and rain-water harvesting. However, to obtain greater benefits (i.e., food security, biodiversity conservation, environmental protection and sustainable livelihood), target oriented large scale adaptation planning is now needed.

Considering the above mentioned contexts, this study focuses on identifying the intermingling causes of salinity increase and their relationships, to evaluate the impacts of salinity intensification on different components of coastal ecosystems focusing the relationship and dependency with one another and subsequently developing adaptation pathways to cope with and to enhance resilience to salinization.

\subsection{Research objectives and questions}

My study, therefore, focuses on addressing the following three-fold objectives:

Objective 1: To improve the understanding of the salinization processes across the southwest coastal region of Bangladesh;

Objective 2: To identify how different components of coastal ecosystems (particularly the Sundarbans mangrove vegetation, Royal Bengal tiger habitat and coastal people) are affected by salinization; and

Objective 3: To develop adaptation pathways for the mostly affected coastal systems to cope with and to enhance resilience to salinization. 
These objectives were addressed through stepwise methods using a multidisciplinary research framework combining both qualitative and quantitative approaches. At the first step, the related hydro-climatic variables (i.e., temperature, precipitation, fresh water flow, tidal water level) to salinity increase were analysed to evaluate the likely relationships of these variables with salinity increase. Secondly, ecological status of the Sundarbans mangrove vegetation (i.e., composition, regeneration, canopy cover and density) along the salinity gradient was surveyed to reveal the possible changes in mangrove vegetation for further changes in salinity levels. In the third step, quality tiger-habitat requirements (i.e., fresh water accessibility, suitable vegetative cover and prey species availability) were assessed to identify the potential aspects of the Sundarbans tiger habitat degradation due to salinity increase. In the last step, we evaluated local people's perception and key informants observation on salinity increase and its processes mainly to develop the driver-pressure-state-impact-response (DPSIR) framework for salinization in south-west coastal region by integrating both the socio-economic and hydro-climatic variables of salinization. We also developed adaptation pathways for southwest coastal region of Bangladesh to cope with and to enhance resilience to salinization considering both top down and bottom up perceptions and observations. Each of these steps is accompanied by a corresponding research question:

Question 1: Is salinity increase in south-west coast of Bangladesh driven by climate change only or also by other environmental or socio-economic changes ? (Chapter 2 and Chapter 5)

Question 2: How is salinity increase affecting the Sundarbans mangrove vegetation? (Chapter 3)

Question 3: How is salinity increase distressing the Sundarbans' tiger habitat? (Chapter 4)

Question 4: What are potential adaptation pathways to cope with and enhance resilience to salinization? (Chapter 5)

\subsection{Thesis outline and methodological design}

This thesis is structured into six different chapters where the objectives and research questions are addressed in four scientific papers from Chapters 2 to 5 following a general introduction in Chapter 1. Chapter 2 represents the hydro-climatic variables of salinity increase and their relationships. Chapter 3 focusses on impacts of these salinization processes on the Sundarbans mangrove vegetation and demonstrates robust findings on ecological status of mangrove vegetation along the salinity gradients - suggesting increasing salinity threats for the 
mangrove vegetation under diverse environmental changes. Chapter 4 explores the impacts of salinization and its range of processes on Bengal tiger's mangrove habitat for drinking water sources, prey availability and suitable vegetative cover to perform different physiological activities. Chapter 5 focusses on socio-economic processes of salinization and target oriented potential measures for the mostly affected coastal systems to cope with salinization. The study's methodology is designed to address the objectives and research questions. An overview of the methodological design and corresponding chapters is shown in Figure 1.2.

To address the first research question, we investigated observed time series data of five hydroclimatic variables (i.e., temperature, precipitation, tidal water-level, freshwater discharge and salinity) and the potential cause-effect relationship among them using different statistical analysis, and extreme climatic indices (Chapter 2). In addition, we surveyed local people and experts to get their perceptions on salinity increase and its processes (Chapter 5).

For the second research question, a vegetation survey was carried out along major salinity transects running from land to sea following standard quadrat method to evaluate different vegetative cover using various quantitative structural indices (i.e., importance value index, species richness, diversity index, evenness and species equitability index) (Chapter 3).

To address the third research question, we analysed five different information sources (i.e., literature review, field observations and analysis of hydro-climatic variables, focussed group discussions with local communities and interviews with experts) to enrich the knowledge platform on how tiger habitat relates to and is affected changing salinity levels (Chapter 4).

For the very last research question, we combined different approaches (i.e., household surveys, key informant interviews, DPSIR framework, multi-criteria analysis and an adaptation pathway approach based on adaptation turning point) to study the causes and impacts of, and to develop adaptation pathways to cope with salinization.

Finally, the main findings of four scientific papers are synthesized and discussed in Chapter 6, along with the study's relevance to national action plans and policies and its scientific contributions to better understand salinization and adaptation planning. The chapter also presents overall recommendations and reflects on strengths and limitations. It provides robust evidence for increasing salinity impacts on different coastal systems and suggests ways to cope with and enhance their resilience to salinization for the studied region. Finally, an outlook for further research on this topic is presented. 


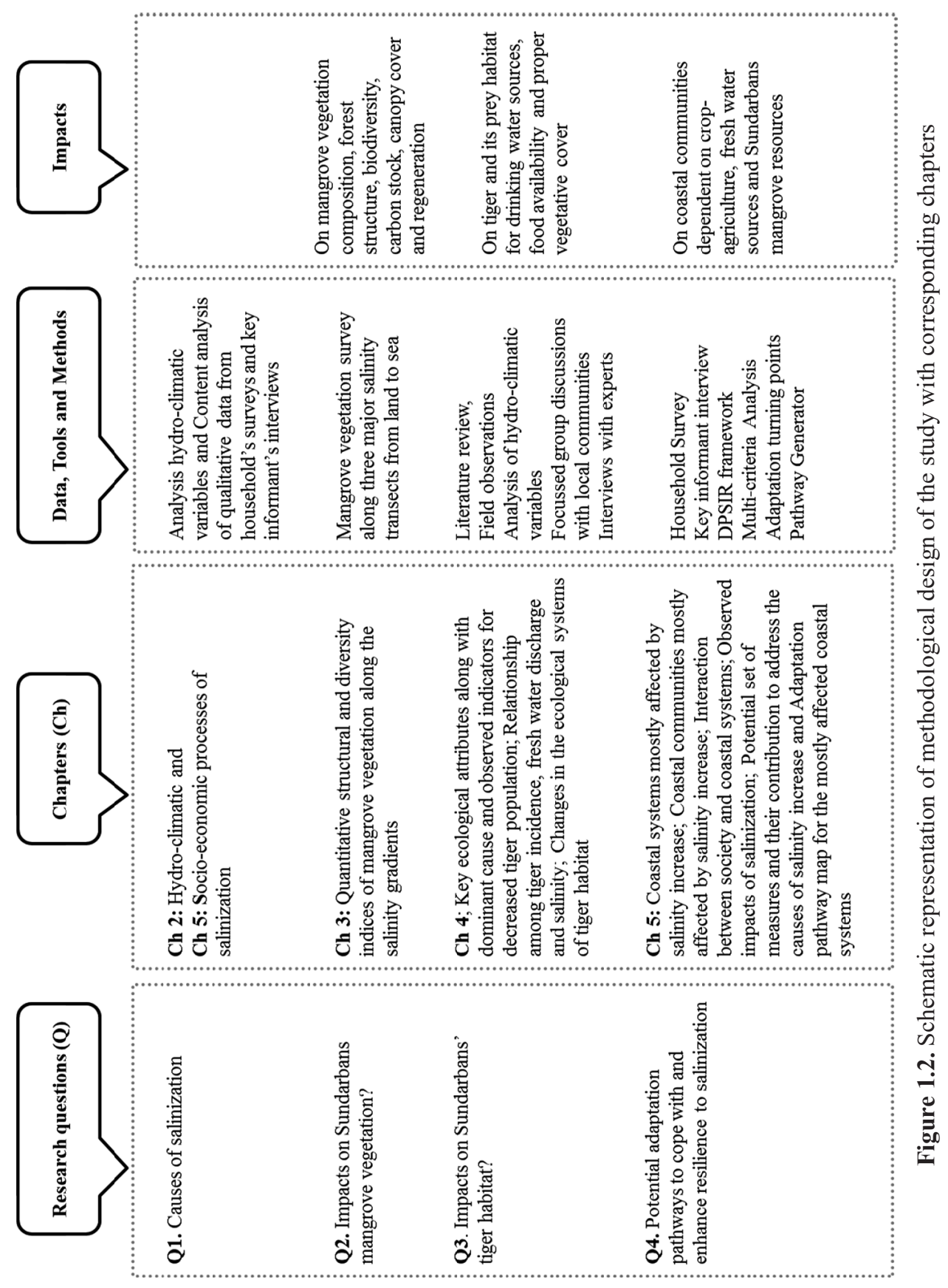




\title{
Chapter 2. Recent Environmental Changes in South-West Coastal Region of Bangladesh
}

\begin{abstract}
Local environmental changes vary spatially because of various contributing local factors. Changes across the south-west coast of Bangladesh are investigated through different hydroclimatic variables i.e., temperature, precipitation, tidal water-level, fresh-water discharge and salinity to assess the extent of hydro-climatic signals and correlation of these variables. The novelty of the research is to coherently evaluate all these interacting variables to detect the potential cause-effect relationship among them and to understand the bio-physical environmental changes across this coastal region. This region has warmed significantly $(p \leq 0.01)$ for both maximum $\left(0.03^{0} \mathrm{C} \mathrm{yr}^{-1}\right)$ and minimum temperatures $\left(0.02^{0} \mathrm{C}^{-1}\right)^{-1}$ from 1981 to 2010. Changes in precipitation pattern indicate at significant seasonal shift from premonsoon $(p \leq 0.01)$ particularly in April $\left(-3.9 \mathrm{~mm} \mathrm{yr}^{-1}\right)$ to post-monsoon $(p \leq 0.05)$ particularly

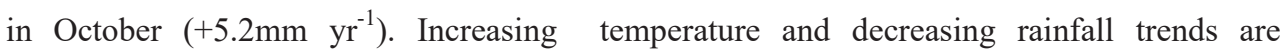

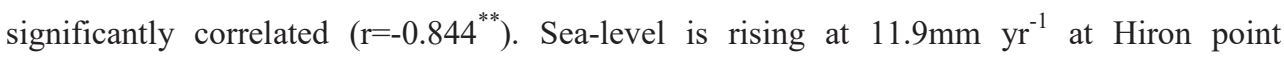
$(p \leq 0.01)$. Fresh-water discharge through Gorai river to the south-west coastal river network after the Farakka barrage construction in 1975 is almost halved (i.e., 41\%) during AugustSeptember-October. The river's water salinity significantly increased by $0.5 \mathrm{ppt}$ on average over the last nine years, particularly in dry and pre-monsoon seasons. Increasing salinity has a significant correlation with rising temperatures, simple daily intensity index of precipitation, reduced upstream flow and sea-level rise. These results indicate that salinity increase across the south-west coast of Bangladesh is driven by a range of processes.
\end{abstract}




\subsection{Introduction}

Coastal ecosystems, such as mangroves, coastal wetlands and coastal inlands, are among the most productive ecosystems in the world. Simultaneously, these coastal systems are also highly vulnerable to climate change including sea-level rise, salt-water intrusion, reduced river flows and increased extreme weather events (e.g. cyclones (Walther et al. 2002; Wong et al. 2014). Coastal regions are estimated to annually provide over US $\$ 33,268 \times 10^{9}$ worth of ecosystem services (e.g. food, timber, raw materials, habitats, ecotourism and many more) per year (Martínez et al.2007). Climate change is becoming evidently one of the dominant drivers of change in these vulnerable ecosystems (Nicholls et al. 2007).

Bangladesh is one of the most climate change affected countries in the world (Kreft et al. 2015). The country lies on the delta of three large river basins, the Ganges, the Brahmaputra and the Meghna, and is affected by sea-level rise and large scale inter-annual climate variability. Its climate is governed by the monsoon (Singh 2001). Bangladesh's combination of high population densities and poverty rates make the country very vulnerable to climate change. Still large parts of its population depend on natural resources and agriculture for their livelihoods and both activities are highly sensitive to climate change (Rahman et al. 2012). Its natural and agricultural systems are already affected by salt-water intrusion, extreme events and reduced dry season water availability (Rahman and Rahman 2015). For example, one third of the country's cultivable lands are covered by the coastal areas which are less than $3 \mathrm{~m}$ above mean sea-level (Shaw et al. 2013).

Especially Bangladesh's south-west coastal region is potentially vulnerable to climate change, mostly for its environmental setting. This region connects the upstream Ganges basin to its downstream. The river flow and rainfall play an important role in maintaining the fresh water flow through the region and in determining the region's salinity levels (IWM 2014). In addition, the region includes the Sundarbans, which is an important UNESCO world heritage ecosystem. These unique mangrove ecosystems provide vital breeding and nursery grounds for different marine species, serves as a natural defence to cyclones and tidal surges, supports the livelihood of many people and, most importantly, houses the last remaining habitats of many endangered species. People in this region mostly depend on agriculture, fishery and resources extraction from the mangroves. However, all these activities are highly sensitive to climate change, and subsequent increases in sea-level rise, salinity and decreased fresh water flows from upstream (mainly during the dry season) (World Bank 2014). 
Over the last decades, climate already significantly changed. For example, mean sea-level increased by $3.2 \mathrm{~mm}$ from 1993 to 2010 (Carton et al. 2005), the average global mean temperature has increased by about $0.8^{0} \mathrm{C}$ (Hansen et al. 2010) and global precipitation patterns are changing (Trenberth 2011). However, substantial spatial variation occurs in their rate (Singh et al. 2010). Even in Bangladesh's coastal area, significant spatial variations is observed (Khan et al. 2000). Therefore, local, regional and global variations and their interactions should be distinguished.

The Intergovernmental Panel on Climate Change (IPCC) in its fourth assessment report observed evidences of climate change in these low lying coastal regions. The evidences included increased temperatures, rainfall variability, inconsistent upstream river discharge and rising sea-levels (Parry, 2007). Although fifth assessment report additionally mentioned increasing ocean acidity (Wong et al. 2014). These changes will ultimately increase salinity (Passeri et al. 2015) and this most likely affects biodiversity by degrading habitats (Sarker et al. 2016) and livelihoods of many coastal people, leading to economic losses and poorer living and health conditions (Huq et al. 2015). These impacts are already being felt across Bangladesh's south-west coast (Karim and Mimura 2008; Ali 1999; Mirza 1998).

This study analyses recent environmental changes in Bangladesh's south-west coastal region. Previous studies have investigated temperature scenarios (e.g. Rahman et. al 2012; Islam 2009), variability and trends of rainfall (Ahasan et al. 2010; Hossain et al. 2014 ), sea-level rise (Bhuiyan and Dutta 2012; Brammer 2014; Pethick and Orford 2013), seasonal changes in water salinity (Hussain et al. 2013; Islam and Gnauck 2011) and reduced fresh water flow from upstream to the coastal river network (Mondal et al. 2013). Most of these studies only focussed on specific locations and individual aspects of regional environmental change. No study thus far evaluated all these factors consistently and integrally to understand the recent regional environmental changes. Additionally, the Bangladesh Government is planning and implementing climate-change adaptation strategies in this region. This requires an improved understanding of recent changes and also allows to better validate different environmental change models and scenarios.

Therefore, this study aims to investigate observational evidences of climate change and climate-change induced problems along Bangladesh's south-west coast. Its specific objectives are to analyse to what extent local hydro-climatic variables (i.e., sea-level, temperature, rainfall, altered riverine flows and salinization intensity in the region's rivers) 
have changed. This paper also analyses the potential cause-effect relationships among these variables.

\subsection{Methods}

\subsubsection{Data and quality check}

The 30 years record of observed daily temperature $\left({ }^{0} \mathrm{C}\right)$ and rainfall $(\mathrm{mm})$ data of nine meteorological stations for the period 1981 to 2010 for the south-west coast were collected from the Bangladesh Meteorological Department. Each station represents one district. Extreme tidal gauge data (monthly maxima and minima) at Hiron Point for the same time period was obtained from Bangladesh Inland Water Transport Authority (BIWTA). Hiron Point is located at the mouth of the Passur estuary on a natural tidal channel within the Sundarbans mangrove forest. BIWTA measures self-recording pressure gauges for the Tidal Water Level (TWL) using the Model MUNRO, U.K in meter. TWL data are converted into $\mathrm{mm}$ to use in this study. Daily fresh water discharge (cumec) from the Ganges through Gorai river at Gorai Railway Bridge to the south-west coastal river network for the period 1964 to 2010 was collected from Bangladesh Water Development Board (BWDB). It was collected for the time period more than 30 years to analyse the fresh water discharge trend before and after Farakka barrage construction. Water salinity (EC) data for the month of November to June from 2000 to 2008 of 12 different stations located in 7 rivers of 3 coastal districts (Khulna, Bagerhat and Satkhira) were also collected from BWDB for both high tide (HT) and low tide (LT) condition. The salinity data before 2000 was not available except for Khulna, however, those data were too irregular to be used for this study. BWDB does not collect salinity data for the month July to October. During monsoon and post monsoon, salinity levels generally remain low. Salinity data was converted into parts per thousand (ppt) as this unit is mostly used in different study. If any missing data for any day of a year was found for a particular station from the above mentioned data set, a simple average method was applied. However, the missing data was less than $2 \%$. The locations of different stations are shown in Figure 2.1. Meta data of these locations is available in supplementary information A (Table A1). 


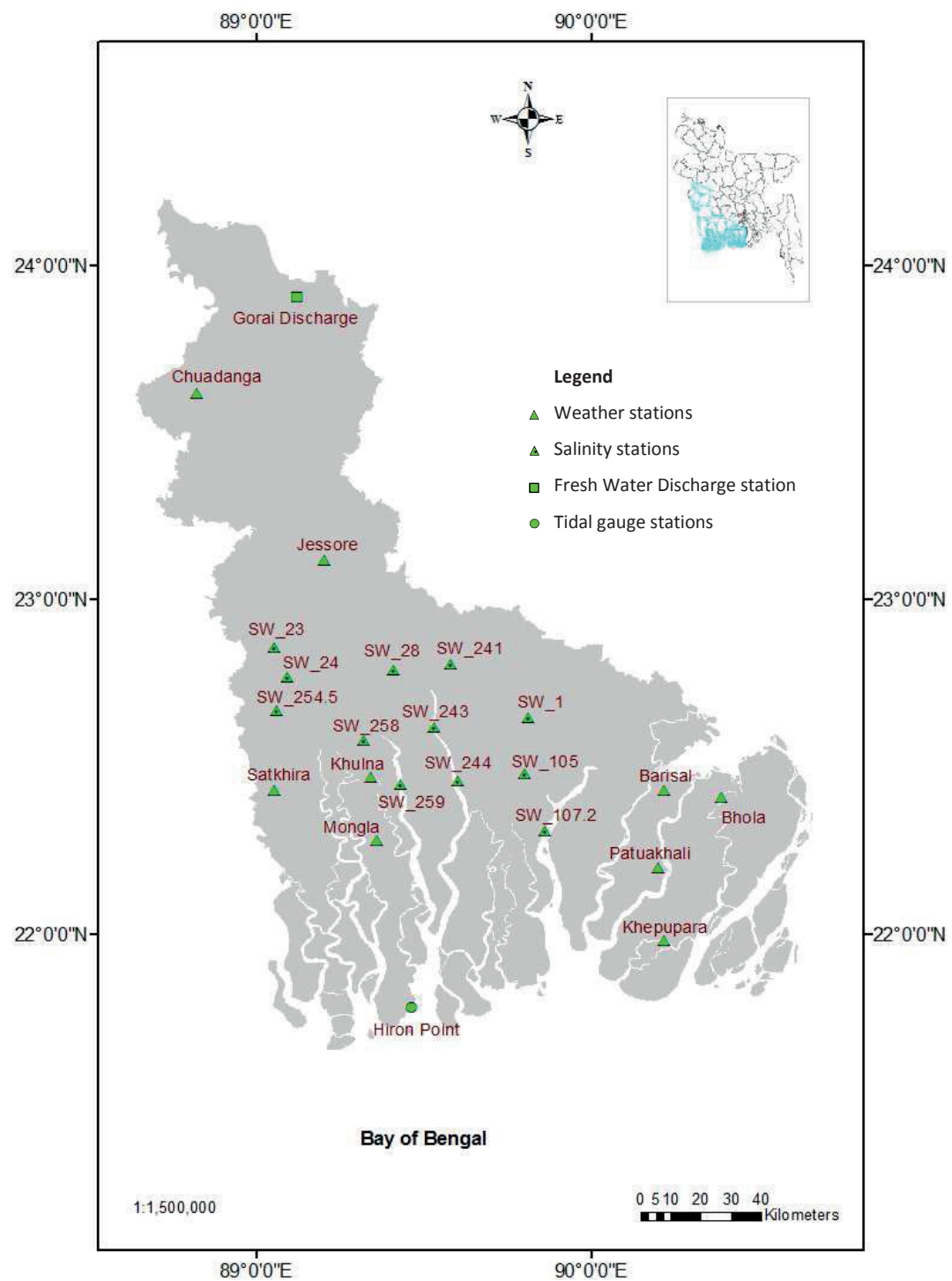

Figure 2.1. Location of different stations in South-West coastal region of Bangladesh

\subsubsection{Analysis}

All the data are processed to obtain monthly, seasonal and annual average values. Seasonal and monthly variations are analysed as temperature and rainfall pattern, discharge flow, sealevel rise and salinity varies significantly across the months of four seasons in Bangladesh (Mirza and Hossain 2004; Bhuiyan and Dutta 2012). The average of each of the selected 
parameters over the stations is considered as the south-west coast average. For our seasonal analysis, four distinct climatic seasons of Brammer (2002) are considered: monsoon (JuneJuly-August-September: hereafter written as JJAS), post-monsoon (October-November: ON), winter/dry season (December-January-February: DJF) and pre-monsoon (March-April-May: MAM). The decadal variations are also studied as climate change and climate change induced problems were observed principally after the 1990s (IPCC 2001). For the analysis of decadal variation, all the datasets were divided into three decades: 1981 to 1990,1991 to 2000 and 2001 to 2010. Anomalies of temperature and rainfall was also explored from average value (as reference value) of each of the parameters over 30 years' time period to see the deviation since 1980. A positive anomaly value indicates that the observed value was greater than the average value from 1981 to 2010 , while a negative anomaly indicates that the observed value was less than the average value. In addition, different extreme temperature and precipitation indicators were also analysed (see Table 2.1 for details) because extreme indices provide insight into local conditions (Zhang et al. 2011). Only the discharge data is divided into pre (1964-1975) and post-Farakka (1976-2010) periods as low discharge was observed after the 1975 due to the construction of Farakka barrage (Mirza 1998). Effective Sea-level rise (SLR) is calculated from the Extreme TWL data following Pethick and Orford 2013. Because Effective SLR varies from eustatic SLR due to the constituent processes like subsidence (Sb), tidal amplitude (TA) and fresh water base level flow (FwQ) reduction. Also Mean SLR trend was calculated from the observed TWL data during high and low tides. Bivariate (Pearson) correlation with 0.05 and 0.01 significance level and simple linear regression model using least squares method with $95 \%$ confidence intervals were done for all the statistical analysis (using IBM SPSS 22) of the monthly, seasonal and decadal variation of the all selected variables, and extreme climatic indices for trend analysis and correlation among the variables. Regression coefficients determined the rate of changes. Confidence limits (upper bound and lower bound) for each of the regression coefficients were also calculated. The significance of the trend correlation coefficients has been tested using the parametric Student's two-tailed ttest. Finally the cause effect linkage among the variables were tested using the yearly and monthly linear regression correlations among the variables. In this case, covariance was calculated to measures the degree to which two variables are linearly associated. Different likelihood terminology used in this study for different analysis based on probability levels for each regression is given in in supplementary information A (Table A2) and level of correlation based on correlation co-efficient values in Table A3. Results of the statistical analysis of all the variables are summarized in Table A4 of supplementary information A. 
Table 2.1. The Extreme Temperature and Precipitation Indices Used in this study

\begin{tabular}{|c|c|c|c|}
\hline ID & Indicator Name & Indicator Definition & Unit \\
\hline & & \multicolumn{2}{|l|}{ Indices of temperature extremes } \\
\hline TXX & Hottest Day & Monthly maximum value of daily max temperature & ${ }^{0} \mathrm{C}$ \\
\hline $\mathrm{TNn}$ & Coldest Night & Monthly minimum value of daily min temperature & ${ }^{0} \mathrm{C}$ \\
\hline DTR & Diurnal temperature range & $\begin{array}{l}\text { Monthly mean difference between daily max and min } \\
\text { temperature }\end{array}$ & ${ }^{0} \mathrm{C}$ \\
\hline SU & $\begin{array}{l}\text { Summer days } \\
\text { (absolute threshold) }\end{array}$ & Annual count when daily maximum temperature $>25^{\circ} \mathrm{C}$ & days \\
\hline TR & Tropical nights & Annual count when daily minimum temperature $>20^{\circ} \mathrm{C}$ & days \\
\hline \multirow[t]{2}{*}{ ETR } & Extreme temperature range & Difference between hottest day and coldest night & ${ }^{0} \mathrm{C}$ \\
\hline & & Indices of precipitation extremes & \\
\hline Rx1day & $\begin{array}{l}\text { Max 1day precipitation } \\
\text { amount (absolute extreme) }\end{array}$ & Monthly maximum 1day precipitation & $\mathrm{mm}$ \\
\hline SDDII & $\begin{array}{l}\text { Simple daily intensity } \\
\text { index }\end{array}$ & $\begin{array}{l}\text { The ratio of annual total precipitation to the number of } \\
\text { wet days }(\geq 1 \mathrm{~mm})\end{array}$ & $\mathrm{mm} /$ day \\
\hline $\mathrm{R} 10 \mathrm{~mm}$ & $\begin{array}{l}\text { Number of heavy } \\
\text { precipitation days (absolute } \\
\text { threshold) }\end{array}$ & Annual count when precipitation $\geq 10 \mathrm{~mm}$ & days \\
\hline PRCTOT & $\begin{array}{l}\text { Annual total wet day } \\
\text { precipitation }\end{array}$ & Annual total precipitation from days $\geq 1 \mathrm{~mm}$ & $\mathrm{~mm}$ \\
\hline
\end{tabular}

Adopted from Peterson et al. 2001

\subsection{Results}

\subsubsection{Maximum and minimum temperature anomalies and extreme indices}

Most of the high anomalies of maximum temperatures are found in the last decade from 2000 to 2010 (Figure 2.2a). Minimum temperature anomalies are found positive from 1987 onwards and the positive trend was constantly increasing from 2002 to 2010 (Figure 2.2b). Departure of maximum temperature from the reference value (30 years average) is significantly increasing at the rate of $0.03^{0} \mathrm{C}^{-1}{ }^{-1}\left(p<0.001 ; \mathrm{R}^{2}=0.376\right)$ and minimum

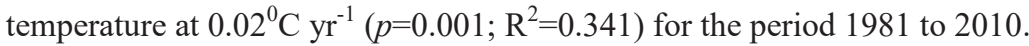

Monthly trends of maximum (Figure 2.2c) and minimum temperature (Figure 2.2d) from 1981 to 2010 show an increase for all months of the year. The increase was mostly in the months of March, April and May i.e. the pre-monsoon season. It is noticeable for both maximum and minimum temperature. However, statistical analysis shows that the trend of maximum temperature particularly in April $\left(p=0.047 ; \mathrm{R}^{2}=0.133\right)$ and May $\left(p=0.001 ; \mathrm{R}^{2}=0.308\right)$ is significantly increasing for last 30 years. Minimum temperature trends are not significant for most of the months. Only for April the $\mathrm{P}$ value was slightly above $0.05\left(p=0.052 ; \mathrm{R}^{2}=0.129\right)$. 
Diurnal temperature range (Figure 2.3a) is likely to increase, however, the increasing trend is not statistically significant ( $p=0.105 ; \mathrm{R}^{2}=0.091$ ). The number of summer days (Figure 2.3b) has not increased $\left(p=0.766 ; \mathrm{R}^{2}=0.003\right)$, however, tropical nights $\left(p=0.036 ; \mathrm{R}^{2}=0.148\right)$ have increased (Figure 2.3c). Increasing trend of extreme temperature range (Figure 2.3d) is virtually certain $\left(p=0.002 ; \mathrm{R}^{2}=0.283\right)$ at $0.07^{0} \mathrm{C} \mathrm{yr}^{-1}$. Thus extreme temperature indices reveal the annual increase of daily minimum temperature more than $20^{\circ} \mathrm{C}$ and intensification in difference between hottest day and coldest night.

\subsubsection{Changes in precipitation pattern and extreme indices}

Precipitation anomalies (Figure 2.4a) and daily precipitation trend (Figure 2.4b) show the variability and decreasing state. Negative precipitation anomalies are seen since 1982, however, it was more frequent from 1992 and from 2008 it was constant. Departure of precipitation from the reference value is likely to decrease at $-6.6 \mathrm{~mm} \mathrm{yr}^{-1}\left(p=0.231 ; \mathrm{R}^{2}=\right.$ $0.051)$ and daily precipitation at $0.02 \mathrm{~mm} \mathrm{day}^{-1}\left(p=0.235 ; \mathrm{R}^{2}=0.050\right)$ for the period 1981 to 2010. Hence, precipitation is likely less than before in south-west coast of Bangladesh, however, it is not statistically significant.

Decadal variation in monthly precipitation is noticeable for all the months. Two years moving average trends for last three decades show that pre-monsoon season precipitation mostly in April and May is constantly decreasing while monsoon precipitation mostly in July and September and post-monsoon precipitation mostly in October is increasing (Figure 2.4c). However, statistical analysis shows that decreasing trend of precipitation only in April is virtually certain at $-3.9 \mathrm{~mm} \mathrm{yr}^{-1}\left(p=0.002 ; \mathrm{R}^{2}=0.298\right)$ and increasing trend in October is extremely likely at $+5.2 \mathrm{~mm} \mathrm{yr}^{-1}\left(p=0.023 ; \mathrm{R}^{2}=0.171\right)$. It indicates the seasonal shift in precipitation from pre-monsoon to post monsoon.

Annual total wet day precipitation (Figure 2.5a) and number of heavy precipitation days (Figure 2.5c) is likely to decrease, however, statistically these extreme indices are not significant. Decreasing trend of Simple Daily Intensity Index (Figure $2.5 \mathrm{~b}$ ) at $0.3 \mathrm{~mm}$ is virtually certain $\left(p=0.000 ; \mathrm{R}^{2}=0.357\right)$. Increasing trend of maximum 1day precipitation (Figure $2.5 \mathrm{~d}$ ) is extremely unlikely $\left(p=0.963 ; \mathrm{R}^{2}=0.000\right.$ ). Accordingly extreme precipitation indices signifies the declining ratio of annual total precipitation to the number of wet days more than or equal to $1 \mathrm{~mm}$. 
a. Maximum temperature anomaly

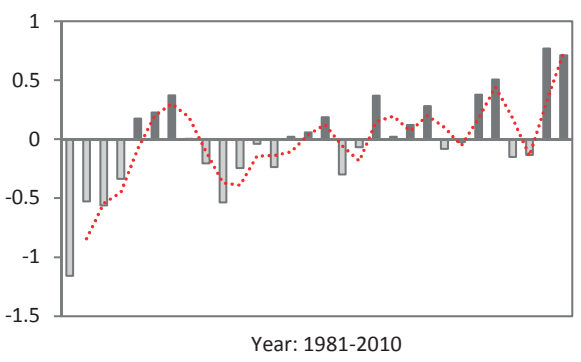

c. Monthly variation (maximum temperature)

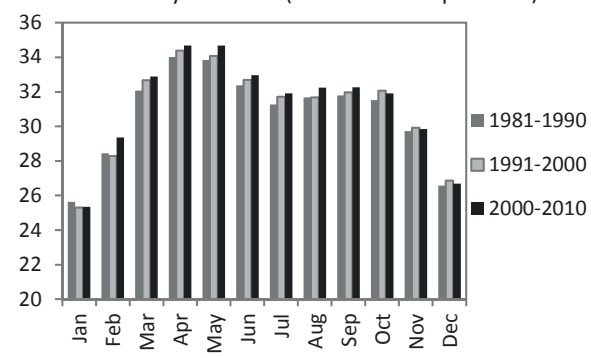

b. Minimum temperature anomaly

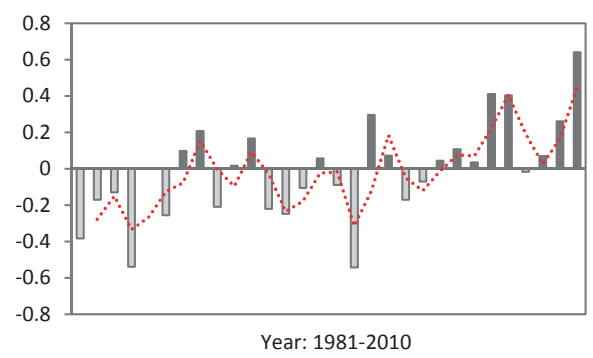

d. Monthly variation (minimum temperature)

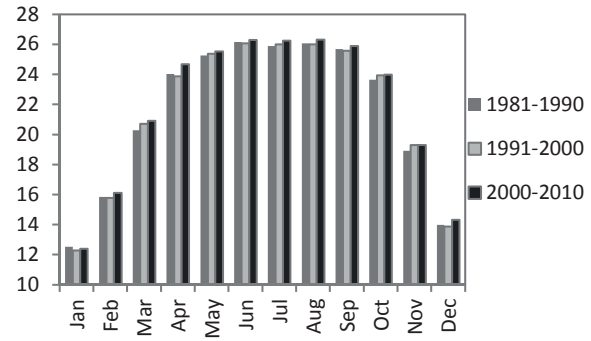

Figure 2.2. Temperature Anomalies $\left({ }^{0} \mathrm{C}\right)$ and Monthly Variation
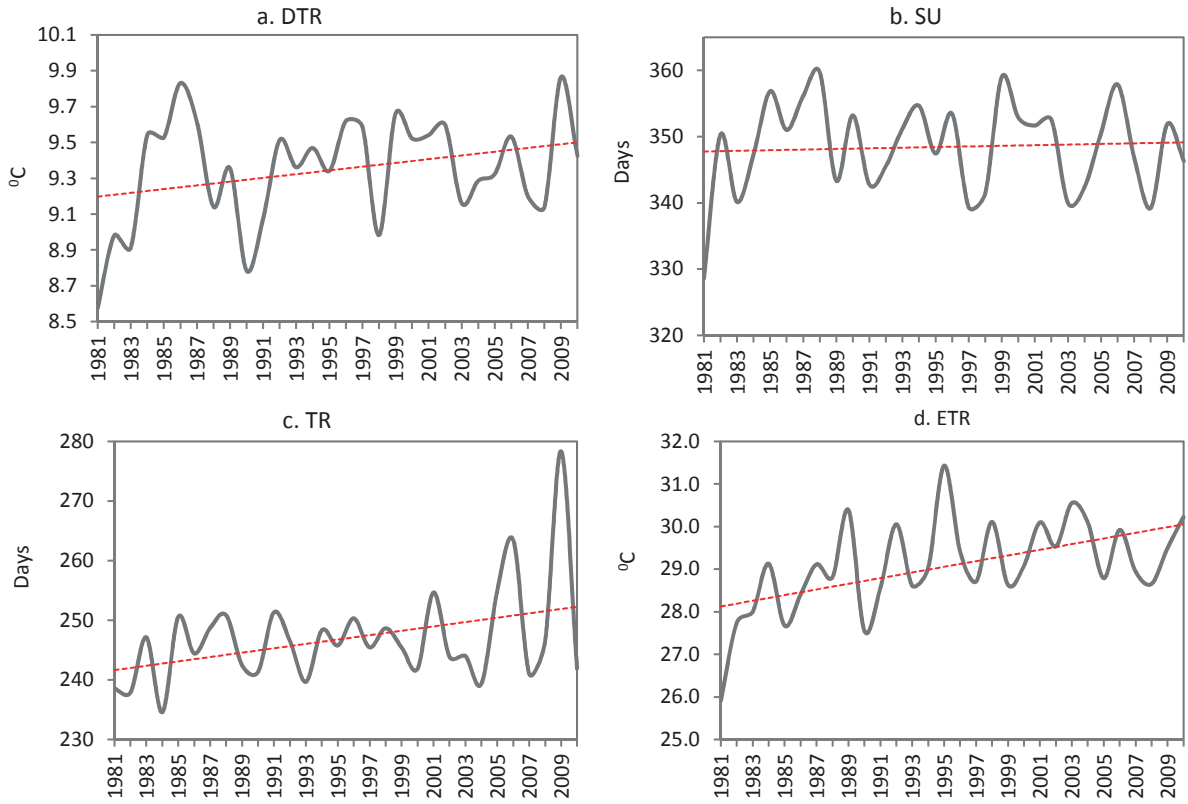

Figure 2.3. Extreme Temperature Indices 

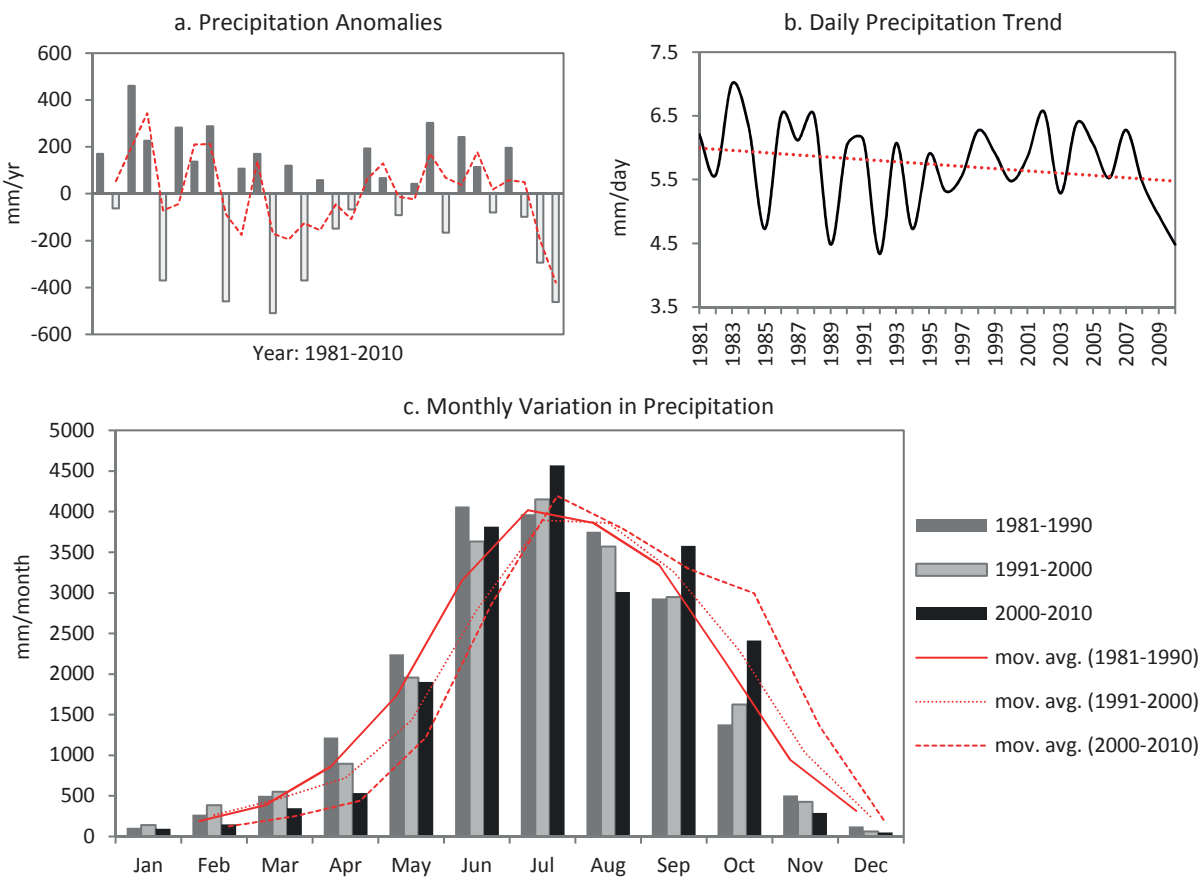

Figure 2.4. Precipitation Anomalies, Daily Trend and Monthly Variation
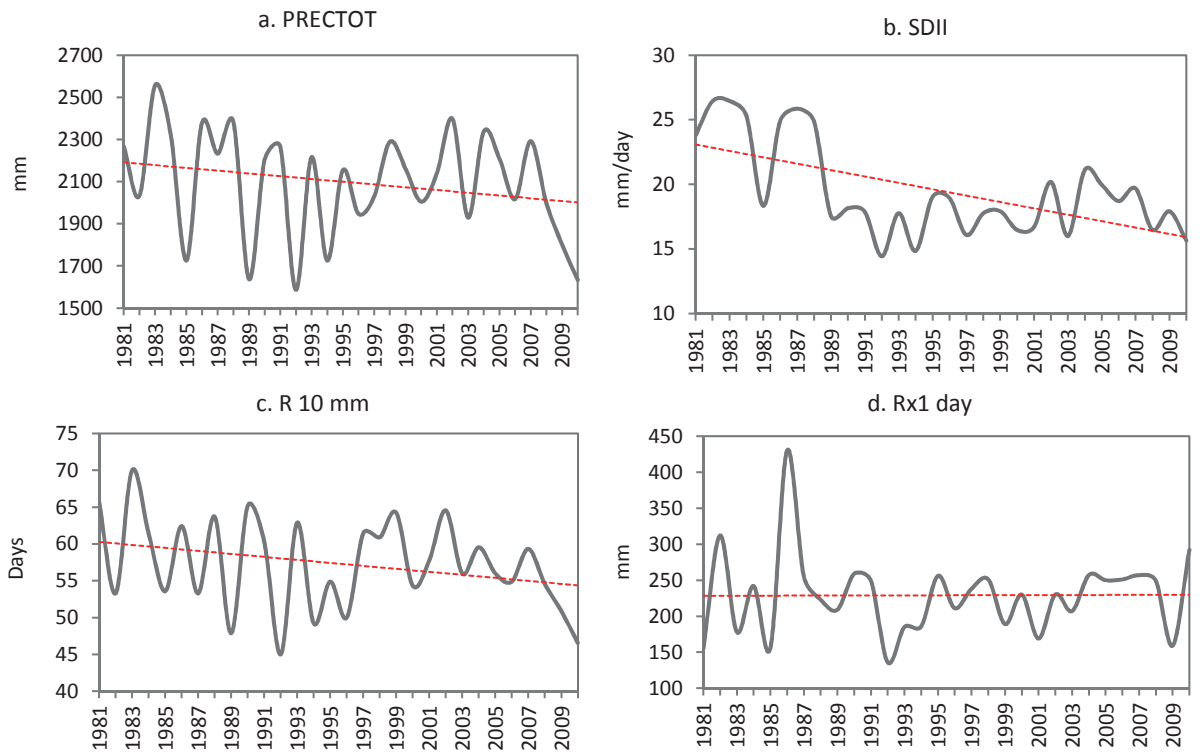

Figure 2.5. Extreme Precipitation Indices 


\subsubsection{Sea-level Rise at Hiron point in the south-west coast of Bangladesh}

TWL maxima is rising at $5.3 \mathrm{~mm} \mathrm{yr}^{-1}\left(p=0.003 ; \mathrm{R}^{2}=0.271\right)$ and minima have reduced at 4.5 $\mathrm{mm} \mathrm{yr}^{-1}\left(p=0.041 ; \mathrm{R}^{2}=0.140\right.$ ). Increasing trend of TWL maxima (Figure 2.6a) and decreasing trend of TWL minima (Figure 2.6b) indicate intensifying the tidal range which will affect Effective SLR. Considering TA, eustatic sea-level and subsidence, calculated Effective SLR has become $11.9 \mathrm{~mm} \mathrm{yr}^{-1}$ (Table A5 in Supplementary information A).

Rise in TWL maxima for last decade (2001-2010) is very precise across the months (Figure 2.6c). Particularly in the months January, February, May, September and December, it is rising constantly for last three decades. However, the rise in January $\left(p=0.008 ; \mathrm{R}^{2}=0.228\right)$, February $\left(p=0.008 ; \mathrm{R}^{2}=0.225\right)$ and May $\left(p=0.009 ; \mathrm{R}^{2}=0.221\right)$ is statistically significant. On the other hand, TWL minima in January $\left(p=0.025 ; \mathrm{R}^{2}=0.166\right)$, July $\left(p=0.016 ; \mathrm{R}^{2}=0.191\right)$ and September $\left(p=0.039 ; \mathrm{R}^{2}=0.144\right)$ have declined over last three decades, in August it is virtually certain ( $\left.p=0.008 ; \mathbf{R}^{2}=0.228\right)$ and for rest of the months variability is seen (Figure $2.6 \mathrm{~d}$ ). TWL maxima is observed highest in August while TWL minima in July.

\subsubsection{Fresh water discharge through Gorai to the south-western river network}

Pre-Farakka mean annual flow is very unlikely to decrease (Figure 2.7a) whereas decreasing annual trend of post Farakka flow at $11.43 \mathrm{~m}^{3} \mathrm{sec}^{-1}$ day $^{-1}$ is virtually certain (Figure 2.7b). And monthly variation in the post Farakka period for last three decades shows the increasing trend (from December to July) mainly in dry season and pre-monsoon (Figure 2.7c) and decreasing trend (from August to November) mainly in monsoon and post monsoon season (Figure 2.7d). However, merely the increasing trend in January is statistically significant ( $p=$ $0.032 ; \mathrm{R}^{2}=0.153$ ) and it is likely to increase at $5.30 \mathrm{~m}^{3} \mathrm{sec}^{-1} \mathrm{day}^{-1}$. On the other hand, decreasing trends of fresh water flow in August and September are virtually certain at 44.86 $\mathrm{m}^{3} \sec ^{-1}$ day $^{-1}\left(p=0.014 ; \mathrm{R}^{2}=0.198\right)$ and $93.15 \mathrm{~m}^{3} \sec ^{-1}$ day $^{-1}\left(p=0.00 ; \mathrm{R}^{2}=0.440\right)$ respectively. Also in October the discharge is extremely likely to decrease at $32.431 \mathrm{~m}^{3} \mathrm{sec}^{-1}$ day $^{-1}$ ( $\left.p=0.049 ; \mathrm{R}^{2}=0.132\right)$. 

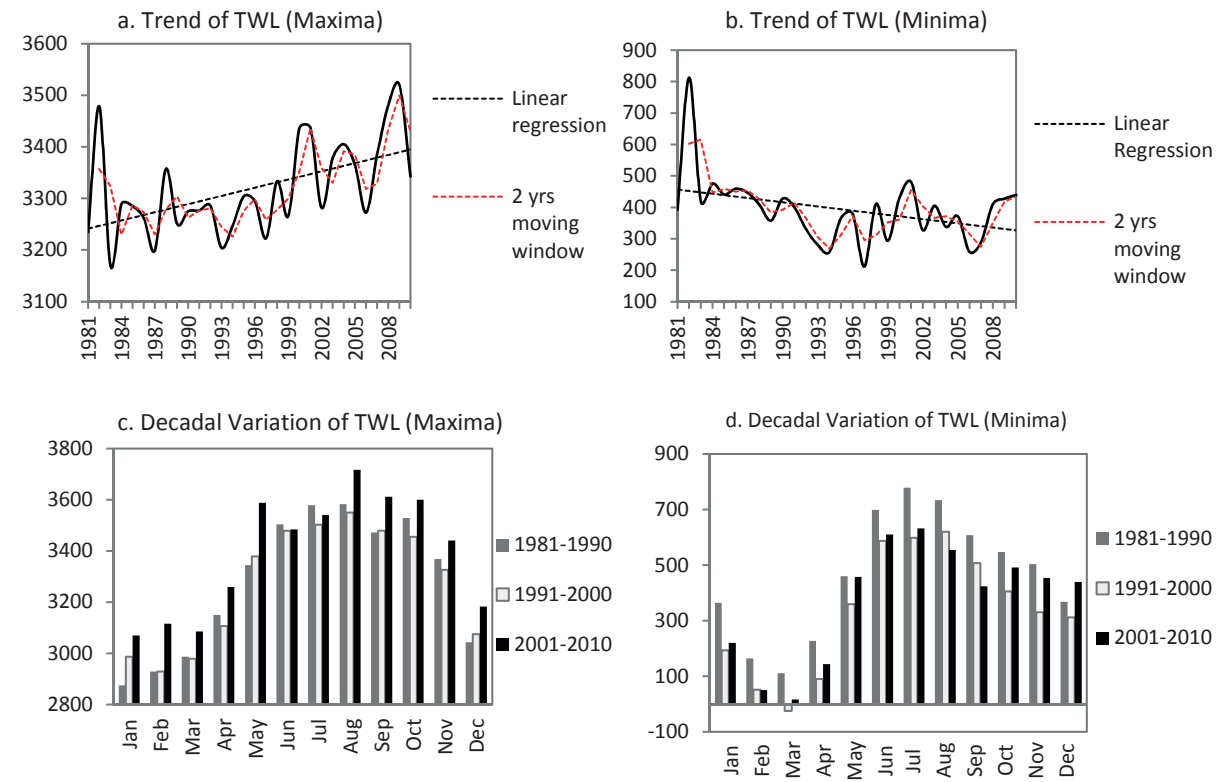

Figure 2.6. Trend of Monthly Extreme TWL (mm) and Decadal Variation
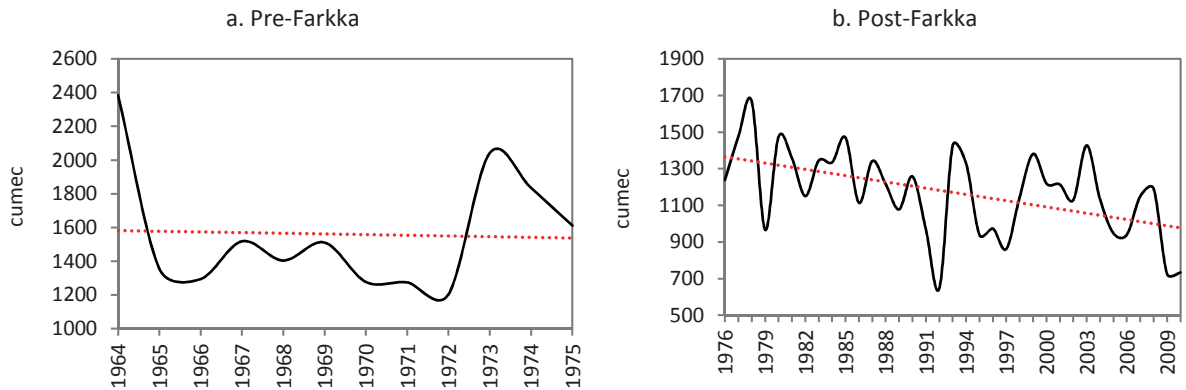

c. Dry season (DJF) and Pre-monsoon (MAM)

d. Monsoon (JJAS) and Post-monsoon ON)

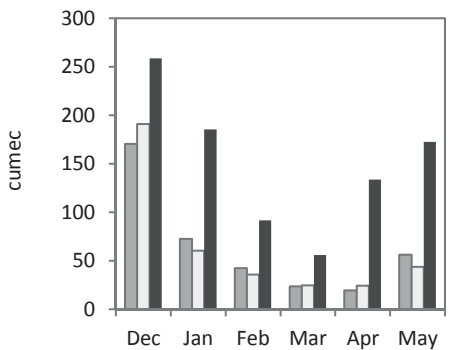

$\square$ 1981-1990

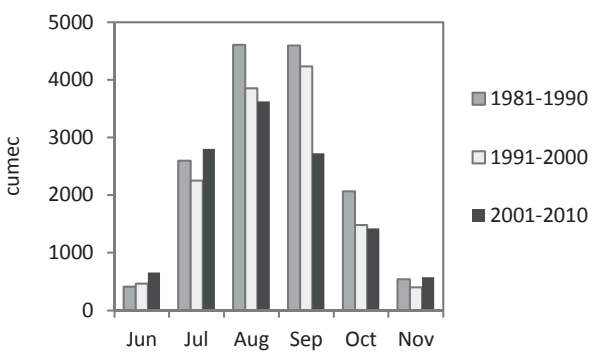

Figure 2.7. Mean Annual Flow before and after Farkka Barrage and Monthly Decadal Flow through Gorai 


\subsubsection{Changes in river water salinity and monthly variation}

River water salinity of all twelve stations of Khulna, Bagerhat and Satkhira during HT and LT has been showing increasing trends since 2000 (Figure 2.8) which are statistically significant. In Bagerhat, water salinity increase in SW105 station of the Gorai river is virtually certain

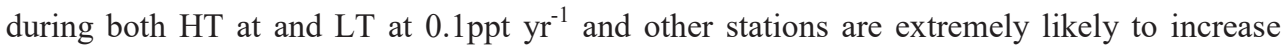
from to $0.3 \mathrm{ppt}$ to $0.5 \mathrm{ppt} \mathrm{yr}^{-1}$. In Khulna, salinity increase in SW28 station of Bhadra river, in SW243 station of Rupsa-Pasur river and in SW258 station of Sibsa river are virtually certain

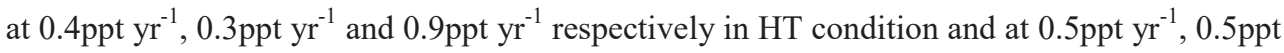
$\mathrm{yr}^{-1}$ and 0.9 ppt $\mathrm{yr}^{-1}$ respectively in LT condition. Other two stations (SW241 in Rupsa-Pasur and SW259 in Sibsa river) salinity are extremely likely to increase at $0.6 \mathrm{ppt} \mathrm{yr}^{-1}$ in LT and at

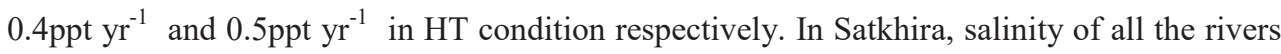

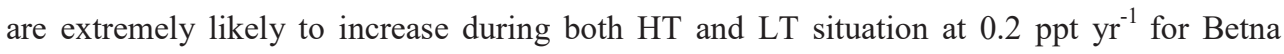

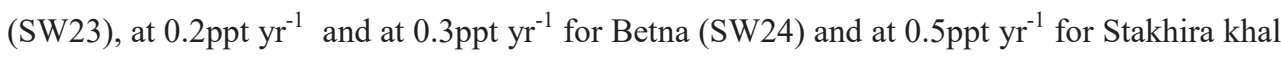
(SW254.5) respectively. The result depicts higher river water salinity in Khulna region than Satkhira and Bagerhat in both high and low tide situation and salinity increase rate is comparatively very high after 2005 .

Monthly variation in river water salinity for three different districts show high salinity level mainly during MAM (pre-monsoon) in both high and low tide situation (Figure 2.9). During low tide, salinity increase in November, March, April, May and June are virtually certain. Salinity in December, January, February, March and April are extremely likely to increase.

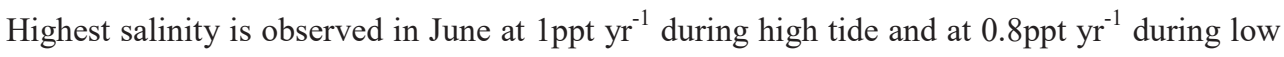
tide followed by May at $0.7 \mathrm{ppt} \mathrm{yr}^{-1}$ and $0.6 \mathrm{ppt} \mathrm{yr}^{-1}$ respectively. The result reveals increasing salinity across the dry season (DJF) as well as pre-monsoon (MAM). 

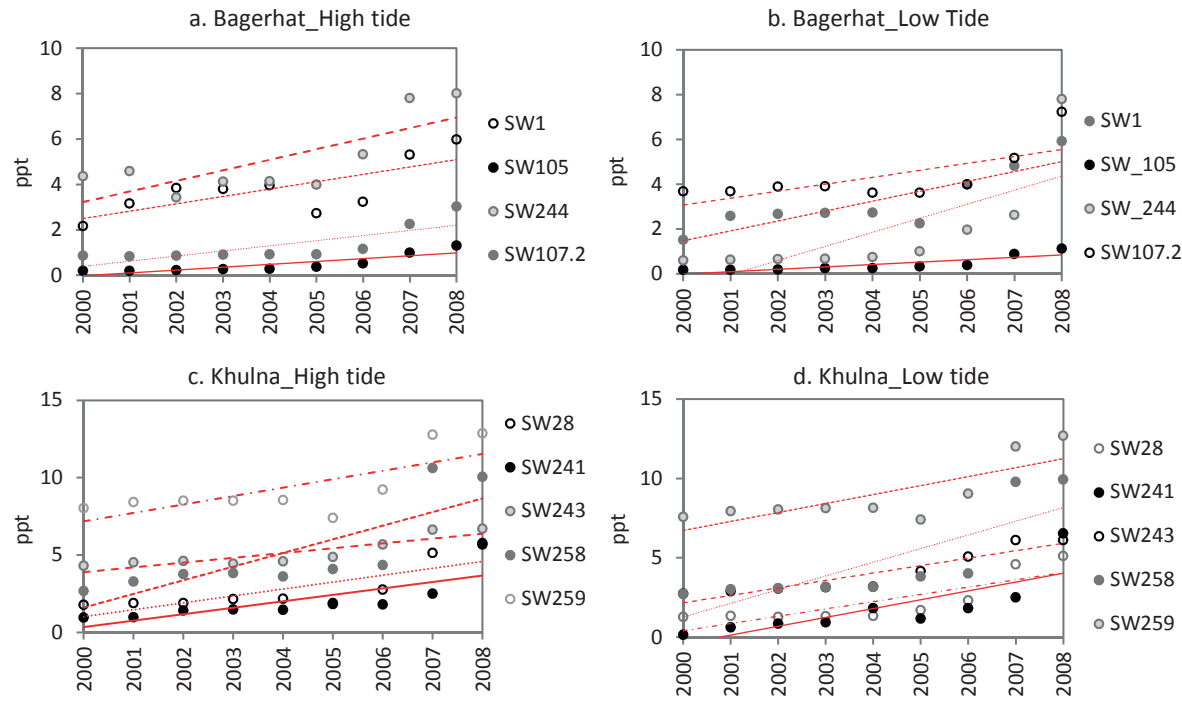

e. Satkhira_High tide

f. Satkhira_Low tide

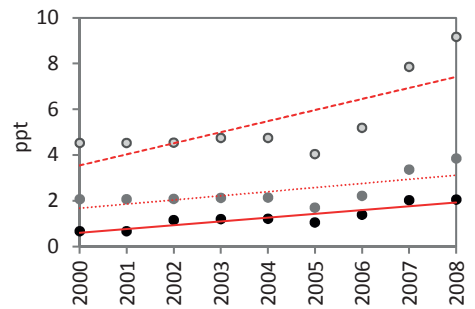

- SW23

- SW24

○ SW254.5

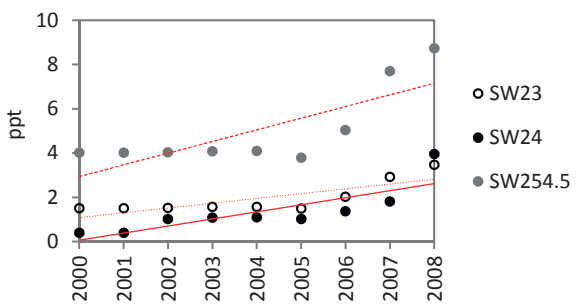

Figure 2.8. River water salinity (EC) trend at three different districts
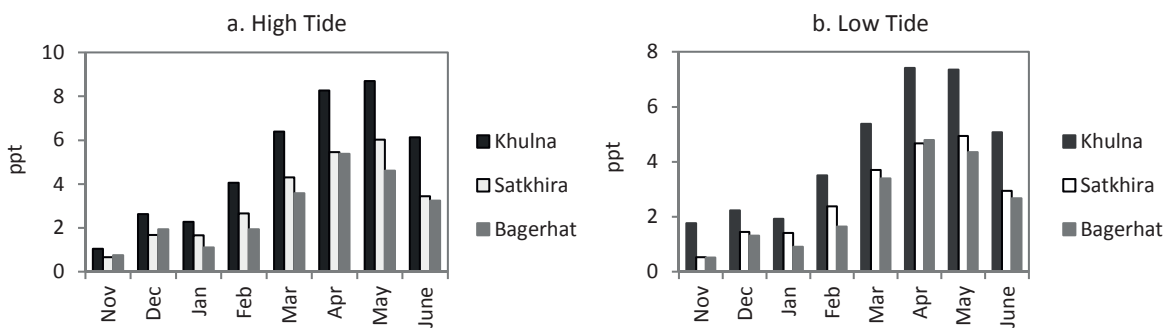

Figure 2.9. Monthly variation of river water salinity during high and low tide at three different districts 


\subsubsection{Possible cause-effect relationships among the selected variables}

Trends per annum of the key parameters used in this study is exhibited in Table 2.2. Maximum $\left(p=0.000 ; \quad \mathrm{R}^{2}=0.376\right)$ and minimum temperature $\left(p=0.001 ; \mathrm{R}^{2}=0.341\right)$ are significantly increasing across the south-west coastal region of Bangladesh. Precipitation is likely to decrease $\left(p=0.231 ; \mathrm{R}^{2}=0.051\right)$. Salinity is virtually certain to increase during high tide $\left(p=0.004 ; \mathrm{R}^{2}=0.724\right)$ and low tide $\left(p=0.003 ; \mathrm{R}^{2}=0.740\right)$. And fresh water discharge through Gorai to the south-west coastal river network is significantly reducing $(p=0.003$; $\mathrm{R}^{2}=0.243$ ).

Correlations among statistically significant yearly trends of the variables reveal that salinity increase during both high tide and low tide has moderately high correlation with minimum temperature increase $\left(\mathrm{r}=+0.600^{* *}\right.$ and $\left.\mathrm{r}=+0.572^{* *}\right)$ and TWL rise $\left(\mathrm{r}=+0.608^{* *}\right.$ and $\mathrm{r}=$ $\left.+0.599^{* *}\right)$; and moderate correlation with maximum temperature increase $\left(\mathrm{r}=+0.562^{* *}\right.$ and $\mathrm{r}=$ $\left.+0.519^{* *}\right)$, SDII $\left(\mathrm{r}=-0.411^{*}\right.$ and $\left.\mathrm{r}=-0.362^{*}\right)$ and reduced fresh water discharge $\left(\mathrm{r}=-0.408^{*}\right.$ and $\left.r=-0.437^{*}\right)$. On the other hand, ETR is moderately correlation with SDII $\left(r=-0.420^{*}\right)$ as well as with reduced fresh water discharge $\left(r=-0.426^{*}\right)$. Also SDII has moderate correlation with tidal water level (minima) $\left(r=+0.490^{*}\right)$. In addition, reduced fresh water discharge is moderately correlated with maximum temperature increase $\left(\mathrm{r}=-0.409^{*}\right)$. All these correlations are statistically significant at 0.01 level $\left(^{* *}\right)$ and at 0.05 level $\left(^{*}\right)$. For detail of the statistical analysis on the correlation among statistically significant yearly trends of the variables, see supplementary information A (TableA4-f).

Correlations among statistically significant monthly trends of the variables (supplementary information A: TableA4-g) disclose that salinity increase in April during both high and low tide has a moderate correlation with precipitation decrease in April $\left(r=-0.408^{*} ; \mathrm{r}=-0.484^{* *}\right)$ and low correlation during low tide with maximum temperature increase in April ( $\mathrm{r}=$ $\left.+0.373^{*}\right)$. Also salinity increasing trend in May is moderately correlated during high tide and low tide with the increasing trend of maximum temperature $\left(r=+0.464^{* *} ; r=+0.504^{* *}\right)$. In addition, trend of salinity increase in January and February during high tide and in May during high tide as well as low tide are significantly correlated with tidal water level rise (maxima) and reduced fresh water discharge (supplementary information A: TableA4-g). Besides, precipitation decrease in April has a very high correlation with increasing temperature in this particular month $\left(\mathrm{r}=-0.844^{* *}\right)$. Rising tidal water level in May is also moderately correlated with maximum temperature increase in May $\left(\mathrm{r}=+0.463^{*}\right)$. 
Table 2.2. Trends of different hydro-climatic variables used in this study

\begin{tabular}{llll}
\hline Parameters & Trend & Time Series & Years \\
\hline Maximum temperature & $+0.03{ }^{0} \mathrm{C} \mathrm{yr}^{-1}$ & $1981-2010$ & 30 \\
Minimum temperature & $+0.02{ }^{0} \mathrm{C} \mathrm{yr}^{-1}$ & $1981-2010$ & 30 \\
Precipitation & $-6.559 \mathrm{~mm} \mathrm{yr}^{-1}$ & $1981-2010$ & 30 \\
Effective Sea-level rise & $+10.3 \mathrm{~mm} \mathrm{yr}^{-1}$ & $1981-2010$ & 30 \\
Mean Sea-level rise & $+0.4 \mathrm{~mm} \mathrm{yr}^{-1}$ & $1981-2010$ & 30 \\
Salinity (high tide) & $+0.4 \mathrm{ppt} \mathrm{yr}^{-1}$ & $2000-2008$ & 9 \\
Salinity (low tide) & $+0.5 \mathrm{ppt} \mathrm{yr}^{-1}$ & $2000-2008$ & 9 \\
Fresh water discharge (Post Farakka) & $-4187.5 \mathrm{cumec} \mathrm{yr}^{-1}$ & $1976-2010$ & 35 \\
\hline
\end{tabular}

Developed cause effect relationships based on the statistically significant correlations among the parameters discussed above disclose that fact that salinity increase is the effect of different interacting causes like less precipitation, temperature increase, reduced fresh water discharge and TWL rise (Figure 2.10). Less precipitation and reduced fresh water discharge is significantly correlated with increasing temperature and vice versa. TWL rise is not found to be correlated with these variables except maximum temperature increase. However, correlation of salinity with all the selected hydro-climatic variables is statistically significant.

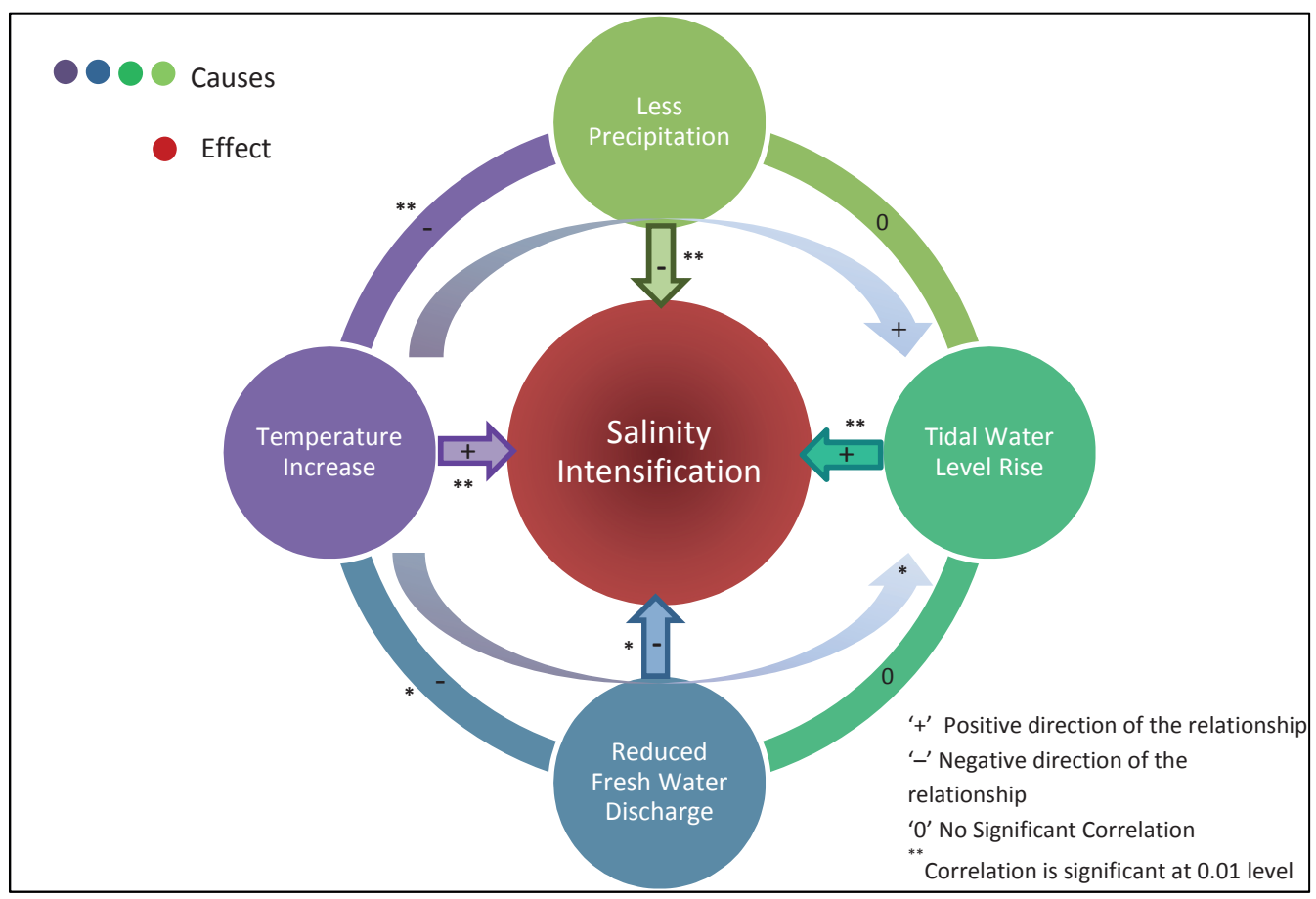

Figure 2.10. Cause-effect relationships diagram among the selected parameters

(For the statistical analysis see TableA4-f and TableA4-g of the supplementary information A) 


\subsection{Discussion}

The economy of south-west Bangladesh is highly dependent on natural resources and large parts of the population depend on agriculture and fisheries for their livelihoods. This region, however, is highly vulnerable to environmental changes. Our analyses show that over the last decades there have been significant changes in different hydro-climatic variables. The most important changes we observed are a reduction in rainfall during the pre-monsoon and dry season, increasing precipitation during the late and post-monsoon season, reduced fresh water discharge from upstream river particularly in August-September-October, increases in tidal water levels and salinity intensification. Several of these changes show significant correlation suggesting different relations between the environmental changes, we observed. In particular, the increasing salt intrusion during the dry season is probably caused by a combination of sealevel rise, reduced flow of upstream rivers and a later onset of the monsoon.

The changes' extent in different hydro-climatic variables and cause-effect relation among the variables are crucial to advance the understanding of environmental changes in this region. Our results disclose the fact that salt intensification results from a combination of different climate signals (i.e., getting warmer, seasonal precipitation shifts, SLR) and hydrological changes (i.e., insufficient upstream discharge). Also different causes of salinity increase are inter-related with one another. For example, increasing temperatures alter precipitation patterns, rise the TWL and reduce discharge rates. This study reveals that environmental changes in Bangladesh's south-west coastal region are governed by a complex interacting alterations in different hydro-climatic variables.

Detailed analysis of the observed temperature data from 1981 to 2010 clearly show extensive trends in maximum and minimum temperature anomalies and extreme indices (particularly ETR and SU) with stronger trends in the last decade. These are consistent with warming over the whole 30 years period. The current mean decadal temperature increase of $0.25^{\circ} \mathrm{C}$ along the south west coast is substantially higher than the global average increase of $0.12^{\circ} \mathrm{C}$ per decade (IPCC 2014). The ETR significantly shows more hottest summer days and fewer coldest winter nights. These also signifies the increasing trend of both maximum and minimum temperature anomalies. Monthly variation showed significant warming in pre-monsoon season particularly for maximum temperatures in April and May and minimum temperatures in April. However, temperatures and their extremes show significant warming in all seasons but most in the colder months (Donat et al. 2013). This variation reveals that local or regional 
changes are very heterogeneous. We have also found significant correlation among rapid warming of the south west coast with precipitation, TWL, salinity and fresh water discharge to the coastal river network. These relationships reveal that increase in temperature drives other environmental changes in this region.

Our analyses of the changes in rainfall over the last 30 years show that total precipitation has slightly reduced. More important, however, are the reductions in rainfall during the dry season and pre-monsoon period. This potentially increases the water stress in the region during the end of the dry season. A later onset of the monsoon also potentially facilitates the salt intrusion during the April -May period. While in the pre-monsoon period the rainfall is reducing and during the post monsoon period the rainfall is increasing. This indicates that the monsoon period is shifting to later in the year. An analysis by Hasan et al. (2013) shows that also for future climate projections the monsoon is shifting to later in the year, especially, increased rainfall during the post monsoon season. Significant decreases in precipitation, particularly in April, and increases, mostly in July and October, confirm the increasing precipitation trends during the monsoon and post-monsoon seasons and the seasonal precipitation shift from pre-monsoon to post monsoon. This significantly correlates with increasing maximum temperatures in April. Simple daily intensity index shows significant decrease while daily precipitation trend was not statistically significant which indicate the increase in the number of wet days $(\geq 1 \mathrm{~mm})$. SDDI is also found significantly correlated with ETR and salinity increase. These correlations among monthly variations and extreme indices indicate temperature increase as an actor for seasonal change in precipitation over the southwest coast of Bangladesh. Because temperature increase affect atmospheric moisture through a more active hydrological cycle, leading to increases in water holding capacity throughout the atmosphere at a rate of about $7 \%$ per ${ }^{\circ} \mathrm{C}$ (IPCC 2007). Thus rising temperature results in changes in precipitation patterns. Global extreme precipitation indices showed more areas with significant increasing trends than areas with decreasing trends (Donat et al. 2013). Furthermore, long-term observed trend of precipitation for Bangladesh reported in Islam and Uyeda (2007) showed increasing trends. However, we have found that decreasing trend of precipitation in the particular months for south-west coastal region of Bangladesh is much higher than the increasing trends of other months for last three decades. It accordingly appears that changes in precipitation in a coastal region of Bangladesh differ from the changes in the country as a whole and the rate of the changes depend on the maximum temperature and ETR of this region. 
Significant increase in TWL maxima and decrease in TWL minima indicate that the increasing trend of the tidal range is likely to result into higher Effective SLR. Our data shows an increase in Effective SLR of $11.9 \mathrm{~mm} \mathrm{yr}^{-1}$ while Mean SLR is only increasing by $0.4 \mathrm{~mm}$ $\mathrm{yr}^{-1}$. However, global Effective SLR rates range from 0.5 to $12.5 \mathrm{~mm} \mathrm{yr}^{-1}$ (Ericson et al.

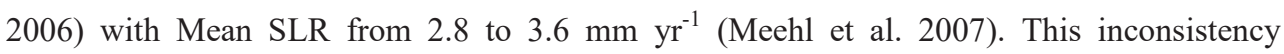
between Mean SLR and Effective SLR is mostly the result of tidal range amplification. Although Effective SLR is the response of different processes like subsidence, tidal amplitude, fresh water discharge and eustatic sea-level changes (Pethick and Orford 2013), the dominant process responsible for Effective SLR at south-west coast is probably due to the amplification of tidal range. This process alone accounts for almost $50 \%$ of the increase in Effective SLR along the south-west coast. Probable causes of rapid increase in tidal range at south-west coast are constricted rivers and channels by unplanned polders and embankments in a densely populated coastal zone, and deepened rivers and channels by dredging (IWM 2014). Spencer et al. (2016) also mentioned varying assumption about coastal dikes and polders in relation to SLR as infrastructures limit lateral accommodation space and cause coastal squeeze. We have also found monthly variation of sea-level along the south-west coast with absolute maxima during August and minima during March. This variation may be for the southern oscillation phenomenon (Singh et al. 2010) and monsoon induced TWL increase (Singh 2001). On the other hand, we have found significant positive correlation between decreasing trend of SDDI and TWL (minima) which indicate that increased evaporation rate due to increase in both maximum and minimum temperature and ETR may lower the sealevel during low tide. In addition, increasing trend of TWL (maxima) is found to be significantly correlated with salinity increase during both high and low tide situation which clearly indicate that SLR is one of the causes of salinity intrusion in south-west coast of Bangladesh. Because significant rise in sea-level particularly in January, February and May reveals that it is not monsoon induced sea-level rise. Rather it is part of eustatic SLR associated with other factors like tidal amplitude and subsidence. In addition to temperature increase and changes in precipitation pattern, SLR is also accountable for intensification of salinity in south-west coastal region of Bangladesh.

The Gorai river is the main source of freshwater flow into south-west Bangladesh. The flow of the Gorai river started to reduce since 1964. The construction of Farakka barrage on the Ganges River in 1975 to divert the water to Bhagirathi-Hooghly River in India is one of the main reasons for further drastic reduction after 1975 (Mirza 1997). Monthly variation shows 
significant increase of discharge in January mostly during the last decade (2001-2010). It is possibly related to the significant increasing trend of rainfall in post-monsoon and dry season in India (Jain and Kumar 2012). Mirza (1998) reported the reduction in flow mostly during dry season (DJF) till 1992. Nonetheless, the dry season (DJF) except December and premonsoon (MAM) flow is below the threshold value of minimum environmental flow. Estimated environmental flow at Gorai is 233 cumec (Moly et al 2015). On the other hand, constant and significant reduction in discharge mostly in August and September for last three decades (from 1981 to 2010) may perhaps has a relation with significant increase in temperature and less rainfall during monsoon over all regions in India (Jain and Kumar 2012). However, still the monsoon (JJAS) except June and post-monsoon (ON) flow except November is above the environmental flow. Mean monthly decadal flow for four different seasons compared to the environmental flow reveals that insufficient discharge through Gorai to the south-west coastal region remains from November to June. High salinity level during this period also indicate that reduced and insufficient discharge is also responsible for intensification of salinity in south-west coastal region of Bangladesh.

In average, river water salinity increasing rate in south-west coastal region of Bangladesh is calculated 0.5 ppt per year which varies from 0.1 to $0.9 \mathrm{ppt}$. In general, the station closest to the coast showed the highest increase in salinity. Salinity level were particularly high during the later dry season and pre-monsoon period. The highest salt concentrations were observed during the months April and May. However, salinity standard for drinking water quality ranges from 0.6 to $1 \mathrm{ppt}$ (DeZuane 1997) and tipping point of new salt tolerant variety of rice is 6.4 ppt (Islam 2015). After 2005, almost all the stations show river water salinity above the drinking water standard and near to the tipping point of salt tolerant rice variety. However, river water salinity from 2007 remains above the tipping point of salt tolerant rice variety. Seasonal variation reveals from November to June, salinity level remains above the drinking water standard in all three districts of south-west coastal region during both high tide and low tide. Salinity level particularly in April and May crosses the tipping point of salt tolerant rice variety mostly in Khulna region. Salinity level remains very high for April and May for all three districts. However, Hussain et al. (2013) predicted maximum increase of salinity during monsoon (JJAS) followed by winter (DJF). It might be for not to consider all the hydroclimatic variables as we have discovered that salinity increase is significantly correlated with the other hydro-climatic variables selected for this study i.e. temperature increase, changes in precipitation, TWL rise and reduced fresh water discharge from the Ganges basin through 
Gorai river to the south-west coastal river network. Increase in both maximum and minimum temperature and ETR may cause more water to evaporate into the atmosphere leading to reduce fresh water discharge and consequently to a rise in salinity levels in addition to sealevel rise due to the expansion of sea water resulting from global warming. Moreover, back salt water effect due to high SLR at south-west coast and less fresh water flow from upstream rivers to coastal river network will further accelerate the salinity intensification process. These relationships reveal that salinity increase is not only the effect of one or two causes rather the result of a range of processes (i.e., warming temperatures, changes in precipitation, TWL rise and reduced fresh water discharge of the Gorai river).

Different other studies have also indicated through observational or modelling approaches that increases in sea-level rise (Bhuiyan and Dutta 2012), lower fresh water discharge (Mahmuduzzaman et al. 2014) and sea surface temperature and precipitation (Singh 2001) are causing increased salt water intrusion. Also cyclones, and increased shrimp farming are mentioned as possible causes for increased salt water intrusion (Khan et al. 2000; Deb 1998). Unfortunately, these studies only considered one variable of salinity increase. Hence, our study is innovative by establishing relationships among several hydro-climatic variables of salinity increase. It is likely that the rapid increase in salt intrusion during April-May is caused by a combination of reduced upstream river flows, increased high tides and lower rainfall during the dry season and pre monsoon period. Especially the lower upstream flow and reduced rainfall are observed during the March, April, May period explain that salt intrusion problems are accumulating during these months.

Though salinity data was available for only nine years, this relatively short period data clearly shows significant increasing trends for all stations. Moreover, these trends have already crossed the threshold for the drinking water standard and salt tolerant rice varieties. Consequently, current trends of river water salinity are likely to intensify the regional drinking water crisis, reduce agricultural productivity and increase food scarcity. In addition, more than half of the coastal people who depend on the natural resources only are likely to become vulnerable. Because rich and biodiverse low saline mangroves, such as Sundarbans of southwest Bangladesh, can only tolerate up to 15 ppt salinity (Hossain et al. unpublished manuscript). As these natural resources are exposed to increasing salinity levels, they become less productive. Our previous study showed substantial changes in mangrove resources along 
the salinity gradient (Hossain et al. unpublished manuscript) Thus, rapid salinity increases substantially threaten people's livelihoods as well.

Several of the trends we are observing in the selected hydro-climatic variables are likely to continue in the future. First of all, sea-level rise is most likely to continue, however, by how much will depend on future rate of global warming and the stability of the Greenland and Antarctic ice sheets (Wong et al. 2014). Still all projections show an increase in sea-level. The future trends in rainfall are less clear for Bangladesh. Most climate models indicate an overall increase in rainfall for Bangladesh. However, the climate models are especially consistent in their projected increase in monsoon rainfall (Menon et al. 2013). The trends of the dry season are less clear. Most studies on climate change impacts on future precipitation in Bangladesh have focussed on extreme precipitation (Shahid 2011). However, our analyses shows that there is a need to also investigate future trends in dry season and pre-monsoon season rainfall. Zaman et al. (2016) showed that future climate change could reduce Ganges flows into Bangladesh during the months of April and May and thus, will further exacerbate salt water intrusion during these months. Our historic analyses in combination with these future assessment indicate that salinization will become a more and more serious problem in the coastal region of south-west Bangladesh. It is important to acknowledge that these problems originate from a range of different processes such as rising temperatures, reduced dry season rainfall, sea-level rise and lower upstream flows. Future plans to adapt land and water management need to take these range of processes into account.

\subsection{Conclusions}

The study provides clear current trends of climatic signals and hydrological variables and determined the relationship among major processes to understand the bio-physical environment changes across the south-west coast of Bangladesh. Temperature increase, changes in precipitation patterns, TWL rise and reduced fresh water discharge have substantial contribution to instant salinity increase in south-west coastal region of Bangladesh. The relationships among these hydro-climatic variables in a complex and dynamic coastal system is quite complicated. However, we could identify the relationships among the selected variables as we evaluated coherently all these interactive variables in one platform. This is how, this piece of research has become novel to find out the potential cause-effect relationship among the hydro-climatic variables. It reveals that intensification in salinity is due to a range 
of process of different hydro-climatic variables. This improved understanding of recent changes in and the relationships among the environmental variables will help decision makers to better adapt to future changes and scientists to better validate different environmental change models and scenarios. We have also discussed possible implications of recent biophysical changes in the environment due to interacting hydro-climatic variables on the south west coastal region of Bangladesh. It reveals that intensification in salinity, due to a range of process of different hydro-climatic variables, is not only an extensive threat for agriculture, livestock, poultry, fisheries and forestry but also for human health and livelihood.

\section{Acknowledgements}

We would like to thank Bangladesh Meteorological Department (BMD), Bangladesh Water Development Board (BWDB) and Bangladesh Inland Water Transport Athority (BIWTA) for providing the data. We are grateful to all who helped in collecting the data especially Engineer Amanullah Selim of BWDB and Shamsun Naher, Joint Director, Hydrography Department of BIWTA. This study received support from the Nuffic NFP fellowship programme (NFP-PhD.12/307). 


\title{
Chapter 3. Ecological Status of Mangrove Vegetation along Salinity Gradients in the Sundarbans World
}

\section{Heritage Ecosystem}

\begin{abstract}
Gradual salinity increase due to climate change induced sea-level rise and reduced dry season freshwater flows from upstream has become a big threat for the mangroves in the Sundarbans world heritage ecosystem. How this salinity increase affects the Sundarbans mangrove is poorly understood for inadequate scientific knowledge on the relationship of mangrove vegetation with salinity gradient. Understanding, the relations between salinity gradient and vegetation composition, forest structure, diversity, canopy cover, regeneration status, carbon content are important to better manage and protect this globally important ecosystem under a changing environment. In this study, for the first time, we make the relationship of Sundarbans mangroves' ecological status with salinity gradient from various aspects. Salinity is very likely to increase in all three ecological zones. Importance value index reveals that the globally endangered species, $H$. fomes is now suppressed by wide range of salt tolerant $E$. agallocha. and C. decandra. However, average aboveground carbon content of H. fomes is found higher (i.e., $136 \mathrm{Mg} / \mathrm{ha}$ ) than E. agallocha (i.e., $62 \mathrm{Mg} / \mathrm{ha}$ ) and C. decandra (i.e., 19 $\mathrm{Mg} / \mathrm{ha}$ ). Vegetation composition show that $H$. fomes prefers the low saline habitat whereas Exoecaria agallocha prefers moderate saline and Cariops decandra high saline habitat. Species richness and diversity of the mangroves also decline with increased salt concentrations. Mangrove ecosystem condition demonstrates the sensitivity of canopy cover and regeneration to high salt concentrations. All these results indicate the likelihood of reduced biodiversity and declined carbon-stock in the Sundarbans mangrove in near future due to further changes in salinity gradient.
\end{abstract}

Under review as:

Hossain P R, Ludwig F and Leemans R. Ecological Status of Mangrove Vegetation along Salinity Gradients in the Sundarbans World Heritage Ecosystem. This manuscript is submitted to the Biodiversity and Conservation Journal. 


\subsection{Introduction}

The Sundarbans is the largest contiguous mangrove forest in the world spreading over the south western part of Bangladesh $\left(6,017 \mathrm{~km}^{2}\right)$ and the West Bengal State in India $\left(4,000 \mathrm{~km}^{2}\right)$. This unique ecosystem provides vital breeding and nursery grounds for diverse marine resources, serves as a natural defence to cyclones and tidal surges, supports the livelihood of about 3.5 million coastal people and most importantly harbours the last remaining habitat of many globally endangered species of flora eg. Sundri (Heritiera fomes), and fauna eg. Royal Bengal Tiger (Panthera tigris) and Ganges river dolphin (Platanista gangetica). It is declared as a World Heritage Site in 1997 by UNESCO and designated as a Ramsar site under the Ramsar Convention in 1992 because of its outstanding ecological importance, universal value, biological diversity and ecosystem services (Sanyal 1999).

The Sundarbans' mangrove ecosystem is associated with the fresh water flow from the Ganges basin and the salty sea water from the Bay of Bengal. The resulting balanced salinity gradient is now being threatened by climate change induced sea level rise and low fresh water flow from upstream due to the diversion by the Farakka barrage on the Ganges river basin in India. Sea level rise along the Bangladesh coast is $5.93 \mathrm{~mm} \mathrm{yr}^{-1}$ which is substantially higher than the global average (i.e., 1.0-2.0 $\mathrm{mm} \mathrm{yr}^{-1}$ ) (Karim and Mimura 2008). In addition, Ganges' fresh water flow into the Sundarbans is reduced from $3700 \mathrm{~m}^{3} \mathrm{~s}^{-1}$ to $364 \mathrm{~m}^{3} \mathrm{~s}^{-1}$ since 1975 (Wahid et. al 2007). As a result, the Sundarbans is indicated as one of the most vulnerable mangrove ecosystems as well as climate change hot spots on the globe (Mitra et al. 2009). The already observed signs (for example, top dying of $H$. fomes, slow forest growth, reduction in number of Royal Bengal Tiger) of degrading and declining forest cover demonstrate that the Sundarbans is stressed by the impacts of climate change (i.e., sea level rise) as well as other environmental changes (i.e., low freshwater flow). Both are contributing to change the salinity gradients of mangroves in the Sundarbans world heritage ecosystem.

Salinity plays an important role in development of mangrove forest and phytosociological structure of mangrove forests (Twilley and Chen 1998). The salinity gradient in the Sundarbans mangrove forest differentiate three different salinity zones that determine forest distribution (Curtis 1933). Iftekhar (1999) regarded changes in salinity as a major disturbance in the Sundarbans. This disturbance alters species composition (Ameen 1999) or triggers other species to become dominant (IUCN 2003). Although salinity clearly has increased in the Sundarbans over the last decades (Hoque et al. 2006), to what extent this change can affect 
the vegetation of the mangrove forest is poorly known. In addition, we have very limited knowledge on ecological status of Sundarbans mangrove (i.e., forest structure, vegetation composition, bio-diversity, canopy cover, regeneration status and carbon content) along salinity gradient to understand the impacts of change in the salinity concentrations. This knowledge gap makes it difficult to adjust forest management to take these changes into account. Hence, we aim to generate spatially explicit baseline information on ecological status of Sundarbans mangrove along salinity gradient and to improve the understanding on how salt concentrations affect ecosystem functioning. This understanding is needed to conserve the globally threatened mangrove ecosystem in a future changing environment. We hypothesize that the change in salinity gradient favours a shift in mangrove composition towards more salt tolerant species with reduced carbon-stock and biodiversity.

\subsection{Material and Methods}

\subsubsection{Study area}

The Sundarbans Mangrove Forest Reserve is located in the south-western part of Bangladesh between $21^{\circ} 30^{\prime} \mathrm{N}$ to $22^{\circ} 30^{\prime} \mathrm{N}$ Latitudes and $89^{\circ} 00^{\prime} \mathrm{E}$ to $89^{\circ} 55^{\prime} \mathrm{E}$ Longitudes (Figure 3.1). It is the single largest tract of mangrove forest in the world (Chaudhuri and Naithani 1985). The Sundarbans covers about 0.6 million hectares of which two-thirds is forest. The remainder are water bodies (Rahman 1998; Runkel and Ahmed 1997; Katebi 2001). The Sundarbans is an over 4000 years old deltaic swamp (Ali 1998) between 0.9 to $2.1 \mathrm{~m}$ above mean sea level (Karim 1994). The area is formed by the deposition of silt from the Brahmaputra and Ganges rivers (Bandyopadhya 1968; Alim 1984; Gopal and Chauhan 2006). The forest is characterized by three different ecological salinity zones. These are the oligohaline zone (i.e. almost fresh or less saline water), the mesohaline zone (moderately saline) and the polyhaline zone (salt water or strongly saline). These zones are respectively located in the north-east corner, the central and the south-eastern part, and the southern and western part of the Sundarbans (Chaffey et al. 1985). The dominant species of oligohaline zone is H. fomes, the mesohaline zone is Exoecaria agallocha and the polyhaline zone is Cariops decandra (Hussain and Karim 1994). H. fomes is already declared endangered globally and critically endangered regionally (Kathiresan et al. 2010). According to IUCN-Bangladesh (2001), the Sundarbans supports more than 300 plant species, 120 fish species, 35 reptile species, 300 bird species and 32 mammal species. The Sundarbans is also important for the national economy (i.e. $41 \%$ of forest revenue). 


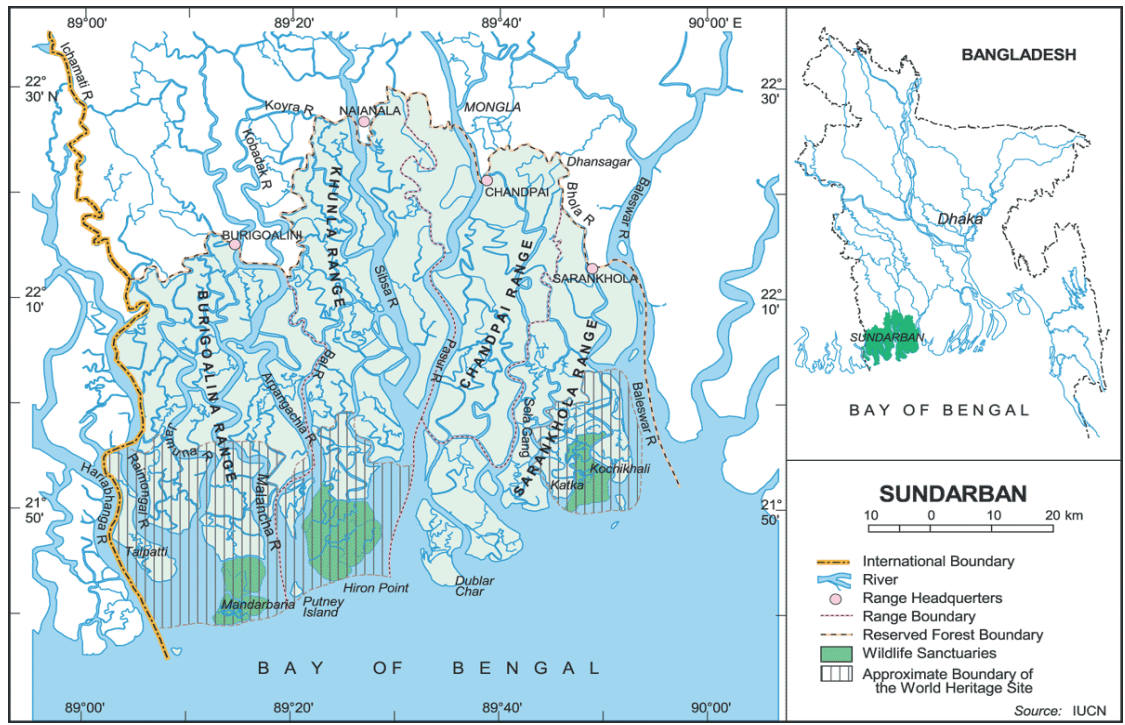

Figure 3.1. Location of Sundarbans Mangrove Forest in Bangladesh (IUCN-Bangladesh 2001)

\subsubsection{Data Collection}

A vegetation survey was carried out along major salinity Transects during December 2013 and January 2014. Three Transects were selected running from land to sea to cover different type of vegetation and salinity gradients following English et al. 1997. The three Transects are approximately $25 \mathrm{~km}$ apart from each other and have been selected to represent the three main ecological salinity zones (Figure 3.2). In total 55 quadrats, each $10 \mathrm{~m} \times 10 \mathrm{~m}$, were sampled at approximately $5 \mathrm{~km}$ distance along each Transect by combining a stratified and systematic sampling approach.

Quantitative vegetation data (i.e. no. of trees, diameter at breast height (dbh, at $1.37 \mathrm{~m}$ or $4.5 \mathrm{ft}$ above ground), canopy cover, regeneration status and top-dying affected trees) had been collected using the standard quadrat method (Clarke 2009; Cintron and Novelli 1984; Kathiresan and Khan 2010). The quadrat size was determined on the basis of species area curves (Misra 1968). Quadrats were taken about $10 \mathrm{~m}$ to $15 \mathrm{~m}$ inland from the shore for each vegetation site, following Chen and Twilley (1999). Plants were identified in the field using the Reddy's (2008) "Field Identification Guide for Indian Mangroves" and Tomlinson's (1986) "Botany of Mangroves". Only true mangrove tree species, which are found exclusively in the mangrove habitat and do not extend into terrestrial communities (FAO 2007; 
Tomlinson 1986), within each plot were identified. Trees with a dbh $\geq 5 \mathrm{~cm}$ within each plot were counted and measured. At each observation point, mangrove condition as indicated by canopy cover and recruitment was recorded on a scale from no human or natural impact (1) to sever impact (5) (Table 3.1) (Ellison 2012). Water samples were also collected from the nearest water body at the observation point. Here salinity was estimated by a hand held electrical conductivity (EC) meter with a measuring range from 0.01 to 19.90 deci Siemens per meter $(\mathrm{dS} / \mathrm{m})$. Carbon content of the dominant species from each saline zone was collected from USAID's IPAC project. They prepared protocols for measuring and reporting carbon stocks in mangrove Forests with special reference to carbon assessment for Sundarbans Reserve Forest of Bangladesh (Donato, Kauffman and Stidham 2009) and measured the carbon content of the mangroves in 2010.

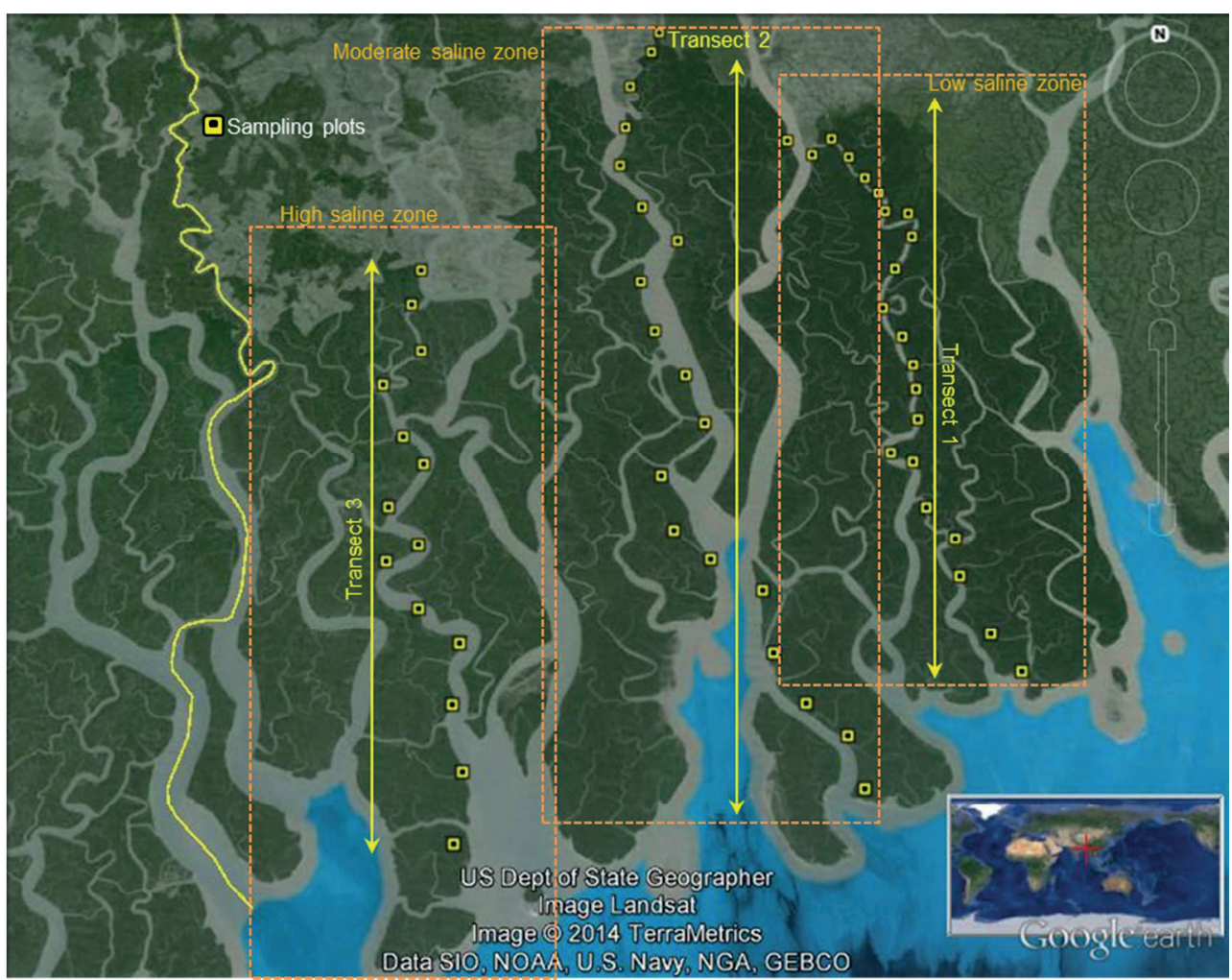

Figure 3.2. Transects and location of sampling plots in three different salinity zones

\subsubsection{Data Analysis}

Various quantitative structural indices, such as density, frequency and basal area (Curtis and McIntoch 1951; Shukla and Chandal 1993), the relative frequency (RF), relative density (RD) 
and relative dominance (RDo) (Mueller-Dombois and Ellenberg 1974; Rasingam and Parthasarathy 2009) and the importance value index for each species were calculated using the standard methodology of Curtis (1959) to reveal the relative contribution of each true mangrove species to the mangrove vegetation structure (Bambang and Ati 2006). Species composition along the salinity gradient was identified based on the abundance of each tree species found in one plot. The first three dominant species was stated from high to low abundance as vegetation composition in a plot. Importance values for tree species was calculated on a 300 scale (i.e. RF, RD and RDo) and for non-timber species on a 200 scale (i.e. RF and RDo) according to Kent and Coker (1992). To assess the species diversity in each salinity zone, different diversity indices were analysed. The three selected indices were species richness $(S)$ (Whittaker 1976), Shannon-Weiner's diversity index $(H)$ (Shannon and Weaver 1949) and Simpson's diversity index $(D)$ (Simpson 1949). The Pearson Correlation and simple linear regression analysis were used (IBM SPSS Statistics 22.0) to evaluate the relationship between salinity gradient and distance from North to South as well as from East to West. Density of the three main dominant species along the salinity gradients was also analysed. Besides carbon content $(\mathrm{Mg} / \mathrm{ha})$ of the dominant species (i.e., H. fomes, E. agallocha and $C$. decandra) from each saline zone (i.e., low, mid and high) was also compared in terms of varying carbon content with different salt concentrations.

Table 3.1. Ranking Condition of the Plots based on the Sensitivity factors

\begin{tabular}{llll}
\hline \multirow{2}{*}{ Rank } & Condition & Sensitivity factors & \\
\cline { 3 - 4 } & & Canopy Cover (\%) & Regeneration \\
\hline 1 & No or slight impact & $76-100$ & All species producing seedlings \\
2 & Moderate impact & $51-75$ & Most species producing seedlings \\
3 & Rather high impact & $31-50$ & Some species producing seedlings \\
4 & High impact & $11-30$ & Just a few seedlings \\
5 & Severe impact & $1-10$ & No seedlings \\
\hline
\end{tabular}

(Adopted from Ellison 2012)

\subsection{Results}

\subsubsection{Salinity increase across the Sundarbans}

Measured salinity of the collected water samples in all three ecological zones of Sundarbans mangrove show the evidence of salinity increase compared with the previous studies (Table 
3.2). It reveals not only the upper range (i.e., sea side) increase in salinity level but the lower range (i.e., inland side) as well. Moreover, salinity increasing rate in three ecological zones also indicate that the low saline zone (oligohaline) is gradually getting replaced by the moderate saline zone (mesohaline) and the moderate saline zone by the high saline zone (polyhaline).

Table 3.2. Salinity increase in three different ecological zones of Sundarbans mangrove

\begin{tabular}{llll}
\hline \multicolumn{2}{l}{ Salinity Range (EC) } & \multicolumn{2}{l}{ Source } \\
\cline { 1 - 3 } Oligohaline zone & Mesohaline zone & Polyhaline zone & \\
\hline 0 to 2 & 2 to 4 & $>4$ & Siddiqi, 2001 \\
\hline 0 to 5 & 5 to 15 & $>15$ & Hoque et al. 2006 \\
\hline 1 to 17 & 5 to $>20$ & $>16$ & Measured salinity in 2014 \\
\hline
\end{tabular}

\subsubsection{Vegetation Structure of Sundarbans Mangrove}

True mangroves recorded from three different salinity zones of the Sundarbans Mangrove Forest in this study are listed in Table 3.3. The identified twelve true mangrove species belong to seven different families. Among the identified species, ten are tree species and two are palm species. All the species were found in Transect 1 and only four of these species are oligohaline to relatively fresh water species. Rest of them are moderate to high salt tolerant species. The seven common species in all transects, are Avicennia officinalis, C. decandra, E. agallocha, Sonneratia apetala, Xylocarpus mekongensis, Nypa fruticans and Phoenix padulosa. All these common species of the Transects are moderate to saline water tolerant species except $N$. fruticans. Hence salinity preference of the identified species indicate that the Sundarbans mangrove is now covered mostly by moderate to salt tolerant species rather than the relatively fresh and/or oligohaline species.

The quantitative structure of the vegetation shows that E. agallocha has the highest importance value index followed by $C$. decandra and $H$. fomes (Figure 3.3). The three most dominant species in Transects 1 and 2 were E. agallocha, H. fomes and S. apetala while in Transect 3, the dominant species were E. agallocha, C. decandra and S. apetala. However, $H$. fomes was absent in the salt water zone of Transect 3. The results show that E. agallocha, which is the moderate saline water tolerant species, has become the dominant species in all three salinity zones of Sundarbans and suppressed the abundance of Sundri (H. fomes). 


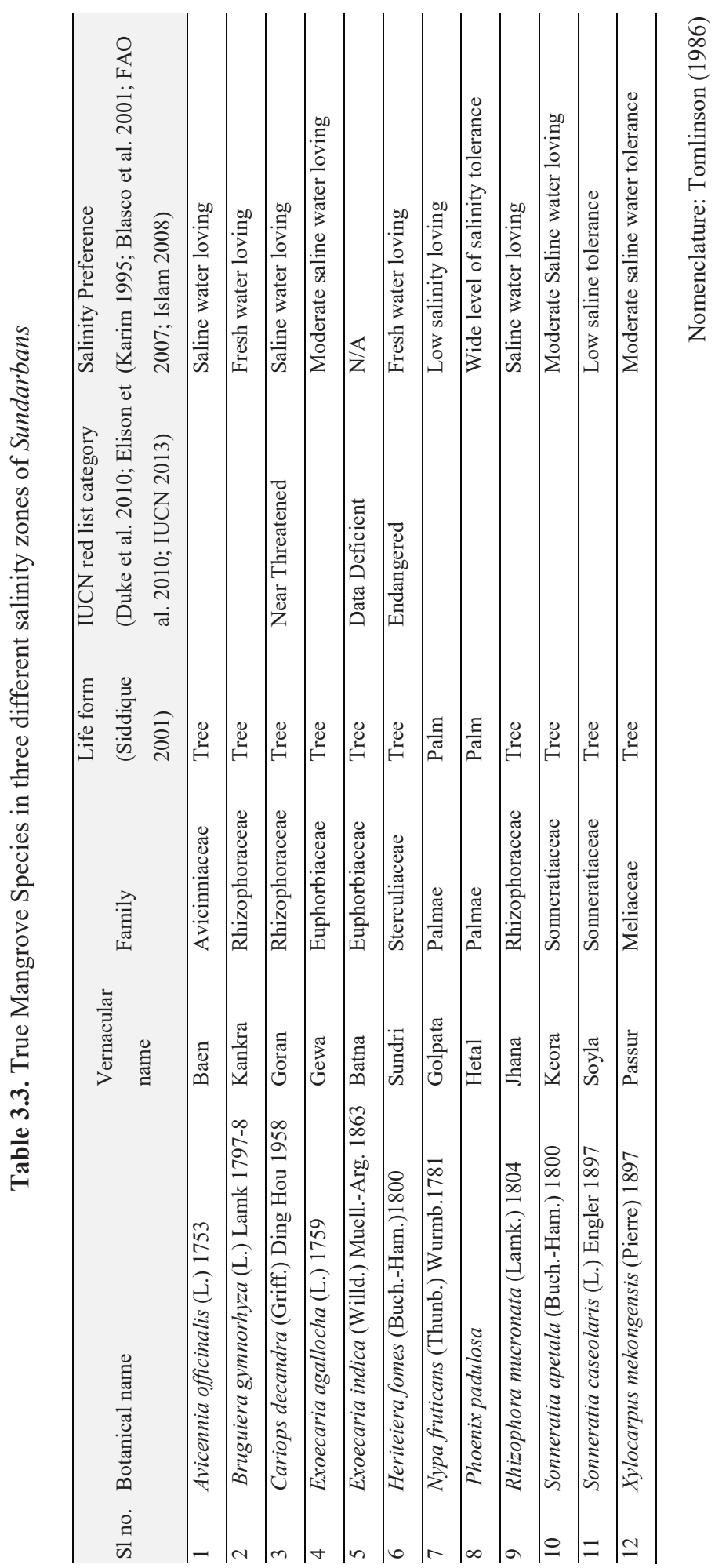




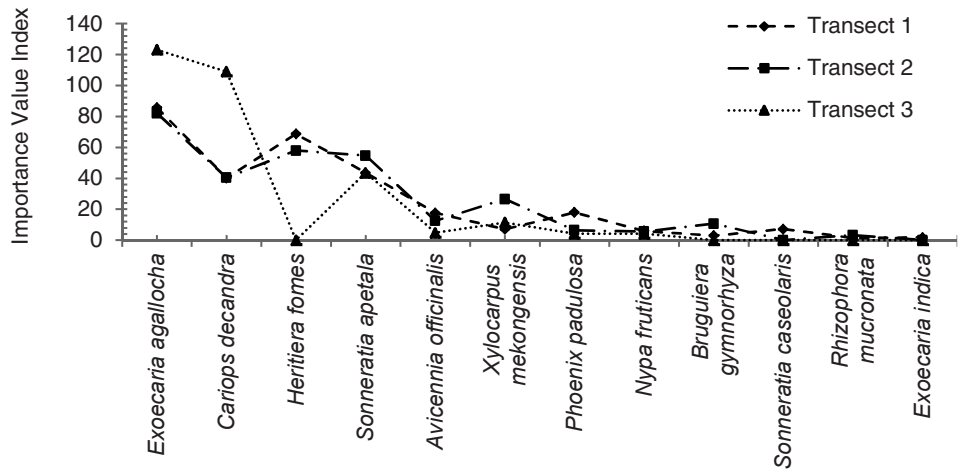

Figure 3.3. Dominance Curve for the true mangrove species in three ecological salinity zones

\subsubsection{Salinity gradient and Composition of Sundarbans Mangrove}

The salinity concentration significantly increases from north to south (Figure 3.4). The salinity of the three different transects differs significantly (For the results of statistical analysis see Appendix A and B). Salinity was highest $(>15)$ in the southern and western parts of Sundarbans ( $45 \%$ of the sample plots) and lowest $(<5)$ in the north eastern part $(28 \%$ of the sample plots). Central part was moderate saline ranging from 5 to 15 ( $28 \%$ of the sample plots). Vegetation composition shows very sharp change with the increasing salinity gradient. H. fomes is found to be the dominant species in $17 \%$ of the plots along the salinity gradient from 0.9 to 4.7 , E. agallocha in $28 \%$ of the plots along the salinity gradient from 2.2 to 19.9 and C. decandra in $33 \%$ of the plots along the salinity gradient from 14.5 to $>20$.

\subsubsection{Vegetation Density along Salinity Gradients}

Density of three most dominant mangrove species of Sundarbans differ along salinity gradients and with distance from land to sea (Figure 3.5). However, our statistical analysis does not indicate a significant relation between salinity gradient and density of the tree species. The number of $H$. fomes trees per hectare $(\mathrm{dbh}>5 \mathrm{~cm})$ is comparatively high in the Transect 1 (100 to 5900 trees per ha) within the salinity range from 0.9 to 17.3 compared to Transect 2 (100 to 1700 trees per ha) having salinity from 5.3 to 15.0 . The highest density in Transect 1 was found at 1.9 and in Transect 2 at 9.8. So, salinity and density varied inversely for $H$. fomes.

The percentage of top dying affected trees are noticeable along the salinity gradients in Transect 1 (Figure 3.6). Affected H. Fomes by top dying was found high at 3.6 along Transect 1 in the oligohaline zone and at 14.5 along Transect 2 in the mesohaline zone. On the other 
hand, the highest density of E. agallocha in Transect 1 is 5600 trees per ha at 0.9 , in Transect 2 is 5200 trees per ha at 11.2 and in Transect 34100 trees per ha at 17.1. This indicates that this species is distributed at wide range of salinity concentration. Density of $C$. decandra was high in all Transects at salinity concentration higher than 10. Results show that that true mangrove species vary in their response to the salinity gradients from west to east, south to north and vice versa.

\begin{tabular}{|c|c|c|c|c|c|c|c|}
\hline \multirow{3}{*}{$\begin{array}{l}\text { Plots along } \\
\text { Transects }\end{array}$} & \multirow{3}{*}{$\begin{array}{l}\text { Distance } \\
(\mathrm{km})\end{array}$} & \multicolumn{3}{|c|}{$\sim 25$} & \multicolumn{3}{|c|}{$\sim 50$} \\
\hline & & \multicolumn{2}{|c|}{ Transect 1} & \multicolumn{2}{|c|}{ Transect 2} & \multicolumn{2}{|c|}{ Transect 3} \\
\hline & & Salinity & $\begin{array}{l}\text { Vegetation } \\
\text { Composition* }\end{array}$ & Salinity & $\begin{array}{l}\text { Vegetation } \\
\text { Composition* }\end{array}$ & Salinity & $\begin{array}{l}\text { Vegetation } \\
\text { Composition* }\end{array}$ \\
\hline Plot 1 & & 0.9 & $\mathrm{Hf}+\mathrm{Ea}+\mathrm{Pp}$ & 5.3 & $\mathrm{Ea}+\mathrm{Sa}+\mathrm{Hf}$ & 15.7 & $\mathrm{Ea}+\mathrm{Cd}+\mathrm{Nf}$ \\
\hline Plot 2 & $\sim 5$ & 1.8 & $\mathrm{Hf}+\mathrm{Ea}+\mathrm{Ao}$ & 5.4 & $\mathrm{Cd}+\mathrm{Ea}+\mathrm{Hf}$ & 16.7 & $\mathrm{Sa}+\mathrm{Cd}$ \\
\hline Plot 3 & $\sim 10$ & 1.9 & $\mathrm{Hf}+\mathrm{Ea}+\mathrm{Ao}$ & 5.5 & $\mathrm{Sa}+\mathrm{Ea}+\mathrm{Hf}$ & 17.1 & $\mathrm{Ea}+\mathrm{Cd}$ \\
\hline Plot 4 & $\sim 15$ & 1.9 & $\mathrm{Hf}+\mathrm{Pp}+\mathrm{Ea}$ & 9.2 & $\mathrm{Bg}+\mathrm{Xm}+\mathrm{Ao}$ & 18.9 & $\mathrm{Ea}+\mathrm{Cd}$ \\
\hline Plot 5 & $\sim 20$ & 1.9 & $\mathrm{Hf}+\mathrm{Ea}+\mathrm{Ao}$ & 9.8 & $\mathrm{Ea}+\mathrm{Xm}+\mathrm{Bg}$ & 19.3 & $\mathrm{Ea}+\mathrm{Cd}$ \\
\hline Plot 6 & $\sim 25$ & 2.2 & $\mathrm{Ea}+\mathrm{Hf}+\mathrm{Sa}$ & 10.7 & $\mathrm{Xm}+\mathrm{Nf}+\mathrm{Hf}$ & 19.5 & $\mathrm{Ea}+\mathrm{Cd}$ \\
\hline Plot 7 & $\sim 30$ & 2.3 & $\mathrm{Pp}+\mathrm{Hf}+\mathrm{Ea}$ & 11.2 & $\mathrm{Sa}+\mathrm{Ao}+\mathrm{Hf}$ & 19.9 & $\mathrm{Ea}+\mathrm{Cd}$ \\
\hline Plot 8 & $\sim 35$ & 3.0 & $\mathrm{Cd}+\mathrm{Ao}+\mathrm{Sa}$ & 11.3 & $\mathrm{Fa}+\mathrm{Sa}$ & $>20$ & $\mathrm{Ao}+\mathrm{Sa}$ \\
\hline Plot 9 & $\sim 40$ & 3.6 & $\mathrm{Hf}+\mathrm{Ea}+\mathrm{Pp}$ & 11.5 & $\mathrm{Ea}+\mathrm{Pp}$ & $>20$ & $\mathrm{Cd}$ \\
\hline Plot 10 & $\sim 45$ & 3.6 & $\mathrm{Hf}+\mathrm{Pp}+\mathrm{Cd}$ & 12.0 & $\mathrm{Ea}+\mathrm{Pp}$ & $>20$ & $\mathrm{Cd}$ \\
\hline Plot 11 & $\sim 50$ & 3.8 & $\mathrm{Hf}+\mathrm{Ea}+\mathrm{Cd}$ & 13.0 & $\mathrm{Ea}+\mathrm{Xm}$ & $>20$ & $\mathrm{Cd}$ \\
\hline Plot 12 & $\sim 55$ & 4.3 & $\mathrm{Cd}+\mathrm{Ea}+\mathrm{Hf}$ & 14.5 & $\mathrm{Cd}+\mathrm{Ea}$ & $>20$ & $\mathrm{Cd}$ \\
\hline Plot 13 & $\sim 60$ & 4.7 & $\mathrm{Hf}+\mathrm{Ea}+\mathrm{Bg}$ & 15.0 & $\mathrm{Sa}+\mathrm{Ao}$ & $>20$ & $\mathrm{Cd}$ \\
\hline Plot 14 & $\sim 65$ & 4.6 & $\mathrm{Sc}+\mathrm{Sa}+\mathrm{Nf}$ & 16.3 & $\mathrm{Cd}+\mathrm{Ea}$ & $>20$ & $\mathrm{Cd}$ \\
\hline Plot 15 & $\sim 70$ & 4.9 & $\mathrm{Nf}+\mathrm{Sa}+\mathrm{Rm}$ & 17.0 & $\mathrm{Cd}+\mathrm{Ea}$ & - & - \\
\hline Plot 16 & $\sim 75$ & 6.6 & $\mathrm{Cd}+\mathrm{Ea}+\mathrm{Hf}$ & 18.7 & $\mathrm{Cd}+\mathrm{Ea}$ & - & - \\
\hline Plot 17 & $\sim 80$ & 12.6 & $\mathrm{Ea}+\mathrm{Sa}$ & $>20$ & $\mathrm{Ao}+\mathrm{Sa}$ & - & - \\
\hline Plot 18 & $\sim 85$ & 14.0 & $\mathrm{Ea}+\mathrm{Xm}$ & $>20$ & $\mathrm{Sa}+\mathrm{Cd}$ & - & - \\
\hline Plot 19 & $\sim 90$ & 17.0 & $\mathrm{Cd}+\mathrm{Sa}$ & $>20$ & $\mathrm{Cd}+\mathrm{Sa}$ & - & - \\
\hline Plot 20 & $\sim 95$ & 17.1 & $\mathrm{Cd}+\mathrm{Sa}$ & - & - & - & - \\
\hline Plot 21 & $\sim 100$ & 17.2 & $\mathrm{Cd}+\mathrm{Ea}$ & - & - & - & - \\
\hline Plot 22 & $\sim 105$ & 17.3 & $\mathrm{Sa}+\mathrm{Ea}$ & - & - & - & - \\
\hline
\end{tabular}

*Based on the abundance of a species in a plot

$\mathrm{Hf}=H$. fomes; $\mathrm{Ea}=E$. agallocha; $\mathrm{Pp}=P$. padulosa $; \mathrm{Ao}=A$. officinalis; $\mathrm{Cd}=C$. decandra; $\mathrm{Bg}=B$. gymnorhyza; $\mathrm{E}=E$. indica; $\mathrm{Nf}=N$. fruticans; $\mathrm{Rm}=R$. mucronata; $\mathrm{Sa}=\mathrm{S}$. apetala; $\mathrm{Sc}=\mathrm{S}$. caseolaris; $\mathrm{Xm}=X$. mekongensis

Figure 3.4. Vegetation composition along salinity gradients 

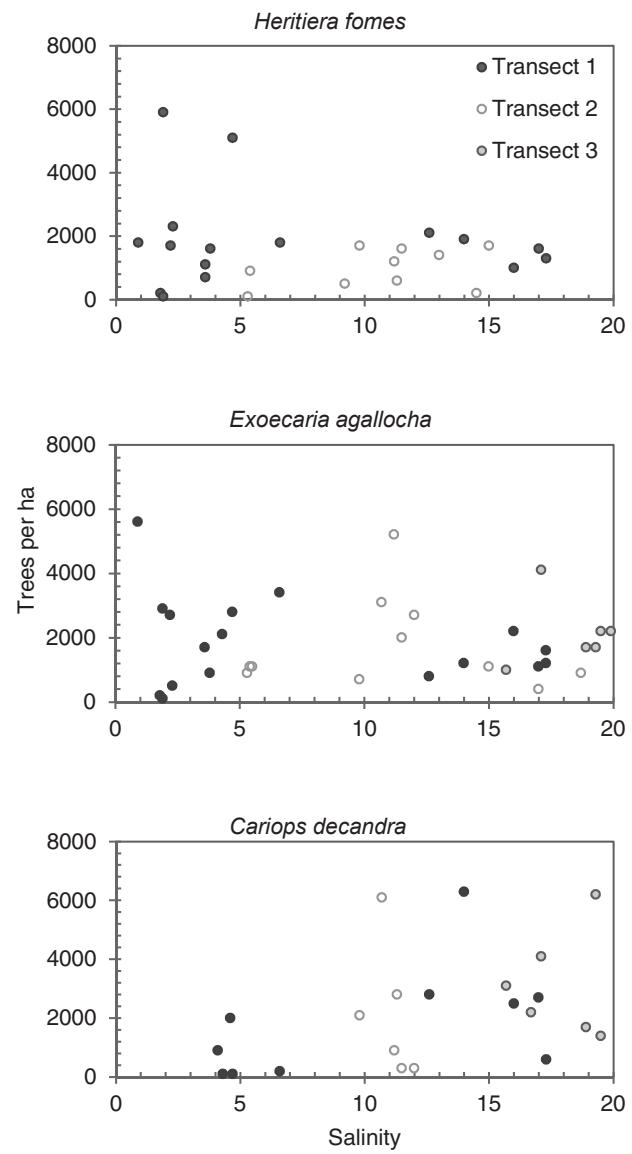

Figure 3.5. Density of three most dominant mangrove species along the salinity gradients

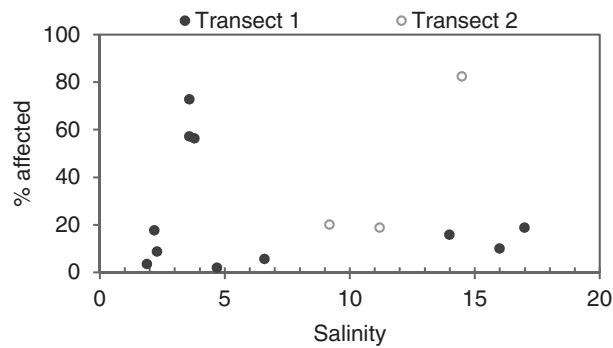

Figure 3.6. Percentage of $H$. fomes affected by top dying along the salinity gradients

\subsubsection{Vegetation Diversity in three different salinity zones from east to west}

The lowest diversity, evenness and richness was found along Transect 3 (Table 3.4), which probably is due to the high level of salinity of the area and dominance of a few saline 
mangrove species like E. agallocha, C. decandra and S. apetala. This indicates that this zone is disturbed either due to natural or anthropogenic impacts. Highest diversity and richness was found along Transect 1 followed by Transect 2. This likely is due to their low salinity levels compared to Transect 3 . However, the species equitability index is high along the moderate saline water zone and this indicates that the species are uniformly distributed across the habitat of this zone and each species has a relatively narrow niche. Different indices show that mangroves in the low saline zone is biodiverse and has a narrow ecological niche for each species.

Table 3.4. Diversity Indices for three different salinity zones of Sundarbans Mangrove Forest

\begin{tabular}{llll}
\hline Indices & $\begin{array}{l}\text { Transect 1 } \\
\text { (South East) }\end{array}$ & $\begin{array}{l}\text { Transect 2 } \\
\text { (South Central) }\end{array}$ & $\begin{array}{l}\text { Transect 3 } \\
\text { (South West) }\end{array}$ \\
\hline Species Richness $(S)$ & 12 & 10 & 7 \\
\hline Shannon-Wiener's Diversity Index $(H)$ & 1.675 & 1.607 & 0.965 \\
Shannon's equitability $\left(E_{H}\right)$ & 0.674 & 0.698 & 0.496 \\
\hline Simpson's Diversity Index $(D)$ & 4.350 & 3.930 & 2.270 \\
Simpson's Equitability $\left(E_{D}\right)$ & 0.363 & 0.393 & 0.324 \\
\hline
\end{tabular}

\subsubsection{Mangrove ecosystem condition in three different salinity zones}

Relevant biological parameters that are most likely affected by increasing salinity, are considered as the most sensitive factors for the impact assessment. These factors were canopy cover and regeneration status of the mangrove. Along Transect 1,73\% of the sample plots has more than $75 \%$ canopy cover (Figure 3.7 ) and in $32 \%$ of the plots all species are producing seedlings (Figure 3.8). This low saline zone transect has a fairly continuous canopy of trees but possibly some gaps and regrowth with isolated damage to trees or sapling. However, canopy cover and regeneration rates of plots along Transects 2 and 3 are much lower. In most of the areas of the moderate saline zone, tree canopy cover ranges between 51 and $75 \%$ and most of the species are producing seedlings. In the salt water zone canopy cover ranges from 31 to $50 \%$ and only some species are producing seedlings. Plots along Transect 2 in the moderate saline water zone showed broken canopy of trees with lower regrowth and recruitment areas. Also some trees were cut and stripped. However, the impact was highest in the salt water zone with uneven tree canopies. The majority of the area did not show regrowth with bare mud. Summarizing the result indicate that the salinity gradient affects canopy cover and regeneration status of mangrove. 
Sundarbans mangrove's ecological status along salinity gradients

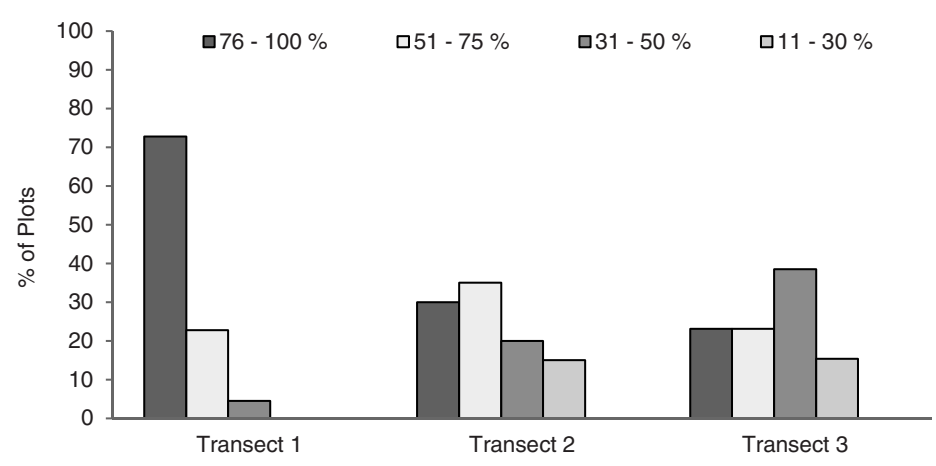

Fig. 3.7. Condition of the plots along the Transects based on the percentage of canopy cover

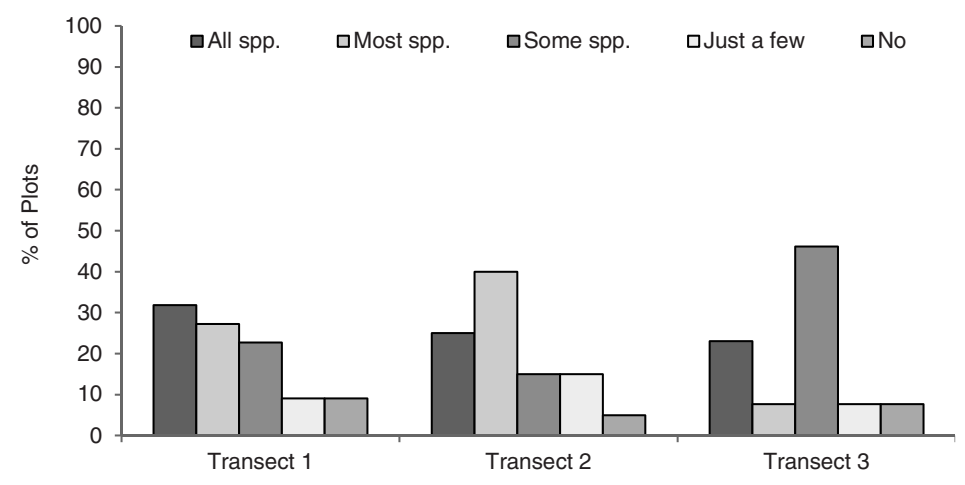

Figure 3.8. Condition of the plots along the Transects based on regeneration status (see table 1 for explanation of different classes of Figure 6 and 7)

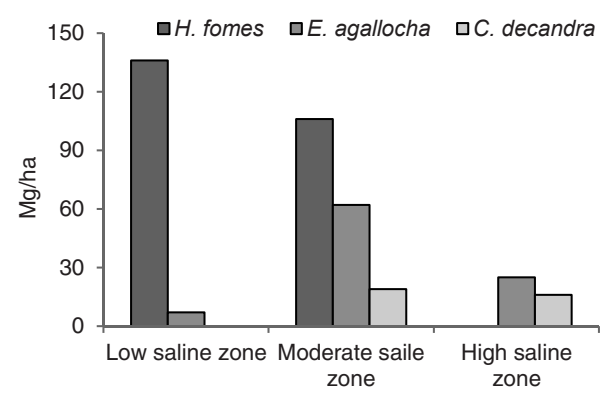

Figure 3.9. Carbon content of three most dominant mangrove species in three salinity zones 


\subsubsection{Carbon content of three most dominant mangrove species in three different salinity} zones

Average above ground carbon content of $H$. fomes, the low saline loving species, is higher than the rest two species in low and moderate saline zone (Figure 3.9). On the other hand, $C$. decandra, high salt tolerant species contains the lowest carbon. However, the moderate saline tolerant species, E. agallocha contains higher carbon in the moderate saline zone than the high saline. Also, H. fomes contains higher carbon in the low saline zone than the moderate saline zone.

\subsection{Discussion}

Salinity is one of the essential physical factors needed for ecological development of mangrove forests (Tomlinson 1986). However, if salinity concentrations become too high it also limits the growth and development of the mangrove vegetation. Too high salt concentrations can result in large scale vegetation loss and negatively affect biodiversity (Nandy et al. 2007). Our results show that the current salinity gradients from north to south and east to west of the Sundarbans have a large impact on the vegetation composition and diversity of the mangrove forest. Our results also indicate that different species are adapted to different salt concentrations. H. fomes prefers the low saline environment and seems to be adapted to a relatively narrow range of salt concentrations (i.e., 1 to $12 \mathrm{EC}$ ). E. agallocha

prefers the moderate to high saline environment and occurs over a relatively large range of salt concentrations (i.e., 5 to $20 \mathrm{EC}$ ). C. decandra prefers the high saline environment (15 to $>20$ EC). The salinity preference of the mangrove species and sharp changes in the composition of the vegetation along the salinity gradient indicate that salt concentrations have a large influence on the vegetation of the Sundarbans mangrove forest. Sarker et al. (2016) also reported declining abundance of $H$. fomes with increased salt concentrations.

Hassan and Razzaque (1983) showed that a major part of the Sundarbans had become mesohaline. Twenty years later salinity has radically increased and IWM (2003) showed that major parts of the mangrove had become polyhaline and movement of the polyhaline zone to the mesohaline zone. Also our data shows an increase in the salt water zone within the Sundarbans mangrove from South-West to North-East direction. As salinity data was only collected once, our data by itself cannot confirm an increase in salinity. However, a 
comparison with previous studies (Hoque et al. 2006; Siddique 2001) clearly shows substantial increase in salinity in the Sundarbans mangrove forest.

Vegetation structure of the forest from east to west reveals that a major part of the Sundarbans mangrove forest is currently covered by a wide range of salt tolerant species such as $E$. agallocha and high salt tolerant species such as C. decandra. On the other hand, H. fomes, the globally endangered and regionally critically endangered species, is now absent in large parts of the Bangladesh part of the Sundarbans. However, Nazrul-Islam (2003) reported that number of $H$. fomes was lowest only in high saline zone. As $H$. fomes is a less salt tolerant species and therefore, is likely to be outcompeted by more salt tolerant species in high saline condition. Also on the Indian side of the Sundarbans gradual increases in salinity caused $H$. fomes to disappear, while the area now is covered mostly by shrubs and saline tolerant grasses (Chaudhury and Choudhury 1994).

In addition, top dying affected $H$. fomes trees are found in the low and moderate saline zone. Top dying was especially severe in plots of mesohaline zone where up to $70 \%$ of the trees were affected by top dying. It may be due to direction of increasing salt concentration which is observed from south-west to north-east direction. Troup (1921) first reported about sporadic occurrence of top dying of $H$. fomes in the Sundarbans and Curtis (1993) reported severe top dying. According to Rahman (1995), increased salinity and reduced fresh water discharge are the possible causes of top dying. High salinity levels in the root zones affect the rate of photosynthesis (Ball 1998) and results in the plant dying from the top. Consequently, true mangroves with narrow ecological ranges such as $H$. fomes can be used as indicator species to identify any disturbance in the environment. In case of the Sundarbans, the top dying and shrinking area of the low saline environment are probably caused by the salt intrusion which has occurred over the last decades. Sharp negative response of $H$. fomes to high level of salt concentrations indicate that further salinity increase could make this globally endangered and regionally critically endangered species to become extinct in near future.

Especially during the dry season saltwater intrusion has increased in the Sundarbans over the last decades (Mirza 1998; Smith et al. 2009; Huq et al. 1996). This is mainly due to a combination of sea level rise and reduced freshwater flow from upstream rivers. Dry season flows have reduced due to a combination of increased water extraction and diversion. It is likely that this increase in salinity is causing changes in vegetation and could be one of the drivers of the top dying of $H$. fomes. This increasing salinity is probably having a negative 
impact on the biodiversity of the Sundarbans as well. Because species composition, density, quantitative structure and diversity of the forest as well as canopy cover and regeneration status show declining status with high salt concentrations. At high saline conditions mangrove species use more energy to maintain their water balance and ion concentration; this reduces the growth and re-production rates (Clough 1984). For example, high salinity reduces the biomass in Bruguiera gymnorrhiza (Naidoo 1990) and causes denaturing of terminal buds in Rhizophora mangle seedlings (Koch and Snedaker 1997). Another study by Hossain et al. (2014) reported no germination of $H$. fomes seeds from moderate to high salt concentrations.

Diversity of vegetation in three different salinity zones show that the low saline zone of Sundarbans mangrove is much richer in biodiversity compared to the high salinity zones and diversity reduces with increasing salt concentrations. Salt concentrations also affect regeneration, survival, abundance, distribution and canopy cover of the mangrove. The plots with higher salt concentrations showed lower regeneration and more uneven canopy cover compared to plots in the low saline environment. Rich biodiversity and ecosystem conditions in the low saline zone may be related to its accessibility to fresh water supply from the upstream rivers. To protect the rich biodiversity in the low saline zone of the Sundarbans sufficient fresh water supply from the upstream rivers through Gorai channel is essential. However, this freshwater supply is continuously decreasing due to riverbed sedimentation, upstream developments and increased water extraction (Wahid et al. 2007). If salinity continues to increase, species adapted to the low saline environment are likely to be replaced by more salt tolerant species. A case study from Jharkhali island of India also revealed that increased salt concentrations were probably responsible for a reduction in biodiversity while salt resistant Avicennia spp., Phoenix padulosa and Derris trifoliata invaded the area (Chowdhury and Maiti 2013).

Without major interventions, salt water intrusion is likely to continue in the future (Zaman et al. 2016). Sea-level is likely to continue to rise and also dry season upstream water extractions are likely to increase which will result in lower dry season river flows. Fresh water influx during dry season is currently below the ecological flow (i.e., 234 cumec) to balance the river-water salinity (Moly et al. 2015) and below the minimum required flow (i.e., $194 \mathrm{cumec}$ ) to maintain the oligohaline (i.e., low saline) zone of the mangrove (Aziz and Paul 2015). This could result in further biodiversity loss. Also carbon contents of three dominant species of three salinity zones show the likely relationship between carbon storage of mangrove species 
and salt concentration. High salt tolerant species like $C$. decandra can store less carbon than the moderate like E. agallocha and less salt tolerant species like H. fomes. Also the carbon content of $H$. fomes varied along the salinity gradient from east to west. Carbon content of $H$. fomes was higher in the low saline zone than the moderate saline zone. Since importance value index indicates that $H$. fomes has started to be suppressed already by the salt tolerant species, carbon sink of the Sundarbans mangrove is also likely to decline.

Although salinity of the Sundarbans mangrove has increased during the last decades, still it is not considered as a significant concern in the Integrated Resources Management Plans of the Sundarbans (2010-2020) for biodiversity conservation and sustainable management in any of its ten strategic and mutually interlinked programs. Biswas and Choudhury (2007) reviewed the past 34 years of forest management practices in Bangladesh and found Sundarbans as the least studied forest in Bangladesh. In this line, our study is a valuable first step to relate ecological status (i.e., composition, density, diversity, canopy cover, regeneration and carbon content) of Sundarbans mangrove with salinity gradient and to improve the understanding on how salt concentrations affect mangrove ecosystem functioning in this world heritage site. These explicit findings suggest to take necessary initiatives to increase fresh water influx in the Sundarbans mangrove as a conservation strategy for this globally important ecosystems. Since Sundarbans mangrove has developed on a river dominated delta, sufficient amount of freshwater influx is needed to maintain its balanced saline environment, and consequently its healthy ecosystems.

\subsection{Conclusions}

This study gives the novel insight of ecological status of Sundarbans mangrove from different aspects like vegetation composition, structure, density, diversity, canopy cover, regeneration status and carbon content along salinity gradient for the first time to fill in the knowledge gap of relation of Sundarbans mangrove vegetation with salinity concentrations. We have found significant relation of mangrove vegetation with salinity and discussed what is likely to happen if present salinity gradient level gradually changes for future sea level rise and reduced upstream freshwater flow. It shows that further changes in salinity gradient will favour a shift in mangrove composition towards more salt tolerant species. However, the possibility of inland migration by the low saline zone mangrove species probably are inhibited by human settlements and infrastructure, high population pressures, shrimp farming, 
agriculture and rapid urbanization. Therefore, the biodiverse low saline zone of the mangrove forest is threatened by future developments in particular possible increases in salt water intrusion. We, hence, recommend to consider salinity as an important factor for future management strategy to protect the biodiversity of the Sundarbans world heritage ecosystem and also to safeguard the globally endangered and regionally critically endangered species (i.e., H. fomes) for conserving the rich carbon sink of this irreplaceable ecosystem. Most importantly, this spatially explicit information on Sundarbans' mangrove habitat preference for balanced salt concentrations indicates to take required actions for maintaining the ecological flow of the inter-connected upstream rivers, particularly during dry season.

\section{Acknowledgements}

We would like to thank the Chief Conservator of Forest, Bangladesh Forest Department for giving us the permission and the Divisional Forest Officers of Sundarbans East and West for providing security to work in the field. We are grateful to all who helped in data collection, especially A. Emon and P. Madani. We thank N. Mamnun for helping in preparation for the field work and N. Aziz for helpful discussions. We also appreciate Ruhul Mohaiman Chowdhury to provide us the Carbon content data from the IPAC project. This study received support from the Dutch Nuffic NFP fellowship programme (NFP-PhD.12/ 307). 


\title{
Chapter 4. Salinity increase and habitat degradation of Royal Bengal Tiger in the Sundarbans Mangrove of
}

\section{Bangladesh}

\begin{abstract}
Climate change induced sea-level rise and reduced upstream fresh water influx have started to imbalance the saline environment in the Bangladesh's Sundarbans mangroves. Simultaneously, a downward trend of the Royal Bengal Tiger population is observed in these mangroves. We, therefore, hypothesize that the gradual salinity increase degrades tiger habitat and this ensues its drastic population reduction. This study aims to explore how increasing salinity affects three key aspects of tiger habitat requirements: availability of fresh drinking water, sufficient prey population and diverse vegetative cover. Previous studies and observations on tiger population and their habitats are too limited to directly relate salinity increase to habitat degradation. Hence, we have combined and analysed five different information sources (i.e. literature, hydro-climatic data, focus group discussions with local communities, expert interviews and field observations). Local communities and experts opined about prey depletion and frequent intensive cyclones as the key ecological attributes for the population reduction. However, hydro-climatic data, literature and field observations indicate that habitat degradation is triggered by bio-physical and environmental changes. Lack of fresh water availability during dry season, increasing temperature during summer, changes in rainfall pattern and sea-level rise are contributing to change the salt concentrations and, consequently to change the vegetation pattern, which probably contribute to the tiger's habitat degradation and its principal prey depletion. Also tiger incidences (i.e., stray, injured and dead) are potentially related to reduced fresh water influx and salinity increase, particularly in May. Salinity increase and its range of processes, therefore, are likely the key factors in degrading tiger and its prey habitats. Hence, measures to maintain the ecological flow of fresh water influx to balance the mangrove's saline environment and adaptive mangrove landscape management are necessary to conserve the Bengal tigers in the Sundarbans.
\end{abstract}

The manuscript corresponding to this chapter is currently under preparation for journal submission. 


\subsection{Introduction}

The Sundarbans mangroves spread over the south western part of Bangladesh $\left(\sim 6000 \mathrm{~km}^{2}\right)$ and the West Bengal State in India $\left(\sim 4000 \mathrm{~km}^{2}\right)$ and represent the last remaining mangrove habitat for Royal Bengal tiger, Panthera tigris tigris (Linnaeus 1758), in the world. All world's tiger population have declined by $70 \%$ in the last 30 years (Grooten, Almond \& McLellan 2012). This downward trend categorized the Bengal tiger as globally endangered (Chundawat, Khan \& Mallon 2011). To reverse this current downward trend, protecting their habitats is identified as potentially the best conservation strategy (Walston et al., 2010). Otherwise, conservation efforts likely collapse blowing time and money (Aziz, Barlow, Greenwood \& Islam 2013).

Predominantly Bengal tigers were endemic in different parts of Bangladesh, such as the Chittagong Hill Tracts, the Brahmaputra river basin and the Sundarbans mangroves (Wikramanayake et al. 2011). However, currently only 106 Bengal tigers are found in the Sundarbans mangroves (Dey et al. 2015). Hence, the Bengal tiger is categorized as 'Critically Endangered' (IUCN-Bangladesh 2000). Still the Bangladesh's Sundarbans mangrove signifies one of the two largest tiger populations globally (Khan 2012). Wild-life sanctuaries of Bangladesh's Sundarbans are declared as a World Heritage Site by UNESCO (Sanyal 1999) and designated as a Level-I Tiger Conservation Unit because of its outstanding ecological potential for the long-term conservation of this unique species (Wikramanayake 1999).

Several studies mentioned poaching of the Royal Bengal tiger and its main prey (i.e. spotted deer) as the main reason for the drastic population reductions in the Sundarbans (Khan 2004; Mohsanin et al. 2013; Aziz et al. 2013). A few studies focussed on the tiger's habitat preferences and its main prey species (e.g. Khan \& Chivers 2007; Reza, Feeroz \& Islam 2002). Other studies focused on human-tiger conflicts and human consumption of tiger prey (e.g. Azad, Hashem \& Hossain 2005; Khan 2010; Neumann-Denzau \& Denzau 2010; Mohsanin et al. 2013). Since salinity is a key bio-physical component of the Sundarbans, changes in salinity level will also affect tiger population and their habitats. This probably has been overlooked.

The Sundarbans mangrove of Bangladesh is formed at the transient zone of the Bengal delta where tidal water from the Bay of Bengal and fresh water flow from the GangesBrahmaputtra-Meghna river basin converge (Figure 4.1a). Hence balanced saline environment is one of the key habitat requirements for stable growth of flora and living condition of fauna 
in the Sundarbans. However, this balanced saline environment is stressed from both sides (i.e., Bay of Bengal and Ganges-Brahmaputtra-Meghna river basin) by sea level rise and reduced fresh water influx correspondingly, resulting rapid salinity increase (Gopal \& Chauhan 2006; Smith et al. 2009; Loucks et al. 2010). The Bangladesh Tiger Action Plan (BTAP 2009-2017) identified salinity increase to affect tiger and its prey distribution (Ahmad et al. 2009) and the BTAP research agenda (2009-2017) highlighted the urgency to research this (Barlow et al. 2011).
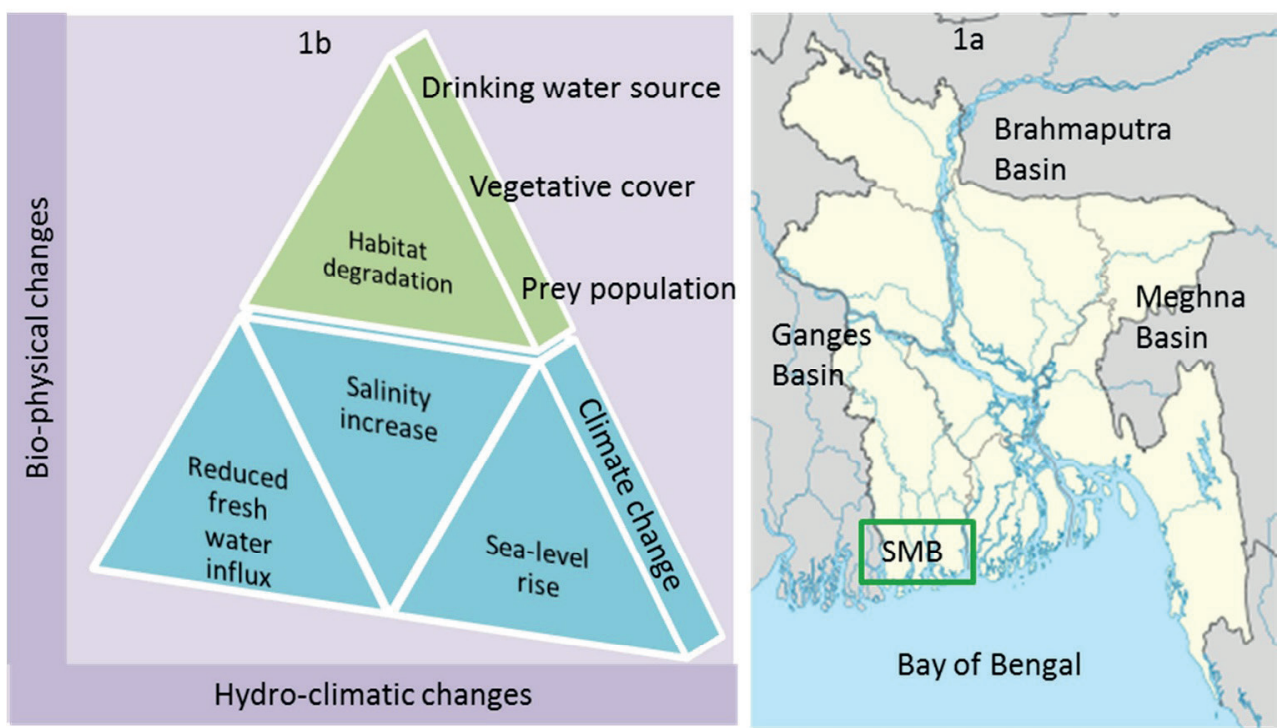

Figure 4.1. Problem statement and hypothesis for Royal Bengal Tiger population reduction in the Sundarbans Mangrove of Bangladesh (SMB)

A good quality habitat of the Royal Bengal tiger consists of sufficient prey population for food, certain types of vegetation for stalking, resting, breeding, ambush, feeding, defaecation and interaction, and availability of fresh water to drink (Khan \& Chivers 2007). When good quality habitat is less than half of the total habitat, tigers no longer breed successfully and gradually disappear from an area (Smith, Ahern \& McDougal 1998). However, current management practices to ensure suitable tiger habitat ignore the knowledge of how tiger's habitat in the Sundarbans is stressed by the hydro-climatic and salinity changes in this ecosystem. Considering the global, regional and national importance of Bangladesh's Sundarbans as the last remaining mangrove habitat for tigers, examining possible impacts of hydro-climatic and salinity changes is important to identify the priority issues for tiger habitat 
management and accordingly long term conservation. Identifying how bio-physical and environmental changes (i.e., climate change, sea level rise, hydrological changes and their impacts, such as fresh water influx during the dry season) are affecting the quality habitat of Bengal tiger is needed.

We hypothesize that gradual salinity increase, due to hydro-climatic and environmental changes, has become an additional threat for good quality habitat of tiger ensuing drastic population reduction (Figure $4.1 \mathrm{~b}$ ). We, therefore, aim to examine the potential impacts of salinity increase on tiger's habitat. Our study provides new insights for long term tiger-habitat conservation due to bio-physical changes in the mangroves.

Our previous studies on coastal environmental change and ecological status of Sundarbans mangrove (Hossain et al. unpublished manuscripts) showed significant changes in the hydroclimatic variables resulting in salinity increase and also in shifting mangrove vegetation along salinity gradients. Since tigers are at the top predators in the mangrove ecosystem, any biophysical changes are most likely to affect different components and species of the ecosystem, on which quality tiger habitat depends. To address the lack of knowledge on how tiger habitat relates to changing salinity, we analysed five different information sources (i.e., literature review, field observations and analysis of hydro-climatic variables, focussed group discussions with local communities and interviews with experts).

\subsection{Materials and Methods}

The literature review was based on all publications in the ISI-Web of Science and we searched with the following keywords. Additionally, we searched local and regional documents.

The observed data set of hydro-climatic variables, that we developed to assess the total environmental change in south-west coastal region of Bangladesh (Hossain et al. unpublished manuscripts), was used. We used tidal water level, fresh water flow, salinity, temperature and precipitation data to identify the trends of these hydro-climatic variables and also correlate these trends with the Tigers' quality-habitat requirements (i.e., prey population, vegetative cover and availability of fresh water).

We did ten focussed group discussions (FGDs) in total consisting of six or seven persons using a pre-selected discussion format following a systematic sampling. FGDs, which are a 
standard method, provides a greater understanding of the attitudes, behaviour, opinions or perceptions of participants (Hennink 2007). Six FGDs had been conducted in the nearest upazillas (sub-district) of the Sundarbans (i.e., Koira, Shyamnagar and Sharankhola). These FGDs consisted of different local community members, like fishermen, fuelwood collectors, honey, thatching material, crab and shrimp fry harvesters. These people frequently visit the forest to support their livelihoods. Group meetings with local communities are important to learn about local conditions and resource use (Lynam et al. 2007.). The other four FGDs were conducted within the Sundarbans mangroves with field-level forest staffs, who have practical experiences on conserving habitats at different patrol posts (i.e., Kokilmoni, Nilkomol, Dublar char, Alorkul and Katka). During the FGDs, we discussed particularly the likely causes, ecological attributes and observed indicators of tiger population reduction and prospective conservation strategies to address those.

Furthermore, we interviewed ten experts on these topics to cross check the observations of local communities and field staffs. In addition, potential impacts of observed changes in the hydro-climatic variables on tigers and their habitat were also discussed.

Finally, we visited three wild-life sanctuaries (i.e., Sundarbans east in the low saline zone, Sundarbans West in the high saline zone and Sundarbans south in moderate saline zone) for field observations on tiger and its prey habitats (Figure 4.2). Because field observations prevent from being misled by community and professional myths (Paulhus \& Vazire 2007) and often provide more valid information than other research methods (Walsham 2006).

All information gathered from these different methods were analysed to determine the most likely relationship between salinity increase and habitat degradation of the Royal Bengal tiger. 


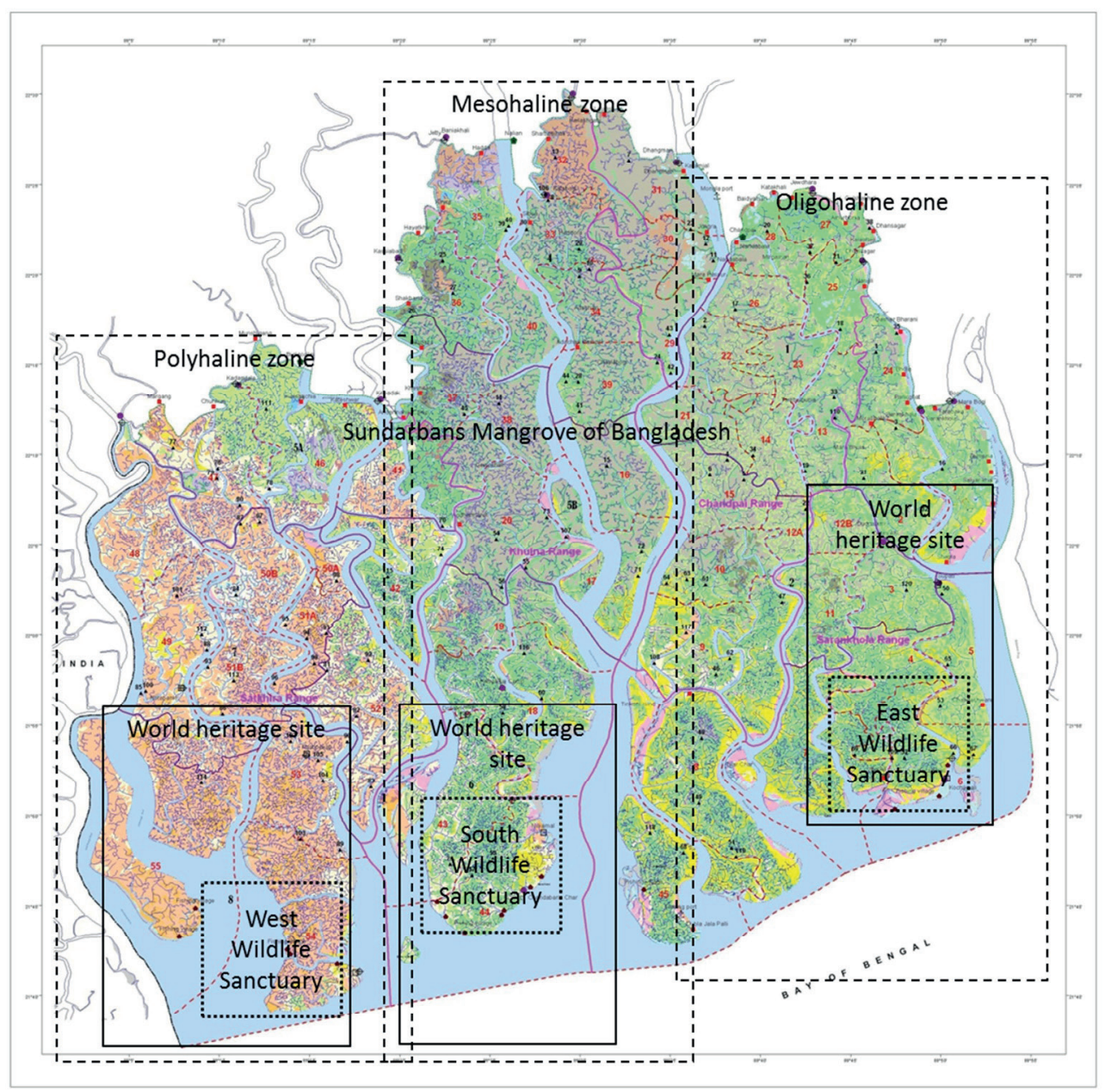

Figure 4.2. Sundarbans Mangrove of Bangladesh and its wildlife sanctuaries

\subsection{Results}

\subsubsection{Information on tiger and its population}

Information on tiger population trends in the Sundarbans mangrove of Bangladesh are listed in Table 4.1, principle prey-species density in Table 4.2, tiger density and human-tiger conflicts in three different saline zones in Table 4.3 and frequency of human-tiger conflict in the high saline zone in Table 4.4. Tiger population and its prey species density are remarkably at decreasing state. Tiger density is found highest in the low saline zone, however, humantiger conflict incidents are found highest in high saline zone, percentage of which is growing. 
Table 4.1. Royal Bengal Tiger population trend from 1975 to 2014

\begin{tabular}{llll}
\hline Year & Tiger population & Methods used & Source \\
\hline 2014 & 106 & Camera Trap & Dey et al. 2015 \\
2009 & 400 & Pug mark and radio-telemetry & GTRP 2012 \\
2004 & 200 & Camera trap & Khan 2012 \\
1992 & 359 & Khal survey and Home range & Tamang 1993 \\
1982 & 430 & Khal survey and Home range & Salter 1984 \\
1975 & 350 & Pug mark & Hendrichs 1975 \\
\hline
\end{tabular}

Table 4.2. Prey species density of Royal Bengal Tiger in the Sundarbans mangrove

\begin{tabular}{|c|c|c|c|c|}
\hline \multirow[b]{2}{*}{ Year } & \multicolumn{3}{|c|}{ Density (individuals $/ \mathrm{km}^{2}$ ) } & \multirow[b]{2}{*}{ Source } \\
\hline & $\begin{array}{l}\text { Spotted deer } \\
\text { (Axis axis) }\end{array}$ & $\begin{array}{l}\text { Wild boar } \\
\text { (Sus scrofa) }\end{array}$ & $\begin{array}{l}\text { Rhesus macaque } \\
\text { (Macaca mulatta) }\end{array}$ & \\
\hline 2005 & 12.4 & 0.4 & 4.5 & Khan 2012 \\
\hline 2000 & 70.4 & 7.9 & 15.8 & Reza et al. 2002 \\
\hline 1985 & 13.2 & 0.0 & 17.1 & Khan \& Ahsan 1986 \\
\hline 1975 & 20.0 & 5.0 & 10.0 & Hendrichs 1975 \\
\hline
\end{tabular}

Table 4.3: Density of tiger and human-tiger conflicts incidents in the Sundarbans mangrove

\begin{tabular}{llll}
\hline Saline zones & Forest Range & $\begin{array}{l}\text { Tiger density/100km }{ }^{-2} \\
(\text { Adopted from Dey et al. } \\
2015)\end{array}$ & $\begin{array}{l}\text { Human-tiger conflict } \\
\text { incidents (Adopted from } \\
\text { Barlow et al. 2011) }\end{array}$ \\
\hline $\begin{array}{l}\text { Oligohaline (less saline) zone } \\
\text { Mesohaline (moderately saline) zone }\end{array}$ & Shulna & 1.08 & 3 \\
Polyhaline (high saline) zone & Satkhira & 2.70 & 9 \\
\hline
\end{tabular}

Table 4.4: Human-tiger conflict in the Polyhaline (high saline) zone of Satkhira Forest Range (SFR)

\begin{tabular}{lll}
\hline Period & Percentage (\%) of casualties in SFR & Source \\
\hline $1971-1983$ & 35.4 & Siddiqi \& Choudhury 1987 \\
$1984-2000$ & 45.0 & Reza et al. 2002 \\
$2001-2005$ & 86.6 & Neumann-Denzau \& Denzau 2010 \\
\hline
\end{tabular}




\subsubsection{Bio-physical changes, salinity increase and likely impacts on tiger and its habitat}

The identified biophysical changes that contribute to salinity increase from the observed data set, show increased average air temperatures, decreased total annual precipitation, reduced upstream freshwater influx and tidal water-level rise (Figure 3.3). Besides, increase in seasurface temperatures, erosion and accretion have also been identified in previous studies. Since the erosion rate is higher than the accretion rate, tiger's mangrove habitat loss is expected. In addition, tidal water-level rise also contributes to habitat loss. Such habitat loss probably reduces breeding individuals. Reduced fresh water influx in association with tidal water-level rise contributes to salt-water intrusion and thus salinity increase. Both the upper and lower salinity bounds in all three salinity zones across the Sundarbans are increasing very rapidly. Salinity increase is degrading tiger habitat by creating a drinking water crisis inside the mangroves. Besides vegetation is already affected by the observed salinity increase. Also changes in precipitation and temperature affect the mangroves' plant physiology and regeneration. All these changes are likely to affect tiger's prey population and its habitat.

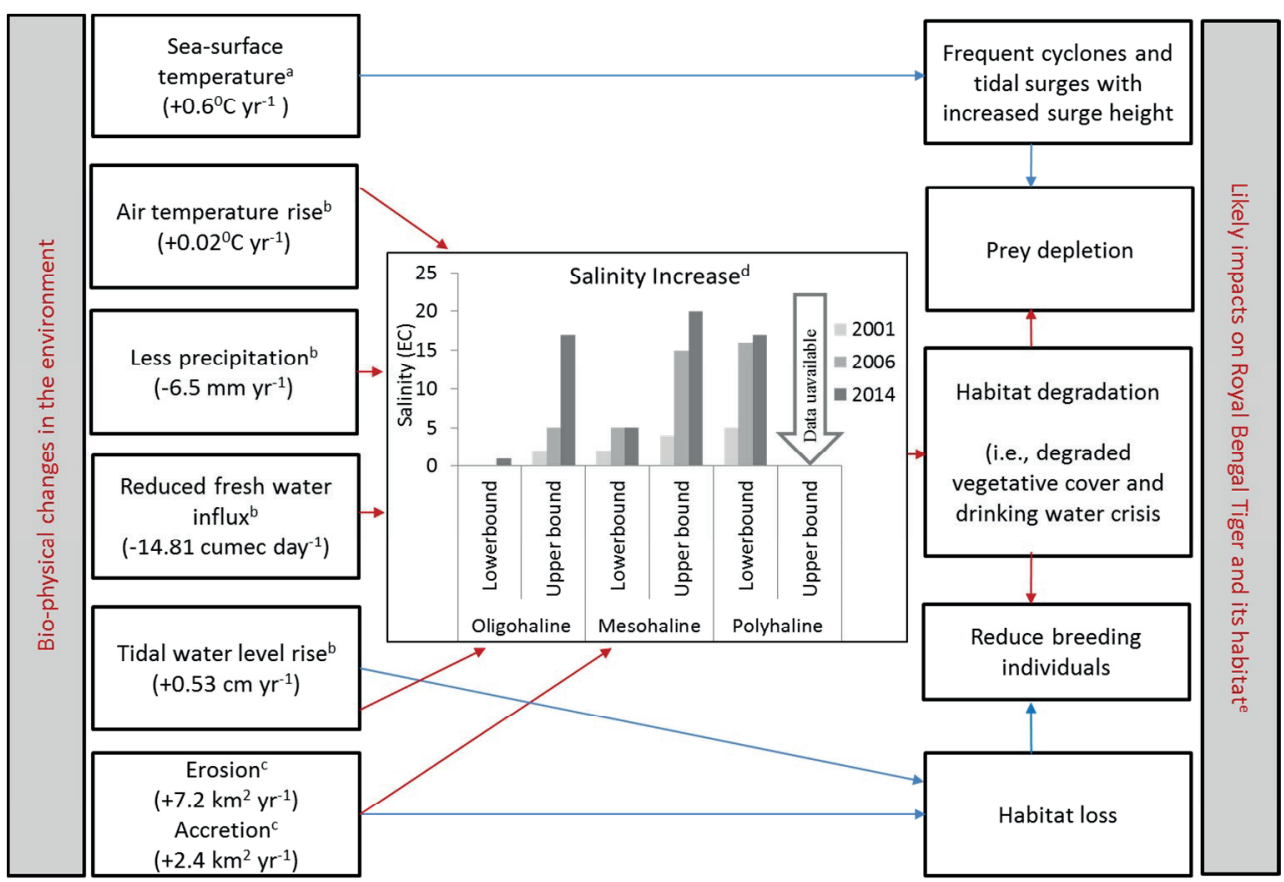

${ }^{\mathrm{a}}$ Khan, Singh \& Rahman 2000; ${ }^{\mathrm{b}}$ Observed data from 1981 to 2010; ${ }^{\mathrm{c}}$ Rahman, Dragoni \& El-Masri 2011;

${ }^{\mathrm{d}}$ Adopted from Siddiqi 2001, Hoque et al. 2006 and Hossain et al. unpublished manuscript; ${ }^{\mathrm{e}}$ Expert response and literature review

Figure 4.3. Bio-physical changes, salinity increase and likely impacts on RBT habitat in Sundarbans 


\subsubsection{Key ecological attributes along with the causes and indicators of reduced tiger population}

The observed hydro-climatic data and the literature review show that habitat degradation, salinity increase and sea-level rise are the key ecological attributes for the drastic reduction of tiger population in the Sundarbans mangrove (Table 4.5). The review also shows that the dominant cause of habitat degradation is salt-water intrusion through reduced upstream fresh water influx and sea-level rise. Trends in indicators, such as increased abundance of salt tolerant species, invasion of top dying disease, human-tiger conflicts, habitat loss, temperature and sea level rise, support these attributes and dominant causes. On the other hand, local communities and experts believe that prey depletion through poaching and more frequent intensive cyclones with increased surge height are the key ecological attributes for tiger population reduction. Increasing number of forest robbers, local people's consumption of tiger's prey and consecutive intensive cyclones in 2007, 2008 and 2009 support the attributes and causes mentioned by the local communities and experts. Most of the experts and FGDs, therefore, recommend effective legal enforcement to control prey depletion and enhanced coastal afforestation programmes to reduce the cyclone damages. Literature and observations suggest that periodic (re)-excavation of silted rivers can maintain the ecological flow of the rivers during the dry season and this helps to reduce habitat degradation in the whole mangrove landscape. 


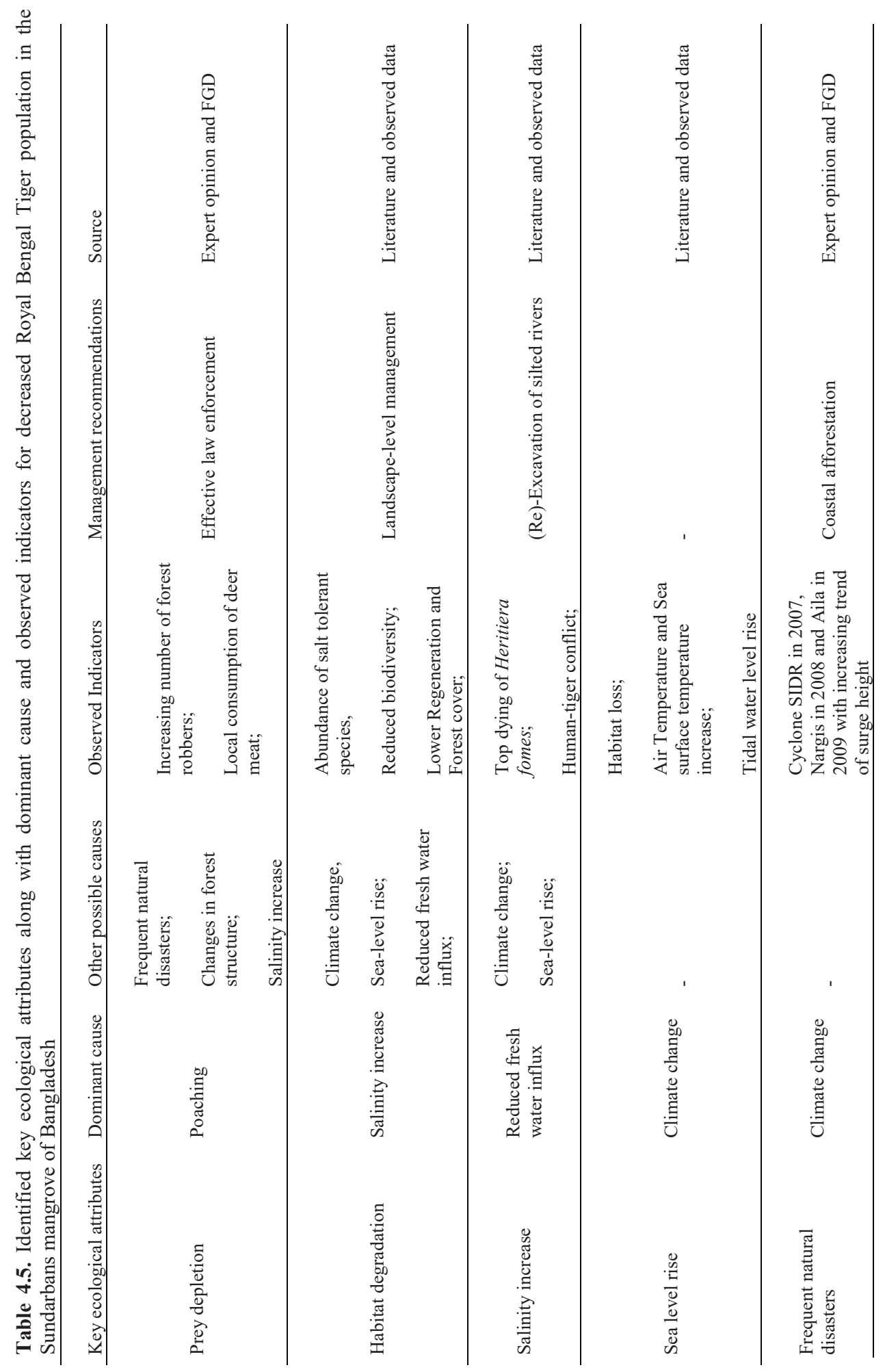




\subsubsection{Relationship among tiger incidences, reduced fresh-water discharge and salinity}

increase

Fresh-water influx from January to May ranges from 47-120 cumec, while from June to December, it remains from 227 to 4153 cumec (Figure 4.4a). Tiger incidences (i.e., stray, injured and dead) are found highest in May. This indicates a possible relationship with reduced fresh-water influx. At the same time, the peak period of south-western river-water salinity (i.e., 4 to $6 \mathrm{ppt}$ ) occurs during in the period March to June. This possibly also relates with the highest tiger incidences in May (Figure 4.4b).
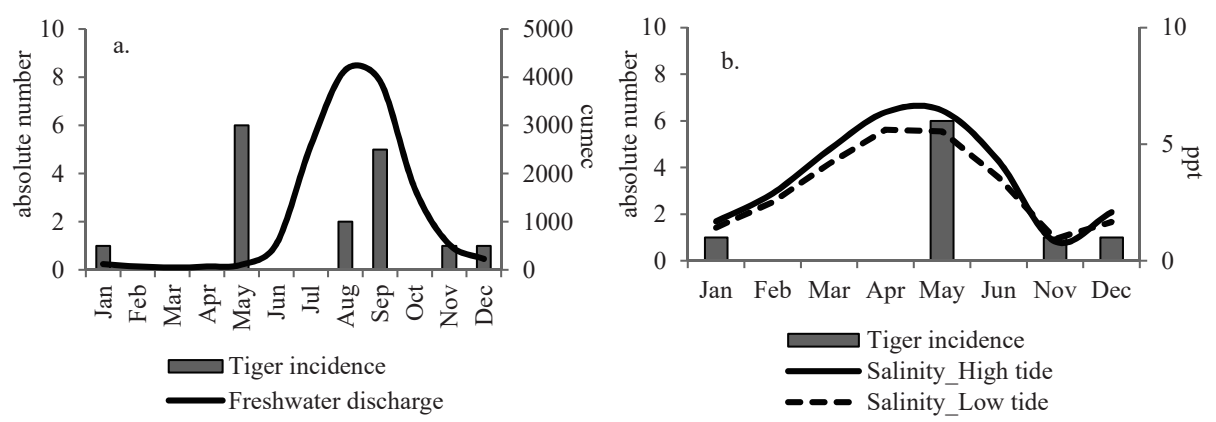

Figure 4.4. Relationship among monthly tiger incidence, fresh water discharge (cumec) and salinity (ppt)

\subsubsection{Changes in the ecological systems of Royal Bengal Tiger habitat in the Sundarbans}

Ecological systems (including drinking water sources, prey, vegetation) of tiger habitats are degrading in the Sundarbans of Bangladesh (Figure 4.5). Low freshwater influx during the period from January to May and highest river-water salinity during the period from March to May likely contribute to this drinking water crisis. Tiger's principle prey most probably decline due to frequent and intensive cyclones with high tidal surges, changes in climate (i.e., increasing temperatures and decreasing precipitation trends during pre-monsoon season) and less available fodder. Also changes in vegetation due to climate change, reduced freshwater influx and salinity increase possibly affect tiger and its prey habitats for different activities, like resting, breeding, stalking, ambush, scratch, drinking, feeding, defaecation and movement. 


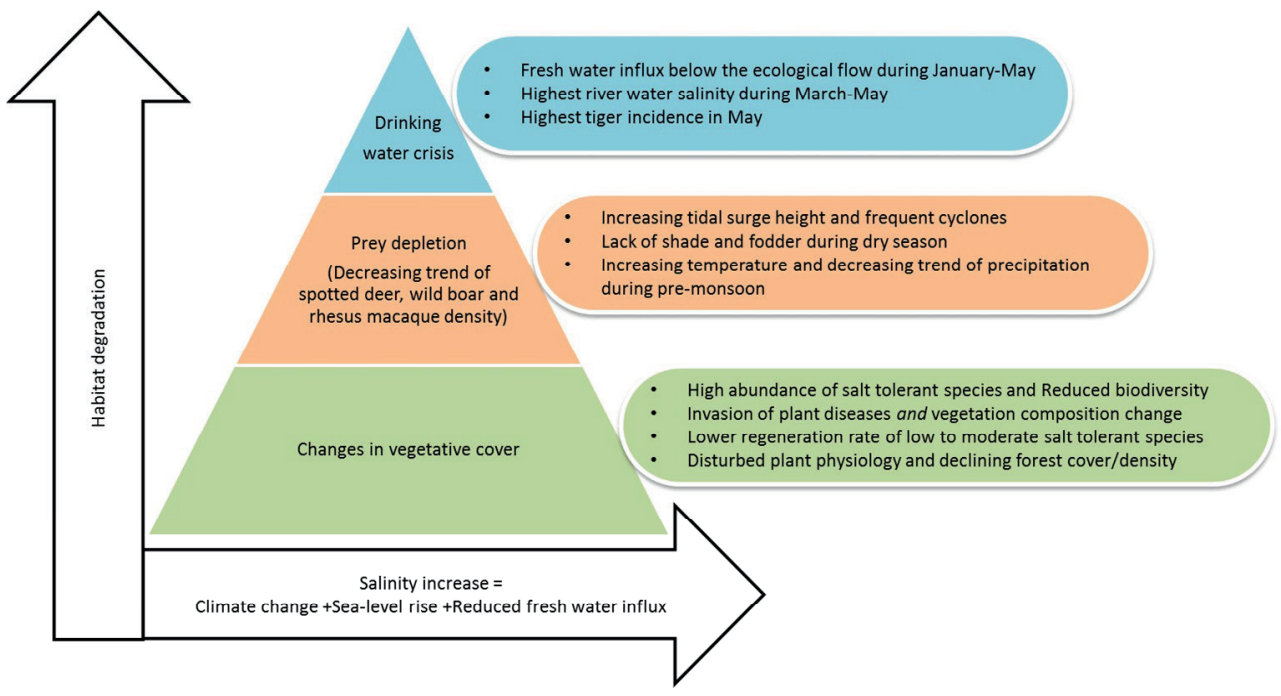

Figure 4.5. Changes in the ecological systems of Royal Bengal Tiger habitat in the Sundarbans

\subsection{Discussion}

The Royal Bengal tiger population has already decreased in the Sundarbans mangrove of Bangladesh (Tamang 1993; Khan 2012; Dey et al. 2015). In this study, we revealed the likely causes of this downward trend in Sundarbans tigers. Initially five different information sources that covered different aspects (i.e., ecological attributes, dominant cause, observed indicators) disclose the possible relationships between habitat degradation and salinity increase for the decreased tiger population. Four of the five identified ecological attributes are directly related to climate change and its impacts (i.e., sea-level rise, reduced upstream flow and salinity increase). Observed hydro-climatic trends also support these attributes. Salinity increase contributes to biodiversity decline, reduced forest-cover, increased abundance of salt tolerant species, changed vegetation composition and invasions of diseases like top dying (Rahman \& Asaduzzaman 2010; Hossain et al. 2014). Sea-level rise contributes to direct loss of vegetative cover (Loucks et al. 2010). Climate change disturbs plant physiology, phenology and reduces vegetation (Sarker et al. 2016). Fresh water influx during the dry season is currently below the normal ecological flow (i.e., 234 cumec) necessary to balance the riverwater salinity (Moly, Mirza, Rahman \& Saadat 2015) and below the minimum required flow (i.e., 194 cumec) to maintain the oligohaline (i.e., low saline) zones of the mangroves (Aziz \& Paul 2015). So salinity increase and its range of processes (i.e., climate change, sea-level rise 
and reduced fresh water influx) are most likely degrading mangrove vegetation in the Sundarbans.

Our study also recognizes that degraded vegetative cover likely affects both the tiger and its prey habitats. Because tigers prefer the comparatively low saline zone mangrove woodlands to patrol their territories, to hunt and feed, and to scratch soft barked trees to mark their territory and sharpen their claws (Khan \& Chivers 2007; Linkie et al. 2003; Kotwal \& Mishra 1995; Johnsingh 1983). This zone probably also has more available prey, drinking water sources and suitable vegetative cover for the tigers. Besides, the tigers also use grasslands to take rest and sea beaches to interact and mate (Khan \& Chivers 2007). So, a diverse and heterogeneous landscape is needed for different activities of the Sundarbans tigers.

In addition, they also need sufficiently available drinking water as a tertiary carnivore (Sunquist \& Sunquist 2002). Reza, Feeroz \& Islam (2001) recorded most of their tiger trails from the fresh water-hole area in the Sundarbans during March to July. However, salinity increase and its consequent range of processes are degrading tiger habitat by creating a severe drinking water crisis inside the mangroves particularly during the dry season. This finding is supported by the observed hydro-climatic data. The results show how the lowest fresh water influx during January-May and the consequent highest salinity levels are related to the highest tiger incidences in May.

Besides, the highest number of human-tiger conflicts are observed in the polyhaline (i.e., high saline) zone, particularly in dry season (Reza et al. 2002), though tiger density is lowest in this zone (Dey at al. 2015). These conflicts are increasing in this zone (Barlow et al. 2011) despite the downward tiger population trend in the Sundarbans and the relatively low tiger density in the polyhaline zone. Several studies mentioned the frequency of human intruders that are responsible for these conflicts. However, mangrove intruders frequencies are comparatively higher in the oligohaline zone than in the polyhaline zone (Azad et al. 2005; NeumannDenzau \& Denzau 2010), while the conflicts are highest in the polyhaline zone. This thus indicates that the lack of fresh water sources due to low fresh water influx and high salinity during that period, is responsible for the increasing number of conflicts. Some of the experts suspected that the physiology of the Sundarbans tiger is affected by the salinity increase. Although no scientific evidence exists, as a result, hypertonicity probably creates aggressiveness. Another interesting reason for the increasing number of human-tiger conflicts can be migratory or transient tigers (Barlow et al 2009). As the polyhaline zone of the 
Bangladesh Sundarbans is geographically attached to the Indian part of the Sundarbans, the possibility of having migratory tigers here exists. Since migratory tigers do not have established territories, they may face problems to perform their different activities, in searching their prey and in approaching fresh water sources (Neumann-Denzau \& Denzau 2010). However, this is never studied in detail. Hence, the tiger densities and the increasing number of human-tiger conflicts in the polyhaline zone are unlikely due to lack of fresh water sources only, but also to the unavailability of proper wooded habitat and insufficient prey.

The tiger's prey also need proper wooded habitat for food, drinking water and shade (Duckworth et al. 2015). For example, spotted deer need fallen fruits, leaf litter and grasses while the wild boars need roots and tuber as fodder. The feeding habits of the tiger's prey also indicate that these species need different vegetative cover for forage. In addition, spotted deer needs shade and fresh water, particularly in summer (Duckworth et al. 2015). Also, their browsing behaviour during early morning and late evening (field observations) indicate the susceptibility to day-time high temperatures, for which they prefer shaded vegetative cover. So, climatic signals like air-temperature increase during summer and late onset of monsoon along the south-west coast of Bangladesh (Hossain et al. unpublished manuscript) will also create stress on physiological activities of spotted deer. Our literature review reinforces the already declining trend of tiger's prey species in the Sundarbans. Further degradation of vegetative cover, lack of fresh water sources and climate-change signals will affect tiger's prey population to further decrease.

However, our FGDs with forest staffs and local communities who are dependent on Sundarbans for their livelihood, and the expert interviews identified poaching as the dominant cause of tiger's prey depletion. The perspectives of their perception were increasing local deer meat consumption rate and increased number of illegal intruders in the forests. Khan (2010) and Mohsanin et al. (2013) also identified human consumption of tiger prey as a major cause for tiger's prey depletion in the Sundarbans. However, these findings are related to only spotted deer. Other prey species (i.e., wild boar and rhesus monkey) are also declining. Hence, poaching can be a threat for deer population in the Sundarbans, but degraded vegetative cover and lack of fresh water sources are largely affecting all prey species. We also observed abundant spotted deer mostly in the oligohaline zone, considerable presence of rhesus monkey in the mesohaline (moderate saline) zone and a few wild boar in the polyhaline zone during our field visits. Differences in tiger's prey availability across the three different salinity zones are probably for the differences in vegetation composition along the salinity gradients and 
consequently availability of different foods for different prey species. The oligohaline zone is highly biodiverse and, has sufficient forage and fresh water sources for tiger's prey species. This thus confirms the availability of sufficient food for tiger. On the other hand, the polyhaline zone is less diverse in vegetation, has insufficient forage and freshwater sources for tiger's prey species and, therefore, supports comparatively a small number of tiger's prey population. Also we observed the abundance of deer population around the Keora (Sonneratia apetala) forest stands, where they feed on Keora leaves and litter. However, Keora is a moderate saline (6-15ppt) tolerant species and seed viability of this species is very low (less than three months; Kathiresan et al. 2010). Therefore, this mangrove species is vulnerable to salinity increase. For instance, in the Indian Pichavaram and Muthupet mangroves, the reintroduction of Keora failed because of high salinity (Rahman \& Asaduzzaman 2010). Thus, degradation of mangrove vegetation and lack of fresh water sources due to increasing salinity surely affect tiger and its prey habitats. Hence, habitat degradation is very likely to be the major cause for Royal Bengal tiger population reduction.

Most of the experts suggested to ensure effective law enforcement to protect the existing spotted deer population. Also local communities suggested the same but focused more on controlling the illegal intruders. Both thus suggest to control prey poaching. On the other hand, Khan \& Chivers (2007) recommended to manage the entire Sundarbans mangrove landscape to conserve the tigers. This differs from previous conservation efforts taken by Bangladesh Forest Department, which focussed mainly on tiger and its prey poaching, and reducing human-tiger conflicts. However, only controlling poaching, human-tiger conflict and/or mangrove landscape management, without addressing the bio-physical environmental changes like sea-level rise and reduced fresh water influx, will not reduce the downward tiger population trend. Our analysis clearly shows that changes in hydro-climatic variables and relationships of these changes with the availability of fresh drinking water sources and with diverse vegetative covers across the Sundarbans are not only distressing the tiger population but all its prey species as well. Therefore, initiatives to control and adapt to sea-level rise, and to ensure the required regional flow of upstream fresh water to the river network connected to the Sundarbans are urgently needed.

Since freshwater water influx plays a substantial role in determining the diverse vegetative covers and drinking water availability for tiger and its prey species, measures like (re)excavation of silted rivers and development of upstream reservoir or barrage to maintain ecological flow of sediment laden fresh water from upstream rivers during the dry season 
need to be considered as well. Measures to increase sediment laden freshwater influx will not only reduce salinity but erosion as well. Thus, these measures will also help to restrict changes in vegetation. Proper vegetative cover will give space to perform various activities of tiger self-sufficiently and will also provide enough forage and shade for tiger's prey species to sustain healthy prey population for the Sundarbans tigers. In addition, a sufficient amount of sediment laden fresh water influx throughout the year will also help in land-reclamation. This will slow or even reduce tiger's mangrove habitat loss due to climate-change induced sealevel rise. Therefore, ensuring a sufficient amount of fresh water influx is needed to conserve the last remaining mangrove habitats for the Sundarbans tigers.

Conversely, sea-level rise is a global issue, which cannot be halted nationally, regionally or locally. Therefore, international initiatives are also crucial to mitigate further sea-level rise to conserve one of the world's most important tiger habitats in the Sundarbans.

A very limited and scattered data on tiger and its prey occurrences and habitats did not allow to statistically correlate the discussed hydro-climatic variables and bio-physical changes to the tiger habitat requirements in the Sundarbans. However, five different information layers helped us to explore the most likely relations of tiger's habitat degradation from three different aspects (i.e., fresh water sources for drinking, principle prey for food and vegetative cover for performing different activities) with salinity increase and its range of processes (i.e., climate change signals, sea-level rise, reduced fresh water influx). Though the relationships are not statistically tested, they seem robust and are the valuable first step to improve measures to halt the decline to the Sundarbans tiger population.

\subsection{Conclusions}

The Royal Bengal tiger habitats in the Sundarbans of Bangladesh are influenced by a number of macro-level hydro-climatic changes. Salinity increase, which is mainly caused by climate change, sea-level rise and reduced fresh water influx, most likely degrades all the mangrove vegetation and tiger habitats, prey population and fresh drinking water sources. This degradation reduces the quality of the tiger habitats. However, previous conservation efforts did not focus on habitat degradation. Diversity of mangrove vegetation and availability of freshwater are required for both Bengal tiger and its prey habitats. Therefore, sufficient amount of fresh water influx need to be ensured all year round to maintain the diverse vegetative cover and also to increase the number of fresh drinking water sources inside the 
forests for all species. The downward trend of the tiger and its prey population are likely more associated with bio-physical changes in the environment than to, for example, poaching. We have discussed many evidences. However, hardly any of these changes are considered for tiger conservation. This can explain why previous conservation efforts were less successful. Hence, actions need to be taken to reduce current rapid salinity increase along the Sundarbans coast, in addition to controlling poaching, reducing human-tiger conflicts and managing landscapes for a better conservation of tigers, their prey species and their habitats.

\section{Acknowledgements}

This research is funded by Nuffic under the NFP fellowship programme in 2012. We would like to thank the Bangladesh Forest Department for giving us permission to visit the wildlife sanctuaries in the Sundarbans and also for ensuring security issues. We thank all the experts, who shared their views and recommendations on the research theme. We also appreciate the field level forest staffs for sharing their experiences and their cooperation during our field observations. We are grateful to the local communities for their spontaneous discussion and suggestions to conserve the Royal Bengal tiger. 


\title{
Chapter 5. Adaptation pathways to cope with salinization in south-west coastal region of Bangladesh
}

\begin{abstract}
Salinization in coastal regions of Bangladesh challenges sustainable development of different sectors like agriculture, forestry, fisheries, livestock and health. Particularly its south-west region largely risks increased salinity due to its geographical location and environmental settings. This study analyses the causes of salinity increase, their cascading impacts on different coastal systems and their livelihood implications, and assesses potential coping measures through innovative adaptation pathways for the mostly affected coastal systems. These pathways integrate bottom-up and top-down perceptions in adaptation planning through a driver-pressure-state-impact-response framework, multi-criteria analysis and adaptation turning point approaches. We surveyed 200 households and interviewed 20 key informants. We observed that household-level respondents' perceptions are more closely related to socioeconomic aspects than to the bio-physical environmental aspects and focus on issue based action. However, the key informants focus more on the bio-physical changes and the largescale measures. The developed framework shows that salinity increase is an interconnected process of climatic-social-ecological-economic systems in the coastal environment. It also shows that responses already taken (i.e., polders and shrimp farming) to cope with salinization have later become pressures (i.e. riverbed siltation, waterlogging and intensive salinization) on the systems. In total, we identified six interconnected causes of salinity increase and twenty four potential measures to address them. Also we distinguished three coastal systems (i.e., crop-agriculture, drinking water sources and the Sundarbans mangrove) mostly affected by salinity increase. Finally we proposed sixteen adaptation pathways for these coastal systems based on the multi-criteria analysis and adaptation turning points of the potential measures.
\end{abstract}

Re-submitted as:

Hossain P R, Ludwig F and Leemans R. Adaptation pathways to cope with salinization in south-west coastal region of Bangladesh. The manuscript corresponding to this chapter is resubmitted to the Ecology and Society Journal after addressing the positive review comments. 


\subsection{Introduction}

Climate change impacts such as sea level rise, more frequent natural disasters and sea water intrusion are considered as the major causes for salinity increase in the world's deltaic regions (Nicholls and Cazenave 2010). For instance, several studies found that the Mekong delta (Renaud et al. 2015), the Nile delta (El Barmelgy and Rasheed 2016) and the Ganges tidal floodplain (Rahman and Rahman 2015) face increasing salinity problems. As part of Ganges delta, Bangladesh is experiencing similar problems, particularly in its south-west region (Khanom 2016). This exposed coastal region lies about 1.5 meters above mean sea-level and this makes it vulnerable to sea-level rise, inundation and salt-water intrusion (Chowdhury 2009).

Recent research has shown that salt intrusion rapidly increases in the region. From 2000 to 2009, salt-water intrusion increased up to $15 \mathrm{~km}$ north of the coast due to sea-level rise, and currently in the dry season, salt-water intrudes up to $160 \mathrm{~km}$ inland due to reduced upstream river flows (SRDI 2010). This salt intrusion has large impacts on both ecological and socioeconomic systems which provide essential social, economic and ecosystem services. Hence, its highly diverse ecosystems, like the world's largest single tract of mangroves (the Sundarbans), wetlands (vast network of rivers of the Ganges-Brahmaputra tidal plains) and inlands (mostly crop-agriculture) have already started to be severely affected by this salinization (Rabbani et al. 2013, Rasel et al. 2013, Sarker et al. 2016). In addition, this salinization leads to extreme drinking water scarcity for about 6.2 million people (Abedin et al., 2014).

The general causes and impacts of increasing salinity at large regional scale are broadly recognized (e.g. Khan et al. 2011, Mahmuduzzaman et al. 2014). However, understanding local socio-economic and bio-physical conditions is often too incomplete to identify the intermingling causes of the salinity increase and its cascading impacts on different coastal systems for integrated and sustainable adaptation planning (Nandy et al. 2013). For instance, extensive shrimp farming in the south-west coast of Bangladesh has created a direct conflict with crop agriculture. Shrimp farming has not only damaged agriculture but also agroforestry, fisheries, livestock and physical infrastructures (Nowreenet al. 2014). Most coastal development interventions have largely focussed on structural protection measures like dams, embankments, polders through top-down approaches and have largely ignored the complex and dynamic social, ecological and economic systems in the region (Ayers et al. 2014). 
Therefore, adaptation approaches are unlikely to be effective if not all parts of the environment (i.e., bio-physical and socio-economic) are taken into account while identifying potential measures (Fussel 2007). In addition to the infrastructural developments both upstream (the Farakka barrage) and downstream (polders and embankments), climate change and sea-level rise exacerbate the salinity increase. Climate change increased the frequency and severity of hydro-climatic extremes, such as cyclones, tidal surges and floods (PenningRowsell et al. 2013).

Although salt intrusion clearly has increased over the last decade, future salt intrusion rates are highly uncertain due to unknowns in future climate change (Dessai and Sluijs 2008) and upstream developments. As a result, policy makers often struggle where, when and which different measures need to be implemented. To deal with such uncertain futures, adaptation pathways based on adaptation turning points have been developed (Wise et al. 2014). Such adaptation pathways support decision making under uncertain future conditions (Haasnoot et al. 2014). It has been mainly used in the developed countries to identify potential flood defence measures in the Netherlands (Haasnoot et al. 2013) and robust options for coastal natural resource management in Australia (Bosomworth et al. 2015). However, the approach is relatively new in developing countries, such as Bangladesh.

A saline environment has always been part of Bangladesh's south-west part and local people have been living with salt for the last three decades. However, the recent excessive salinization and its unfavourable impacts have forced people to already take small scale adaptation measures, like salt tolerant crops, raising the plinth of the houses and tube-wells, afforestation and rain-water harvesting. However, large scale initiatives are not yet considered. Hence, to obtain greater benefits (i.e., food security, biodiversity conservation, environmental protection and sustainable livelihood), large scale adaptation planning is now needed. In this context, Bangladesh Climate Change Strategy and Action Plan (BCCSAP 2009) was prepared. Implementing this action plan fundamentally requires to better identify the causes of salinity increase and characterize its impacts because local adaptation is highly context dependent. Therefore, individual communities and ecosystems may require different adaptation plans based on varying causes and impacts of salinization (Huq et al. 2015).

In the context of BCCSAP 2009 and the problems policy makers have with implementing timely adaptation measures under changing climatic and socio-economic conditions, this study aims to develop adaptation pathways to cope with salinization in Bangladesh's south- 
west coastal region. To develop the adaptation pathways, we studied the interconnected causes of salinity increase, the social and natural systems affected by salinity increase and how they are affected. We also identified potential adaptation measures along with their contribution and adaptation turning points to address the identified causes and mostly affected coastal systems.

\subsection{Methods}

This study focusses on three districts (Figure 5.1A) of Bangladesh's south-west coast (i.e., Khulna, Bagerhat and Satkhira), in terms, people of these three districts are severely affected by salinity increase. In our previous studies, we looked into the bio-physical changes in the coastal environments and the Sundarbans mangrove, and we found significant changes over the forest and hydro-climatic variables due to climate change, climate-change induced problems and reduced upstream river flow (Hossain et al. unpublished manuscripts). Hence, we selected these three districts to study the causes and impacts of, and adaptation pathways to cope with salinization through household surveys, key informant interviews, driverpressure-state-impact-response (DPSIR) framework, multi-criteria analysis and adaptation pathway approach based on adaptation turning point (Table 5.1).

B)

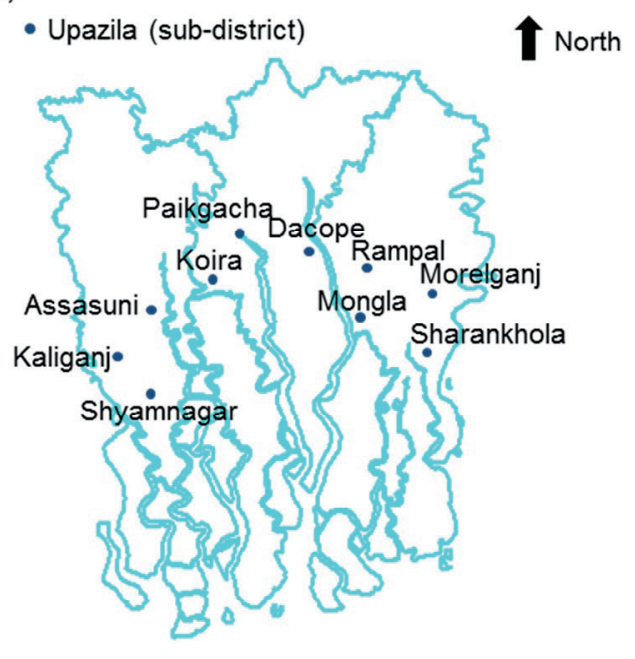

A)

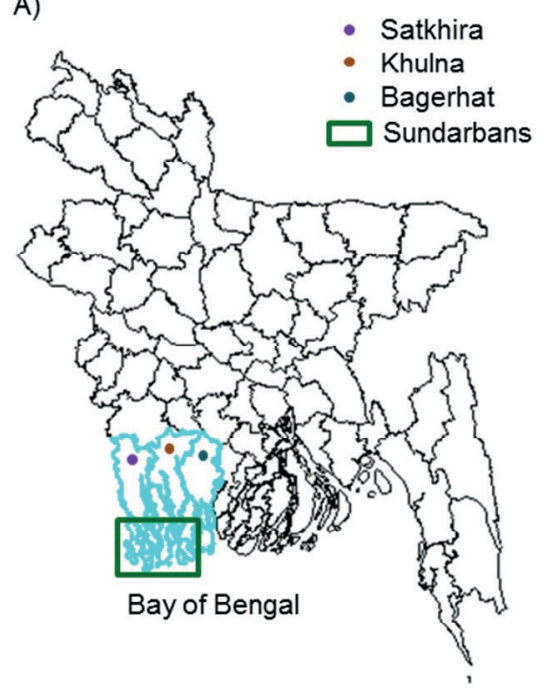

Figure 5.1. Study area 
As part of our bottom up approach, 200 households through simple random sampling from 10 selected upazilas (sub-units of district) based on nearness to the coast (Figure 5.1B) of 3 above-mentioned districts were surveyed during December 2015 and January 2016 with a structured questionnaire. This questionnaire focussed to gather information on respondents' socio-economic status along with their views on salinization, affected livelihoods and coastal systems, ways of being affected, and finally to have their opinion on potential (i.e., shortmedium-long term) measures that consider their own perceived risks along with their turning points and contributions.

Table 5.1. Approaches used in this study along with their specific purpose

\begin{tabular}{|c|c|c|}
\hline Approaches used & Description & Purpose \\
\hline Household level survey & $\begin{array}{l}\text { Local people's opinion on a } \\
\text { structured questionnaire }\end{array}$ & To get bottom up perceptions \\
\hline Key informant interview & $\begin{array}{l}\text { Observation of the knowledgeable } \\
\text { persons on a structured } \\
\text { questionnaire }\end{array}$ & To get top down perceptions \\
\hline DPSIR framework & $\begin{array}{l}\text { Integration of the information on } \\
\text { driving forces-pressure-state- } \\
\text { impact-response }\end{array}$ & $\begin{array}{l}\text { To make socio-ecological- } \\
\text { economic connections }\end{array}$ \\
\hline Multi-criteria analysis & $\begin{array}{l}\text { Analysis of a measure under } \\
\text { different criteria i.e., effectiveness, } \\
\text { side effects, cost, feasibility and } \\
\text { uncertainty }\end{array}$ & $\begin{array}{l}\text { To identify the suitable adaptation } \\
\text { measures }\end{array}$ \\
\hline Adaptation turning point (ATP) & $\begin{array}{l}\text { A situation (for this study salinity) } \\
\text { where a measure's threshold is } \\
\text { reached }\end{array}$ & To develop adaptation pathway \\
\hline Adaptation Pathway & $\begin{array}{l}\text { A set of measures that can be } \\
\text { implemented gradually depending } \\
\text { on the ATP }\end{array}$ & $\begin{array}{l}\text { To develop large scale adaptation } \\
\text { plan }\end{array}$ \\
\hline
\end{tabular}

The households survey resulted in too little information on mid and long term adaptation measures and potential adaptation turning points. To fill this gap, 20 key informants from different government and non-government organizations; universities and research institutes (Figure 5.2) were interviewed from July to August 2017 for getting top-down perceptions on the same issues. Key informants were selected from water, agriculture, forestry, fisheries, environment and planning sector by systematic sampling based on their research and work experience.

The DPSIR framework (Smeets and Weterings 1999) was used to integrate the information of local people's perceptions and key informants' opinion to determine connections among the climatic, social, ecological and economic systems (Pinto et al. 2013). 


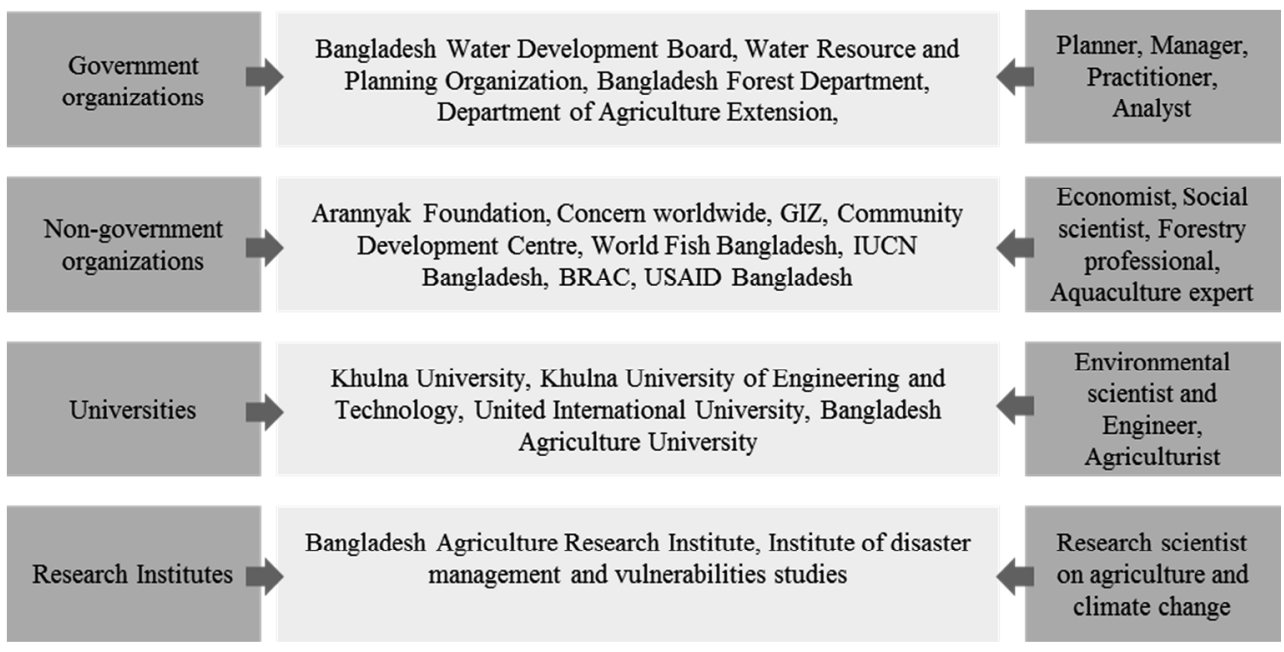

Figure 5.2. Categories of key Informants from different organizations and Institutes

The assessment of potential adaptation measures identified by two different levels of respondents was done using a multi-criteria analysis (Phi 2011). Measures were with regard to five different criteria: effectiveness, side effects, cost, feasibility and uncertainty which can be scored from being very negative (---) to being very positive $(+++)$. The criteria and their ranges were described to the respondents (Table 5.2) in local language to score the measures. Each positive score is assumed to be valued by +1 and each negative score by -1 to rank them for identifying suitable measures.

Table 5.2. Description with score card for the selected criteria of multi-criteria analysis

\begin{tabular}{|c|c|c|c|c|}
\hline \multirow{2}{*}{ Criteria } & \multirow{2}{*}{ Description } & \multicolumn{2}{|l|}{ Range } & \multirow{2}{*}{ Score } \\
\hline & & +++ & --- & \\
\hline Effectiveness & $\begin{array}{l}\text { Ability of a system to cope with the } \\
\text { consequences }\end{array}$ & $\begin{array}{l}\text { Highly } \\
\text { effective }\end{array}$ & Not effective & \multirow{5}{*}{$\begin{array}{l}\text { Each positive score } \\
\text { is assumed to be } \\
\text { valued by }+1 \text { and } \\
\text { each negative score } \\
\text { by }-1 \text { to rank them } \\
\text { for identifying the } \\
\text { suitable measures }\end{array}$} \\
\hline Side effects & $\begin{array}{l}\text { Secondary effects both positive and } \\
\text { negative ones which are not directly } \\
\text { related to the primary purpose }\end{array}$ & $\begin{array}{l}\text { Positive } \\
\text { effect }\end{array}$ & $\begin{array}{l}\text { Negative } \\
\text { effect }\end{array}$ & \\
\hline Cost & $\begin{array}{l}\text { Comprise of construction/implementation } \\
\text { cost, maintenance cost and transaction } \\
\text { costs }\end{array}$ & No cost & High cost & \\
\hline Feasibility & $\begin{array}{l}\text { Looks at the barriers that can potentially } \\
\text { hamper the adaptation process. As for } \\
\text { example, limited technical capacity, } \\
\text { economic strength, socio-cultural } \\
\text { acceptance and potential conflicts with } \\
\text { current legal settings }\end{array}$ & $\begin{array}{l}\text { Highly } \\
\text { feasible }\end{array}$ & Not feasible & \\
\hline Uncertainty & $\begin{array}{l}\text { Performance of a measure under a wide } \\
\text { range of changes in climatic and socio- } \\
\text { economic conditions }\end{array}$ & $\begin{array}{l}\text { No } \\
\text { uncertainty }\end{array}$ & $\begin{array}{l}\text { Highly } \\
\text { uncertain }\end{array}$ & \\
\hline
\end{tabular}


Finally, the adaptation pathway maps for the mostly affected coastal systems were developed considering the top-down and bottom-up perceptions on the affected systems, dominant cause of salinity increase in that particular system and suitable measures along with the adaptation turning points for each of the potential measures under which a measure is no longer sustainable. It is a very new approach for Bangladesh, but, likely helps to develop an adaptation plan to cope with and enhance resilience to salinization (Reeder and Ranger 2011).

\subsection{Results}

\subsubsection{Demographic and socio-economic status of the household level respondents}

Most of the respondents of the survey are male, on average 35 years old and illiterate (Table 5.3). We found nine different professions among the respondents. Agriculture is the dominant profession followed by shrimp farmers and people dependent on other services derived from Sundarbans.

Table 5.3. Demographic and socio-economic status of the household level respondents

\begin{tabular}{lllll}
\hline Category & Characteristic & Percentage (\%) & & \\
\cline { 3 - 5 } & & Khulna & Bagerhat & Satkhira \\
\hline Gender & Male & 62 & 70 & 83 \\
& Female & 38 & 30 & 17 \\
\hline Age & $21-30$ & 22 & 7.5 & 15 \\
& $31-40$ & 32 & 39 & 45 \\
& $41-50$ & 30 & 26 & 18 \\
& $51-60$ & 13 & 16 & 10 \\
& 61-70 & 3 & 11 & 7 \\
& 71-80 & 0 & 0 & 5 \\
\hline \multirow{5}{*}{ Education } & Illiterate & 38 & 48 & 55 \\
& Primary & 33 & 31 & 20 \\
& Secondary & 23 & 18 & 15 \\
& Higher Secondary & 2 & 4 & 2 \\
& Graduate & 2 & 0 & 7 \\
& Post graduate & 2 & 0 & 2 \\
\hline Profession & Agri-crop farmer & 22 & 19 & 38 \\
& Shrimp farmer & 14 & 14 & 13 \\
& Fish farmer & 0 & 13 & 0 \\
& Businessman & 5 & 11 & 0 \\
& Daily labour & 10 & 13 & 13 \\
& Sundarbans dependent & 17 & 15 & 18 \\
& Homestead agro-forestry & 13 & 11 & 12 \\
& Crab farmer & 10 & 0 & 5 \\
\hline & Livestock and poultry farmer & 9 & 3 & \\
\hline
\end{tabular}




\subsubsection{Dominant cause of salinity increase}

Household respondents identified nine causes for the observed salinization (Figure 5.3A). In Satkhira, people perceive extensive shrimp farming as its main cause followed by siltation and polders. Also in Khulna, people identified extensive shrimp farming as the main cause followed by polders and waterlogging. However, in Bagerhat most respondents perceive that tidal water-level rise is the main cause behind salinity increase, followed by polders, water logging and reduced upstream flow. Key informants, however, explain salinization by a combination of different processes (Figure 5.3B). They identified reduced upstream flow as the dominant cause in combination with polders and water logging, and closely followed by extensive shrimp farming and siltation.

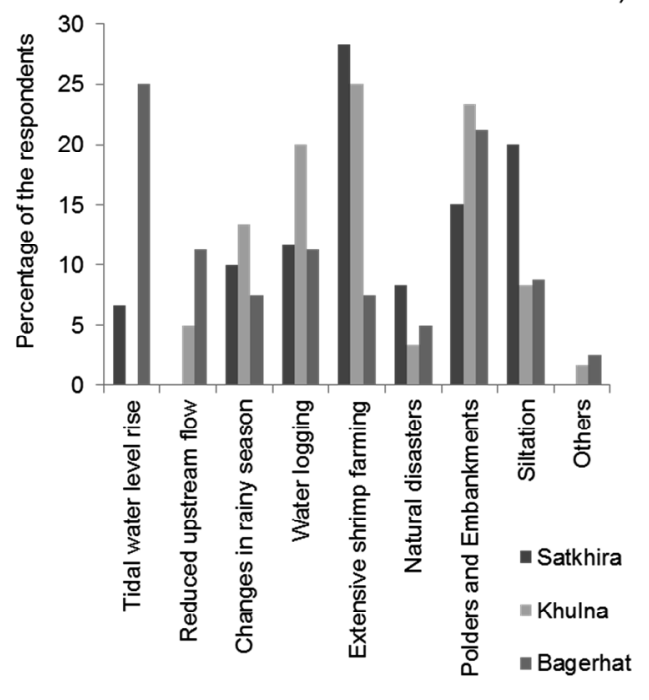

A)

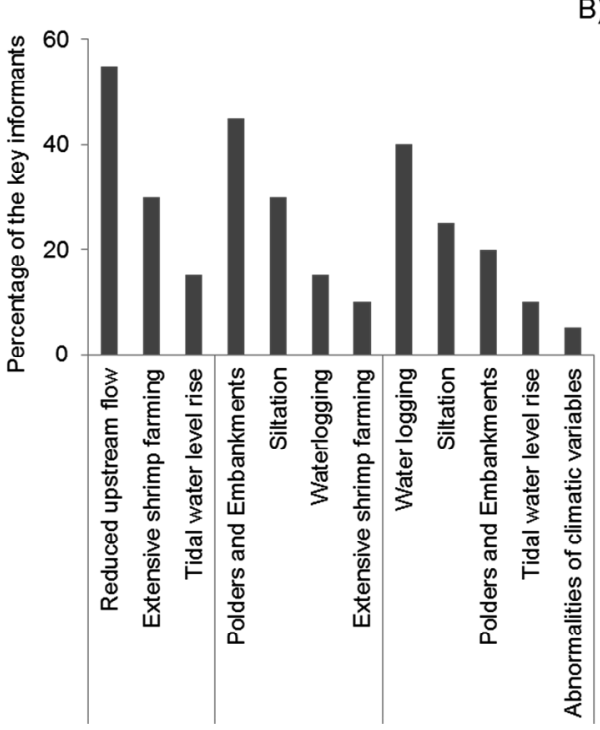

Figure 5.3. Perceived causes of salinity increase by different categories of respondents

\subsubsection{Coastal systems affected by salinity increase}

Household respondents identified seven coastal systems that are affected by salinity increase (Figure 5.4A). Almost half of the people in Satkhira, Khulna and Bagerhat and most key informants (Figure 5.4B) think that crops are affected most. Experts identified similar vulnerabilities but eliminated aquaculture. Also most articulated crop-agriculture. However, experts also indicate Sundarbans mangrove is the second most affected coastal system while the household respondents highlighted drinking water sources and health. 
A)

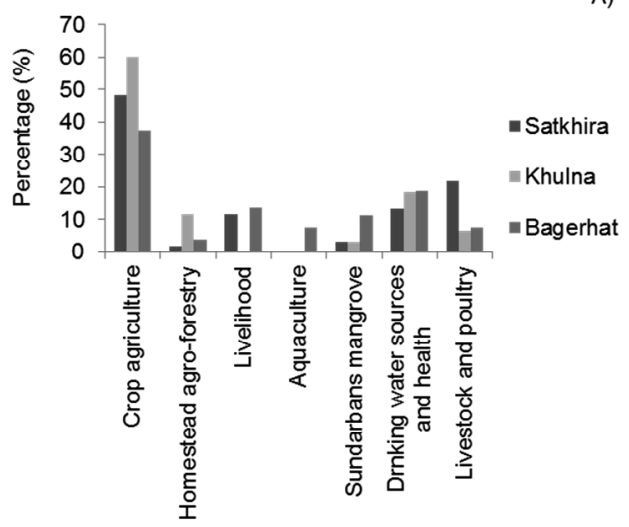

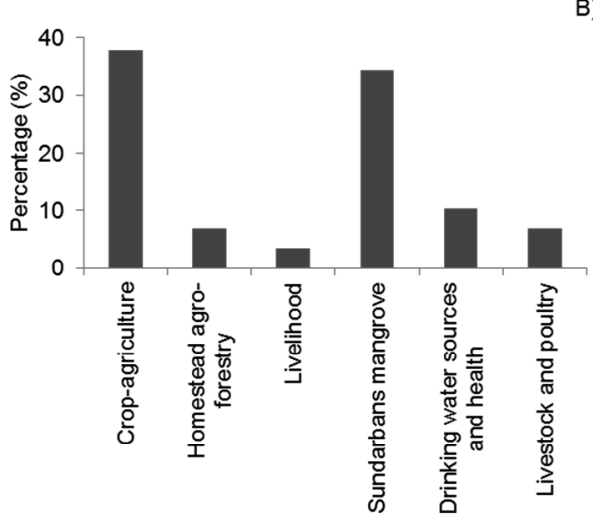

Figure 5.4. Coastal systems mostly affected by salinity increase in south-west region

\subsubsection{Coastal communities affected by salinity increase}

Household respondents identified five different communities that are affected by salinity increase (Figure 5.5A). Crop farmers are most severely affected coastal communities followed by Sundarbans dependent communities. On the other hand, experts identified only three communities that are affected by salinization (Figure 5.5B). More than half of the experts indicated the Sundarbans dependent people as the most affected communities followed by landless agri-labourers and crop farmers.

A)
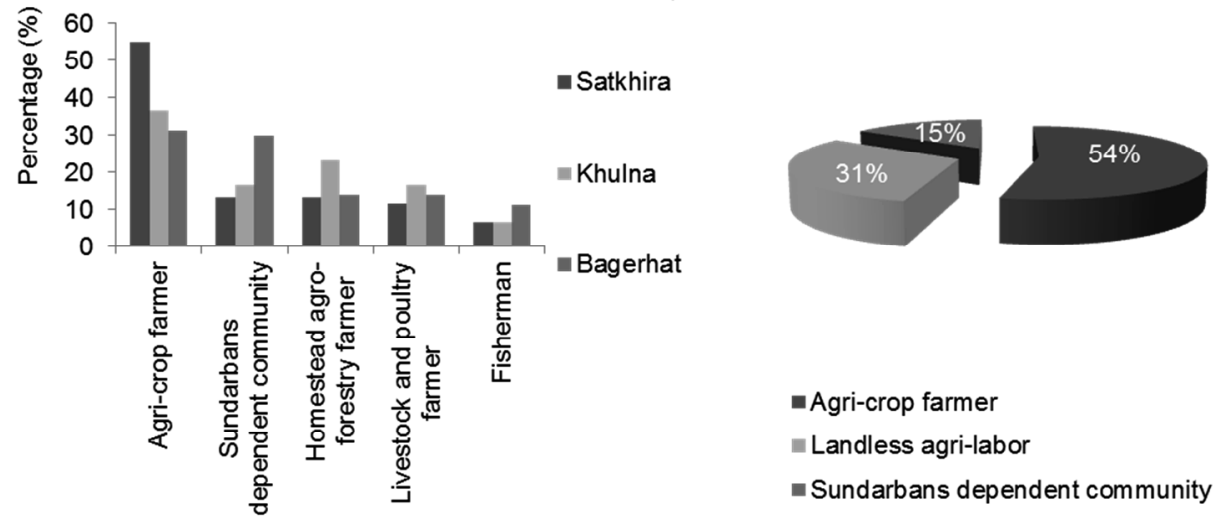

Figure 5.5. Coastal communities mostly affected by salinity increase 


\subsubsection{Ways of being affected}

Both respondents identified similar effects on different coastal systems (Table 5.4). Crop agriculture is affected by degrading of soil quality. This results in less production and profit, land use changes (mostly shifts from crop agriculture to shrimp farming), which causes loss of agri-lands and uncertainties ensuing from changes in agriculture pattern and food insecurity. The extent of homestead tree coverage is reduced gradually for lower productivity and in some cases no production at all. Local fish species are also threatened. The livestock and poultry sector are suffering from the fodder crisis, which contribute to increasing rearing cost. Sundarbans mangrove habitats degraded and this results in reduced forest growth and biodiversity, changes in vegetation, invasion of the undesirable top-dying disease, production of less forest resources (i.e., lack of heathy trees, reduction in number of wild animals and decreasing fish species). Changes in or loss of livelihoods triggers unemployment and outmigration. Salinization of surface and ground water sources is creating a drinking water crisis. This generates different diseases and health problems like skin diseases, diarrhoea, digestion problems, and increase infant's diseases (i.e., anaemia, jaundice) and pregnancy complications (i.e., high blood pressure and eclampsia).

Table 5.4. Observed effects of salinity increase

\begin{tabular}{|c|c|c|}
\hline \multirow[b]{2}{*}{ Systems affected } & \multicolumn{2}{|l|}{ Ways of being affected } \\
\hline & $\begin{array}{l}\text { Household level respondents } \\
\text { (local people) }\end{array}$ & $\begin{array}{l}\text { Key informants } \\
\text { (Experts/resource persons) }\end{array}$ \\
\hline \multirow{5}{*}{ Crop-agriculture } & Reduced soil fertility; & Degradation of soil quality \\
\hline & Less production and profit & Less production \\
\hline & \multirow{3}{*}{$\begin{array}{l}\text { Land use change (mostly crop agriculture to } \\
\text { shrimp) } \\
\text { Loss of agri-lands }\end{array}$} & Uncertainty \\
\hline & & Change in agriculture pattern \\
\hline & & Food insecurity \\
\hline \multirow{2}{*}{ Homestead agro-forestry } & \multirow{2}{*}{ No or less production } & No or less production \\
\hline & & Reduction in homestead tree coverage \\
\hline \multirow{3}{*}{ Livelihood } & \multirow{3}{*}{ Livelihood loss /change } & Livelihood change \\
\hline & & Unemployment \\
\hline & & Migration \\
\hline Aquaculture & Threatened local fresh water fish species & - \\
\hline \multirow{7}{*}{ Sundarbans mangrove } & \multirow{7}{*}{$\begin{array}{l}\text { Lack of healthy trees; } \\
\text { Thin forest/Reduced forest cover; } \\
\text { Less forest resources (both timber and non- } \\
\text { timber); } \\
\text { Reduction in number of wild animals; } \\
\text { Less amount of fish; }\end{array}$} & Vegetation change \\
\hline & & Reduced tree growth \\
\hline & & Invasion of top dying \\
\hline & & Reduced stock density \\
\hline & & Reduced biodiversity \\
\hline & & Habitat degradation \\
\hline & & Decreasing trend of fish resources \\
\hline \multirow{5}{*}{$\begin{array}{l}\text { Drinking water sources and } \\
\text { health }\end{array}$} & Drinking water crisis; & \multirow{5}{*}{$\begin{array}{l}\text { Salinization of open and ground water } \\
\text { sources; } \\
\text { Pregnancy time high blood pressure; } \\
\text { Eclampsia }\end{array}$} \\
\hline & Skin diseases; & \\
\hline & Diarrhoea and Digestion problems; & \\
\hline & New born babies with different types of & \\
\hline & $\begin{array}{l}\text { difficulties; } \\
\text { Pregnancy problems }\end{array}$ & \\
\hline Livestock and poultry & $\begin{array}{l}\text { Increased cost of rearing livestock and poultry; } \\
\text { Fodder crisis }\end{array}$ & Fodder crisis \\
\hline
\end{tabular}




\subsubsection{DPSIR framework for salinity increase}

The developed DPSIR framework (Figure 5.6) shows salinization drivers are not only related to bio-physical changes in coastal environments but also with socio-economic circumstances. Most of the identified pressures are man-made and not environmental. Ecological, social and economic state of different coastal systems, mostly crop agriculture, wetlands and Sundarbans mangrove, are threatened due to salinity increase. Threatened states of the these systems are creating conflicts among ecosystem, human health and socio-economic functions which eventually lead towards small and large scale measures, action plans and policy responses. However, the responses are inadequate to address the identified pressures of salinity increase. Rather one of the responses i.e., polders has become the pressure for salinity increase initiating sedimentation on the river bed and water logging.

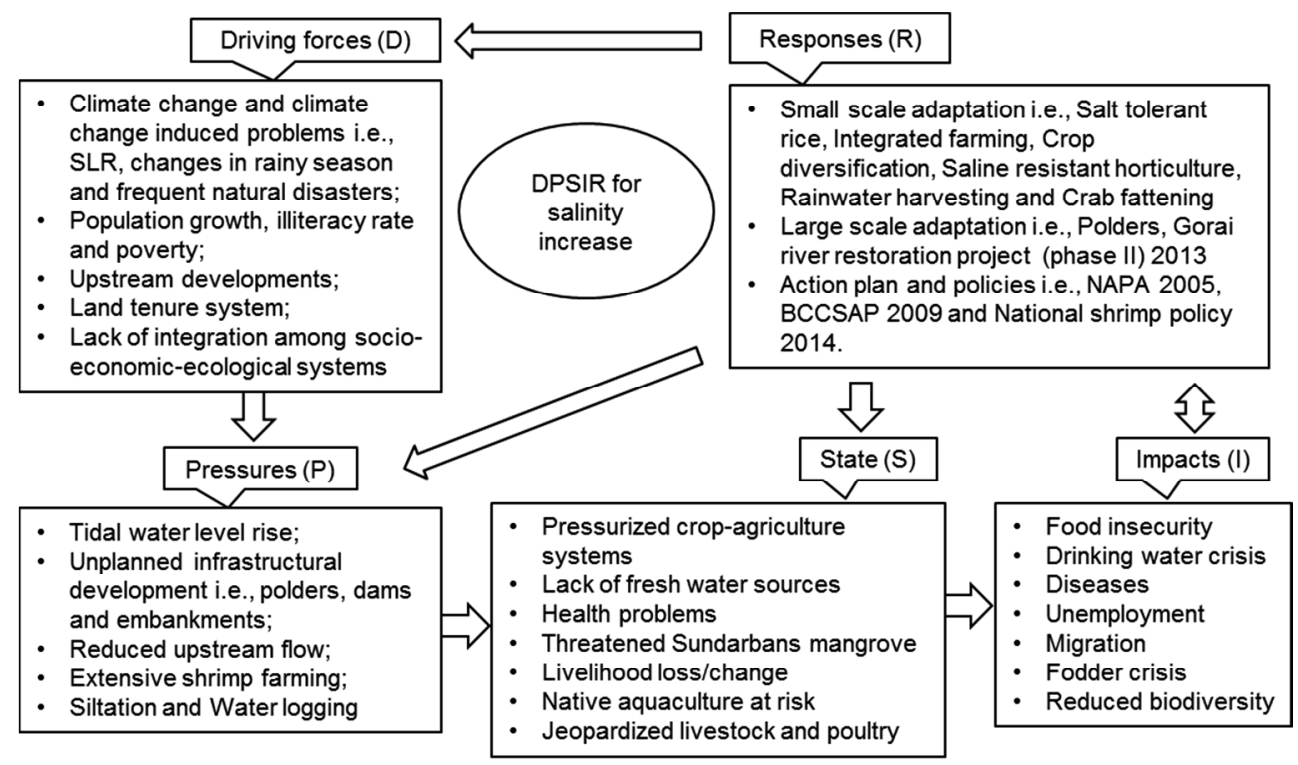

Figure 5.6. Interaction between society and coastal systems

\subsubsection{Potential measures to address the identified salinization drivers and pressures} along with their contribution and multi-criteria analysis

Local people identified five short-term and two mid-term measures to address salinization drivers and pressures. These measures should contribute to halt salinization of new lands, to maintain the natural flow of the tidal rivers, to connect the rivers with their flood plains and to extend fresh water sources (Table 5.5). However, they did not identify any long-term 
measure. A multi-criteria analysis of these measures shows that local government's initiative to stop on purpose ingression of salt water is the most effective short-term measure and land zoning is identified as the most suitable mid-term measure (Supplementary information to the Chapter 5 Table C1). On the other hand, key informants identified in total 18 potential measures to cope with salinization (Table 5). Among the identified measures, planned shrimp farming is the most suitable short-term measure followed by tidal river management (TRM) as the mid-term measure and long term coastal land use zoning ((Supplementary information to the Chapter 5 Table $\mathrm{C} 2$ ).

\subsubsection{Adaptation pathways to cope with salinization for the mostly affected coastal systems}

Key informants identified 31 possible ways at different adaptation turning points from 7 to 20ppt for the mostly affected coastal systems ((Supplementary information to the Chapter 5 Table C3). Among these, 16 measures had been filtered through multi-criteria analysis as the suitable measures. These are visualized in the adaptation pathway map (Figure 5.7). For cropagriculture, most suitable measures include crop diversification, adaptive agriculture, alternate cropping, arable field management. A combined approach of crop diversification, arable field management and alternate cropping is expected to sustain salinity levels till 12ppt. Saline resistant horticulture is expected to sustain salinity levels till $15 \mathrm{ppt}$. However, for long term adaptation planning (i.e., salinity level up to 20ppt), land zoning is the most suitable measure to promote agriculture, to improve farmers' socio-economic conditions and resolve the conflicts between crop and shrimp farming. For drinking water sources, the adaption pathway map shows six measures at different turning points. Among them rainwater harvesting, pond sand filter, pond excavation and managed acquirer recharge (MAR) are identified as the most suitable measures to be implemented in salinity ranges from 7 to 20ppt. For Sundarbans, public awareness combined with strengthening the Bangladesh Forest Department, ban catching fish during dry season and cannel (re)-excavation are potential measures to deal with salinity levels from 10 to 12 ppt. Periodic or scheduled (re)-excavation to mainly restore the Gorai river is the next adaptive measure for salinity levels between 12 to 15 ppt. However, if salinity levels cross 15ppt, TRM and a Ganges Barrage are suitable measures. These adaptation measures are expected to assist in sediment management and ensure ecological flow for the downstream rivers during the lean period with salinity levels beyond 17ppt. 


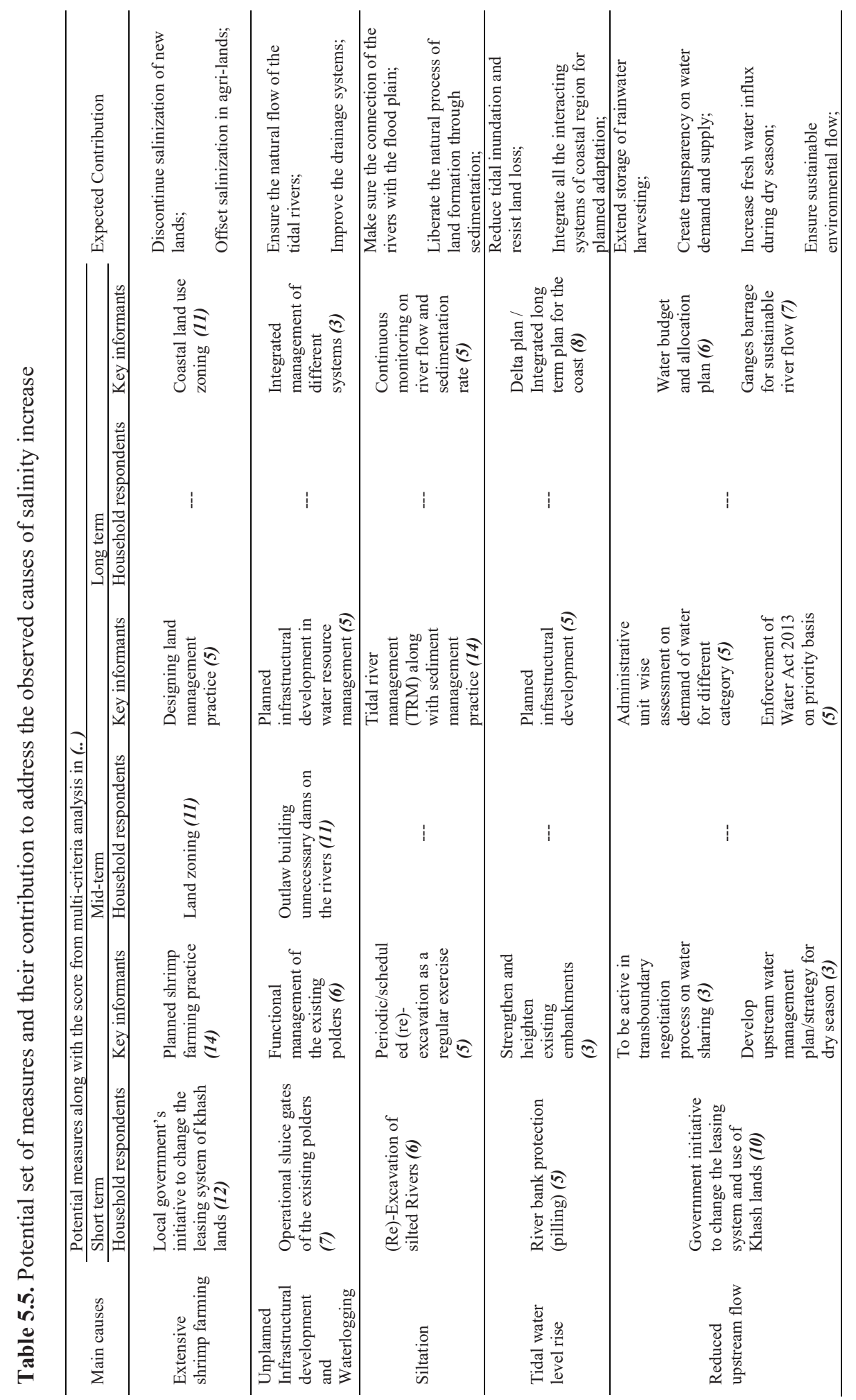


- Transfer station to new action I Adaptation tipping point (ATP) of an action - Adaptation pathways
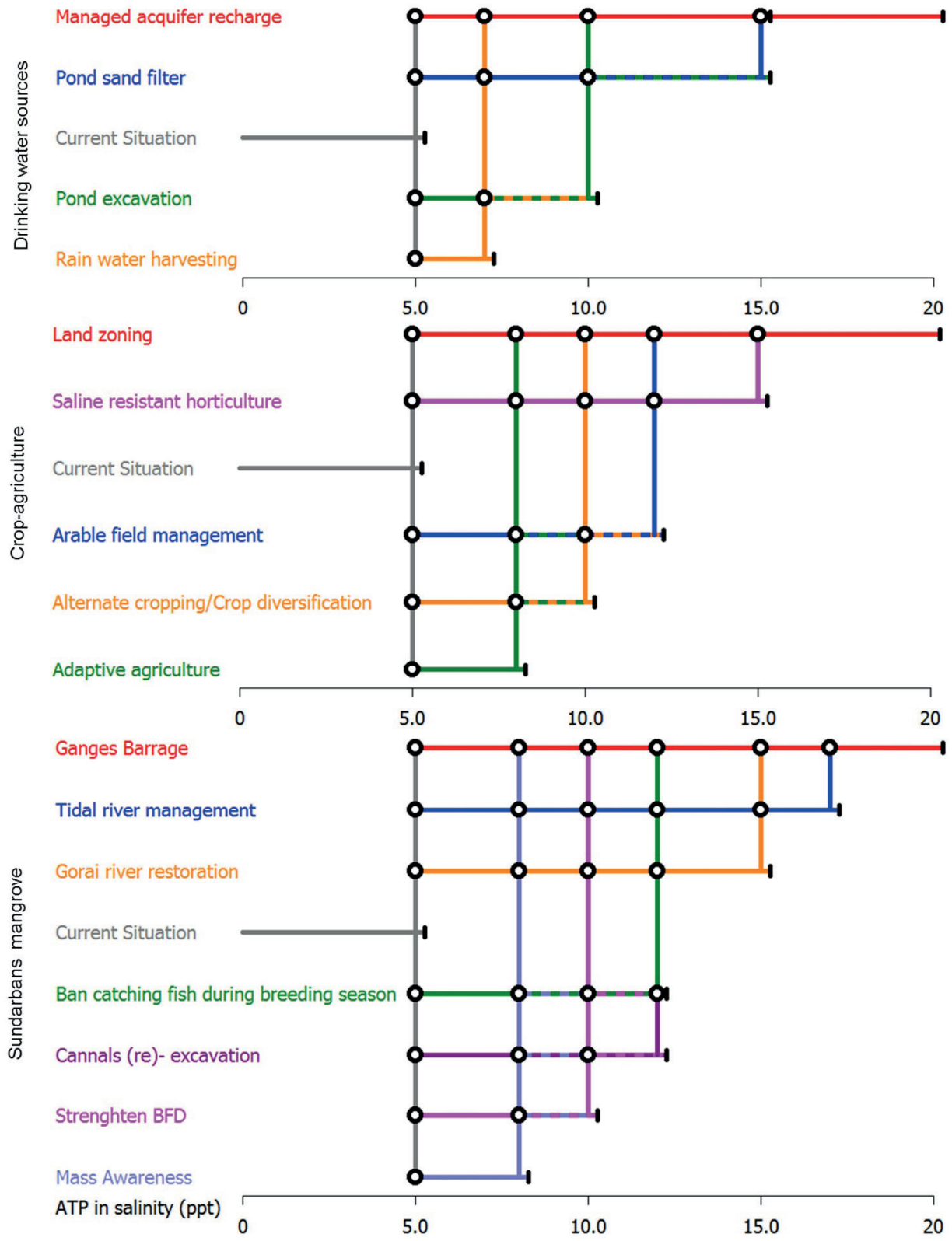

Figure 5.7. Adaptation pathway map for the mostly affected coastal systems 


\subsection{Discussion}

This study identifies six major interconnected climatic-social-ecological-economic issues responsible for salinity increases in the south-west of Bangladesh. Salinization problems started from the 1960s, when polders were introduced to defend this region against flood and tidal surges and to maintain a saline free zone for agri-cultural activities. Later on the polders contributed to reducing floodplain storage which caused river beds' sedimentation and serious water logging (WARPO 2001). This process was enhanced with the development of a barrage in 1975 on the Ganges River at Farakka. This resulted reduced upstream flow (Mirza 1998). Therefore, the river flow declined substantially during the dry season and this further accelerated large changes in the hydrology and induced sedimentation in the Gorai river (the only offtake of the Ganges for the south-western rivers). As a result, salt water started to intrude further inland (Rahman et al. 2000) and accelerated salinization. To cope with increasing salinity, shrimp farming was introduced during the 1980s (Swapan and Gavin 2011). The farming expanded gradually from water logged lands to the privately owned inlands and recently also on government owned fallow lands (i.e., the Khash lands). These trends resulted in intensive salinization. In addition, climate change induced sea and tidalwater level rise intensified salinization through stronger salt-water intrusion. Currently, tidalwater level is rising at increasing rates (i.e., 10 to $12 \mathrm{~cm}$ per decade) due to land subsidence (Bhuiyan and Dutta 2012).

To better connect these climatic-societal-economic-ecological driver and pressures, and their implications on different coastal systems, we utilized DPSIR framework. It shows that the construction of polders across the south-west coast of Bangladesh has not improved coping with salinization but augmented the process which in turn introduced shrimp farming. When polders were constructed, different climatic and biophysical changes in the coastal environment were ignored before implementing the structural solution. This resulted in unexpected negative consequences of polder development and consequently stimulated shrimp farming. Expansion of shrimp farming further accelerated the natural process of salinization induced by climate change. Thus salinization in Bangladesh's south-west region is not influenced by only climate change but also by ecological, societal and economic processes. However, until now how the different processes driving salinization are connected, is poorly acknowledged (Zaman et al. 2016). As a result of earlier adaptation measures, such as polders, development and shrimp farming have become a major salinization pressure. In particular, cropping systems are affected by extensive shrimp farming and water-logging 
while the Sundarbans mangrove by reduced upstream flows and tidal water level rise. Our DPSIR framework can be used for future adaptation planning to avoid the continuation of mal-adaptation.

Salinity is likely to increase in the future but by how much is uncertain. Salinity increase is affecting basic needs of coastal people (i.e., drinking water sources and livelihood dependent on mostly crop-agriculture and Sundarbans mangrove). Hence, our adaptation pathways clearly show which measures can be implemented to cope with different levels of salinity. Some of the current measures are suitable, if salt intensification remains limited. For example, rainwater harvesting is a traditional measure to supply drinking water. However, uncertainties associated with this practice are the changed rainfall pattern, storage facilities and future salt concentrations. Other suitable measures (i.e., pond excavation and pond sand filter) are related to surface water sources. However, these sources are exposed rises in tidal water-levels, floods, cyclones and tidal surges. Therefore, these measures are probably unsustainable in the long run. Hence, mechanisms to recharge ground water resources need to be adopted to ensure long term safe drinking water supply. Managed aquifer recharge likely is the most suitable measure to ensure availability and quality of drinking water sources. In addition, such recharge also serves to control salt-water intrusion, prevent land subsidence and sustain other coastal systems' functioning. However, aquifer conditions must be suitable and water sources need to be ensured. This measure is successfully implemented for coastal urban areas in Australia (Dillon et al. 2009).

Artificial water logging conditions for shrimp farming are also accelerating the salinization of fresh water resources through seepage and natural bleaching. Most of the khash lands leased to shrimp farmers are located in the inland part of the coastal zone, which is topographically and hydrologically unsuitable for shrimp farming. Shrimp farmers transport salt water through narrow channels from the rivers and development of earthen embankments on the rivers. Leasing the Khash lands for shrimp farming is thus increasing transport of saline water from the rivers to more inlands. So as a short-term measure, local people suggested to limit leasing the khash lands to the shrimp farmers. Also better planned and regulated shrimp farming can be a suitable measure to reduce the conflict with crop-agriculture. In the long term, changed leasing systems and better planning may not be able to resist extensive shrimp farming. Therefore, improved regulations that follows natural salinity gradients, and coastal land use zone planning are needed. Improved coastal zone management should clearly outline the 
space for the conflicting sectors such as fresh water resources, shrimp, agriculture and forestry.

Land zoning was also identified as the most suitable long-term measure by experts to strengthen crop-agriculture. Other potential measures such as crop diversification, adaptive agriculture, alternate cropping, arable field management are currently implemented locally to adapt to moderate salt water intrusion. However, these adaptive agriculture measures will not be sufficient if the main pressure on the whole agriculture system (i.e., shrimp farming) is not addressed (Swapan and Gavin 2011); and at high levels of future salt intrusion, crop systems will continue to disappear. Hence, coastal land zoning that considers the natural salinity gradients and local land suitability in terms of hydro-climatic variables and socio-economic conditions for different land uses is likely the most suitable adaptation measure to promote both crop-agriculture and shrimp farming.

Local people suggested to use khash lands for storing fresh water during the monsoon to deal with reduced upstream flow, instead of using the increasingly saline water for shrimp farming. This is probably a suitable measure for fresh water sources and agriculture during the dry season. However, the continuously increasing land demand by the increasing population challenges the implementation of this measure Therefore, key informants want to actively negotiate the transboundary process of water sharing as a more suitable immediate measure. However, previous records do show little progress in these negotiations (Morton 2011). So water sharing is probably a poor option due to a highly uncertain outcome. Other options, like upstream water management strategies for the dry season and, administrative unit wide assessments on water demand, water budgets and water allocation plans, can be developed but are currently too immature for implementation. Main uncertainties involve population growth and land demand, flash floods during monsoons and upstream agricultural water demand during the dry seasons. The Ganges barrage is the most suitable long-term measure to increase fresh water flow into the south-west, and therefore, increase freshwater resources availability and reduce salinization in the Sundarbans. Reduced upstream flow is the major cause for salinity increase in the Sundarbans mangrove (Bhuiyan and Dutta 2012) and a Ganges barrage could probably solve this. However, such barrage is very costly and also has several negative impacts. For instance, it will submerge a large area. This will make people's livelihoods vulnerable if proper replacements are not arranged. 
Moreover, the adaptation pathways also prescribed a range of measures to ensure long term adaptation of the Sundarbans mangrove forest to future climate change. To improve the sustainable use and management of the forest, improved awareness raising and training of forest department staff is needed. However, to save the forest ensuring increased freshwater flow into the system is necessary to reduce salinity increase. Periodic (re)-excavation to restore the Gorai river can potentially increase the freshwater inflow. However, continuous (re)-excavation may not be an economically viable measure in the long-term sustainability. Therefore, large scale tidal river management is proposed to ensure the connection of the rivers to the flood plain and to restore the natural process of land formation through sedimentation. This will in turn reduce river bed siltation, water logging and the effects of tidal water-level rise on the Sundarbans mangrove. This measure will not only protect the Sundarbans against salinization but also stimulate crop-agriculture and fresh water sources. Such management is actually periodically cutting and closing polders, developed by local people to reduce drainage congestion induced by the polders (Hossain et al. 2015). It is successfully implemented locally in the Hari river basin in the southern part of Jessore district for land reclamation (Paul et al. 2013). Shampa and Paramnik (2012) also suggested this socially acceptable and low cost eco-technique to mitigate water-logging problems in the Kobadak river basin area of Satkhira district. Also the multi-criteria analysis shows that the measure is highly effective and feasible because it has low cost and positive side effects. The only challenge of this measure is the large scale implementation and identification of the proper flood plains (locally called beels) for the tidal water inflow. Although it is a people oriented approach, a good coordination among local stakeholders, government and nongovernment entities is needed to overcome the challenges of large scale implementation and long term sustainability.

The methodology adopted in this study to develop adaptation pathways is a combination of different approaches with each approach having its own purpose. During our literature review, we identified that previous adaptive measures in the south-west coast of Bangladesh pressured the system afterward. The main reason behind this is probably the top-down decision-making approach (Fraser et al. 2006). Therefore, to fill this knowledge gap we surveyed local people to study their perception complemented with the key informant interviews. This part of our study is robust. It integrates both top-down and bottom-up observations. In addition, our previous study on environmental changes in the Bangladesh's south-west coast revealed that salinity increase comprises a range of processes (Hossain et al. unpublished manuscript). So, 
to provide a comprehensive understanding of these salinization processes to connect the climatic-societal-economic-ecological systems (Pirrone et al. 2005), we applied a DPSIR framework. This is another robust part of our study as it facilitates adaptation planning. Qualitative (i.e., multi-criteria analysis) and quantitative (i.e., adaptation turning points) assessment to identify the potential adaptation measures and develop the adaptation pathway consequently, were based entirely on the perception and observation of the key informants and local people. Hence, the adaptation turning points prescribed for each of the measures may not be precise as we did not test the measures. However, it indicated a salinity range when shifting or adding another measure is necessary. the adaptation turning points can be improved through multiple climate model projections and calculation uncertainties ranges to develop more robust adaptation pathways (c.f. Tanaka et al. 2015). However, when using models the number of measures which can be tested, are often limited. The developed adaptation pathways in our study included a large set of measures, which can be implemented at different salinity levels. This study, therefore, is a valuable first step in merging the top down and bottom up perceptions, in developing the DPSIR framework for salinity increase and adaptation pathways to cope with salinization.

\subsection{Conclusions}

The south-west coastal region of Bangladesh consists of complex interacting dynamic ecological and social systems. Hence, adaptation planning to cope with salinization is a complex endeavour for this region. The identified salinization pressures and impacts result from a series of systemic interactions in coastal environments. These are affecting the socioecological-economic systems (i.e., crop-agriculture, drinking water sources and Sundarbans mangrove). Hence, adaptation to recent and future changes to improve livelihoods of local people is necessary, which is recognised from the DPSIR framework. Already several measures have been adopted for crop-agriculture and drinking water sources, but, no measures have been taken for Sundarbans mangrove. The already adopted measures need upscaling to adopt to future salinization. This study also reveals that if the societal value of the coastal environment that supports life and livelihood of many coastal communities, is ignored during adaptation planning, salinization likely gives rise to severe ecological, economic and social problems and conflicts. Our adaptation pathways consider the societal values and top-down perceptions, which prescribe land zoning, managed aquifer recharge and tidal river management, both which are expected to sustain at high salinity concentrations for crop- 
agriculture, fresh water sources and the Sundarbans mangrove. The combined measures will be able to obtain greater long-term benefits for the studied region. Also the developed pathways will assist policy makers to identify a series of options that could be implemented under changing climate and complex social system.

\section{Acknowledgements}

This study was made possible by a grant from Nuffic under the NFP fellowship programme (NFP-PhD.12/307). We would like to thank all the key informants and local people who provided valuable information for this work. We are grateful to all who helped in conducting interviews and surveys, especially Abdullah Al Masud, Khulna University; Engineer Peerzada Ibna Far Madani, Khulna University of Engineering and Technology; Siddikur Rahman Rana, Wageningen University and Md. Aziz Ullah Emon, Chittagong University 


\section{Chapter 6. Synthesis}

\subsection{Introduction}

The general causes and impacts of increasing salinity at global and larger regional scales are broadly recognized (Khan et al. 2011; Mahmuduzzaman et al. 2014). However, local biophysical and socio-economic conditions and their connections to salinization are often overlooked for integrated and sustainable adaptation planning (Nandy et al. 2013). Identifying the intermingling causes of salinity increase and its cascading impacts on different local coastal systems is therefore poorly understood. This $\mathrm{PhD}$ thesis aims first to better understand the salinity increase and its processes across the south-west coast of Bangladesh, then to evaluate the impacts of increasing salinity on this region's ecosystems (i.e., the Sundarbans mangrove vegetation, Royal Bengal tiger habitat and coastal people) and, finally, to identify target-oriented measures to develop adaptation pathways to cope with and to enhance resilience to salinization. These aims were justified and four research questions were defined (Chapter 1) and addressed (Chapters 2-5).

In Chapter 2, I investigated local environmental changes through different hydro-climatic variables (i.e., temperature, precipitation, tidal water-level, freshwater discharge and salinity) and the potential cause-effect relationship among them. In Chapter 3, I explored the relationship of the Sundarbans mangroves' ecological status (i.e., vegetation composition, forest structure, diversity, canopy cover, regeneration status and carbon content) with the salinity gradient. In Chapter 4, I identified the likely impacts of salinity increase on quality tiger habitat requirements in the Sundarbans mangrove (i.e., availability of freshwater, sufficient prey population and diverse vegetative cover). In Chapter 5, I and my collaborators evaluated local people's perception (bottom-up approach) and expert's observation (top-down approach) on salinization, its impacts on coastal communities and different coastal systems, and potential measures to address its processes. Finally, adaptation pathways for the mostly affected coastal systems (i.e., drinking water sources, crop agriculture and the Sundarbans mangrove) were developed. These integrated the bottom up and top down perceptions, observations and recommendations to cope with salinization in Bangladesh's south-west coastal region. The key research questions, principal results and major conclusions from each part of the study are summarized in Table 6.1. In this Chapter, I will synthesize the main findings (Section 6.2) and their relevance to national action plans and policies (Section 6.3), and my new scientific insights and contributions to salinization and adaptation planning 
(Section 6.4), and provide overall recommendations (Section 6.5) for the studied region to enhance resilience to salinity increase and its processes. Finally, I provide the research's strengths and limitations (Section 6.6), discuss future outlook (Section 6.7) and summarize overall conclusions (Section 6.8).

\subsection{Synthesis of the main findings}

In this section, I have focused on synthesis of major findings from Chapters 2 to 5. I start with different bio-physical and socio-economic processes of salinity increase and potential measures to address them (Section 6.2.1). Then, I discuss the impacts of salinity increase and its processes on the Sundarbans mangrove vegetation, Royal Bengal Tiger habitat and coastal people (Section 6.2.2). Finally, I reflect on possible ways of adaptation to cope with and enhance resilience to salinization (Section 6.2.3). Also, I have summarized all these main findings in Figure 6.1. It shows the major processes of salinization along with potential measure to address those. The figure also demonstrates the impacts of salinization on Sundarbans mangrove vegetation, Royal Bengal tiger's mangrove habitat and coastal communities together with prospective large scale adaptation options to cope with and enhance resilience to salinization. 
Synthesis

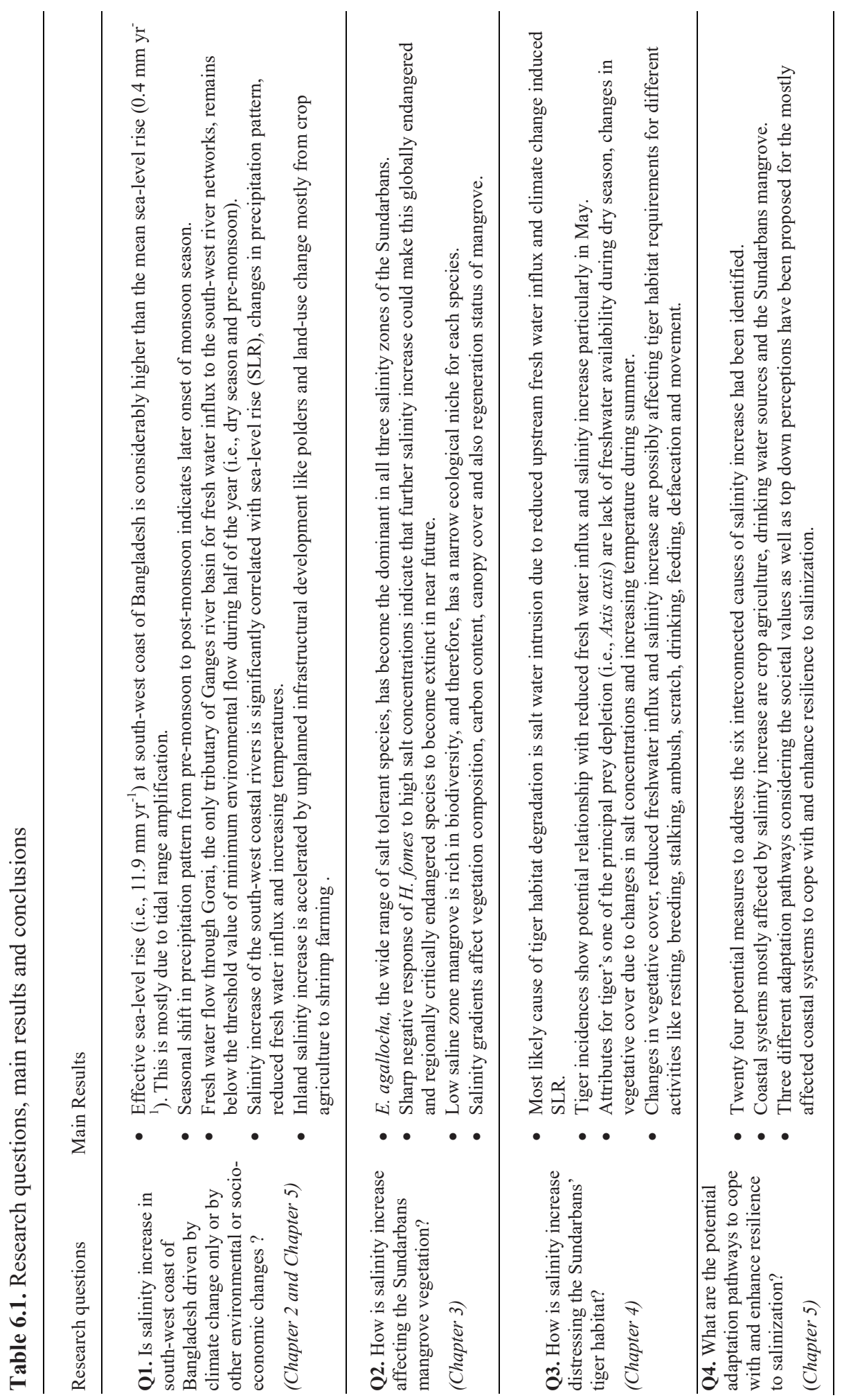




\subsubsection{Bio-physical and socio-economic processes that increase salinity, and potential measures to address them}

Climate change, sea-level rise (SLR) and reduced freshwater influx are the major bio-physical processes involved in rapid salinity increases across Bangladesh's south-west coastal region (Chapter 2). Salinity intensification is significantly correlated with the changes of all the selected hydro-climatic variables. Results show that increasing salinity of coastal wetlands is not driven by only climate change (i.e., temperature rise and late onset of monsoons) or climate-change induced global concerns, like SLR, but also by other regional environmental changes (i.e., reduced freshwater influx). In addition to these hydro-climatic variables, the local socio-economic processes, like unplanned and massive shrimp farming and infrastructural development (i.e., polders) are contributing to inland salinity increase in this region (Chapter 5). These socio-economic processes also contributed to other bio-physical complications, like reducing floodplain storage, river beds' siltation and serious water logging. Furthermore, reduced fresh water influx during half of the year (dry season and premonsoon) further accelerated large changes in the hydrology and induced sedimentation in the Gorai riverbed (the only offtake of the Ganges for the south-western rivers). As a result, back salt-water effect due to SLR started to accelerate salinization of the coastal wetlands and inlands as well. In particular, the extensive salinization during the dry season is likely caused by a combination of sea level rise, reduced flow of upstream rivers and a later onset of the monsoon. All these results indicate that salinization across the south-west coast of Bangladesh is driven by a range of interconnected bio-physical and socio-economic processes. Since several of these observed trends likely continue in the future due to further climate change and anthropogenic modifications to the hydrological cycle. Also the extent and severity of wetland and inland salinization are most likely to further increase. We, therefore, identified potential coping measures by integrating bottom-up (household surveys) and top-down perceptions (key-informants interviews) through a driver-pressure-state-impact-response (DPSIR) framework and multi-criteria analysis (Chapter 5). Since unplanned and massive shrimp farming is a locally initiated socio-economic process that increases inland salinization, household respondents recommended to stop on-purpose ingression of salt water and land zoning by local government's initiatives as the most suitable measures to reduce its extent. Conversely, experts suggested planned and regulated shrimp farming as the most suitable short-term measure, followed by tidal river management as the mid-term measure and longterm coastal land-use zoning to adapt to inland salinization caused by unplanned shrimp 
practices. To address unplanned infrastructural development and waterlogging, both types of respondents proposed operational sluice gates and functional management of the existing polders.

On the other hand, reduced fresh water influx is mostly caused by a regional disputes between India and Bangladesh. Hence, experts suggest to actively negotiate the transboundary water sharing, although previous records show little progress in these negotiations. Besides, upstream water-budget and allocation plans can be a potential measure to ensure sufficient fresh water supply to the downstream areas. However, these are currently too immature to implement due to the many associated uncertainties, like population growth and land demand, flash floods during monsoons and upstream agricultural water demand during the dry seasons. The development of a Ganges barrage in Bangladesh could potentially increase the freshwater flows in the Southwest and the Sundarbans particularly during the dry season. Such a barrage, however, is very costly and has several other negative impacts. For instance, it submerges a large area and this makes people's livelihoods vulnerable if proper replacements are not arranged.

Climate change and SLR are global issues, which cannot be halted nationally, regionally or locally by, for example, protecting riverbanks or by strengthening and heightening the existing embankments. Therefore, international initiatives are also crucial to mitigate further changes in the climate system and thus SLR, to address salinization of coastal wetlands. Nonetheless, experts suggested planned infrastructural developments and integrated long-term delta plans to adopt to climate change and its impacts. 

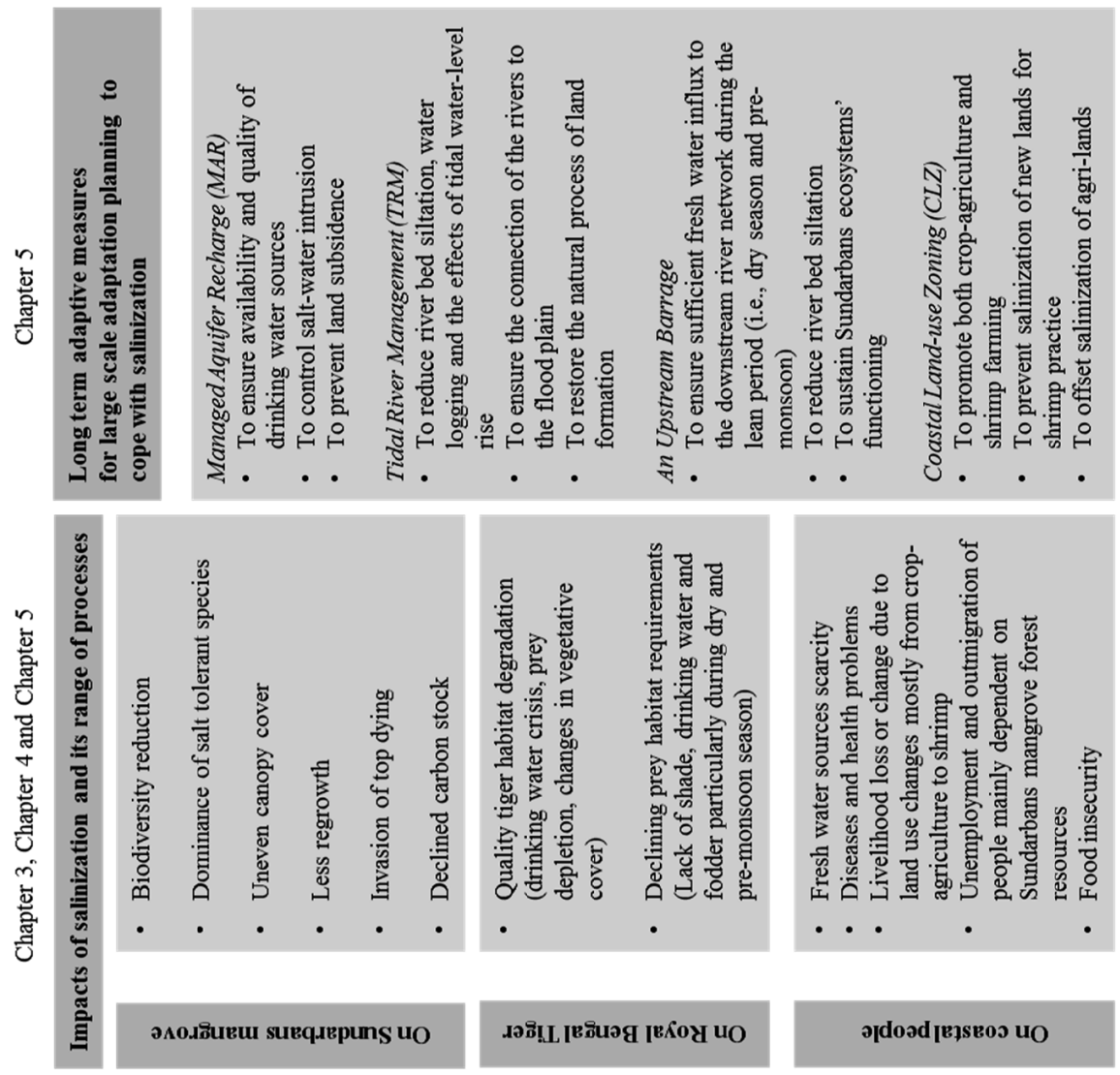

吕
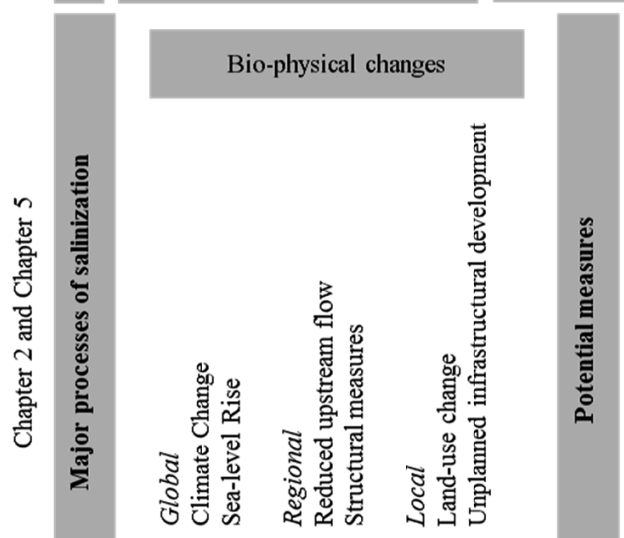

э!ฺвแ! ן-о..рКН

ว|doəd ןв]sหos uO

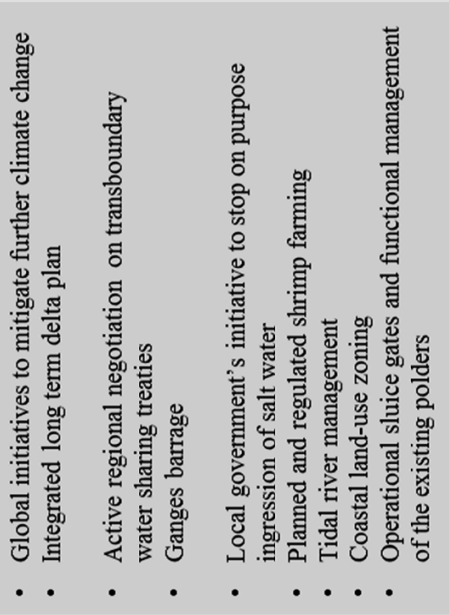




\subsubsection{Impacts of salinity increase on the Sundarbans mangrove vegetation, Royal Bengal} Tiger habitat and coastal people

Salinity (both the upper or sea side and lower or land side limit) is very likely to increase across the Sundarbans due to a range of processes (particularly climate change, SLR and reduced freshwater influx). All the selected variables of mangrove vegetation (i.e., species composition, density, richness, diversity, canopy cover, regeneration and carbon content) decline with increased salt concentrations (Chapter 3). Less diverse and wide range of salt tolerant mangroves like Exoecaria agallocha and Cariops decandra, have already started to dominate over the highly diverse but less salt tolerant mangroves like Heritiera fomes. As $H$. fomes is a less salt tolerant species and, therefore, is likely to be outcompeted by more salt tolerant species in high saline conditions. Also most of the top dying affected $H$. fomes trees are found in the plots of mesohaline zone. This may be due to direction of increasing salt concentrations, which is observed from south-west (Polyhaline zone) to north-east direction (mesohaline zone). Besides, the carbon content of H. fomes was lowest in the mesohaline zone. H. fomes is already declared as a 'globally endangered' and 'regionally critically endangered' species, due to decreasing trend of its current populations. Results also reveal sharp negative responses of $H$. fomes to high level of salt concentrations. Such response indicates that further salinity increase can possibly further narrow down the ecological range of this threatened species, intensify the severity of the top dying disease and reduce this species to extinction soon. Moreover, differences in vegetation in three different salinity zones articulate that diversity reduces with increased salt concentrations. In addition, the plots with higher salt concentrations showed lower regeneration and more uneven canopy cover compared to plots in the low saline environment. Also carbon contents of three dominant species of three salinity zones show the likely relationship between carbon storage of mangrove species and salt concentration. High salt tolerant species, like $C$. decandra, can store less carbon than the moderate and less salt tolerant species like E. agallocha and $H$. fomes respectively. Since the importance-value index indicates that $H$. fomes has started to be suppressed already by the salt tolerant species, the carbon sink of the Sundarbans mangrove will also likely decline. All these results reveal the likelihood of reduced biodiversity and declined carbon-stocks in the Sundarbans mangrove in the near future due to further changes in salt concentrations. 
Simultaneously, a downward trend of the Royal Bengal Tiger population and its prey species (i.e., spotted deer, wild boar and rhesus macaque) density is observed in these mangroves (Dey et al. 2015). Tiger density is found highest in the low saline zone but human-tiger conflict incidents are highest in high saline zone. Both local communities and experts contemplate that prey depletion and frequent intensive cyclones mainly cause the population reduction. Conversely, my hydro-climatic data, literature review and field observations indicate that climate change and its impacts like sea-level rise and salinity increase are contributing to degrade the quality tiger and its prey habitat requirements (i.e., drinking water sources, prey population and vegetative cover) in the Sundarbans (Chapter 4). Tiger incidences (i.e., stray, injured and dead) are potentially related to reduced fresh water influx and salinity increase, particularly in May. This indicates drinking water scarcity for the tigers in the mangroves. Changes in mangrove vegetation due to increasing salinity (Chapter 3) possibly affect key activities of the tiger, such as resting, breeding, stalking, ambush, scratch, drinking, feeding, defaecation and movement. In addition, salt induced vegetation changes affect prey habitat. As tigers prefer the comparatively low saline zone mangrove woodlands probably for availability of prey, drinking water sources and suitable vegetative cover to perform their necessary activities. Also tiger's principle prey (i.e., spotted deer) needs fallen fruits, leaf litter and grasses as fodder. All these are accessible mainly in the low saline mangroves. Besides, spotted deer drink fresh water frequently and need shade, particularly in summer. Thus, climatic signals, like rising air-temperatures during summer and late onset of monsoon, will all create stress on physiological activities of spotted deer. Hence, further changes in climate, fresh water availability and vegetative cover will affect not only the Bengal tigers, but also their prey habitat to degrade.

Salinization is also affecting coastal communities by affecting different coastal systems (e.g., drinking water sources, crop agriculture and the Sundarbans mangrove), which are related to basic needs of local people (e.g., drinking water, health and livelihood). Crop farmers and the Sundarbans dependent communities are identified as the most affected communities. How salinization is affecting these communities and different coastal systems was also discussed (Chapter 5). Crop agriculture is mostly affected by soil quality degradation due to salinity increase and land-use changes (mostly shifts from crop agriculture to shrimp farming). These result in lower production and profits, loss of agricultural lands, food insecurity and uncertainties due to the shifts in agriculture patterns by salinization. Also the Sundarbans mangrove habitats are degrading and this results in reduced forest growth and biodiversity, 
changes in vegetation composition and invasion of the undesirable top-dying disease. These result in lower production rates of the key forest resources, such as heathy trees and number of wild animals, and decreasing trends of non-timber forest resources, such as fish and honey. Therefore, changes in or loss of livelihoods of the peoples dependent on the natural resources triggers unemployment and outmigration. In addition, salinization of surface and ground water sources is creating drinking water crisis (Abedin et al. 2014). This generates different diseases and health problems like skin diseases, diarrhoea, digestion problems, and increase infant's diseases and pregnancy complications (Khan et al. 2011).

\subsubsection{Adaptation pathways for the mostly affected coastal systems to cope with salinization in Bangladesh's south-west coastal region}

Most of the household respondents and also key informants articulated crop agriculture followed by the Sundarbans mangrove and fresh water sources as the most affected coastal systems by salinity increase. The results reveal that household-level respondents' perceptions are more closely related to socio-economic aspects than to the bio-physical environmental aspects and focus on issue-based action. However, the key informants focus more on the biophysical changes and the large-scale measures. The DPSIR framework shows that responses already taken (i.e., polders and shrimp farming) to cope with salinization, have later become systemic pressures (i.e., riverbed siltation, waterlogging and intensive salinization).

Social perceptions and experts' observations were integrated in adaptation planning through a qualitative (i.e., multi-criteria analysis) and quantitative (i.e., adaptation turning point approaches) assessment and, proposed sixteen adaptation options for the identified mostly affected coastal systems (Chapter 5). For crop agriculture, most suitable measures include adaptive agriculture, crop diversification, alternate cropping and arable field management. A combined approach of adaptive agriculture, crop diversification/alternate cropping and arable field management is expected to sustain salinity levels at approximately 12ppt. Saline resistant horticulture is expected to sustain salinity levels at approximately $15 \mathrm{ppt}$. However, for long-term adaptation planning (i.e., salinity level $>15 \mathrm{ppt}$ ), land zoning is likely the most suitable measure to promote agriculture, to improve farmers' socio-economic conditions and to resolve the conflicts between crop and shrimp farming.

For drinking water sources, managed aquifer recharge is the most likely long-term suitable measure to ensure availability and quality of drinking water. Such recharge also serves to control salt-water intrusion, prevent land subsidence and sustain other coastal systems' 
functioning (Dillon et al. 2009). However, aquifer conditions must be suitable and water sources need to be ensured. Also rainwater harvesting, pond-sand filter and pond excavation are identified as potential measures. These measures are already adopted but can be threatened by changing rainfall patterns, tidal water-level rise, floods, cyclones and tidal surges. Therefore, these measures can be unsustainable in the long term. Hence, mechanisms to recharge ground water resources need to be adopted to ensure long-term safe drinking water supply.

For the Sundarbans, improved awareness combined with providing the forest department officials with the necessary enhanced ecological trainings is needed to improve the sustainable use and management of the forests. However, ensuring increased freshwater flow into the system is necessary to save the forests by reducing salinity increase and its impacts on vegetation and the Royal Bengal tiger and its prey habitats. Hence, periodic (re)-excavation to restore the Gorai river can potentially increase the freshwater inflow. However, continuous (re)-excavation may not be a long-term economically viable measure. Therefore, tidal river management and an upstream barrage (i.e., Ganges Barrage) are proposed to ensure the connection of the rivers to the flood plain, to restore the natural process of land formation through sedimentation and to increase fresh water flow to the downstream rivers. Such river management will reduce river bed siltation, water logging and the effects of tidal water-level rise on the Sundarbans mangrove, while the barrage will ensure fresh water flow for the Sundarbans during the dry period. However, more in-depth assessments are needed to construct an upstream barrage as it has several negative environmental and socio-economic impacts. For instance, it will submerge a large area which will make people's livelihoods vulnerable if proper replacements are not arranged. Nonetheless, tidal river management seems the most suitable measure, which will not only protect the Sundarbans against salinization but also stimulate crop agriculture and enhance fresh water sources.

\subsection{Relevance of the study to national action plans and policies}

A saline environment has always been part of Bangladesh's south-west region. However, the recent excessive salinization and its unfavourable impacts on natural systems force the government to prepare different strategies and action plans, such as the Bangladesh Climate Change Strategy and Action Plan (BCCSAP; 2009), the Integrated Resource Management Plan for the Sundarbans (IRMP; 2010-2020), the Bangladesh Tiger Action Plan (BTAP; 2009-2017) and the National Shrimp Policy 2014. These action plans and policies are 
principally aimed to eradicate poverty and achieve economic and social well-being through adaptation. Local adaptation, however, is highly context dependent (Haque et al. 2015). Implementing these action plans and policies, therefore, fundamentally requires to better identify the interconnected processes of the salinization and characterize its cascading impacts. In this line, the outcomes of this study are very much related to the goals of the recent action plans and policies (Table 6.2). The analysis on five different hydro-climatic variables, their cause-effect relationship and impacts of these changes on the Sundarbans mangrove vegetation, the Sundarbans tigers' habitat and coastal people helps decision makers to achieve the goals of the recent action plans and policies mentioned above.

Most of the previous coastal development interventions (like dams, embankments and polders) have been taken through top-down approaches (Ayers et al. 2014) and have largely ignored the complex and dynamic social, ecological and economic systems in this region. As a result, structural developments could not improve the situation to cope with salinization, rather augmented the process which in turn introduced shrimp farming. Extensive shrimp farming in the south-west coast of Bangladesh has created a direct conflict with crop agriculture later on. However, until now how the different processes driving salinization are connected, is poorly acknowledged. In this line, our developed DPSIR framework for salinity increase that integrates the top-down and bottom-up approaches, can be used as a basis for future adaptation planning. This framework will help to avoid the continuation of maladaptation and, consequently, to achieve the adaptation goals of these timely and problemoriented action plans and policies.

In particular, this study is highly relevant to BCCSAP's priority areas for research on climate change and coastal ecosystems. Although salinity across the south west coastal region is increasing gradually, future salt intrusion rates are highly uncertain due to unknowns in future climate change and upstream developments. As a result, policy makers often struggle where, when and which different measures need to be implemented. To deal with such uncertain future, adaptation pathways based on adaptation turning points that are developed in this study, will be able to support decision making under uncertain future conditions. In the context of BCCSAP-2009 and the problems policy makers have with implementing timely adaptation measures under changing climatic and socio-economic conditions, this study assesses and improves the understanding of recent changes in and the relationships among the environmental variables and impacts of these environmental changes on key coastal systems. 
Based on these assessments, three different adaptation pathways were developed to cope with salinization in Bangladesh's south-west coastal region. Thus, the outcomes of this research will assist policy makers to better adapt to future changes in salinization under changing climate and complex social system. 


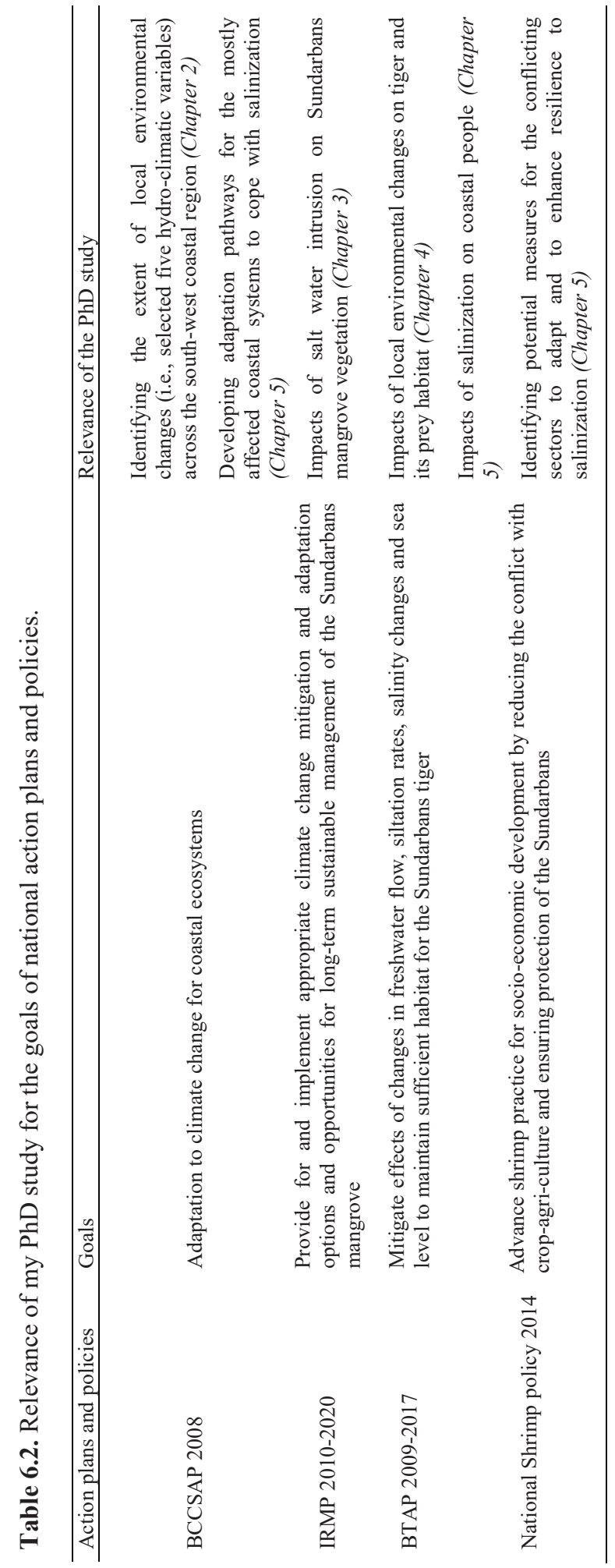




\subsection{Scientific contributions to the insights of salinization and adaptation planning}

\subsubsection{Multidisciplinary research approach}

The south-west coastal region of Bangladesh is located at the transient zone of the Bengal delta where tidal water from the Bay of Bengal and fresh water flow from the GangesBrahmaputtra-Meghna river basin converge. Hence, this region is stressed from both sides by climate-change impacts (e.g., sea level rise) and regional hydrological changes (e.g., reduced fresh water influx). This results in rapid salinity increase (Gopal and Chauhan 2006; Smith et al. 2009; Loucks et al. 2010). Adequate understanding of these interconnected regional processes of salinization and effective and timely adaptation planning for the mostly affected key coastal systems (particularly the Sundarbans mangrove, crop agriculture and fresh water sources) are highly challenging research topics due to not only local, regional and global drivers and pressures, but also uncertainties associated with the salinization processes. Adaptation in such complex and dynamic ecosystems requires knowledge, research frameworks and approaches that integrate and thus effectively utilize different scientific disciplines, like climatology, ecology, hydrology, coastal management and adaptation science. Our interdisciplinary research advances the knowledge to understand the interconnected processes of salinization and cascading salinization impacts on different coastal inland systems, and to demonstrate several scientific approaches for developing adaptation pathways.

\subsubsection{Scientific basis for climate-change adaptation planning}

Adaptation process requires four different sequential steps: identification of the causes of the problem, then assessment of the impacts, selection of adaptation options for specific impacts and finally evaluation of the identified options to make definite choices (Ludwig and Swart 2010). All these steps were comprehensively performed to develop adaptation pathways for the south-west coastal region of Bangladesh. Foremost, the interconnected causes of coastal wetlands and inland salinization and mostly affected systems (Chapters 2 and 5) were identified to better connect the climatic-societal-economic-ecological driver and pressures and their implications on different coastal systems. Also the impacts of salinization on three key components (mangrove vegetation: Chapter 3; tiger habitat: Chapter 4; and coastal people: Chapter 5) of the selected most affected coastal systems were studied to better identify the function oriented coping measures. Based on these impacts studies, potential local measures for the root causes of salinization and large scale measures for the key coastal systems were 
proposed to cope with and to enhance resilience to salinization (Chapter 5). Thus, this study provides the scientific basis for climate-change adaptation planning for conservation and sustainability of the identified most affected coastal systems.

\subsubsection{Impact study focussing the relationship and dependency of ecosystems components with one another}

The methodology adopted in this pioneering climate-change impact study on an ecosystem focusses on the relationship and dependency of the ecosystem's components with one another. First, hydro-climatic variables were analysed to understand the recent environmental changes in this region and the cause-effect relationship among the selected variables. In addition, local people and related professionals were interviewed to capture the socio-economic variables associated with salinization. Then, a DPSIR framework was applied to provide a comprehensive understanding of salinization and the range of interconnected hydro-climatic and socio-economic processes. This improved understanding of recent changes in and the relationships among the hydro-climatic and socio-economic variables will help decision makers to better adapt to future changes and scientists to better validate different environmental change models and scenarios. Besides, forest-plot conditions were studied following three transects in three different ecological zones along the salinity gradients for the climate-change impact study on the Sundarbans mangrove vegetation. As the least studied forest type in Bangladesh (Biswas \& Choudhury 2007), such knowledge is urgently needed to conserve the globally threatened mangrove ecosystem in a changing environment. Also five different information sources (i.e., literature, field observations and hydro-climatic analyses, focussed group discussions with local communities and key-informants interviews) were analysed to address the lack of knowledge on how tiger habitat relates to changing salt concentrations. Thus, this study provides new insights for long-term tiger-habitat conservation due to bio-physical changes in the environment.

Overall, this is the first integrated climate-change impact study that addresses the range of interconnected hydro-climatic and socio-economic processes of salinization across the southwest coastal region and assesses the impacts of these processes on the ecosystems in terms of relationship among ecological status of mangrove vegetation, habitat for the Sundarbans tiger and its prey, and the livelihoods of local people. Besides, adaptation pathways developed in this study integrate both top-down and bottom-up perceptions and observations (based on multi-criteria analysis and adaptation turning points) and can support decision making under uncertain future salinity conditions due to unknowns in future climate change and upstream 
developments. Moreover, the study's results and methodological framework can contribute to cross-sectoral impact studies that address the linkages between climate change and other coastal systems (like crop agriculture, livestock and poultry, aquatic ecosystems, homestead agro-forestry, fresh water sources and human health, energy and industry) and thus, harmonize adaptation planning.

\subsection{Recommendations}

\subsubsection{Consider the range of identified interconnected salinization processes for future decision making}

My study improves the required understanding of salinization processes by providing enriched knowledge on salinization impacts on the Sundarbans mangrove vegetation, mangrove habitat for royal Bengal tigers and coastal communities. It focusses on the relationship and dependency of the ecosystems' components with one another, and for effective large-scale adaption planning. My results reveal that salinity intensification across the south-west coast of Bangladesh is driven by a range of hydro-climatic variables (i.e., rising temperatures, late onset of monsoon, SLR and reduced freshwater influx particularly during dry season), socio-economic changes (from crop agriculture to shrimp farming) and infrastructural developments, both upstream (e.g., the Farakka barrage) and downstream (e.g., polders). Thereby, challenges to conserve the Sundarbans mangrove and its outstanding universal value, to sustainably accommodate coastal people and their livelihoods and to adapt these ecosystems as a whole are exceedingly growing. Hence, future plans to adapt to coastal inlands and wetlands management need to consider the range of interconnected processes for sustainable development in this region.

\subsubsection{Consider salinity increase as the main driving force for the Sundarbans mangrove- habitat degradation}

Our study enriches the knowledge how salt concentrations in the Sundarbans mangrove is changing and affecting ecosystem functioning in this world-heritage site. Our results show that reduced fresh water influx, climate change (i.e., increasing temperatures during summer and late onset of monsoon) and SLR are particularly contributing to change the salt concentrations in the Sundarbans mangrove and, consequently, to change the vegetation pattern. This likely contributes to the tiger's habitat degradation and its principal prey depletion. Also further changes in salinity gradient will favour a shift in mangrove 
composition towards more salt tolerant species with reduced biodiversity and reduced carbon storage. These changes are most likely to affect different coastal communities (like fisherman, golpata-thatching material harvester and honey harvester), who depend on the natural resources for their livelihoods. Salinity increase, therefore, was recommend to consider as an important challenge for future management strategies to protect this irreplaceable ecosystem through which other coastal systems (wetlands and inlands) and resources (aquatic resources both marine and fresh water) are governed by.

\subsubsection{Take initiatives at national-level for large-scale integrated adaptation planning}

Dominant causes of salinization across the south-west coastal region are climate-change induced sea-level-rise (global), reduced fresh water influx (regional) and land-use change along with unplanned infrastructural development (local). These issues also result in other complications like back-water effects, river-bed siltation and water-logging, which also contribute to accelerate the salinization processes. All these processes are affecting key coastal systems like the Sundarbans mangrove, crop agriculture, fresh water sources and human health. In addition, these systems are interlinked with one another. A single measure, therefore, is incapable to deal with neither these interconnected salinization processes nor the interlinked affected coastal systems. Combined measures, then, are vital for adaptation planning with proper coordination among different sectors and across different scales. Since climate change and SLR are global issues, national level measures are often insufficient to address these problems. Issues, such as reduced fresh water influx, can be addressed regionally, while unplanned land-use changes and infrastructural developments can be fixed through local and national level initiatives. Hence, taking necessary effective initiatives was suggested for maintaining the ecological flow of the transboundary upstream rivers in combination with local level periodic (re)-excavation of the silted rivers, planned coastal land zoning to regulate land-use changes and tidal river management to reduce back-water effects, river bed siltation and water-logging. In this line, large-scale integrated national-level adaptation planning is crucial to address the above mentioned interconnected salinization processes and to cope with the changes in these dynamic and complex coastal systems.

\subsection{Reflections on strengths and limitations of the study}

Several earlier studies (e.g., Bhuiyan and Dutta 2012; Khan et al. 2011; Haque 2006; Mirza 1998) looked at salinity increase and its impacts on coastal ecosystems in this region. 
However, hardly any of those looked at the range of interconnected hydro-climatic and socioeconomic processes and the cause-effect relationships of those processes. Also impacts of salinity increase and its range of processes on the ecosystems' key components in terms of relationship with one another were overlooked. Hence, our study is a valuable first step to integrate these aspects in one platform, to get an overview of how the whole coastal systems are interconnected and affected by salinization, though it has some limitations as well. Meanwhile individual approaches were sufficiently discussed in the previous chapters (i.e., Chapters 2 to 5). Therefore, this section provides an analytical reflection on the overarching research framework employed in this thesis.

Cause-effect relationships among several hydro-climatic variables and DPSIR framework to integrate socio-economic variables of salinity increase established in this study are innovative. The relationships disclose the fact that salt intensification results from a combination of different climate signals (i.e., rising temperatures, late onset of monsoon and SLR), hydrological changes (i.e., insufficient upstream discharge particularly during dry season and pre-monsoon: January to May) and also socio-economic shifts (i.e., extensive shrimp practice and infrastructural developments). However, statistical analysis (linear regression correlations) to explore the cause-effect relationship among the hydro-climatic variables was too simple due to the arbitrary time-series data. As observed hydro-climatic data was collected from different concerned departments (as for example, climate data from BMD, sea-level data from BIWTA, salinity and discharge data from BWDB), the time-series data for all collected variables differed in quality and coverage. In particular, the salinity data was available only for the period 2000-2008, while other hydro-climatic data (temperature, rainfall, discharge. tidal water level) were available for the period 1981-2010. Besides, all the hydro-climatic variables are probably not directly related to increasing salinity, but indirectly affect salinity increase. For example, temperature is contributing to the thermal expansion of ocean water and the melting of mountain glaciers. Both are contributing to sea-level rise and they likely directly increase salinity. Thus the likely relationships among the hydro-climatic variables were identified. Besides socio-economic variables of salinity increase were identified from the households surveys and key informants interviews. Both hydro-climatic and socio-economic variables were included in the developed DPSIR framework. This is the study's most robust part as it integrates all variables associated with salinization on the same podium to provide a comprehensive understanding of its range of processes. Different other studies have also indicated through observational or modelling approaches that increases in sea-level rise 
(Bhuiyan and Dutta 2012), lower fresh water discharge (Mahmuduzzaman et al. 2014) and sea-surface temperature and precipitation (Singh 2001) are causing increased salt water intrusion. Also cyclones and increased shrimp farming are mentioned as possible causes for increased salt water intrusion (Khan et al. 2000; Deb 1998). Unfortunately, these studies only considered one variable of salinity increase. Hence, our study is innovative by establishing relationships among several hydro-climatic and socio-economic variables of salinity increase in one platform.

Also this study is a valuable first step to relate ecological status (i.e., composition, density, diversity, canopy cover, regeneration and carbon content) of the Sundarbans mangrove with salinity gradients and to improve the understanding on how salt concentrations affect mangrove ecosystem functioning in this world heritage site, in particular relating mangrove vegetation with habitat for the royal Bengal tiger and its prey. However, salinity and vegetation data were collected only once because of restricted time and funding. Hence, our data by itself cannot confirm salinity increase in the Sundarbans' wetlands and these data are thus inept to reveal the particular changes in mangrove vegetation and correspondingly Bengal tiger and its prey habitat due to the changes in salinity levels. Also a very limited and scattered data on tiger and its prey occurrences and habitats did not allow to statistically correlate the discussed hydro-climatic variables and bio-physical changes to the tiger habitat requirements in the Sundarbans. However, ecological status of mangrove vegetation along salinity gradients reveal how mangroves are governed by salt concentrations and thus implies likely changes in mangrove vegetation due to further salinization. Besides our wide-ranging findings on the changes in hydro-climatic variables, field observations, local people's perception and concerned expert's insights presumably assist us to predict the most likely further changes in mangrove habitat for Bengal tiger and its prey due to salinity increase and, they seem robust.

Furthermore, household surveys followed by key-informant interviews represents a new approach to integrate both top-down and bottom-up observations and perceptions on salinization, its impacts and potential measures in adaptation planning. Because previous adaptive measures in the south-west coast of Bangladesh stressed the system probably by the top-down decision-making approach (Fraser et al. 2006). Most coastal development interventions have largely focussed on structural protection measures (e.g., dams, embankments and polders) through top-down approaches and have largely ignored the complex and dynamic social, ecological and economic systems in the region (Ayers et al. 
2014). As a result, extensive shrimp farming in the south-west coast of Bangladesh has created a direct conflict with crop agriculture. This conflict largely affects the socio-economic status of local inhabitants. In addition, massive polderization results more ecological complications like riverbed siltation and water logging. Therefore, integrating top down and bottom up perceptions and observations before implementing large scale structural measures is crucial for sustainability of socio-economic-ecological systems. Considering these gaps in decision making process, top-down and bottom-up observations and perceptions are merged in adaptation planning.

In addition, both qualitative (i.e., multi-criteria analysis) and quantitative (i.e., adaptation turning points) assessment of the identified potential adaptive measures were applied to develop an adaptation pathway that shifted a salinity range to another domain, if needed. Since future salt intrusion rates are highly uncertain due to unknowns in future climate change (Dessai and Sluijs 2008) and upstream developments, policy makers often struggle where, when and which measures need to be implemented. To deal with such uncertain futures, developed adaptation pathways can support decision making to cope with salinization. However, potential adaptive measures and their turning points prescribed may not be precise as these were not tested and validated through projecting future salinity changes and estimating the uncertainties associated with salinization. Hence, multi-criteria analysis, possible contributions and suitable conditions along with pros and cons of each measure are considered in developing the pathway. Also a salinity range, when shifting or adding another measure is necessary, is indicated based on the tipping points of each potential measures. Thus the pathway developed in this study is novel as a valuable first step to provide a large set of target oriented potential measures having a salinity range for shifting or adding another measure under uncertain future conditions.

\subsection{Future outlook}

This thesis focussed on climate-change impacts, particularly salinity increase, on three key components (i.e., the Sundarbans mangrove vegetation, the Sundarbans tiger habitat and coastal communities) of coastal ecosystems in south-west coast of Bangladesh followed by target oriented potential measures to cope with salinization. This multidisciplinary research increases the understanding of salinization processes, salinity impacts on the Sundarbans mangrove and coastal inland ecosystem functioning, and large scale adaptation planning under changing climate and complex social systems. However, limitations of our study 
discussed in Section 6.6 indicate scope to further improve this knowledge platform. Several points for improvement and other research directions, in this regard, are discussed here:

Improving the data set (both spatial and temporal) to more precisely analyse the associated variables of salinization;

Using high resolution satellite images to identify the particular changes in mangrove vegetation and consequently tiger habitat degradation;

Developing a model which includes all the identified variables to predict the consequences of future salinization scenarios; and

Testing the developed adaptation pathways based on these future salinization scenarios.

Although the focus of this thesis has been limited to increasing salinity impacts, its research framework and methodology adopted potentially address the impacts of other coastal changes (like infrastructural developments and land-use change) that are likely to affect the natural coastal ecosystems (i.e., the Sundarbans mangrove, marine wetlands and inland ecosystems) only, but also the communities who are dependent on these ecosystems for their life (e.g., food and water) and livelihoods (e.g., timber and non-timber forest resources, fishing, aquatic resources, crop production). Hence, the next step can be, for instance, to explore the impacts of infrastructural developments and land-use changes on these diverse coastal ecosystems and its major components.

Besides, different hydro-climatic and socio-economic variables of salinization were investigated to better understand its processes. However, other biophysical complications, like riverbed sedimentation and waterlogging, that were stimulated by these hydro-climatic and socio-economic processes, were not examined. While riverbed siltation and waterlogging due to reduced fresh water influx and massive polder development, also contribute to enhance salinization in this region, they affect a large extent and their impacts need to be explores further. In this line, future studies that consider these complications will hopefully develop more comprehensive scenarios for adaptation planning in the studied region.

Furthermore, only one parameter of water (i.e., salinity) was analysed to look at its impacts on different components of mangrove and inland ecosystems. However, other parameters of water quality (e.g., temperature and nutrients) for these ecosystems' components need to be considered as well. Since the studied region is densely populated with extensive human 
activities, water quality indicators for different ecosystems need to be examined to get more transparent image whether water salinity is the foremost concern or not.

\subsection{Conclusions of the $\mathrm{PhD}$ thesis}

This study provides an improved understanding of recent changes in and relationships among the identified hydro-climatic and socio-economic variables of salinization. This results in novel insights of the ecological status of the Sundarbans mangrove vegetation along the salinity gradient and the degradation of quality-tiger habitat in these mangroves due to salinity increase that is caused by a range of processes (Figure 6.2). Also possible implications of recent environmental changes due to interacting hydro-climatic and socio-economic variables on different interlinked socio-ecological-economic systems (i.e., crop agriculture, drinking water sources and the Sundarbans mangrove) were discussed and target-oriented adaptation pathways were developed considering both societal values and top-down perceptions.

Global climate change, regional hydrological modifications and local socio-economic shifts are the major processes associated with rapid salinization across the south-west coastal region of Bangladesh (Chapters 2 and 5). Salinity increase and its range of processes are not only contributing to reduce world's largest and last remaining tract of mangrove's (i.e., Sundarbans) biodiversity and its carbon stocks (Chapter 3), but also degrade quality tigerhabitat requirements (through, for example, availability of fresh drinking water, sufficient prey population and diverse vegetative cover) in these mangroves (Chapter 4). Furthermore, intensification in salinity across the south-west coast of Bangladesh has become an extensive threat for human health and livelihoods (i.e., crop agriculture, livestock, poultry, fisheries and forestry). Further changes in salinity and its range of processes will make future efforts to protect and manage these diverse ecosystems more intricate for related different stressors. Hence, target oriented adaptation planning is needed. We, hence, identified potential measures for the dominant causes of salinization and developed adaptation pathways for the mostly affected coastal systems mentioned earlier (Chapter 5).

My findings on ecological status of the Sundarbans mangrove vegetation indicate that further changes in the salinity gradient will favour a shift in mangrove composition towards more salt tolerant species. Therefore, the rich biodiversity and carbon-stocks of the low saline zone mangroves are threatened by climate change and its impacts, in particular by possible increases in salt water intrusion. Also, quality tiger and its prey habitat requirements in these 
mangroves are stressed by salinity increase resulting from a number of macro-level hydroclimatic changes particularly rising summer temperatures, late onset of monsoon and reduced dry season fresh water influx. However, previous conservation efforts neither focused on mangrove's biodiversity loss nor habitat degradation of Bengal tigers. Hence, I consider salinity as an important factor for developing future management strategies to protect the biodiversity and rich carbon sink of the Sundarbans world-heritage ecosystem and also to safeguard the globally endangered and regionally critically endangered plants (e.g., H. fomes) and wildlife (e.g., Panthera tigris) of this irreplaceable ecosystem. Most importantly, my spatially explicit information on the Sundarbans' mangrove habitat shows the need for balanced salt concentrations and broad information sources on Bengal tigers' habitat degradation. Salinity increases indicate that sufficient amounts of fresh water influx are needed to ensure an all-year-round diverse vegetative cover and to also ensure the availability of fresh drinking water sources inside the forests for all species.

Adaptation planning to cope with salinization is a challenging endeavour for the complex, interacting and dynamic ecological and social systems of this region. The identified salinization pressures and impacts on the socio-ecological-economic systems that result from several systemic interactions in coastal environments, highlight the need of target-oriented large-scale adaptation planning. Already several measures, which have been adopted for crop agriculture and drinking water sources, need upscaling to cope with future salinization. However, no measures have yet been taken for the Sundarbans mangrove. Several potential measures for each of the most affected coastal systems were identified. These measures consider both the societal value (bottom-up approach) and experts' observations (top-down approach), and have a salinity range to quickly shift, if the situation demands. This caters for greater long-term benefits of the studied region and also assists policy makers to better plan for adaption under continuously changing climate and complex social systems. 
Synthesis

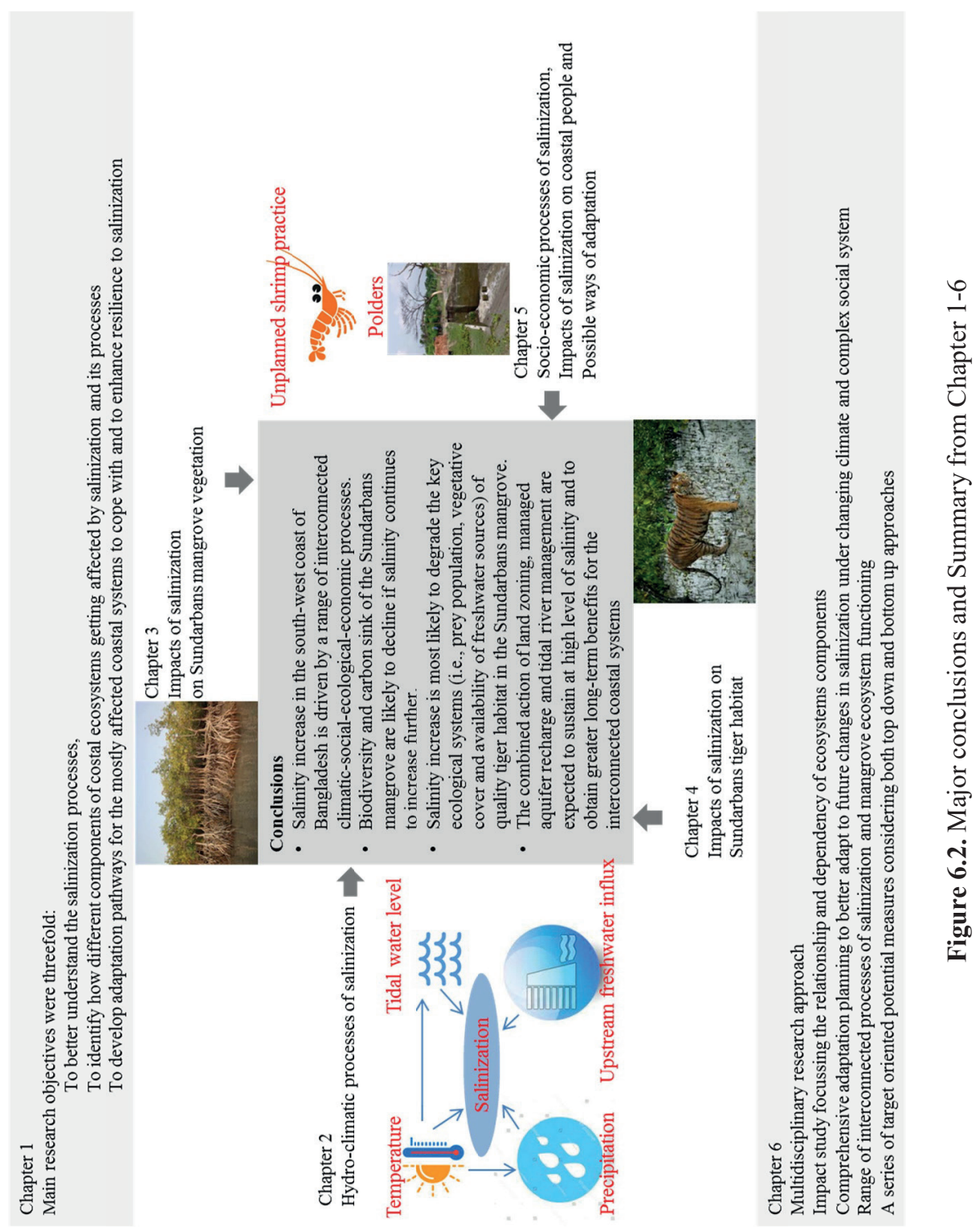




\section{References}

Abedin MA, Habiba U, Shaw R (2014) Community perception and adaptation to safe drinking water scarcity: salinity, arsenic, and drought risks in coastal Bangladesh. International Journal of Disaster Risk Science 5:110-124. https://doi.org/10.1007/s13753-014-0021-6

ADB (1998) Summary initial environmental examination for Sundarbans Biodiversity Conservation Project in Bangladesh. Asian Development Bank, Manila.

Ahasan MN, Chowdhary MA, Quadir DA (2010) Variability and trends of summer monsoon rainfall over Bangladesh. Journal of Hydrology and Meteorology 7(1):1-17. doi: http://dx.doi.org/10.3126/jhm.v7i1.5612

Ahmad IU, Greenwood CJ, Barlow ACD, Islam MA, Hossain ANM, Khan MMH, Smith JLD (2009) Bangladesh Tiger Action Plan 2009-2017. Bangladesh Forest Department, Ministry of Environment and Forests, Government of the People's Republic of Bangladesh, Dhaka, Bangladesh.

Ahmed AU, Siddiqi NA, Choudhuri RA, Huq S, Karim Z, Asaduzzaman M, Mahtab F (1999) Vulnerability of Forest Ecosystems of Bangladesh to Climate Change. In: Vulnerability and Adaptation to Climate Change for Bangladesh. Eds. Huq, S., Karim, Z., Asaduzzaman, M., \& Mahtab. Dordrecht/Boston/London: Kluwer Academic Publishers: 93-111.

Ali A (1999) Climate change impacts and adaptation assessment in Bangladesh. Climate research 12.2-3:109-116. doi:10.3354/cr012109

Ali SS (1998) Sundarbans: its resources and ecosystem. In: Rahman M. A., Shah, M. S., Murtaza, M. G. and Matin, M. A. (eds), Integrated management of Ganges flood plains and Sundarbans ecosystem. Khulna University, Khulna, Bangladesh.

Alim A (1984) Soil and plant interaction in mangrove ecosystems, Paper presented in UNDP and UNESCO Training Seminar on Geology, Sedimentology, Erosion Accretion in Mangrove Areas, Dhaka, pp.1-12.

Ameen M (1999) Development of guiding principles for the prevention of impacts of alien species. Paper presented at a consultative workshop in advance of the 4th meeting of SBSTTA to the CBD organized by IUCN Bangladesh at Dhaka on May 25, 1999. 
Ayers JM, Huq S, Faisal AM, Hussain ST (2014) Mainstreaming climate change adaptation into development: a case study of Bangladesh. Wiley Interdisciplinary Reviews: Climate Change 5(1): 37-51. doi:10.1002/wcc.226

Azad MAK, Hashem MA, Hossain MM (2005) Study on human Royal Bengal tiger Interaction of in situ and ex situ in Bangladesh. Journal of Biological Sciences 5: 250252.

Aziz A, Barlow AC, Greenwood CC, Islam A (2013) Prioritizing threats to improve conservation strategy for the tiger Panthera tigris in the Sundarbans Reserve Forest of Bangladesh. Oryx 47(04): 510-518. https://doi.org/10.1017/S0030605311001682

Aziz A, Paul AR (2015) Bangladesh Sundarbans: present status of the environment and biota. Diversity 7(3): 242-269. doi:10.3390/d7030242

Ball MC (1998) Mangrove species richness in relation to salinity and waterlogging: a case study along the Adelaide River floodplain, northern Australia. Global Ecology and Biogeogrpahy Letters 7(1):73-82. doi: 10.1111/j.1466-8238.1998.00282.x

Bambang HS, Ati DN (2006) Domination and composition structure change at hemic peat natural regeneration following burning; A case study in Pelalawan, Riau Province. BIODIVERSITAS 7:154-158.

Bandyopadhya AF (1968) Soil water characteristics of the mangrove forest of the Sundarbans (India). Indian Forest 112(1):58-65.

Barlow AC (2009) The Sundarbans Tiger Adaptation, Population Status, And Conflict Management (Doctoral dissertation, University of Minnesota).

Barlow ACD, Greenwood CJ, Aziz MA, Ahmad IU, Dey TK, Hossain MA, Islam MM, Islam MA (2011) Bangladesh Tiger Action Plan 2009-2017: Research agenda. Wildlife Trust of Bangladesh report.

Barlow ACD, McDougal C, Smith JLD, Gurung B, Bhatta SR, Kumal S, Mahato B, Tamang DB (2009) Temporal variation in tiger (Panthera tigris) populations and its implications for monitoring. Journal of Mammalogy 90(2): 472-478.

https://doi.org/10.1644/07-MAMM-A-415.1

Barua P, Chowdhury SN, Sarkar S (2010) Climate Change and Its Risk Reduction by Mangrove Ecosystem of Bangladesh. Bangladesh Research Publication Journal 4: 218-225.

BBS (2001) Statistical Year Book. Bangladesh Bureau of Statistics, Dhaka. 
Bhuiyan MJAN, Dutta D (2012) Assessing impacts of sea level rise on river salinity in the Gorai river network, Bangladesh. Estuarine, Coastal and Shelf Science 96: 219-227. doi: $\underline{10.1016 / \text { j.ecss.2011.11.005 }}$

Biswas SR, Choudhury JK (2007) Forests and forest management practices in Bangladesh: the question of sustainability. International Forestry Review 9(2):627-640. doi:10.1505/ifor.9.2.627

Blasco F, Aizpuru M, Gers C (2001) Depletion of the mangroves of Continental Asia. Wetlands Ecology and Management 9(3): 255-266. doi:10.1023/A:1011169025815

Bosomworth K, Harwood A, Leith P, Wallis P (2015) Adaptation Pathways: a playbook for developing options for climate change adaptation in Natural Resource Management. Southern Slopes Climate Change Adaptation. Research Partnership (SCARP): RMIT University, University of Tasmania, and Monash University.

Brammer H (2002) Land use and Land use Planning in Bangladesh. University Press Limited, Dhaka.

Brammer H (2014) Bangladesh's dynamic coastal regions and sea-level rise. Climate Risk Management 1:51-62. doi:10.1016/j.crm.2013.10.001

Chaffey DR, Miller FR, Sandom JH (1985) A forest inventory of the Sundarbans, Bangladesh. Project Report 140. Land Resources Development Centre, Surrey, pp.196.

Chaudhuri AB, Choudhury A (1994) Mangroves of the Sundarbans. Vol. 1. India. The IUCN Wetlands Programme. Bangkok, Thailand, IUCN.

Chaudhuri AB, Naithani HB (1985) A Comprehensive survey of Tropical Mangrove Forests of Sundarbans and Andamans. Part 1. International Book Distributors, Dehra Dun, India, $41 \mathrm{pp}$.

Chen R, Twilley RR (1999) Patterns of mangrove forest structure and soil nutrient dynamics along the Shark river estuary, Florida. Estuaries 22:955-970. doi:10.2307/1353075

Chowdhury A, Maiti SK (2013) Degradation and deterioration of mangrove biodiversity of Indian Sundarbans: a case study from Jharkhali Island, WB, India. Presented at INCCBSD-2013 at NIT- Rourkela.

Chowdhury KR (2009) Tidal River Plan Could Allay Climate Threat in Southwest [online] URL:http://bdnews24.com/bangladesh/2009/09/06/tidal-river-plan-could-allayclimate-threat-in-southwest. 
Chundawat RS, Khan JA, Mallon DP (2011) Panthera tigris tigris. The IUCN Red List of Threatened Species: e. T136899A4348945. http://dx.doi.org/10.2305/IUCN.UK.20112.RLTS.T136899A4348945.en.

Cintron G, Novelli YS (1984) Methods for studying mangrove structure, In: Snedaker SC, Snedaker JG (eds.) The mangrove ecosystem: research methods. United Nations Educational, Scientific and Cultural Organization, Paris, 91-113.

Clarke V (2009) Standard Operating Procedure for Establishing Vegetation Quadrats. Prepared for Significant Native Species and Ecological Communities - Resource Condition Monitoring Project by Department of Environment and Conservation, SOP No: 6.1, Version 1.0, $7 \mathrm{pp}$.

Clough BF (1984) Growth and salt balance in the mangroves Avicennia marina (Forsk.)Vierh. and Rhizophora stylosa Griff. in relation to salinity. Australian Journal of Plant Physiology 11:419-430. doi: 10.1071/PP9840419

Collins M, An SI, Cai W, Ganachaud A, Guilyardi E, Jin FF, Jochum M, Lengaigne M, Power S, Timmermann A, Vecchi G, Witternberg A (2010) The impact of global warming on the tropical Pacific Ocean and El Niño. Nature Geoscience 3(6): 391-397. doi: 10.1038/ngeo868

Curtis JT (1959) The Vegetation of Wisconsin. University of Wisconsin Press, Madison, WI. $657 \mathrm{pp}$.

Curtis JT, McIntosh RP (1951) An upland forest continuum in the prairie-forest border region of Wisconsin. Ecology 31:476-96. doi:10.2307/1931725

Curtis SJ (1933) Working plan for the forest of the Sundarbans division for the period 193157. Vol. 2 and appendix. Bengal Government Press, Calcutta.

Danda AA (2007) Surviving in the Sundarbans: threats and responses: an analytical description of life in an Indian riparian commons.

Deb AK (1998) Fake blue revolution: environmental and socio-economic impacts of shrimp culture in the coastal areas of Bangladesh. Ocean \& Coastal Management 41(1):6388. doi:10.1016/S0964-5691(98)00074-X

Dessai S, van der Sluijs J (2008) Uncertainty and Climate Change Adaptation-a Scoping Study. The Netherlands: Utrecht University. European Environment Agency Copenhagen.

Dey TK, Kabir MJ, Ahsan MM, Islam MM, Chowdhury MMR, Hassan S, Roy M, Qureshi Q, Naha D, Kumar U, Jhala YV (2015) First Phase Tiger Status Report of Bangladesh 
Sundarbans. Wildlife institute of India and Bangladesh Forest Department, Ministry of

Environment and Forests, Government of the People's Republic of Bangladesh.

DeZuane J (1997) Handbook of drinking water quality. John Wiley \& Sons.

Dillon PJ, Pavelic P, Page D, Beringen H, Ward J (2009) Managed aquifer recharge. An Introduction Waterlines Report Series, 13.

DOE (1993) Assessment of the Vulnerability of Coastal Areas to Sea Level Rise and Other

Effects of Global Climate Change, Pilot Study Bangladesh, report prepared by Department of Environment, Govt. of Bangladesh, Dhaka.

Donat MG, Alexander LV, Yang H, Durre I, Vose R, Dunn RJH, Willett KM, Aguilar E, Brunet M, Caesar J, Hewitson B, Jack C, Klein Tank AMG, Kruger AC, Marengo J, Peterson TC, Renom M, Oria Rojas C, Rusticucci M, Salinger J, Elrayah AS, Sekele SS, Srivastava AK, Trewin B, Villaroel C, Vincent LA, Zhai P, Zhang X, Kitching S (2013) Updated analyses of temperature and precipitation extreme indices since the beginning of the twentieth century: the HadEX2 dataset. Journal of Geophysical Research: Atmospheres 118 (5): 2098-2118. doi: 10.1002/jgrd.50150

Donato DC, Kauffman JB, Stidham M (2009) Protocols for Measuring \& Reporting Carbon Stocks in Mangrove Forests With Special Reference to Carbon Assessment for Sundarbans Reserve Forest, Bangladesh. USDA Forest Service, Pacific Southwest Research Station-Northern Research Station, International Programs, Funding support from USAID/Bangladesh. (IPAC project).

Duckworth JW, Kumar NS, Islam MA, Baral HS, Timmins R (2015). Axis axis. The IUCN Red List of Threatened Species: e. T4178A22158006.

Duke N, Kathiresan K, Salmo III SG, Fernando ES, Peras JR, Sukardjo S, Miyagi T (2010) Ceriops decandra. In: IUCN 2013. IUCN Red List of Threatened Species. Version 2013.2.

Duke NC, Meynecke JO, Dittmann S, Ellison AM, Anger K, Berger U, Cannicci S, Diele K, Ewel KC, Field CD, Koedam N (2007) A world without mangroves?. Science 317 (5834): 41-42. doi:10.1126/science.317.5834.41b

El Barmelgy IM, Rasheed SEA (2016) Sustainable Coastal Cities between Theory and Practice (Case Study: Egyptian Coastal Cities). Journal of Sustainable Development 9(4):216. doi: http://dx.doi.org/10.5539/jsd.v9n4p216

Ellison J, Koedam NE, Wang Y, Primavera J, Jin Eong O, Wan-Hong Yong J, Ngoc Nam V (2010) Excoecaria indica. In: IUCN 2013. IUCN Red List of Threatened Species, Version 2. 
Ellison JC (2012) Climate Change Vulnerability Assessment and Adaptation Planning for Mangrove Systems. Washington DC, World Wildlife Fund (WWF).

English S, Wilkinson C, Baker V (1997) Manual for survey of tropical marine resources. $2^{\text {nd }}$ Edition, Townsville, Australian Institute of Marine Science.

Ericson JP, Vörösmarty CJ, Dingman SL, Ward LG, Meybeck M (2006) Effective sea-level rise and deltas: causes of change and human dimension implications. Global and Planetary Change 50(1):63-82. doi:10.1016/j.gloplacha.2005.07.004

FAO (2007) The world's mangroves: 1980-2005. A thematic study prepared in the framework of the Global Forest Resources Assessment 2005. FAO Forestry Paper 153: 77 pp.

Feller IC, Lovelock CE, Berger U, McKee KL, Joye SB, Ball MC (2010) Bio-complexity in mangrove ecosystems. Annual Review of Marine Science 2:395-417.

Fraser ED, Dougill AJ, Mabee WE, Reed M, McAlpine P (2006) Bottom up and top down: Analysis of participatory processes for sustainability indicator identification as a pathway to community empowerment and sustainable environmental management. Journal of environmental management 78(2):114-127. https://doi.org/10.1016/j.jenvman.2005.04.009

Fussel HM (2007) Adaptation planning for climate change: concepts, assessment approaches, and key lessons. Sustainability science 2(2):265-275. doi: https://doi.org/10.1007/s11625-007-0032-y

Gain P (2002) Bangladesh Environment Facing the 21st Century; Society for Environment and Human Development (SHED), Dhaka.

Gitay H, Suárez A, Watson RT, Dokken DJ (2002) Climate change and biodiversity. Geneva, CH: IPCC.

Gopal B, Chauhan M (2006) Biodiversity and its conservation in the Sundarbans Mangrove Ecosystem. Aquatic Sciences 68: 338-354. doi:10.1007/s00027-006-0868-8

Grooten M, Almond R, McLellan R (Eds.) (2012) Living planet report 2012: Biodiversity, bio-capacity and better choices. World Wide Fund for Nature, Gland.

GTRP (2012) Global tiger recovery program 2010-2012. The World Bank, Washington. D.C. Haasnoot M, Kwakkel JH, Walker WE, ter Maat J (2013) Dynamic adaptive policy pathways: a method for crafting robust decisions for a deeply uncertain world. Global environmental change 23(2):485-498.

doi: https://doi.org/10.1016/j.gloenvcha.2012.12.006 
Haasnoot M, Van Deursen WPA, Guillaume JH, Kwakkel JH, Van Beek E, Middelkoop H (2014) Fit for purpose? Building and evaluating a fast, integrated model for exploring water policy pathways. Environmental modelling \& software 60: 99-120.

Doi: https://doi.org/10.1016/j.envsoft.2014.05.020

Haque SA (2006) Salinity problems and crop production in coastal regions of Bangladesh. Pakistan Journal of Botany 38(5): 1359-1365.

Hasan MA, Islam AS, Bhaskaran B (2013) Predicting future precipitation and temperature over Bangladesh using high resolution regional scenarios generated by multi-member ensemble climate simulations. In 4th International Conference on Water \& Flood Management (ICWFM-2013) pp. 575-582.

Hassan MM, Razzaque MA (1983) A preliminary evaluation of the clay mineralogy of the Sundarbans soils. Journal of Bano Biggyan Patrika, Bangladesh.

Hay JE, Mimura N (2006) Supporting climate change vulnerability and adaptation assessments in the Asia-Pacific Region-An example of sustainability science. Sustainability Science 1. doi: https://doi.org/10.1007/s11625-006-0011-8

Hendrichs H (1975) The status of the tiger Panthera tigris (Linne, 1758) in the Sundarbans mangrove forest (Bay of Bengal). Saugetierkundliche Mitteilungen 23: 161-199.

Hennink MM (2007) International focus group research: A handbook for the health and social sciences. Cambridge University Press, Cambridge.

Hensler L (2013) A sustainable future for shrimp production in Bangladesh?. Sustaining ethical aquaculture trade.

Hoque MA, Sarkar MSKA, Khan SAKU, Moral MAH, Khurram AKM (2006) Present Status of Salinity Rise in Sundarbans Area and its Effect on Sundari (Heritiera fomes) Species. Research Journal of Agriculture and Biological Sciences 2(3):115-121.

Hossain F, Khan ZH, Shum CK (2015) Tidal river management in Bangladesh. Nature Climate Change 5(6):492.

Hossain M, Saha S, Salekin S, Siddique MR, Abdullah SR (2014) Salinity influence on germination of four important mangrove species of the Sundarbans, Bangladesh. Poljoprivreda i Sumarstvo 60(2):125.

Hossain MS, Roy K, Datta DK (2014) Spatial and Temporal Variability of Rainfall over the South-West Coast of Bangladesh. Climate 2(2):28-46. doi:10.3390/cli2020028

Huq N, Hugé J, Boon E, Gain AK (2015) Climate change impacts in agricultural communities in rural areas of coastal Bangladesh: A tale of many stories. Sustainability 7(7):84378460. doi: $\underline{10.3390 / \mathrm{su} 7078437}$ 
Huq SU, Ahmed AU, Koudstaal R (1996) Vulnerability of Bangladesh to climate change and sea level rise. In Climate change and world food security (pp. 347-379). Springer Berlin Heidelberg.

Hussain MA, Islam AKMS, Hasan MA, Bhaskaran B (2013) Changes of the seasonal salinity distribution at the Sundarbans coast due to impact of climate change. In 4th International Conference on Water \& Flood Management (ICWFM) pp. 637-648.

Hussain Z, Karim A (1994) Introduction. In: Mangroves of Sundarban. Vol. Two: Bangladesh, Hussain Z and G Acharya (Eds), pp. 1-10. IUCN, Bangkok.

Iftekhar MS (1999) Vegetation dynamics in the Sundarbans and the contribution of salinity between 1985-1995. B.Sc. Thesis. Forestry and Wood Technology Discipline, Khulna University, Khulna, Bangladesh. 54 pp.

IPCC (2001) Climate Change 2001-The scientific Basis. Third Assessment Report of the Intergovernmental Panel on Climate Change Working Group 1 Cambridge University Press. Cambridge, UK.

IPCC (2007) Climate Change 2007-The Physical science Basis; Fourth Assessment Report of the Intergovernmental Panel on Climate Change; Cambridge University Press: Cambridge, UK.

IPCC (2014) Climate Change 2014: Synthesis Report. Contribution of Working Groups I, II and III to the Fifth Assessment Report of the Intergovernmental Panel on Climate Change [Core Writing Team, R.K. Pachauri and L.A. Meyer (eds.)]. IPCC, Geneva, Switzerland, pp. 151.

Islam A (2015) Adaptation Tipping Points to Salinity Management for Boro Rice in Satkhira district of Bangladesh. M.Sc. Thesis. Wageningen University, The Netherlands, pp. 64.

Islam MN (2009) Rainfall and temperature scenario for Bangladesh. The Open Atmospheric Science Journal 3:93-103. doi:1874-2823/09

Islam MN, Uyeda H (2007) Use of TRMM in determining the climatic characteristics of rainfall over Bangladesh. Remote Sensing of Environment 108(3): 264-276. doi: https://doi.org/10.1016/j.rse.2006.11.011

Islam SN (2008) Cultural landscape changing due to anthropogenic influences on surface water and threats to mangrove wetland ecosystems: a case study on the Sundarbans, Bangladesh (Doctoral dissertation, Universitätsbibliothek), 326 pp.

Islam SN, Gnauck A (2011) Water salinity investigation in the Sundarbans rivers in Bangladesh. International Journal of Water 6(1-2):74-91. 
doi: https://doi.org/10.1504/IJW.2011.043318

IUCN (2003) Status of the ecological integrity of the Sundarbans. IUCN Bangladesh Country Office, $80 \mathrm{pp}$.

IUCN (2013) IUCN Red List of Threatened Species. Version 2013.2.

IUCN-Bangladesh (2000) Red Book of Threatened Mammals of Bangladesh. IUCN, Dhaka, Bangladesh, 71pp.

IUCN-Bangladesh (2001) The Bangladesh Sundarbans: A photoreal sojourn. IUCN Bangladesh country office, Dhaka, Bangladesh.

IWM (2003) Sundarbans Biodiversity Conservation Project. Surface water Modelling, TA No. 3158 BAN Final Report Vol. 1 IWM, Dhaka, Bangladesh.

IWM (2014) Salinity in the South-West Region of Bangladesh. Institute of Water Modelling, Bangladesh.

Jain SK, Kumar V (2012) Trend analysis of rainfall and temperature data for India. Current Science(Bangalore) 102(1): 37-49.

Johnsingh AJT (1983) Large mammalian prey-predators in Bandipur. Journal of the Bombay Natural History Society 80: 1-57.

Karim A (1994) Vegetation. In: Hussain, Z. and Acharya, G. (eds.), Mangroves of the Sundarbans, Volume Two: Bangladesh. IUCN, Bangkok, Thailand.

Karim A (1995) Report on mangrove silviculture. Volume 1 Integrated Resource Development of the Sundarbans Reserved Forest FAO/UNDP Project BGD/84/056.

Karim MF, Mimura N (2008) Impacts of climate change and sea-level rise on cyclonic storm surge floods in Bangladesh. Global Environmental Change 18(3): 490-500. doi:10.1016/j.gloenvcha.2008.05.002

Katebi MNA (2001) Sundarbans and forestry. In Haider, R. (Ed.): Cyclone '91 - An Environmental and Perceptional Study. BCAS, Dhaka, pp.79-100.

Kathiresan K, Khan SA (2010) International Training Course on Costal biodiversity in Mangroves Course manual. Annamalie University, India, pp. 116-125.

Kathiresan K, Salmo III SG, Fernando ES, Peras JR, Sukardjo S, Miyagi T, Ellison J, Koedam NE, Wang Y, Primavera J, Jin Eong O, Wan-Hong Yong J, Ngoc Nam V (2010) Heritiera fomes. The IUCN Red List of Threatened Species 2010: e.T178815A7615342. http://dx.doi.org/10.2305/IUCN.UK.2010-

\section{RLTS.T178815A7615342.en.}

Kathiresan K, Salmo III SG, Fernando ES, Peras JR, Sukardjo S, Miyagi T, Ellison J, Koedam NE, Wang Y, Primavera J, Jin Eong O, Wan-Hong Yong J, Ngoc Nam V 
(2010) Sonneratia apetala. The IUCN Red List of Threatened Species: e.T178841A7623713. http://dx.doi.org/10.2305/IUCN.UK.20102.RLTS.T178841A76 23713.en.

Kent M, Coker P (1992) Vegetation Description and Analysis: A Practical Approach. John Wiley and Sons, NY, pp. 167-169.

Khan (2010) unpublished. Consumption of tiger prey by people and tiger straying status along the northern forest-village boundary of the Sundarbans of Bangladesh.

Khan AE, Ireson A, Kovats S, Mojumder SK, Khusru A, Rahman A, Vineis P (2011) Drinking water salinity and maternal health in coastal Bangladesh: implications of climate change. Environmental health perspectives 119(9):1328-1332. doi: $10.1289 /$ ehp. 1002804

Khan ATM, Singh OP, Rahman MS (2000) Recent sea-level and sea surface temperature trends along the Bangladesh coast in relation to the frequency of intense cyclones. Marine Geodesy 23: 1-14. doi:10.1080/01490410050030670

Khan MAR, Ahsan MF (1986) The status of the primates in Bangladesh and a description of their forest habitats. Primate Conservation 7: 102-108.

Khan MMH (2004) Mysterious tigers of the Sundarbans. Tiger: The Ultimate Guide: 94-98.

Khan MMH (2012) Population and prey of the Bengal Tiger Panthera tigris tigris (Linnaeus, 1758)(Carnivora: Felidae) in the Sundarbans, Bangladesh. Journal of Threatened Taxa 4(2): 2370-2380. doi: http://dx.doi.org/10.11609/JoTT.o2666.2370-80

Khan MMH, Chivers DJ (2007) Habitat preferences of tigers Panthera tigris in the Sundarbans East Wildlife Sanctuary, Bangladesh, and recommendations. Oryx 41(04): 463-468.

Khan TMA, Singh OP, Rahman MS (2000) Recent sea level and sea surface temperature trends along the Bangladesh coast in relation to the frequency of intense cyclones. Marine Geodesy 23(2): 103-116.

https://doi.org/10.1080/01490410050030670

Khanom T (2016) Effect of salinity on food security in the context of interior coast of Bangladesh. Ocean \& Coastal Management 130: 205-212.

https://doi.org/10.1016/j.ocecoaman.2016.06.013

Koch MS, Snedaker SC (1997) Factors influencing Rhizophora mangle L. seedling development in Everglades carbonate soils. Aquatic Botany 59(1-2): 87-98. doi:10.1016/S0304-3770(97)00027-2 
Kotwal PC and Mishra GP (1995) Claw marking on trees by tiger, Panthera tigris (Linn.) in Kanha National Park. Journal of the Bombay Natural History Society 92: 111-112.

Kreft S, Eckstein D, Dorsch L, Fischer L (2015) Global climate risk index 2016. Who suffers most from extreme weather events; Weather-related Loss Events in 2014 and 1995 to 2014. Briefing Paper 1-31.

Linkie M, Martyr DJ, Holden J, Yanuar A, Hartana AT, Sugardjito J, Leader-Williams N (2003) Habitat destruction and poaching threaten the Sumatran tiger in Kerinci Seblat National Park, Sumatra. Oryx 37: 41-48. https://doi.org/10.1017/S0030605303000103

Loucks C, Barber-Meyer S, Hossain MAA, Barlow A, Chowdhury RM (2010) Sea level rise and tigers: predicted impacts to Bangladesh's Sundarbans mangroves. Climatic Change 98(1): 291-298. doi:10.1007/s10584-009-9761-5

Ludwig F, Swart R (2010) Tools for climate change adaptation in water management: Inventory and assessment of methods and tools, Dutch National Research Programme Knowledge for Climate, KfC report number KfC 027/2010.

Luther DA, Greenberg R (2009) Mangroves: a global perspective on the evolution and conservation of their terrestrial vertebrates. BioScience 59(7):602-612. doi: $\underline{10.1525 / \text { bio.2009.59.7.11 }}$

Lynam, T, De Jong W, Sheil D, Kusumanto T, Evans, K (2007) A review of tools for incorporating community knowledge, preferences, and values into decision making in natural resources management. Ecology and society 12(1). http://www.ecologyandsociety.org/vol12/iss1/art5/

Mahmuduzzaman M, Ahmed ZU, Nuruzzaman AKM, Ahmed FRS (2014) Causes of salinity intrusion in coastal belt of Bangladesh. International Journal of Plant Research 4(4A): 8-13. doi:10.5923/s.plant.201401.02

Martínez ML, Intralawan A, Vázquez G, Pérez-Maqueo O, Sutton P, Landgrave R (2007) The coasts of our world: Ecological, economic and social importance. Ecological Economics 63(2):254-272. doi:10.1016/j.ecolecon.2006.10.022

Meehl GA, Stocker TF, Collins WD, Friedlingstein P, Gaye AT, Gregory JM, Kitoh A, Knutti R, Murphy JM, Noda A, Raper SCB, Watterson IG, Weaver AJ, Zhao Z (2007) Global Climate Projections. In: Soloman, S., Qin, D., Manning, M., Marquis, M., Averyt, K., Tignor, M. M. B., Miller, H. J. and Chen, Z. (eds.) Climate Change 2007: The Physical Science Basis. Contribution of Working Group I to the Fourth Assessment Report of the Intergovernmental Panel on Climate Change. Cambridge University Press, pp. 747-845. ISBN 9780521880091. 
Menon A, Levermann A, Schewe J, Lehmann J, Frieler K (2013) Consistent increase in Indian monsoon rainfall and its variability across CMIP-5 models. Earth System Dynamics 4(2):287-300. doi:10.5194/esd-4-287-2013

Mirza MMQ (1997) Hydrological changes in the Ganges system in Bangladesh in the postFarakka period. Hydrological Sciences Journal 42 (5): 613-631. doi: https://doi.org/10.1080/02626669709492062

Mirza MMQ (1998) Diversion of the Ganges water at Farakka and its effects on salinity in Bangladesh. Environmental management 22(5): 711-722. doi: https://doi.org/10.1007/s002679900141

Mirza MMQ, Hossain MA (2004) The Ganges Water Dispersion: Environmental Effects and Implications. In Adverse Effects on Agriculture in the Ganges Basin in Bangladesh; Mirza, M.M.Q. Ed.; Kluwer Academic Publishers: Dordrecht, The Netherlands pp. 177-196.

Misra R (1968) Ecology Work Book. Oxford and IBH publication Co, New Delhi, 244 pp.

Mitra A, Gangopadhyay V, Dube A, Schmidt ACK, Banerjee K (2009) Observed changes in water mass properties in the Indian Sundarbans (north-western Bay of Bengal) during 1980-2007. Current Science 97: 1445-1452.

Mohsanin, S, Barlow ACD, Greenwood CJ, Islam MA, Kabir MM, Rahman MM, Howlader A (2013) Assessing the threat of human consumption of tiger prey in the Bangladesh Sundarbans. Animal Conservation 16(1): 69-76. doi: 10.1111/j.1469-1795.2012.00571.x

Moly SH, Mirza ATM, Rahman T, Saadat AHM (2015) Environmental Flow Characteristics of the Gorai River, Bangladesh. International Journal of Scientific Research in Environmental Sciences 3(6): 208. doi:10.12983/ijsres-2015-p0208-0218

Mondal MS, Jalal MR, Khan MSA, Kumar U, Rahman R, Huq H (2013) Hydrometeorological trends in southwest coastal Bangladesh: perspectives of climate change and human interventions. American Journal of Climate Change 2(1): 9.

Morton K (2011) Climate change and security at the third pole. Survival 53(1): 121-132. https://doi.org/10.1080/00396338.2011.555606

MPO (1986) Chapter 7: Salinity. National water plan, Master Plan Organisation, 1: 7-33.

Mueller-Dombois D, Ellenberg H (1974) Aims and methods of vegetation ecology. New York, NY Wiley.

Naidoo G (1990) Effects of nitrate, ammonium and salinity on growth of the mangrove Bruguiera gymnorrhiza (L.) Lam. Aquatic Botany 38(2-3): 209-219. 
doi: https://doi.org/10.1016/0304-3770(90)90006-7

Nandy P, Ahammad R, Alam M, Islam A (2013) Coastal ecosystem based adaptation: Bangladesh experience. In Climate Change Adaptation Actions in Bangladesh 277303. Springer Japan.

Nandy P, Das S, Ghose M, Spooner-Hart R (2007) Effects of salinity on photosynthesis, leaf anatomy, ion accumulation and photosynthetic nitrogen use efficiency in five Indian mangroves. Wetlands Ecology and Management 15(4): 347-357.

doi: https://doi.org/10.1007/s11273-007-9036-8

NAPA (2009) National Adaptation Programme of Action. Ministry of Environment and Forest. Government of the People's Republic of Bangladesh. Updated version of 2005: 63.

Nazrul-Islam AKM (2003) Mangrove forest ecology of Sundarban: the study of change in water, soil and plant diversity. In: Sustainable Environment: a statistical analysis. AK Ghosh, JK Ghosh and MK Mukhopadhaya (Eds), pp. 126-147. Oxford Univ. Press, New Delhi, 197 pp.

Neumann-Denzau G, Denzau H (2010) Examining certain aspects of human-tiger conflict in the Sundarbans forest, Bangladesh. Tiger papers 37: 1-11.

Nicholls RJ, Gazenave A (2010) Sea-level rise and its impact on coastal zones. Science 328(5985): 1517-1520. DOI: 10.1126/science.1185782

Nicholls RJ, Wong PP, Burkett VR, Codignotto JO, Hay JE, McLean RF, Ragoonaden S, Woodroffe CD (2007) Coastal systems and low-lying areas. Climate Change 2007: Impacts, Adaptation and Vulnerability. Contribution of Working Group II to the Fourth Assessment Report of the Intergovernmental Panel on Climate Change M L Parry, O F Canziani, J P Palutikof, P J van der Linden, C E Hanson (Eds.) Cambridge University Press, Cambridge, UK pp. 315-356.

Nowreen S, Jalal MR, Khan MSA (2014) Historical analysis of rationalizing South West coastal polders of Bangladesh. Water Policy 16(2): 264-279. doi: 10.2166/wp.2013.172

Parry ML (2007) Climate Change 2007: Impacts, Adaptation and Vulnerability. Contribution of Working Group II to the Fourth Assessment Report of the Intergovernmental Panel on Climate Change. Cambridge University Press, Cambridge, UK.

Passeri DL, Hagen SC, Medeiros SC, Bilskie MV, Alizad K, Wang D (2015) The dynamic effects of sea-level rise on low-gradient coastal landscapes: A review. Earth's Future 3(6): 159-181. doi:10.1002/2015EF000298 
Paul A, Nath B, Abbas MR (2013) Tidal River Management (TRM) and its implication in disaster management: A geospatial study on Hari-Teka river basin, Jessore, Bangladesh. International Journal of Geomatics and Geosciences 4(1): 125.

Paulhus DL, Vazire S (2007) The self-report method. Handbook of research methods in personality psychology 1: 224-239.

Penning-Rowsell EC, Sultana P, Thompson PM (2013) The 'last resort'? Population movement in response to climate-related hazards in Bangladesh. Environmental science \& policy 27: S44-S59. Doi: https://doi.org/10.1016/j.envsci.2012.03.009

Pethick J, Orford JD (2013) Rapid rise in effective sea-level in southwest Bangladesh: Its causes and contemporary rates. Global and Planetary Change 111:237-245. doi:10.1016/j.gloplacha.2013.09.019

Phi LH (2011) Climate change adaptation in European water sector - A framework for adaptation measures assessment. Internship report, Centre for Water and Climate, Alterra, Wageningen UR.

Pinto R, de Jonge VN, Neto JM, Domingos T, Marques JC, Patrício J (2013) Towards a DPSIR driven integration of ecological value, water uses and ecosystem services for estuarine systems. Ocean and Coastal Management 72: 64-79.

Doi: https://doi.org/10.1016/j.ocecoaman.2011.06.016

Pirrone N, Trombino G, Cinnirella S, Algieri A, Bendoricchio G, Palmeri L (2005) The Driver-Pressure-State-Impact-Response (DPSIR) approach for integrated catchmentcoastal zone management: preliminary application to the Po catchment-Adriatic Sea coastal zone system. Regional Environmental Change 5(2-3): 111-137. doi: https://doi.org/10.1007/s10113-004-0092-9

Rabbani G, Rahman SH, Faulkner L (2013) Impacts of climatic hazards on the small wetland ecosystems (ponds): evidence from some selected areas of coastal Bangladesh. Sustainability 5(4): 1510-1521. doi:10.3390/su5041510

Rahman AF, Dragoni D, El-Masri B (2011) Response of the Sundarbans coastline to sea level rise and decreased sediment flow: A remote sensing assessment. Remote Sensing of Environment 115(12): 3121-3128. doi: https://doi.org/10.1016/j.rse.2011.06.019

Rahman M, Ferdousi N, Sato Y, Kusunoki S, Kitoh A (2012a) Rainfall and temperature scenario for Bangladesh using $20 \mathrm{~km}$ mesh AGCM. International Journal of Climate Change Strategies and Management 4(1): 66-80. doi:10.1108/17568691211200227

Rahman MA (1995) Mangrove plant pathology of the Sundarbans reserved forest in Bangladesh, field document No.3 of FAO/UNDP Project BGD/84/056-Integrated 
Resources Development of the Sundarbans Reserved Forest, Khulna, Bangladesh, $83 p p$.

Rahman MA (1998) Diseases and wood decay of tree species with particular reference to top dying of Sundri and the magnitude of its damage in the Sundarbans in Bangladesh. In: Rahman, M.A., Shah, M.S., Murtaza, G.M., Matin, M.A. (Eds.), Proceedings of the national seminar on integrated management of Ganges flood plains and Sundarbans ecosystem, 16-18 July, 1994, Khulna University, Khulna, Bangladesh, pp. 50- 76.

Rahman MA, Rahman S (2015) Natural and traditional defense mechanisms to reduce climate risks in coastal zones of Bangladesh. Weather and Climate Extremes 7: 84-95. doi:10.1016/j.wace.2014.12.004

Rahman MM, Islam MN, Ahmed AU, Georgi F (2012) Rainfall and temperature scenarios for Bangladesh for the middle of 21 st century using RegCM. Journal of earth system science 121(2): 287-295. doi:10.1007/s12040-012-0159-9

Rahman MM, Hassan MQ, Islam MS, Shamsad SZKM (2000) Environmental impact assessment on water quality deterioration caused by the decreased Ganges outflow and saline water intrusion in south-western Bangladesh. Environmental Geology 40(1-2): 31-40. doi: https://doi.org/10.1007/s002540000152

Rahman MR, Asaduzzaman M (2010) Ecology of Sundarbans, Bangladesh. Journal of Science Foundation 8(1-2): 35-47.

Rasel HM, Hasan MR, Ahmed B, Miah MSU (2013) Investigation of soil and water salinity, its effect on crop production and adaptation strategy. International Journal of Water Resources and Environmental Engineering 5(8): 475-481.

Rashid HE (1991) "Geography of Bangladesh" (Second Revised Edition), The University Press Ltd. Dhaka, Bangladesh.

Rasingam L, Parthasarathy N (2009) Diversity of understory plants in undisturbed and disturbed tropical lowland forests of Little Andaman Island, India. Biodiversity Conservation 18: 1045-1065. doi:10.1007/s10531-008-9496-Z

Reddy CS (2008) Field identification guide for Indian mangroves. University of Chicago, $100 \mathrm{pp}$.

Reeder T, Ranger N (2011) How do you adapt in an uncertain world?: lessons from the Thames Estuary 2100 project.

Renaud FG, Le TTH, Lindener C, Guong VT, Sebesvari Z (2015) Resilience and shifts in agro-ecosystems facing increasing sea-level rise and salinity intrusion in Ben Tre Province, Mekong Delta. Climatic Change 133(1): 69-84. 
doi: https://doi.org/10.1007/s10584-014-1113-4

Reza AHMA, Feeroz MM, Islam MA (2001) Habitat preference of the Bengal tiger, Panthera tigris tigris in the Sundarbans of Bangladesh. Bangladesh Journal of Life Science 13: 215-217.

Reza AHMA, Feeroz MM, Islam MA (2002) Prey species density of Bengal tiger in the Sundarbans. Journal of Asiatic Society Bangladesh, Science 28: 35-42.

Runkel M, Ahmad IU (1997) Sundarbans reserved forests, area, distribution and status of forest types from 1985-1995. GoB/BD, 21pp.

Salter RE (1984) Integrated development of the Sundarbans, Bangladesh: status and utilization of wildlife. FO: TCP/BGD/2309(MF). Report No. W/R0034. FAO, Rome. $59 \mathrm{pp}$.

Sanyal P (1999) Sundarbans-the largest mangrove diversity on globe. Sundarbans Mangal. Naya Prokash, Calcutta, pp 428-448.

Sarker SK, Reeve R, Thompson J, Paul NK, Matthiopoulos J (2016) Are we failing to protect threatened mangroves in the Sundarbans world heritage ecosystem?. Scientific reports 6. doi: $\underline{10.1038 / \text { srep21234 }}$

Shahid S (2011) Trends in extreme rainfall events of Bangladesh. Theoretical and applied climatology 104(3-4): 489-499. doi:10.1007/s00704-010-0363-y

Shampa MIMP, Paramanik M (2012) Tidal river management (TRM) for selected coastal area of Bangladesh to mitigate drainage congestion. International Journal of scientific and Technology Research 1.

Shannon CE, Weaver W (1949) The mathematical theory of communication. University of Illinois Press, Urbana, IL, 117pp.

Shaw R, Mallick F, Islam A (Eds.) (2013) Climate change adaptation actions in Bangladesh. Tokyo, Springer.

Shukla RS, Chandal PS (1993) Plant Ecology. S. Chand and Company Ltd.

Siddiqi NA (2001) Mangrove forestry in Bangladesh. Institute of Forestry and Environmental Sciences, University of Chittagong, pp 201.

Siddiqi NA, Choudhury JH (1987) Man-eating behaviour of tigers of the Sundarbans: Twenty-eight years' record analysis. Tiger paper 14(3): 26-32.

Simpson EH (1949) Measurement of diversity. Nature 163:668. doi:10.1038/163688a0

Singh OP (2001) Cause-effect relationships between sea surface temperature, precipitation and sea-level along the Bangladesh coast. Theoretical and Applied Climatology 68(34): 233-243. doi:10.1007/s007040170048. 
Singh OP, Khan ATM, Murty TS, Rahman MS (2010) Sea-level changes along Bangladesh coast in relation to the southern oscillation phenomenon. Marine Geodesy 24(1): 6572. doi: $10.1080 / 01490410120192$.

Slik JF, Arroyo-Rodríguez V, Aiba SI, Alvarez-Loayza P, Alves LF, Ashton P, Balvanera P, Bastian ML, Bellingham PJ, Van Den Berg E, Bernacci L (2015) An estimate of the number of tropical tree species. Proceedings of the National Academy of Sciences 112(24): 7472-7.

Smeets E, Weterings R (1999) Environmental indicators: Typology and overview 19. Copenhagen: European Environment Agency.

Smith BD, Braulik G, Strindberg S, Mansur R, Diyan MAA, Ahmed B (2009) Habitat selection of freshwater-dependent cetaceans and the potential effects of declining freshwater flows and sea-level rise in waterways of the Sundarbans mangrove forest, Bangladesh. Aquatic Conservation: Marine and Freshwater Ecosystems 19(2): 209225. doi:10.1002/aqc. 987

Smith JLD, Ahern SC, McDougal C (1998) Landscape analysis of tiger distribution and habitat quality in Nepal. Conservation Biology 12(6): 1338-1346. doi: 10.1111/j.15231739.1998.97068.x

Spencer T, Schuerch M, Nicholls RJ, Hinkel J, Lincke D, Vafeidis AT, Reef R, McFadden L, Brown S (2016) Global coastal wetland change under sea-level rise and related stresses: the DIVA Wetland Change Model. Global and Planetary Change 139: 15-30. doi:10.1016/j.gloplacha.2015.12.018.

SRDI (2010) Saline soils of Bangladesh. Soil Resource Development Institute (SRDI), Ministry of Agriculture, Government of Bangladesh.

Sunquist ME, Sunquist FC (2002) Wild Cats of the World. University of Chicago Press, Chicago, USA.

Swapan MSH, Gavin M (2011) A desert in the delta: participatory assessment of changing livelihoods induced by commercial shrimp farming in Southwest Bangladesh. Ocean \& Coastal Management 54(1): 45-54.

doi:https://doi.org/10.1016/j.ocecoaman.2010.10.011

Tamang KM (1993) Wildlife management plan for the Sundarbans reserved forest. Integrated Resource Development of the Sundarbans Reserved Forest, Bangladesh, Vol. 1, UNDP/FAO project no. BGD/84/056. 113pp. 
Tanaka AK, Takahashi Y, Masutomi N, Hanasaki Y, Hijioka H, Shiogama, Yamanaka Y (2015) Adaptation pathways of global wheat production: Importance of strategic adaptation to climate change. Scientific reports 5. doi: 10.1038/srep14312

Tomlinson PB (1986) Botany of Mangroves. Cambridge University Press, New York.

Trenberth KE (2011) Changes in precipitation with climate change. Climate Research 47(1): 123. doi: $10.3354 / \mathrm{cr} 00953$.

Troup RS (1921) The Silviculture of Indian Trees-Volume 1. Clarendon Press, Oxford:153544.

Twilley RR, Chen R (1998) A water budget and hydrology model of a basin mangrove forest in Rookery Bay, Florida. Marine and Freshwater Research 49: 309-323. doi: $\underline{10.1071 / M F 97220}$

Valiela I, Bowen JL, York JK (2001) Mangrove Forests: One of the World's Threatened Major Tropical Environments. Bioscience 51(10): 807-815.

Doi: https://doi.org/10.1641/0006-3568(2001)051[0807:MFOOTW]2.0.CO;2

Vo QT (2013) Valuation of Mangrove Ecosystems along the Coast of the Mekong Delta in Vietnam an approach combining socio-economic and remote sensing methods (Doctoral dissertation), Christian-Albrechts Universität Kiel.

Wahid SM, Babel MS, Bhuiyan AR (2007) Hydrologic monitoring and analysis in the Sundarbans mangrove ecosystem, Bangladesh. Journal of Hydrology 332: 381-395. doi:10.1016/j.jhydrol.2006.07.016

Walsham G (2006) Doing interpretive research. European journal of information systems 15(3): 320-330. doi: https://doi.org/10.1057/palgrave.ejis.3000589

Walston J, Robinson JG, Bennett EL, Breitenmoser U, da Fonseca GA, Goodrich J, Gumal M, Hunter L, Johnson A, Karanth KU, Leader-Williams N (2010) Bringing the tiger back from the brink - the six percent solution. PLoS Biology 8(9): e1000485. doi: https://doi.org/10.1371/journal.pbio.1000485

Walther GR, Post E, Convey P, Menzel A, Parmesan C, Beebee TJ, Fromentin JM, HoeghGuldberg O, Bairlein F (2002) Ecological responses to recent climate change. Nature 416(6879): 389-395. doi:10.1038/416389a.

WARPO (2001) National Water Management Plan (NWMP), Volume 2: Main Report, Water Resources Planning Organization (WARPO), Ministry of Water Resources, Dhaka.

Wells S, Ravilious C, Corcoran E (2006) In the front line: shoreline protection and other ecosystem services from mangroves and coral reefs (No. 24). UNEP/Earthprint. 
Whittaker RH (1976) Evolution and measurement of species diversity. Taxon 21: 231-51. doi: $10.2307 / 1218190$

Wikramanayake ED (1999) Where can tigers live in the future? A framework for identifying high-priority areas for the conservation of tigers in the wild. Riding the tiger: tiger conservation in human dominated landscapes. Cambridge University Press, Cambridge: $255-272$.

Wikramanayake E, Dinerstein E, Seidensticker J, Lumpkin S, Pandav B, Shrestha M, Mishra H, Ballou J, Johnsingh AJT, Chestin I, Sunarto S (2011) A landscape-based conservation strategy to double the wild tiger population. Conservation Letters 4(3): 219-227. doi: 10.1111/j.1755-263X.2010.00162.x

Wise RM, Fazey I, Smith MS, Park SE, Eakin HC, Van Garderen EA, Campbell B (2014) Reconceptualising adaptation to climate change as part of pathways of change and response. Global Environmental Change 28: 325-336.

doi: https://doi.org/10.1016/..gloenvcha.2013.12.002

Wong PP, Losada IJ, Gattuso JP, Hinkel J, Khattabi A, McInnes KL, Saito Y, Sallenger A (2014) Coastal systems and low-lying areas. Climate change 361-409.

World Bank (2014) River Salinity and Climate Change: Evidence from Coastal Bangladesh. Policy Research Working Paper 6817: 42 pp.

WWF (2010) Climate Change Threatens to Wipe Out One of World's Largest Tiger Populations this Century. WASHINGTON, DC.

Zaman AM, Molla MK, Pervin IA, Rahman SM, Haider AS, Ludwig F, Franssen W (2016) Impacts on river systems under $2^{\circ} \mathrm{C}$ warming: Bangladesh Case Study. Climate Services. doi:10.1016/j.cliser.2016.10.002

Zhang X, Alexander L, Hegerl GC, Jones P, Tank AK, Peterson TC, Trewin B, Zwiers FW (2011) Indices for monitoring changes in extremes based on daily temperature and precipitation data. Wiley Interdisciplinary Reviews: Climate Change 2(6): 851-870. doi:10.1002/wcc.147. 


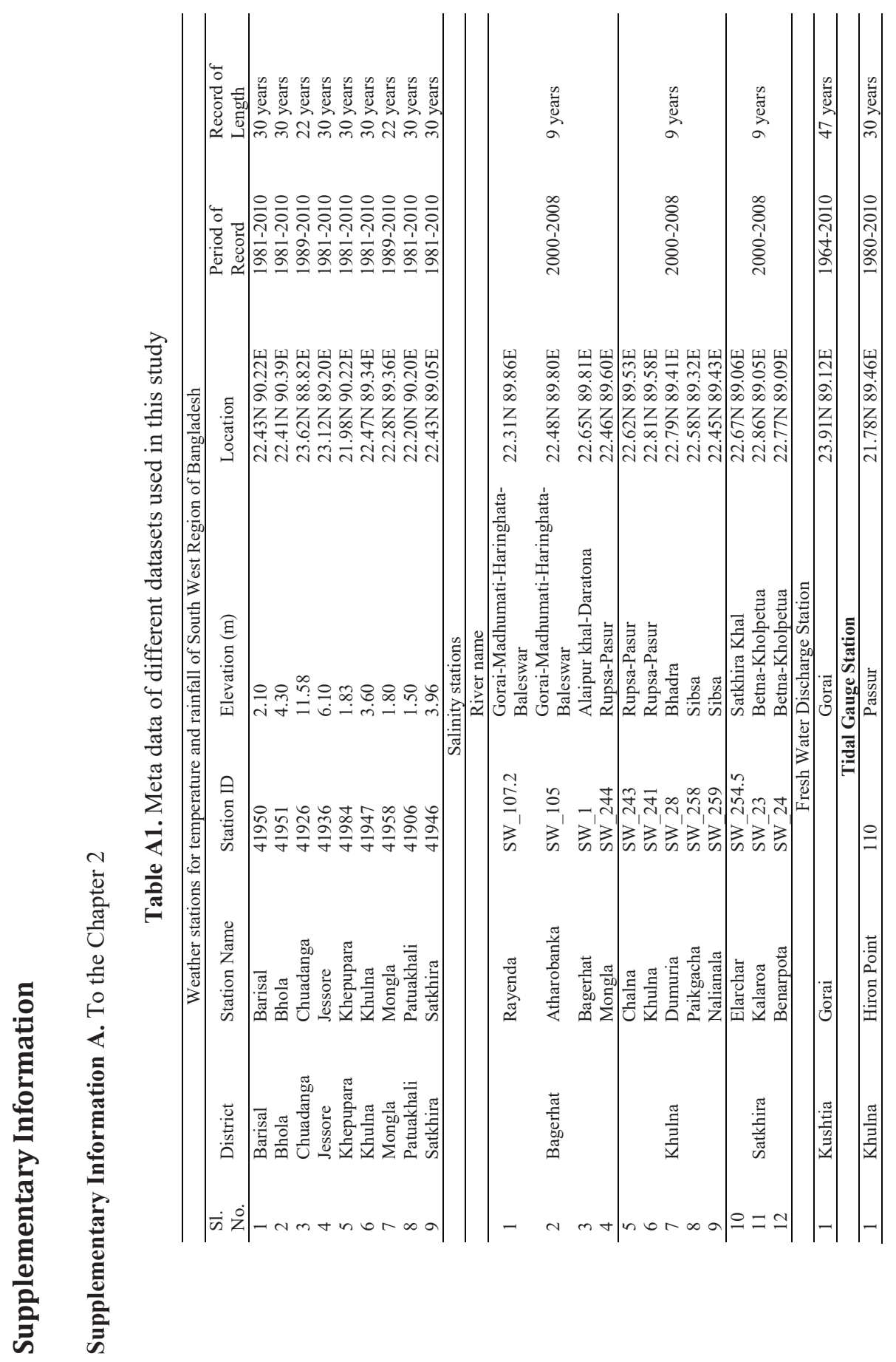


Table A2. Likelihood terminology used in this study based on Probability

\begin{tabular}{lll}
\hline Likelihood & Probability (\%) & P value \\
\hline Virtually certain & $>99$ & $\leq 0.01$ \\
Extremely likely & $>95$ & $\leq 0.05$ \\
Very likely & $>90$ & $\leq 0.1$ \\
Likely & $>66$ & $\leq 0.34$ \\
More likely than not & $>50$ & $<0.5$ \\
About as likely as not & 33 to 50 & 0.67 to 0.5 \\
Unlikely & $<33$ & $>0.67$ \\
Very unlikely & $<10$ & $\geq 0.9$ \\
Extremely unlikely & $<5$ & $\geq 0.95$ \\
Exceptionally unlikely & $<1$ & $\geq 0.99$ \\
\hline
\end{tabular}

Adopted from Houghton 1996, McCarthy 2001 and Solomon 2007

Table A3. Correlation Status based on Correlation Co-efficient

\begin{tabular}{ll}
\hline Correlation Status & Correlation Co-efficient (r) \\
\hline No correlation & $\leq 0.19$ \\
Low correlation & $0.20-0.39$ \\
Moderate correlation & $0.40-0.59$ \\
Moderately high correlation & $0.60-0.79$ \\
High Correlation & $\geq 0.80$ \\
\hline
\end{tabular}

Adopted from Zhu 2016 


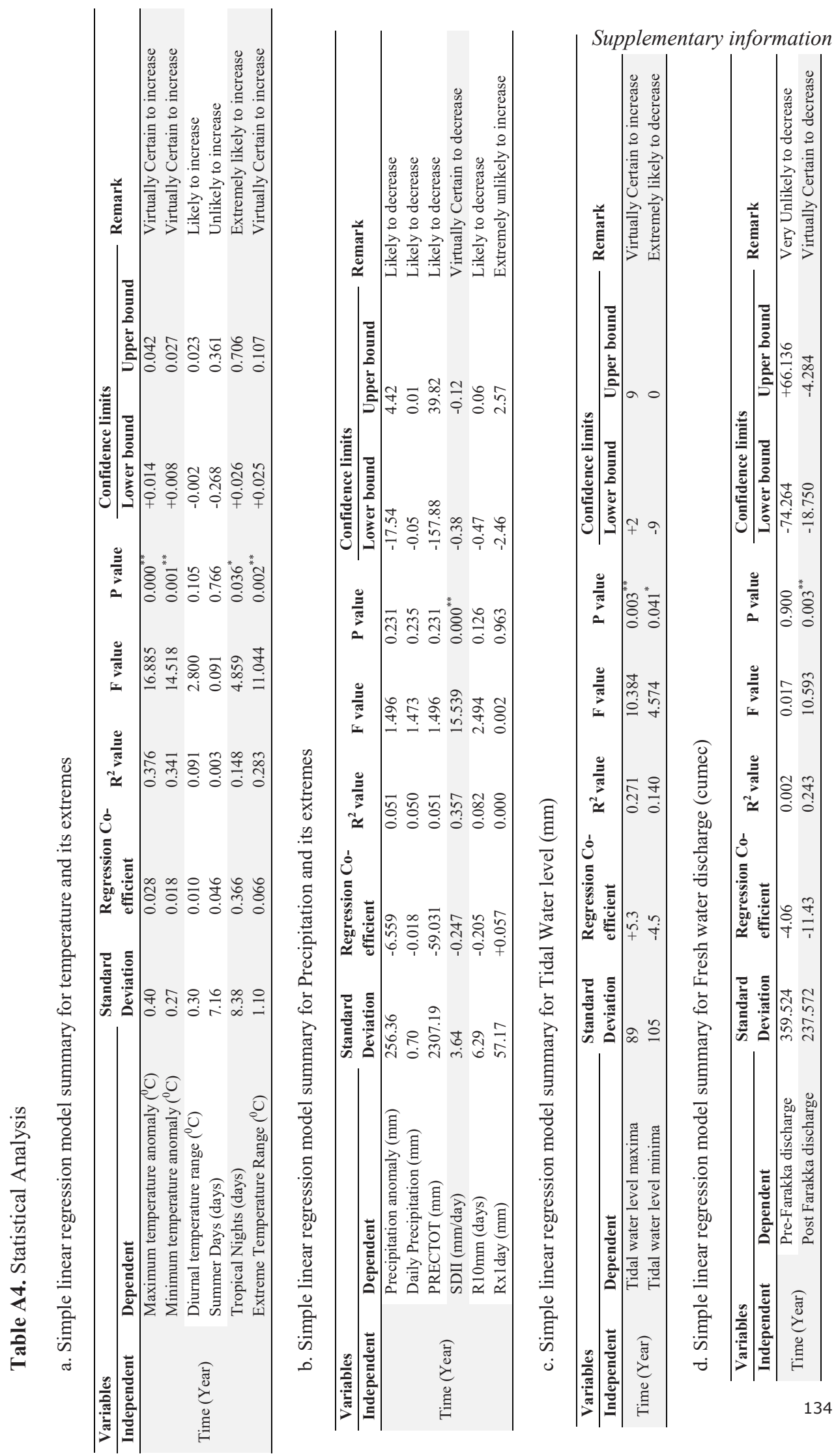




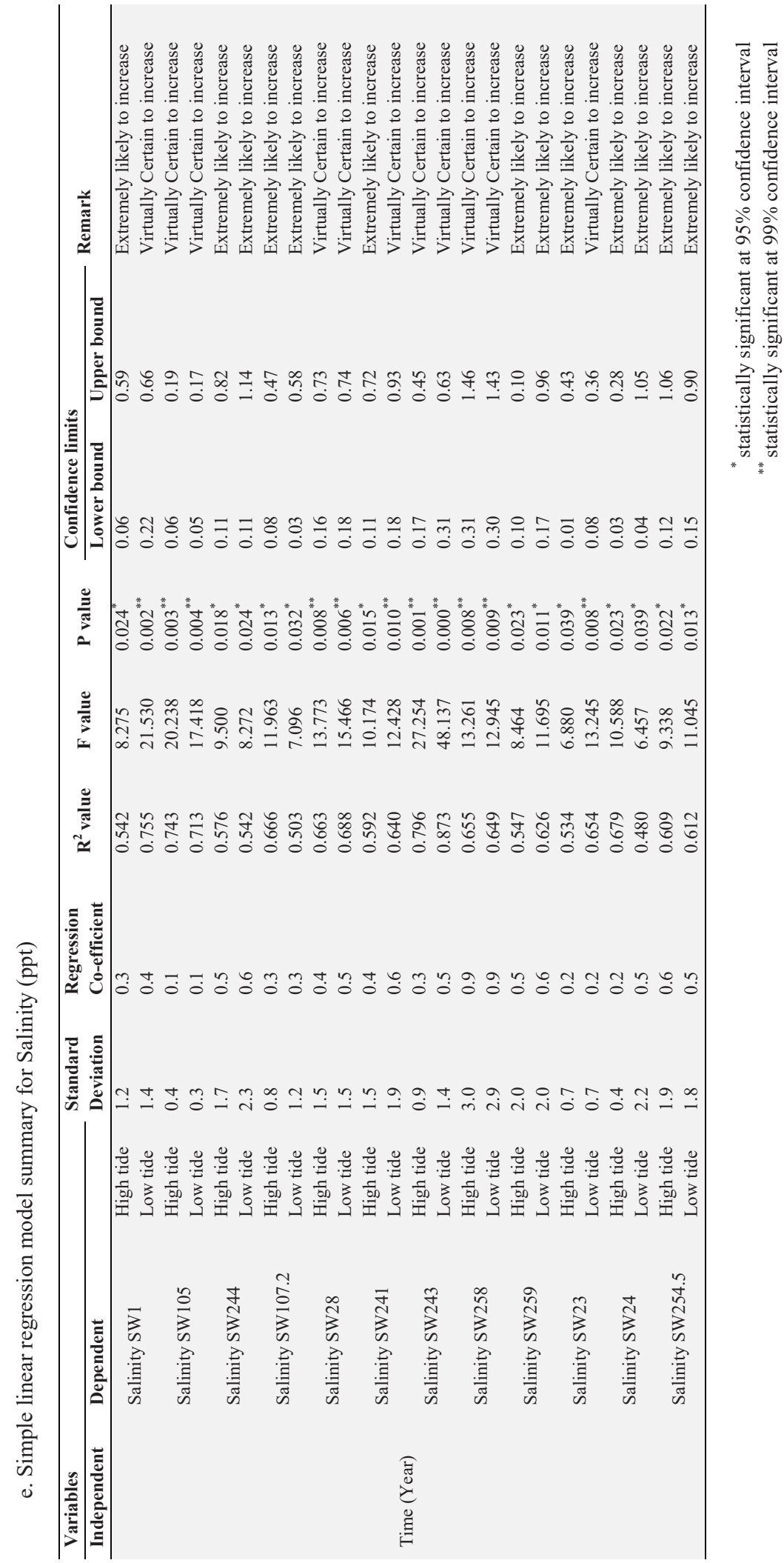




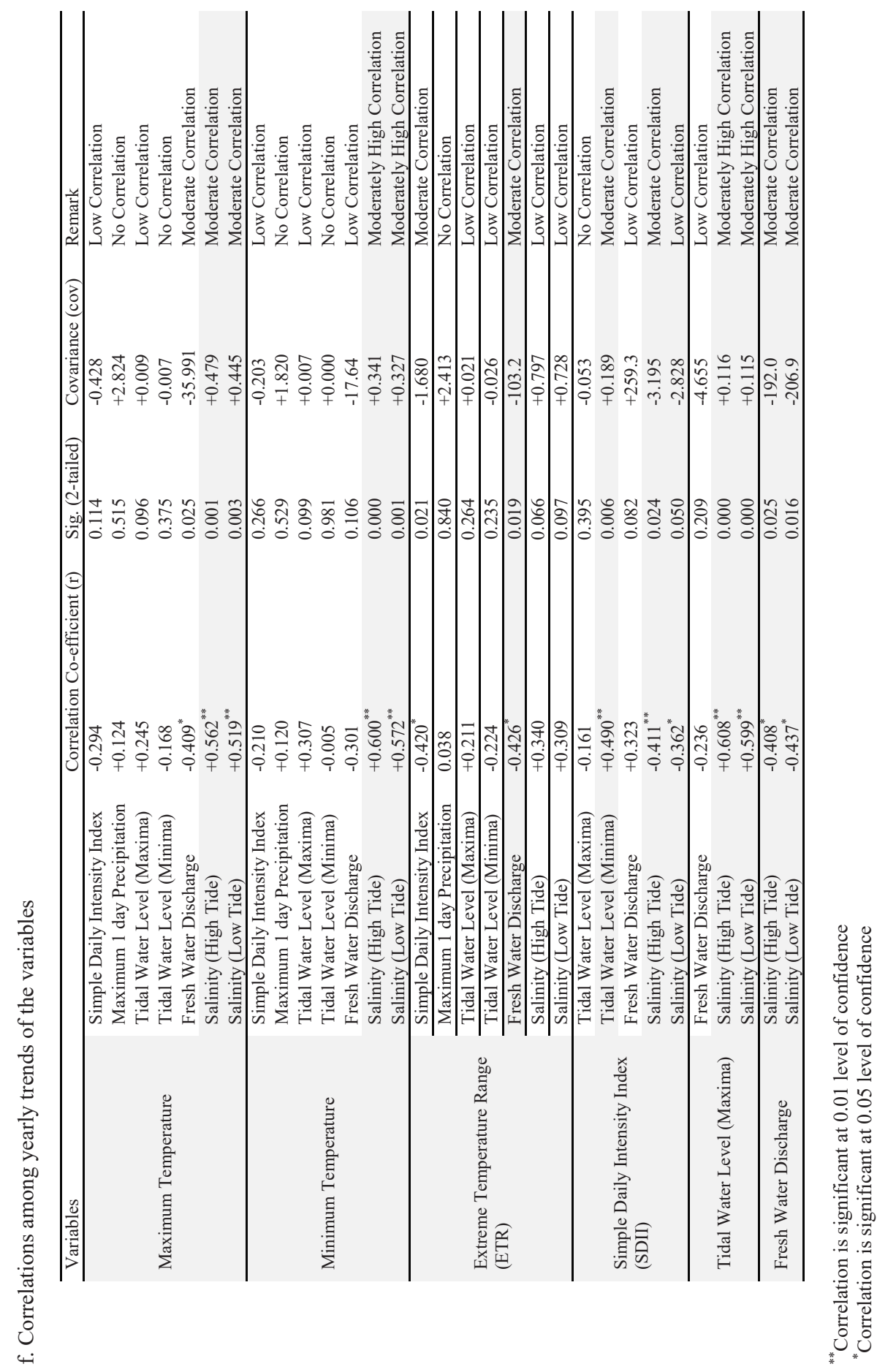




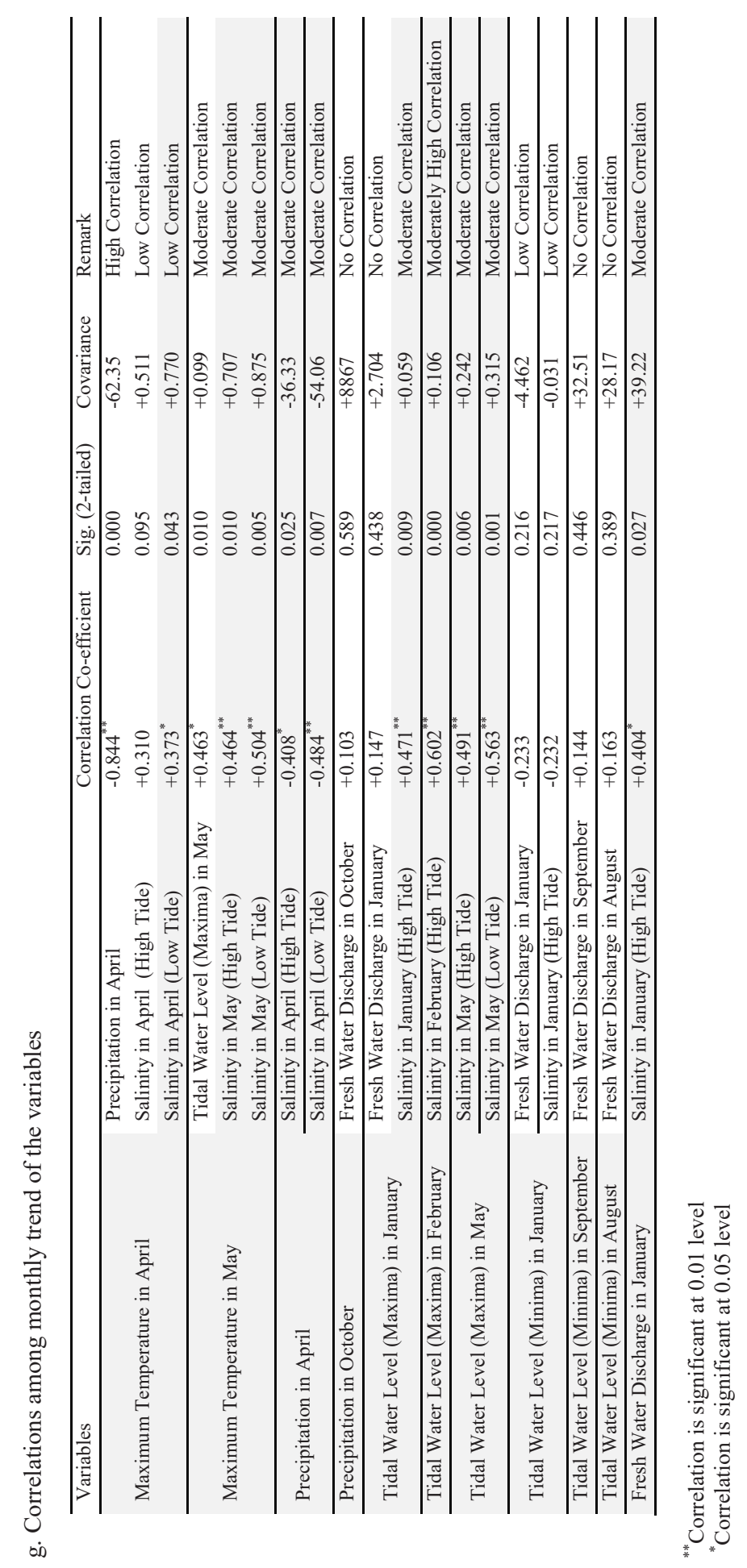


Table A5. Effective SLR at Hiron Point in South-West Coast of Bangladesh

\begin{tabular}{|c|c|c|c|c|c|c|c|}
\hline & & & & Trend (m & & & \\
\hline $\begin{array}{l}\text { Mean } \\
\text { TWL_Max } \\
\text { (Observed) }\end{array}$ & $\begin{array}{l}\text { Mean } \\
\text { TWL_Min } \\
\text { (Observed) }\end{array}$ & $\begin{array}{l}\text { Tidal } \\
\text { Range } \\
(\mathrm{TR})\end{array}$ & $\begin{array}{l}\text { Tidal } \\
\text { Amplitude } \\
\text { (TA) }\end{array}$ & $\begin{array}{l}\text { Eustatic sea- } \\
\text { level (Eu) }\end{array}$ & $\begin{array}{l}\text { Subsidence } \\
(\mathrm{Sb})\end{array}$ & $\begin{array}{l}\text { Fresh Water } \\
\text { Flow (FwQ) }\end{array}$ & $\begin{array}{l}\text { Effective } \\
\text { SLR } \\
\text { (Predicted) }\end{array}$ \\
\hline+5.3 & -4.5 & +9.8 & +4.9 & $+2^{*}$ & $+5^{*}$ & $0^{*}$ & +11.9 \\
\hline
\end{tabular}

TR $=$ TWL_Max - TWL_Min

$\mathrm{TA}=1 / 2$ of TR

$\mathrm{Eu}=2 ; \mathrm{Sb}=5 ; \mathrm{FwQ}=0 *($ Adopted from Pethick and Orford 2013)

Effective SLR $=\mathrm{TA}+\mathrm{Eu}+\mathrm{Sb}+\mathrm{FwQ}$ 
Supplementary Information B. To the Chapter 3

Table B1. Correlation of salinity from north to south

\begin{tabular}{lll}
\hline Variables & Pearson Correlation & Sig. (2-tailed) \\
\hline Salinity and Distance along Transect 1 & $0.886^{* *}$ & .000 \\
Salinity and Distance along Transect 2 & $0.943^{* *}$ & .000 \\
Salinity and Distance along Transect 3 & $0.929^{* *}$ & .000 \\
\hline & & \multirow{2}{*}{ Correlation is significant at the 0.01 level }
\end{tabular}

Table B2. Correlation of salinity from east to west

\begin{tabular}{lll}
\hline Variables & Pearson Correlation & Sig. (2-tailed) \\
\hline Salinity along Transect 1 and 2 & $0.895^{* * *}$ & .000 \\
Salinity along Transect 2 and 3 & $0.844^{* *}$ & .000 \\
Salinity along Transect 3 and 1 & $0.930^{* *}$ & .000 \\
\hline
\end{tabular}

${ }^{* * *}$ Correlation is significant at the 0.01 level 
Supplementary Information C. To the Chapter 5

Table C1. Multi-criteria analysis of the potential measures recommended by the household level respondents to address the perceived causes of salinity increase

\begin{tabular}{|c|c|c|c|c|c|c|c|}
\hline \multirow{2}{*}{$\begin{array}{l}\text { Sl. } \\
\text { No. }\end{array}$} & \multirow[b]{2}{*}{ Potential measures } & \multicolumn{5}{|l|}{ Criteria $^{*}$} & \multirow[b]{2}{*}{ Score } \\
\hline & & Effectiveness & $\begin{array}{l}\text { Side } \\
\text { effects }\end{array}$ & Cost & Feasibility & Uncertainty & \\
\hline 1 & Limit shrimp farming practice & +++ & +++ & +++ & + & + & 11 \\
\hline 2 & $\begin{array}{l}\text { Local government's initiative to prevent on } \\
\text { purpose ingression of salt water }\end{array}$ & +++ & +++ & +++ & ++ & + & 12 \\
\hline 3 & $\begin{array}{l}\text { Outlaw building unnecessary dams on the } \\
\text { rivers }\end{array}$ & ++ & +++ & +++ & ++ & + & 11 \\
\hline 4 & $\begin{array}{l}\text { Operational sluice gates of the existing } \\
\text { polders }\end{array}$ & ++ & +++ & - & ++ & + & 7 \\
\hline 5 & (Re)-Excavation of the silted rivers & +++ & +++ & -- & +++ & - & 6 \\
\hline 6 & Riverbank protection & +++ & +++ & --- & +++ & - & 5 \\
\hline 7 & $\begin{array}{l}\text { Government initiative to change the leasing } \\
\text { system and the use of Khash lands }\end{array}$ & ++ & +++ & +++ & + & + & 10 \\
\hline
\end{tabular}

*For description with score card for the selected criteria please see Table 1 
Table C2. Multi-criteria analysis of potential set of measures recommended by the key informants to address the observed causes of salinity increase

\begin{tabular}{|c|c|c|c|c|c|c|c|c|}
\hline \multirow{2}{*}{$\begin{array}{l}\text { Sl. } \\
\text { No. }\end{array}$} & \multirow{2}{*}{\multicolumn{2}{|c|}{ Potential measures }} & \multicolumn{5}{|l|}{ Criteria $^{*}$} & \multirow[b]{2}{*}{ Score } \\
\hline & & & Effectiveness & $\begin{array}{l}\text { Side } \\
\text { effects }\end{array}$ & Cost & Feasibility & Uncertainty & \\
\hline 1. & \multirow{6}{*}{$\begin{array}{l}\text { Short } \\
\text { term }\end{array}$} & Planned shrimp farming practice & +++ & +++ & +++ & ++ & +++ & 14 \\
\hline 2. & & $\begin{array}{l}\text { Functional management of the } \\
\text { existing polders }\end{array}$ & +++ & +++ & - & ++ & - & 6 \\
\hline 4. & & Periodic/scheduled (re)-excavation & +++ & +++ & -- & ++ & - & 5 \\
\hline 5. & & $\begin{array}{l}\text { Strengthen and heighten the existing } \\
\text { embankments }\end{array}$ & ++ & ++ & - & + & - & \\
\hline 6. & & $\begin{array}{l}\text { Reduce dependency on ground water } \\
\text { extraction for upstream irrigation }\end{array}$ & + & +++ & - & + & -- & 2 \\
\hline 7. & & $\begin{array}{l}\text { To be active in transboundary } \\
\text { negotiation process on water sharing }\end{array}$ & + & +++ & + & + & --- & 3 \\
\hline 8. & \multirow{6}{*}{$\begin{array}{l}\text { Mid- } \\
\text { term }\end{array}$} & Designing land management practice & ++ & ++++ & - & ++ & - & 5 \\
\hline 9 & & $\begin{array}{l}\text { Planned infrastructural development } \\
\text { in water resource management }\end{array}$ & +++ & +++ & --- & +++ & - & 5 \\
\hline 10. & & $\begin{array}{l}\text { TRM along with sediment } \\
\text { management practice }\end{array}$ & +++ & +++ & +++ & ++ & +++ & 14 \\
\hline 11. & & $\begin{array}{l}\text { Administrative unit wise assessment } \\
\text { on demand of water for different } \\
\text { category enforcement of Water Act } \\
2013 \text { on priority basis; }\end{array}$ & ++ & +++ & - & ++ & - & 5 \\
\hline 12. & & $\begin{array}{l}\text { Develop upstream water } \\
\text { management strategy for dry season }\end{array}$ & + & +++ & - & + & - & 3 \\
\hline 13. & & $\begin{array}{l}\text { Enforcement of Water Act } 2013 \text { on } \\
\text { priority basis }\end{array}$ & ++ & +++ & -- & + & + & 5 \\
\hline 14. & \multirow{6}{*}{$\begin{array}{l}\text { Long } \\
\text { term }\end{array}$} & Land use zoning & +++ & ++++ & + & +++ & + & 11 \\
\hline 15. & & $\begin{array}{l}\text { Integrated management of different } \\
\text { systems }\end{array}$ & ++ & ++ & -- & ++ & - & 3 \\
\hline 16. & & $\begin{array}{l}\text { Continuous monitoring on river flow } \\
\text { and sedimentation rate }\end{array}$ & +++ & +++ & --- & +++ & - & 5 \\
\hline 17. & & $\begin{array}{l}\text { Delta plan/Integrated long term plan } \\
\text { for the coast }\end{array}$ & +++ & +++ & -- & +++ & + & 8 \\
\hline 18. & & Water budget and allocation plan & ++ & +++ & -- & ++ & + & 6 \\
\hline 19. & & Ganges barrage & +++ & +++ & --- & +++ & + & 7 \\
\hline
\end{tabular}

*For description with score card for the selected criteria please see Table 1 
Supplementary information

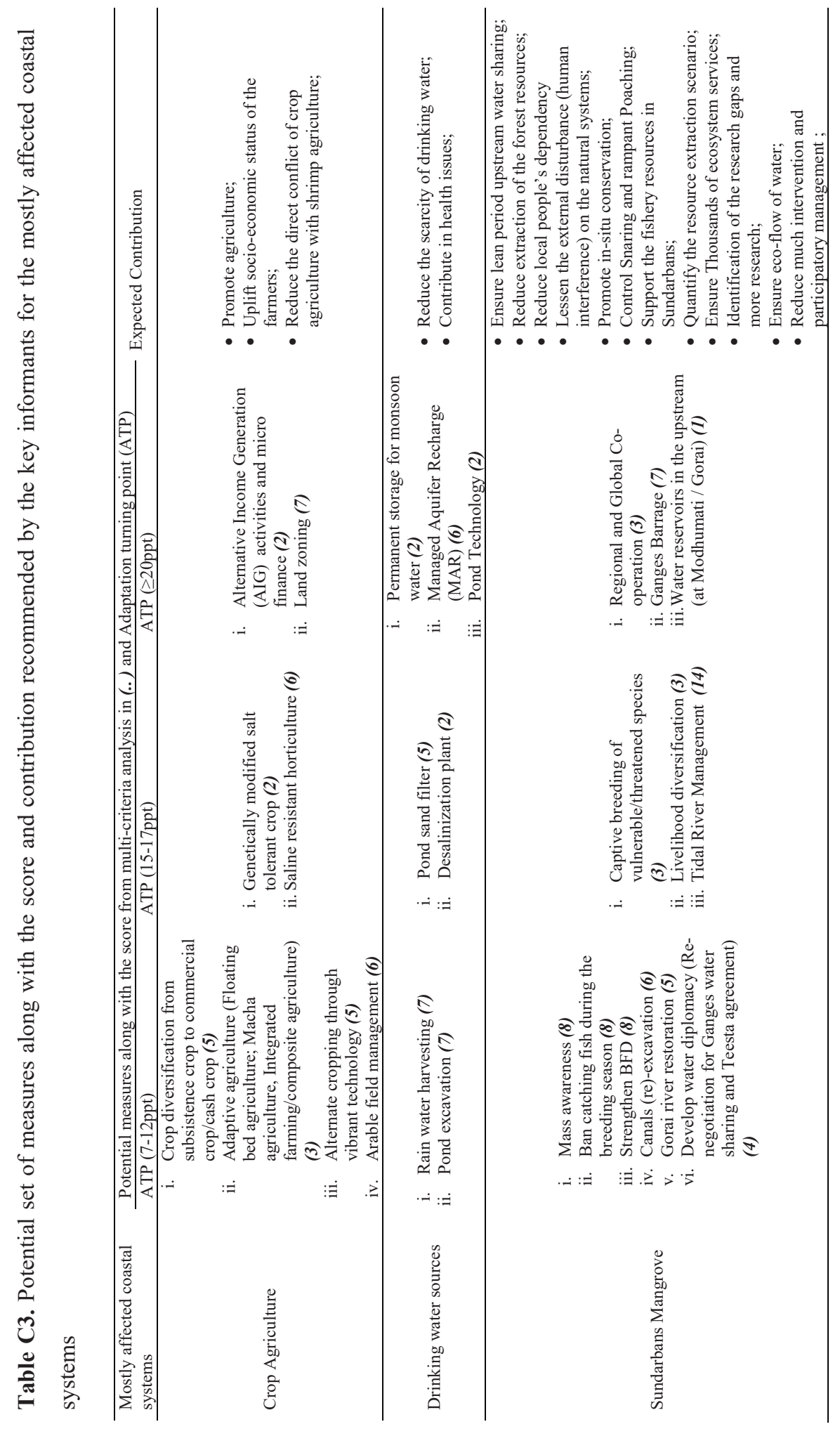




\section{Summary}

The Sundarbans mangrove ecosystems of Bangladesh's south-west coastal region, which together are signified as globally significant UNESCO world heritage site and Ramsar wetlands, simultaneously provide essential social, economic and ecosystem services for the region, contribute to the national GDP and hold outstanding universal value. However, these ecosystems are extremely vulnerable to climate change and its impacts mostly due to the region's environmental setting. This region is exposed to the Bay of Bengal and also connects the upstream and downstream Ganges basin. Therefore, climate change, sea-level rise and dry season low fresh water influx from upstream rivers result large increase in salinity of this region. This salinization has enormous impacts on the region's unique mangrove ecosystems, wetland resources and inland socio-economic activities. Moreover, this salinization leads to extreme drinking water scarcity for millions of people in the region. The resulting lack of drinking water sources, changes in land quality for food production and declining mangrove resources affect adjacent coastal communities life and livelihood. In consequence, people are looking for potential measures to adapt. Hence, assessing the impacts of salinization on different coastal systems for target oriented adaptation planning is now imperative.

My $\mathrm{PhD}$ thesis, therefore, aims to evaluate the impacts of salinity increase on the Sundarbans mangrove ecosystems at different scales (i.e., mangrove vegetation and Royal Bengal Tiger habitat) and on the adjacent coastal communities for identifying target oriented measures to adapt to the climate-change impacts particularly salinity increase. To achieve this aim, I have used a multidisciplinary research framework where both qualitative and quantitative approaches were combined. First, I have analysed hydro-climatic and socio-economic variables of salinity increase to better understand the varying causes of salinization processes and also their cause-effect relationships. Salinity intensification is significantly correlated with the changes of all the selected hydro-climatic variables (temperature, rainfall, tidal water level, fresh water flow). Results show that increasing salinity of coastal wetlands is not driven by only climate change (i.e., temperature rise and late onset of monsoons) or climate-change induced impacts, like sea-level rise, but also by other regional environmental changes (e.g., reduced freshwater influx) (Chapter 2). In addition to these hydro-climatic variables, the local socio-economic processes, like unplanned and massive shrimp farming, and infrastructural development (e.g., polders) are contributing to inland salinity increase in this region (Chapter 
5). Hence, salinization across the south-west coast of Bangladesh is driven by a range of interconnected bio-physical and socio-economic processes.

Secondly, the ecological status of the Sundarbans mangrove vegetation along the salinity gradients was surveyed following major salinity transects to relate mangrove vegetation with and salinity gradients. All the selected aspects of mangrove vegetation (i.e., species composition, density, richness, diversity, canopy cover, regeneration and carbon content) decline with increased salt concentrations (Chapter 3). Less diverse and wide range of salt tolerant mangrove species, like Exoecaria agallocha and Cariops decandra, have already started to dominate over the highly diverse but less salt tolerant mangrove species, like Heritiera fomes. Also most of the top dying affected $H$. fomes trees are found in the plots of mesohaline zone. Besides, the carbon content of $H$. fomes was lowest in the mesohaline zone. All these results reveal sharp negative responses of $H$. fomes to high level of salt concentrations. Such responses indicate that further salinity increase can possibly further narrow down the ecological range of this 'globally endangered' and 'regionally critically endangered' species, intensify the severity of the top dying disease and soon drive this species to extinction. Moreover, different biodiversity indices articulate that diversity reduces with increased salt concentrations. In addition, the plots with higher salt concentrations showed lower regeneration and more uneven canopy cover compared to plots in low saline environments. All these results reveal the likelihood of reduced biodiversity and declined carbon-stocks in the Sundarbans mangrove in the near future due to further changes in salt concentrations.

In the next step, quality tiger habitat requirements (i.e., fresh water accessibility, suitable vegetative cover and prey species availability) were assessed to identify the potential aspects of the Sundarbans tiger habitat degradation due to salinity increase. I analysed five different information sources (i.e., literature review, field observations and analysis of hydro-climatic variables, focussed group discussions with local communities and interviews with experts) to enrich the knowledge platform on how tiger habitat relates to and is affected by changing salinity levels. Salinity increase and a range of processes are contributing to degrade the quality tiger and its prey habitat requirements (i.e., drinking water sources, prey population and vegetative cover) in the Sundarbans (Chapter 4). Tiger incidences (i.e., stray, injured and dead) are potentially related to reduced fresh water influx and salinity increase. This indicates increasing drinking water scarcity for the tigers in the mangroves. Changes in mangrove vegetation due to increasing salinity possibly affect key activities of the tiger such as resting, 
breeding, stalking, ambush, scratch, drinking, feeding, defaecation and movement. In addition, salt induced vegetation changes and climatic signals (e.g., rising air-temperatures during summer and late onset of monsoon) will create stress on physiological activities and habitat of tiger's principle prey (i.e., spotted deer). Hence, further changes in climate, fresh water availability and vegetative cover will affect not only the Bengal tigers, but also their prey habitat to degrade.

In the last step, I evaluated local people's perception and key informants observation on salinity increase and its processes, affected coastal systems and potential coping measures to study the causes and impacts of, and to develop adaptation pathways to cope with and to enhance resilience to salinization. I combined different qualitative and quantitative approaches (i.e., household surveys, key informant interviews, DPSIR framework, multicriteria analysis and adaptation pathway approach based on adaptation turning point) to evaluate and integrate social perceptions and experts' observations. In total, I identified twenty four potential measures to address six interconnected causes of salinity increase (i.e., unplanned and massive shrimp farming, reduced fresh water influx, tidal water level rise, unplanned infrastructural development, siltation and waterlogging) (Chapter 5). For instance, potential measures identified to adapt to salinization caused by unplanned shrimp practices include halting on-purpose ingression of salt water and planning and regulating shrimp farming, tidal river management and land-use zoning. Also I distinguished three coastal systems (i.e., crop-agriculture, drinking water sources and the Sundarbans mangrove) mostly affected by salinity increase. Finally, I proposed three different adaptation pathways for the identified mostly affected coastal systems consisting of sixteen adaptation options. Such as, for crop agriculture, a combined approach of adaptive agriculture, crop diversification/alternate cropping and arable field management is expected to sustain salinity levels at approximately $12 \mathrm{ppt}$ followed by saline resistant horticulture at approximately $15 \mathrm{ppt}$ and at salinity level $>15 \mathrm{ppt}$ land zoning can be the most suitable measure to promote agriculture, to improve farmers' socio-economic conditions and to resolve the conflicts between crop and shrimp farming.

The main five findings of my thesis are: (\#1) Rapid salinization across the south-west coastal region of Bangladesh is driven by a range of interconnected process (in particular global climate change, regional hydrological modifications and local socio-economic shifts) of climatic-social-ecological-economic systems; (\#2) Further changes in the salinity gradient across the Sundarbans mangrove will favour a shift in vegetation composition and forest 
structure towards more salt tolerant species and, consequently, will contribute to reduce its rich biodiversity and carbon sink; (\#3) Quality habitat requirements for Royal Bengal Tiger and its prey species in the Sundarbans mangroves are stressed by salinity increase, resulting from a number of macro-level hydro-climatic changes, particularly rising summer temperatures, late onset of monsoon and reduced dry season fresh water influx; and (\#4) Target-oriented large-scale adaptation planning is necessary to cope with and to enhance resilience to salinization in south-west coastal region of Bangladesh.

My thesis is the first integrated climate-change impact study for Bangladesh's south-west coastal region that addresses the range of interconnected processes of salinization and, assesses the impacts of these processes on the ecosystems in terms of relationship among mangrove vegetation, Sundarbans tiger and its prey habitat and the livelihoods of local people. In addition, the study provides novel insights for effective and target oriented largescale adaptation planning. Thus my study can potentially contribute to achieve the Bangladesh Climate Change Strategy and Action Plan and also the UN Sustainable Development Goals on climate action and nature conservation. With this I hope to contribute in biodiversity conservation of the globally significant and irreplaceable Sundarbans mangrove ecosystems and also in sustainability of coastal people to cope with and enhance resilience to salinization. 


\section{Acknowledgements}

This $\mathrm{PhD}$ thesis results from an unforgettable five years long journey where many people contributed. I would like to thank all who, in one way or other, contributed in this journey. I would like to sincerely thank to my promoter prof dr Rik Leemans and my supervisor prof dr Fulco Ludwig for their guidance and support. Rik, your critical comments and inspiring feedbacks helped me considerably to improve my scientific writing. Thank you for showing me the splendours of the scientific world. Fulco, you gave me not only a lot of opportunities to develop my scientific skills but also necessary freedom to do my own research. Thank you for your dedicated time and efforts for developing me as a scientist. I am so fortunate in many ways to grow under your excellent supervision. I am also thankful to you for your kind support in critical situations of this journey. Last but not the least, I very much appreciate you for coming to Bangladesh and joining my field work in the mangroves and remote coastal villages.

Also I am pleased to have many nice $\mathrm{PhD}$ peers and colleagues in Wageningen: Long, Debora, Somayeh, Dan, Beatriz, Mingtian, Ema, Amandine, Taposh, Kazi, Uthpal, Maryna, Zakir, Erik, Michelle, Jantsje, Catharien, Tanya and many others. It has been a great experience with you all on sharing office, having lunch and enjoying coffee breaks where my knowledge on different cultures get enriched. I am also grateful to great support of my Bangladeshi peers in many ways in Wageningen.

Furthermore, I would like to thank the team I worked with at Bangladesh Centre for Advanced Studies (BCAS), especially Dr. Abu Syed, who inspired me to apply for Nuffic funding to do my PhD research. Also my deepest gratitude goes to Dr. Atiq Rahman (BCAS), who taught me how to deal with a critical situation in a scientific career. In addition, I like to thank Nabir Mamnun and Sunbeam Rahman for sharing their ideas and having always a helping mind.

My PhD research would have never been successful without support of my family: Mahmoda Akhter (my mother), Fahad (my brother), Rima and Sinha (my two sisters), Sami and Shohag (my two brother-in-laws), Emon (my husband) and Ranya (my daughter). When I started my PhD my daughter, Ranya was only 2 years old. I left her to my Mom. She is the only person who had to experience a lot of things for her mummy's PhD without knowing the value of it. Now when I think about those days I feel so sorry for her. Also I am grateful to my mother who supported me all the way. Ammu (mother), all my words will not be enough to express my feelings for your support during my $\mathrm{PhD}$ period. I realize how difficult it is for you to take care of my daughter alone at your age. Fahad, dear brother, I am thankful to you for your kind assistance all the way in my field works from Khulna to Bagerhat and Sundarbans. Finally, Emon, this acknowledgement will end with you. Thanks for your support particularly, at the very beginning of my $\mathrm{PhD}$ project, when I passed very difficult times on planning my field works inside the Sundarbans. You gave me the strength to accomplish it.

Thus I have finished my $\mathrm{PhD}$ thesis. Now new challenges are starting! 


\begin{abstract}
About the author
Peerzadi Rumana Hossain was born on $9^{\text {th }}$ September 1980 in Chittagong city of Bangladesh. After finishing higher secondary school in 1998, she studied Forestry at Chittagong University (1999-2007). She received a BSc degree in 2004 and an MSc degree in 2008, both on Forestry and Environmental Sciences. During her studies, she developed interest in climate change and forest ecology. After her graduation, she worked as a research assistant (from 2008-2009) at Chittagong University in a USDA funded project on identifying and developing the management techniques of suitable forest tree Species of agro-ecological zones using climate change scenarios for Bangladesh. Then she started working as a research officer at Bangladesh Centre for Advanced Studies (2010-2012). There she participated in both consultancy and research projects on sustainable resource development in ecologically important landscapes, urban and peri-urban agriculture, capacity building for study of and adapting to climate change, climate change impacts on diverse ecosystems and biodiversity assessments, which had working areas in South Asia, Africa and Europe. She presented project works at home and abroad, participated in the national and international training programmes, and also organized several national and international workshops and conferences.
\end{abstract}

Rumana received the nfp fellowship from Nuffic in 2012 for $\mathrm{PhD}$ study at Wageningen University \& Research in the Netherlands. She started her PhD within the Earth System Science (later on Water Systems and Global Change) Group of Wageningen University in November 2012. Her PhD thesis is about climate change impacts on coastal ecosystems of Bangladesh for target-oriented adaptation planning. She focusses particularly on the impacts of salinization on different coastal systems (i.e., Sundarbans mangrove vegetation, wildlife habitat and coastal communities) to identify potential measures to adapt to salinization. For this, she integrated and applied multidisciplinary research methods, and developed adaptation pathways to cope with and enhance resilience to salinization in south-west coastal region of Bangladesh. Now, she is looking forward to new challenges in her scientific career. 


\section{SENSE}

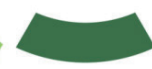

Netherlands Research School for the

Socio-Economic and Natural Sciences of the Environment

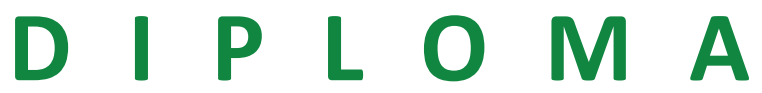

For specialised PhD training

The Netherlands Research School for the

Socio-Economic and Natural Sciences of the Environment

(SENSE) declares that

\section{Peerzadi Rumana Hossain born on 09 September 1980, Chittagong, Bangladesh}

has successfully fulfilled all requirements of the Educational Programme of SENSE.

Wageningen, 04 April 2018

the Chairman of the SENSE board

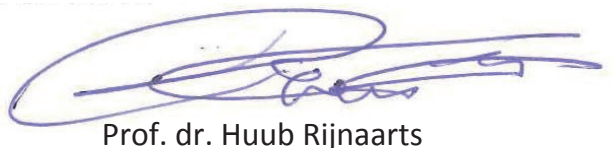

Prof. dr. Huub Rijnaarts the SENSE Director of Education

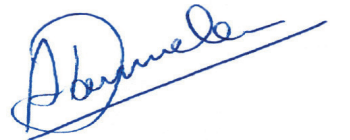

Dr. Ad van Dommelen

The SENSE Research School has been accredited by the Royal Netherlands Academy of Arts and Sciences (KNAW)

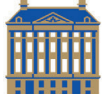

$\begin{array}{llllllllllllllllllllll}K & O & N & I & N & K & L & I & J & K & E & N & E & D & E & R & L & A & N & D & S & E\end{array}$

$\begin{array}{llllllllllllllllllllllll}\text { A } & \text { K } & \text { A } & \text { D } & \text { E } & \text { M } & \text { I } & \text { E } & \text { V } & \text { A } & \text { N } & \text { W } & \text { E } & \text { T } & \text { E } & \text { N } & \text { S } & \text { C } & \text { H } & \text { A } & \text { P } & \text { P } & \text { E } & \text { N }\end{array}$ 


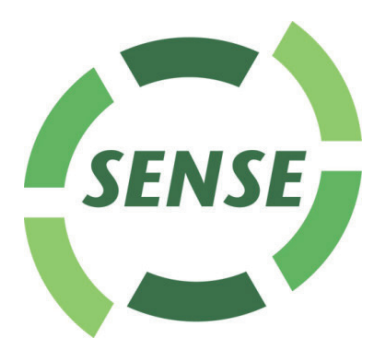

The SENSE Research School declares that Ms Peerzadi Rumana Hossain has successfully fulfilled all requirements of the Educational PhD Programme of SENSE with a work load of $37 \mathrm{EC}$, including the following activities:

\section{SENSE PhD Courses}

- Environmental research in context (2013)

- Research in context activity: Reviewed IPCC WGII AR5 Chapter 27 (2013)

- Introduction to R for statistical analysis (2014)

- Making an Impact - How to increase the societal relevance of your PhD research (2016)

\section{External training at a foreign research institute}

- Impact 2C Summer School, Climate service Centre, Germany (2013)

- Training on GIS, WARPO, Bangladesh (2014)

\section{Management and Didactic Skills Training}

- Organising Urbanizing Deltas of the World Workshop "Adaptation to Future Climate and Land Use Changes in the Bangladesh Delta"' in Dhaka, Bangladesh (2013)

- Guest lecture in the MSc course 'Climate Change Adaptation in developing countries' (2015)

\section{$\underline{\text { Scientific reports }}$}

- Co-author of "Bangladesh tropical forests and biodiversity assessment 2016" for USAID

- Co-author of "Building Urban Resilience- Assessing Urban and Peri-urban Agriculture in Dhaka, Bangladesh 2015" for UNEP

\section{Oral Presentations}

- Impacts of increasing salinity on mangrove vegetation composition in the Sundarbans of Bangladesh. NRG BESS International Conference, 08 September 2014, Southampton, United Kingdom

- Low Emission Development Strategies for Land-Use Change in Forestry of Bangladesh. Workshop on Low emission development strategies in Agriculture and Forestry, $25^{\text {th }}$ September 2013, Dhaka, Bangladesh

- Outreach, training and dissemination of BCAS Activities (South Asia and Bangladesh). Impact 2C-Work package 15 (WP15) Symposium, 02 September 2013, Hamburg, Germany

\section{SENSE Coordinator PhD Education}

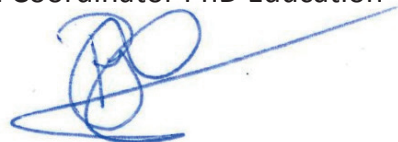

Dr. Peter Vermeulen 


\section{Authorship statement}

PhD candidate's name : $\quad$ Peerzadi Rumana Hossain

First promotor :

Title of PhD thesis :

Rik Leemans

Impacts of Climate Change on Coastal Ecosystems of

Bangladesh

Date of public defence: Wednesday 04 April 2018 at 11:00 AM

Chapter 1. Introduction. I prepared the general research question and its general scientific and social perspective and developed them in the text. My promoter and co-promotor reviewed and provided feedback, which I then took under consideration.

Chapter 2. : Recent Environmental Changes in South-West Coastal Region of Bangladesh: My co-promotor guided me to define the main aim and the research question. I collected the hydro-climatic data. For selecting and performing the data analysis I received guidance from my co-promotor. I wrote the first draft of the manuscript and afterwards my promoter and co-promoter provided feedback through several revision rounds.

Chapter 3. Ecological Status of Mangrove Vegetation along Salinity Gradients in the Sundarbans World Heritage Ecosystem: I proposed the research question and design of the manuscript which I discussed with my co-promoter. I collected all the data, performed the data analysis and wrote the first draft of the manuscript. My co-promoter provided guidance throughout the whole process and feedback on multiple revision rounds of the manuscript. My promoter critically revised the article for journal submission, which I then took under consideration.

Chapter 4. Salinity increase and habitat degradation of Royal Bengal Tiger in the Sundarbans Mangrove of Bangladesh: I proposed the concept and design of this chapter. My co-promotor participated in the discussion that lead to define the research question. I collected the data, performed the data analysis and wrote the first draft of the manuscript. My promoter and co-promoter contributed in the discussion on how to solve multiple challenges, which I then took under consideration for the final version of the manuscript to be published.

Chapter 5. Adaptation pathways to cope with salinization in south-west coastal region of Bangladesh: I proposed the concept and design of this chapter and discussed with my copromotor and other colleagues of my research group. I collected the data, performed the data analysis and wrote the first draft of the manuscript. My co-promotor provided feedback on the manuscript which I took under consideration. My promoter critically revised the article for journal submission,

Chapter 6 Synthesis. I wrote a first draft of this chapter. My promoter and co-promotor reviewed and provided feedback, which I then took under consideration. 
The research described in this thesis was financially supported by Nuffic through the Netherlands Fellowship Programme (NFP).

Financial support from the Water Systems and Global Change group for printing this $\mathrm{PhD}$ thesis is highly appreciated.

Thesis Cover design: $\quad$ Peerzadi Rumana Hossain

Printed by:

Digiforce || ProefschriftMaken 